\title{
WestVirginiaUniversity
}

THE RESEARCH REPOSITORY @ WVU

Graduate Theses, Dissertations, and Problem Reports

2006

\section{Ignition by air injection (CIBAI) for controlled auto-ignition in a CFR engine}

\author{
Fernando Echavarria \\ West Virginia University
}

Follow this and additional works at: https://researchrepository.wvu.edu/etd

\section{Recommended Citation}

Echavarria, Fernando, "Ignition by air injection (CIBAI) for controlled auto-ignition in a CFR engine" (2006). Graduate Theses, Dissertations, and Problem Reports. 2700.

https://researchrepository.wvu.edu/etd/2700

This Dissertation is protected by copyright and/or related rights. It has been brought to you by the The Research Repository @ WVU with permission from the rights-holder(s). You are free to use this Dissertation in any way that is permitted by the copyright and related rights legislation that applies to your use. For other uses you must obtain permission from the rights-holder(s) directly, unless additional rights are indicated by a Creative Commons license in the record and/ or on the work itself. This Dissertation has been accepted for inclusion in WVU Graduate Theses, Dissertations, and Problem Reports collection by an authorized administrator of The Research Repository @ WVU.

For more information, please contact researchrepository@mail.wvu.edu. 


\title{
Ignition by Air Injection (CIBAI) for Controlled Auto-Ignition in a CFR Engine
}

\author{
Fernando Echavarria
}
Dissertation submitted to the College of Engineering and Mineral Resources at West Virginia University in partial fulfillment of the requirements
for the degree of
Doctor of Philosophy
in
Mechanical Engineering
John Loth, Ph.D., Chair
Gary Morris, Ph.D.
Nigel Clark, Ph.D.
John Zondlo, Ph.D.
Scott Wayne, Ph.D.

Department of Mechanical and Aerospace Engineering

Morgantown, WV

2006

Keywords: Compression by Air Injection, Combustion, Controlled Auto-Ignition, Pre-

Ignition, Compression Ignition, Homogeneous Charge Compression Ignition

Copyright 2006 Fernando Echavarria 


\title{
Abstract \\ Ignition by Air Injection (CIBAI) for Controlled Auto-Ignition in a CFR Engine
}

\author{
Fernando Echavarria
}

Compression ignition by air injection (CIBAI) has been successfully achieved in a modified single cylinder, four-stroke, spark ignition cooperative fuel research (CFR) engine. The CIBAI cycle was invented by Professor John Loth and Professor Gary Morris, US patent No's: 6,994,057 Feb. 7, 2006 and 6,899,061 May 31, 2005. This new revolutionary combustion concept has the potential to become an alternative to traditional (SI) spark ignited and compression ignited (CI) diesel engines.

A CIBAI engine consists of two or more even numbers of adjacent cylinders that work in synchronization. One cylinder normally contains a conventional air-fuel mixture at a compression ratio limited by fuel auto-ignition properties while the second cylinder contains air-only at high compression ratio. Only during the compression stroke are these cylinders separated with a closed cylinder-connecting valve (CCV). The CCV valve normally opens near the top dead center (TDC) to allow transfer of high-pressure air from the air-only cylinder into the air-fuel mixture cylinder. Mixing air with pre-evaporated fuel with hot high-pressure air causes rapid two-step pressure rise, first by air addition and second by combustion compression. Ignition by air injection provides high ignition energy allowing very lean mixtures to be ignited for low emissions. Expanding combustion gases in both cylinders results in increased expansion ratio and thus thermal efficiency.

The objective of this dissertation was to demonstrate experimentally the viability of achieving ignition by air injection (CIBAI) for controlled auto-ignition in a CFR engine. This experimental work involved the development of an air injection model, and the design, assembly, and testing of a highly specialized air injection and timing equipment. These experiments were designed to substitute CIBAI ignition for one cycle in a spark ignition engine. The CIBAI engine cycle analysis is included, followed by an analytical model of the air injection process. A controller for the air injection and timing system had been designed, built and tested under different operating conditions until a satisfactory experimental procedure was developed for testing using the CIBAI concept. Based on the measured pressure-time history a numerical modeling code was developed to analyze power and combustion parameters (indicated net work, indicated mean effective pressure (IMEP), net heat release, net heat release rate, mass fraction burned (MFB), temperature history, combustion duration, and ignition delay). Finally, a parametric study was conducted to determine the effect of compression ratio, intake temperature, air-fuel ratio, air preheated charging pressure, and air-injection timing on CIBAI combustion.

Experimental and numerical model results indicated that ignition is readily achieved by air injection (CIBAI) in a CFR engine using the proper air injection system and proper air injection timing strategy. 


\section{Dedication}

To my lovely wife - for her love, patience, support, and encouragement during this long journey. 


\section{Acknowledgments}

I would like to express my sincere gratitude to my research advisor, Dr. Loth, for his teaching, guidance, and support during this research. He has not been only my mentor, teacher, and advisor, but also a person who has taught me to approach engineering from a different perspective.

I would also like to thank Dr. Gary Morris, a member of my committee, for introducing me to the world of microcontrollers and for his valuable contribution to this research. I would like also to thank the remaining members of my committee, Dr. Nigel Clark, Dr. Scott Wayne, and Dr. John Zondlo, with their expertise in engine research, for giving me suggestions, and their interest in this project.

I would like to thank Dr. Jacky Prucz and Dr. Ever Barbero for their support and timely advices during my graduate program, and for allowing me to teach at West Virginia University (WVU). It was a great experience.

My sincere appreciation to all my professors who encouraged me to pursue higher education. I would like to thank Dr. Gorli Harish, Director and Founder of Mahantech Corporation, for his financial support during these three years of graduate school at WVU.

I would like to thank Pat Browning for helping me with the experimental set-up and data acquisition unit. I would also like to thank Mr. Cliff Judy and Mr. Chuck Coleman for their support in the MAE shop, and Mrs. Debbie Willis for her timely information regarding matters related to the MAE department.

Finally, I would like to thank all of my officemates, especially Alejandro Posada and Julio Noriega, for helping me with some of my courses. Thanks to all of you. 


\section{Table of Contents}

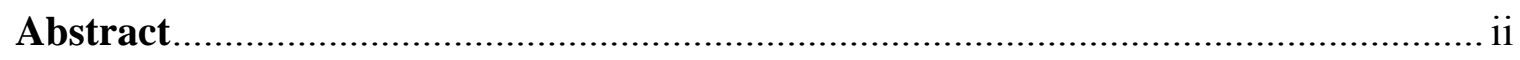

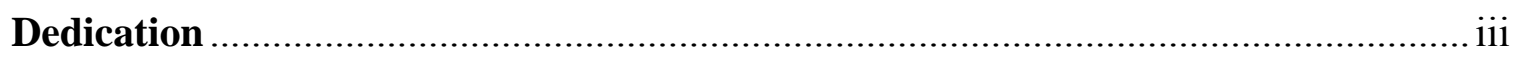

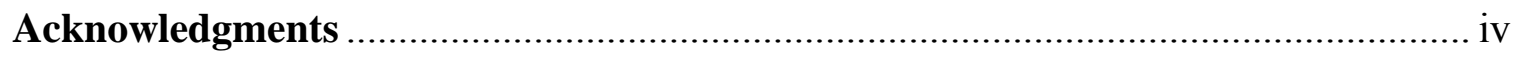

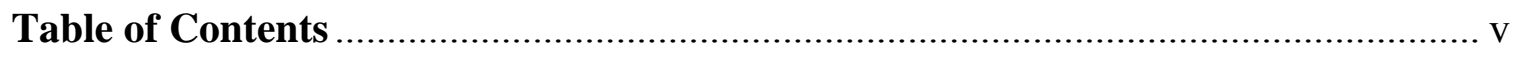

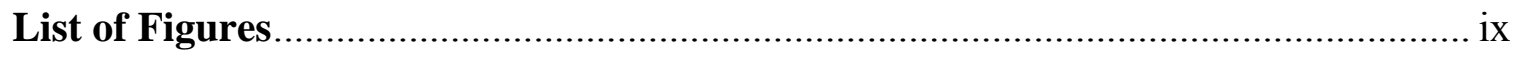

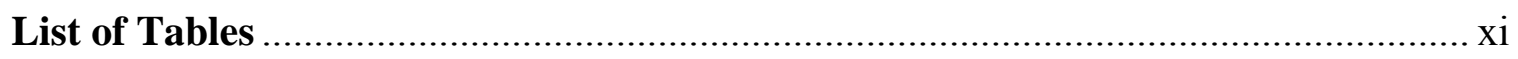

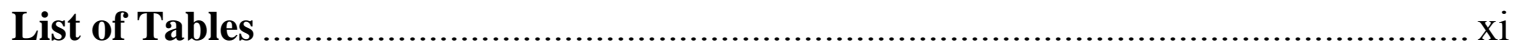

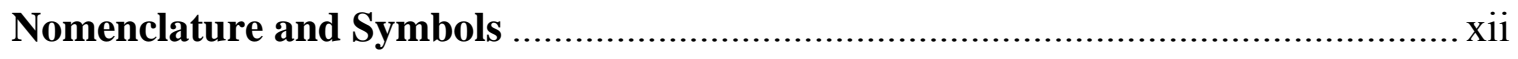

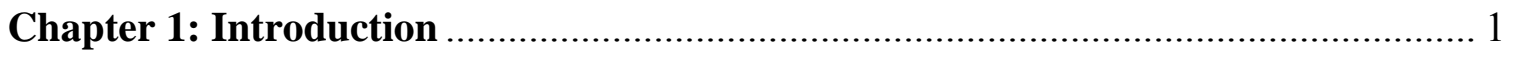

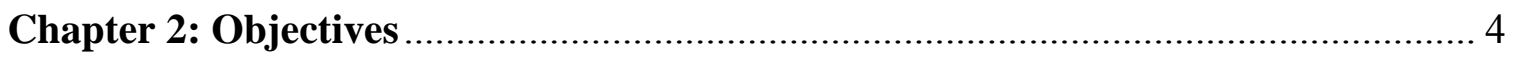

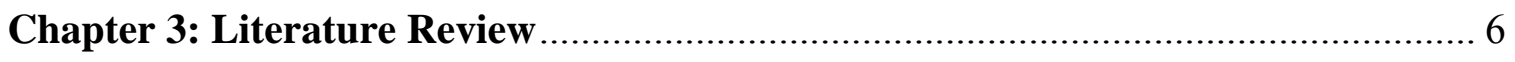

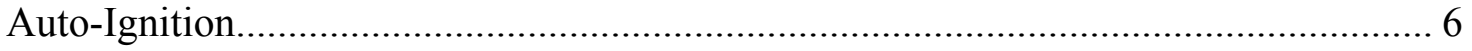

Controlled Auto-Ignition (CAI) ...................................................................... 8

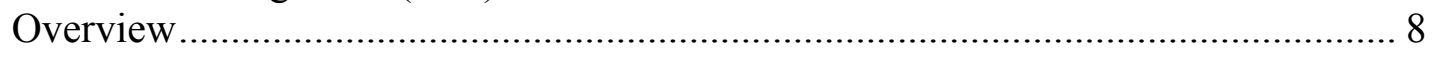

Earlier Research ....................................................................................... 9

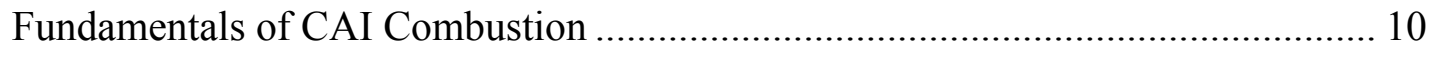

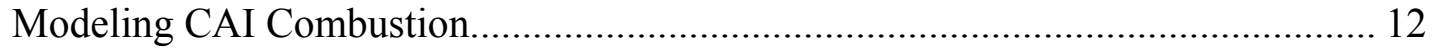

Recent Research in CAI Combustion ............................................................. 12

Chapter 4: Compression Ignition by Air Injection (CIBAI) ................................ 19

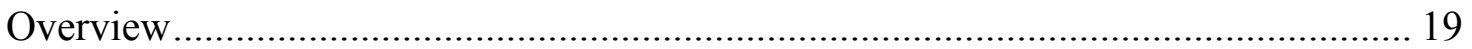

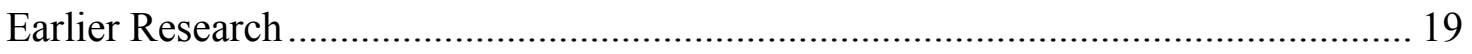

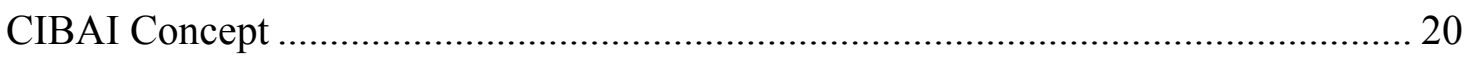

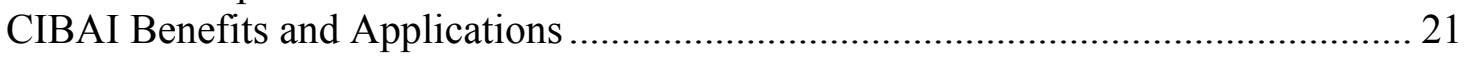

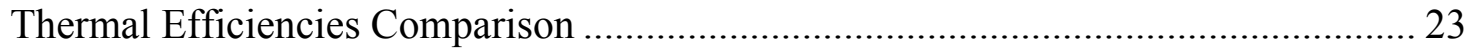

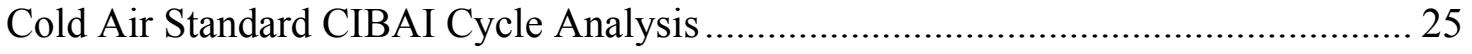

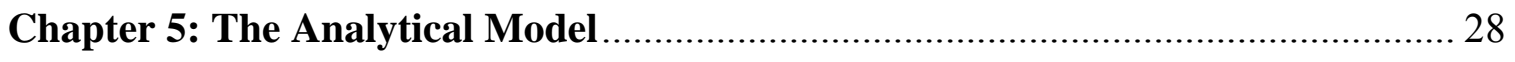

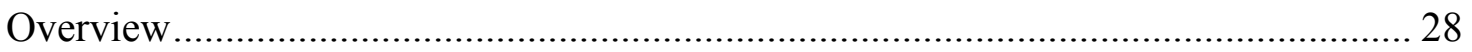




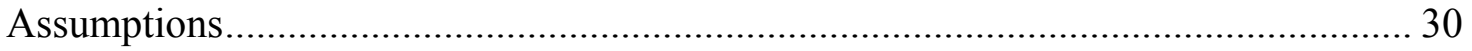

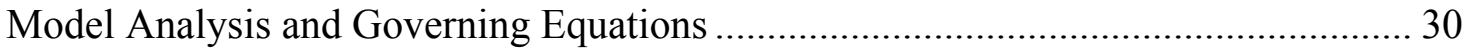

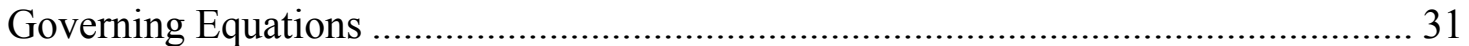

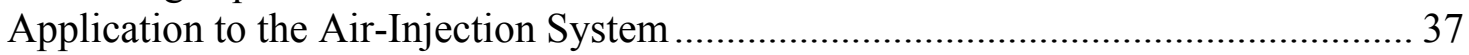

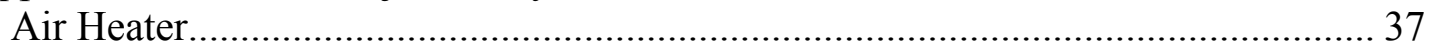

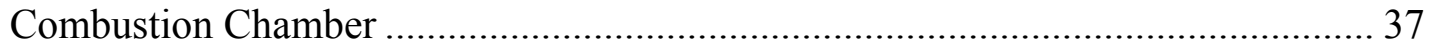

Chapter 6: The-Cold-Air Injection and Thermodynamic Models ........................... 40

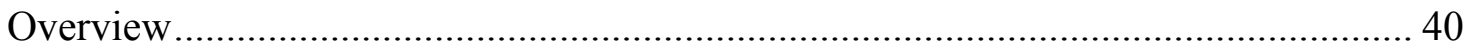

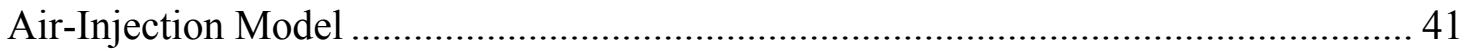

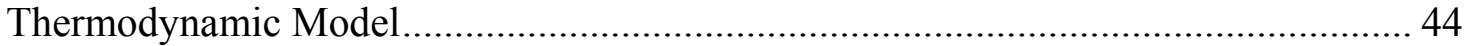

Derivation of the Temperature and Pressure Before Air Injection ............................ 44

Derivation of the Temperature and Pressure After Air Injection ............................. 45

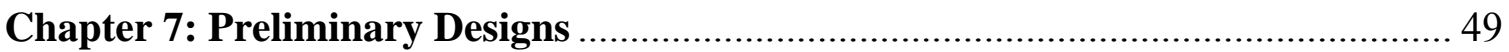

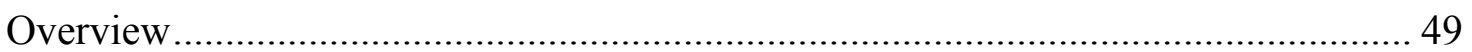

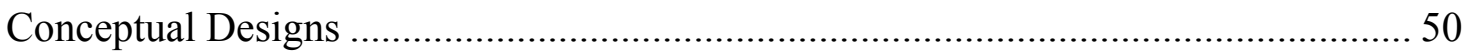

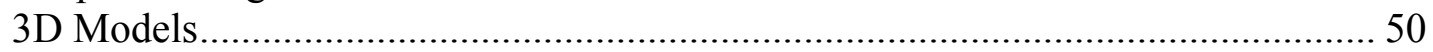

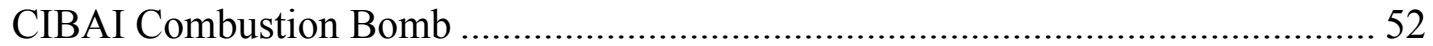

Air-Gun Rapid Compression Machine ………………....................................... 55

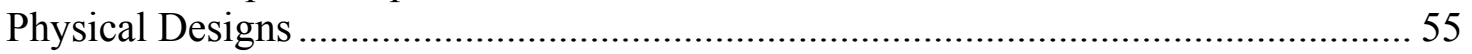

Piston-Cylinder Assembly Design........................................................................ 56

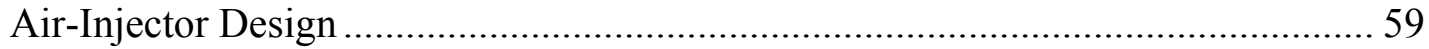

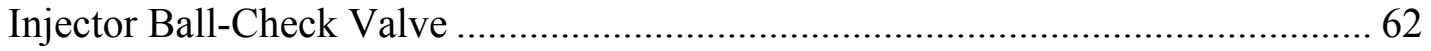

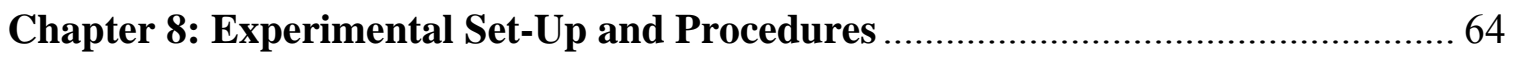

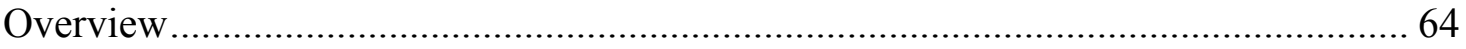

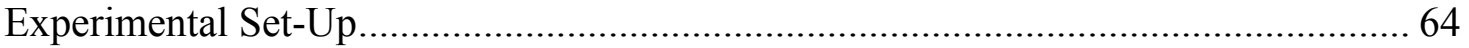

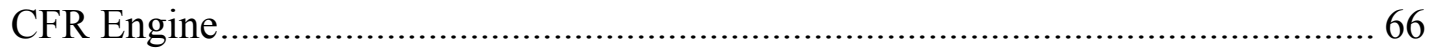

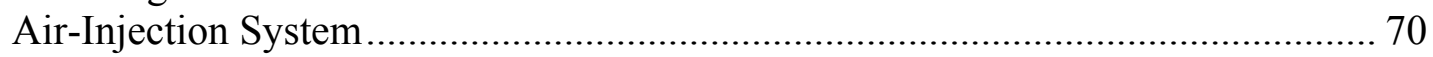

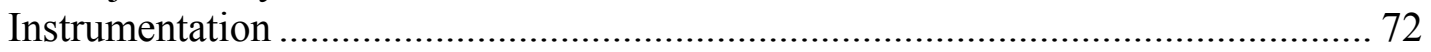

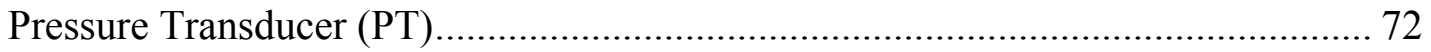

Crank Angle Sensor (CAS) .............................................................................. 73

Intake Air Flow Rate, Pressure and Temperature .................................................. 74

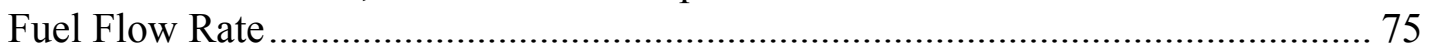

Coolant and Exhaust Temperature .................................................................... 75

Oil Temperature and Pressure ........................................................................ 75

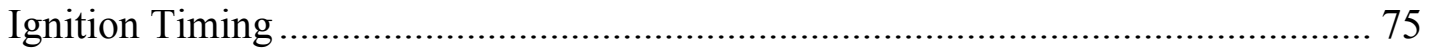

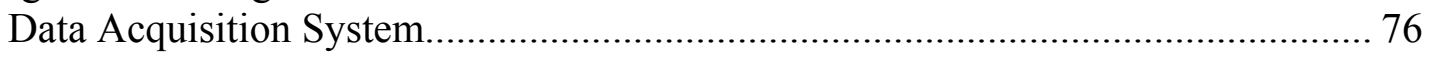

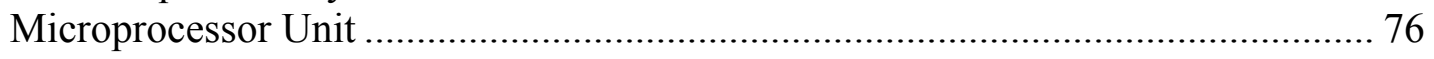

Engine Preparation .................................................................................... 79

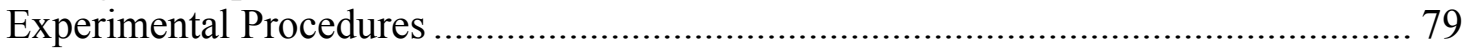

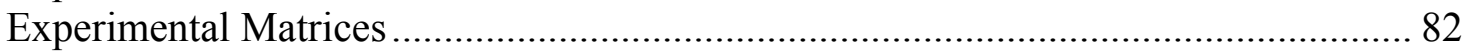


Matrix 1: The Effect of Compression Ratio on CIBAI Combustion ........................ 82

Matrix 2: The Effect of Intake Temperature on CIBAI Combustion ..................... 82

Matrix 3: The Effect of Air Pre-heater Charging Pressure on CIBAI Combustion.. 83

Matrix 4: The Effect of Equivalence Ratio on CIBAI Combustion .........................83

Matrix 5: The Effect of Air-Injection Timing on CIBAI Combustion ...................... 83

Chapter 9: Data Analysis ...................................................................................... 86

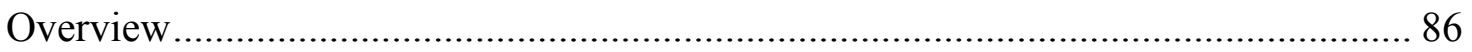

In-Cylinder Pressure History ............................................................................ 86

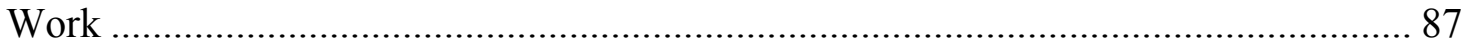

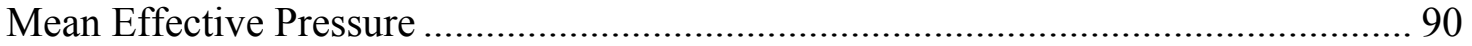

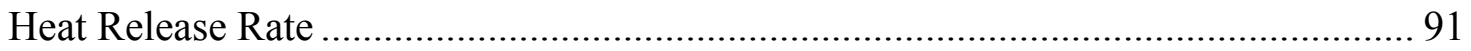

Mass Fraction Burned (MFB) ............................................................................ 93

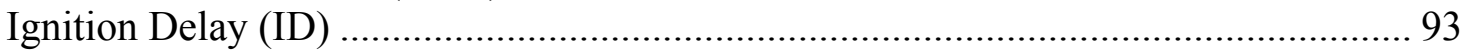

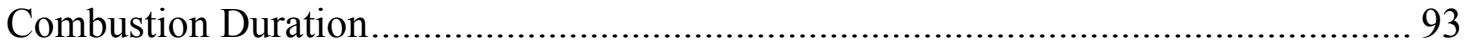

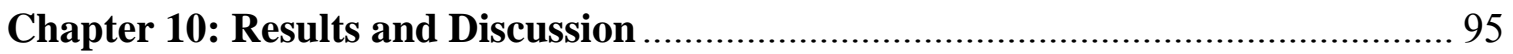

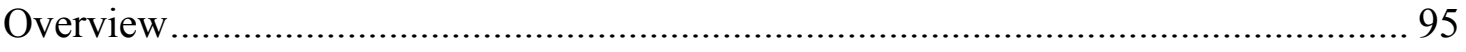

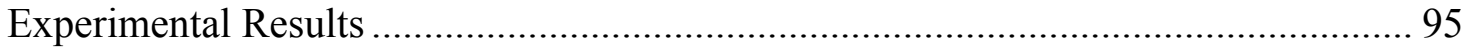

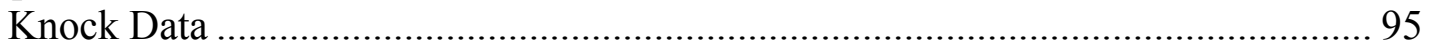

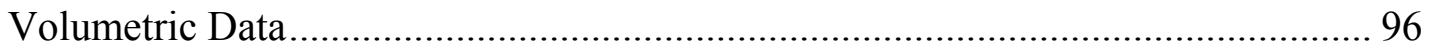

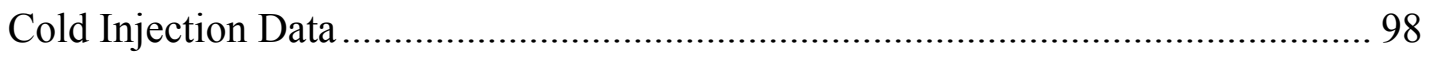

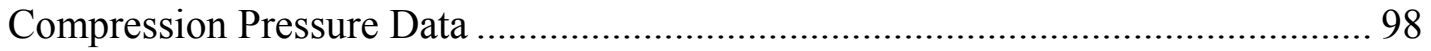

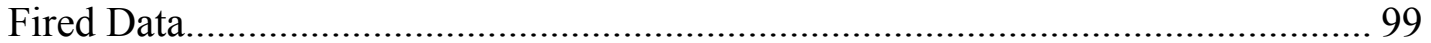

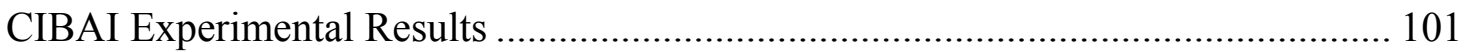

In-Cylinder Pressure History ......................................................................... 101

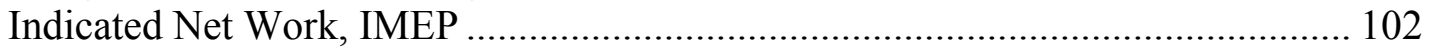

In-Cylinder Bulk Mean Temperature History................................................... 104

Heat Release, MFB, Combustion Duration, Ignition Delay (ID) ........................ 107

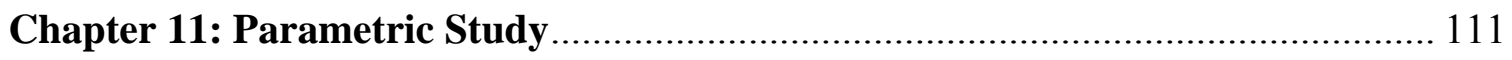

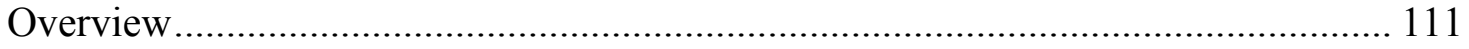

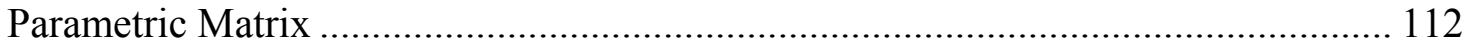

Parametric Study Results .............................................................................. 112

The Effect of Compression Ratio ..................................................................... 113

The Effect of Intake Temperature ........................................................................ 113

The Effect of Air Pre-heater Charging Pressure ............................................... 114

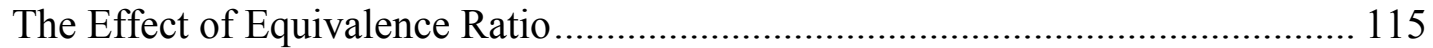

The Effect of Air-Injection Timing................................................................ 115

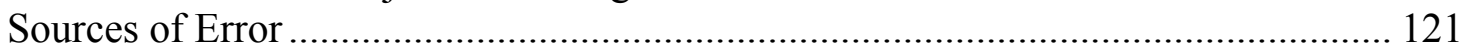

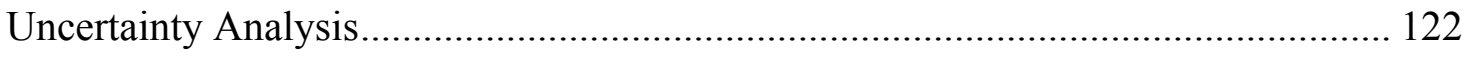

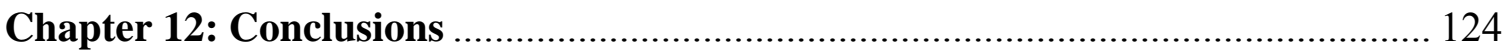


References.

Appendixes.

Appendix A: CIBAI Analytical and Numerical Modeling Program Code 133

Appendix B: Cold-Air-Injection-Model Calculations

Appendix C: Compressed Air Batch Analysis.

Appendix D: Omega Pressure Transducer Datasheet

Appendix E: Solenoid Valve Datasheet.

Appendix F: Double Acting Tie-Rod Hydraulic Cylinder Datasheet...

Appendix G: First Air Injector Design Drawing

Appendix H: Spark Plug Adapter Drawing

Appendix I: Water Cooled Pressure Transducer Adapter Drawing............................ 166

Appendix J: Three (3) Way Ball Valve Datasheet.................................................... 167

Appendix K: Air Pressure Relief Valve Datasheet.................................................. 168

Appendix L: Dytran Piezoelectric Pressure Transducer Datasheet .......................... 170

Appendix M: Kistler Piezotron Coupler Charge Amplifier Datasheet...................... 172

Appendix N: Data Acquisition Unit Electric Diagram ........................................... 174

Appendix O: Omega Data Acquisition Card Datasheet ......................................... 175

Appendix P: Microchip Pic16F72 Chip Diagram..................................................... 176

Appendix Q: Microcontroller Unit Program............................................................ 177

Appendix R: Sample Calculations Air-Fuel and Equivalence Ratios ...................... 178

Appendix S: Sample Estimated In-Cylinder Bulk Temperature 


\section{List of Figures}

Figure 3.1 Ignition delay and the self-ignition temperature ………………………….... 7

Figure 4.1 Four-stroke engine operating on the CIBAI cycle ....................................... 21

Figure 4.2 CIBAI engine in combination with a fuel cell.............................................. 23

Figure 4.3 CIBAI cycle efficiency comparison with Otto and Diesel cycles ................... 24

Figure 4.4 CIBAI cycle ideal pressure ratio $\left(\mathrm{P} / \mathrm{P}_{1}\right)$ vs. crank angle................................ 26

Figure 4.5 CIBAI cycle temperature ratio $\left(\mathrm{T} / \mathrm{T}_{1}\right)$ vs. crank angle ................................. 27

Figure 5.1 Generalized thermodynamic model..................................................... 29

Figure 5.2 The compression ignition by air-injection (CIBAI) model ............................. 29

Figure 6.1 Air injection schematic model.................................................................... 40

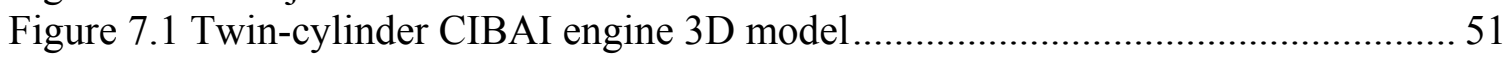

Figure 7.2 Four-stroke four-cylinder CIBAI engine 3D model..................................... 51

Figure 7.3 Cross-sectional diagram of the CIBAI combustion bomb ………………...... 54

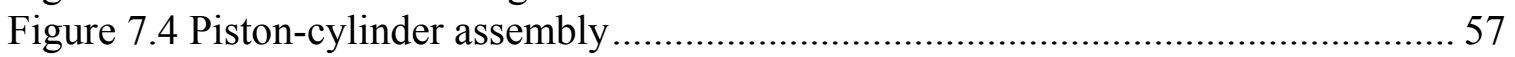

Figure 7.5 Air injector assembly installed in the CFR engine......................................... 60

Figure 7.6 Modified air injector with cooling system..................................................... 61

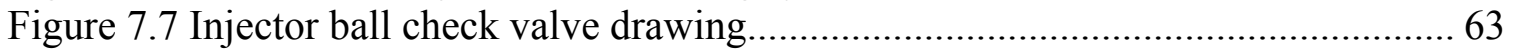

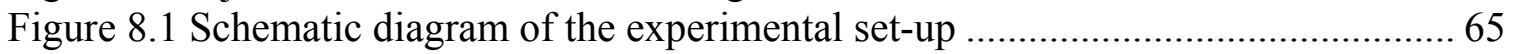

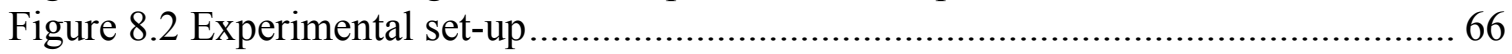

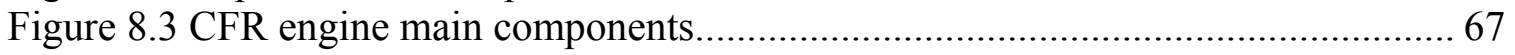

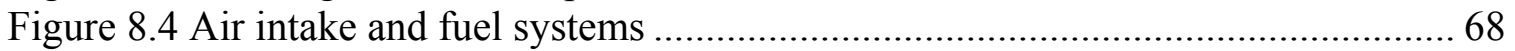

Figure 8.5 Injector ball-check valve and detonation pick-up sensor ................................ 69

Figure 8.6 Air heater and flexible exhaust pipe......................................................... 70

Figure 8.7 Air-injection system ............................................................................... 71

Figure 8.8 Schematic diagram CFR engine instrumentation ........................................... 72

Figure 8.9 Crank angle sensor mounted on CFR engine ............................................. 74

Figure 8.10 Schematic diagram of the microcontroller unit ............................................ 77

Figure 8.11 Air injection strategy controlled by a microcontroller unit........................... 78

Figure 8.12 Air injection timing crank angle diagram................................................ 78

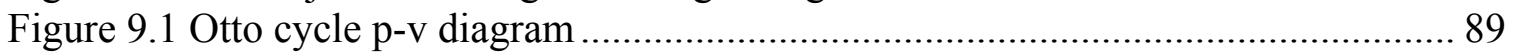

Figure 10.1 Pressure history diagram for motored, cold injection, spark ignition, and

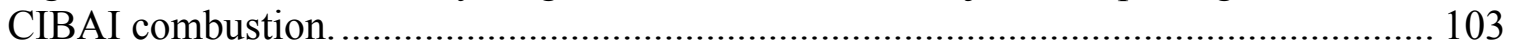

Figure 10.2 In-cylinder pressure-volume diagram for CIBAI and Spark Ignition ......... 104

Figure 10.3 Calculated in-cylinder bulk mean temperature history for CIBAI and spark

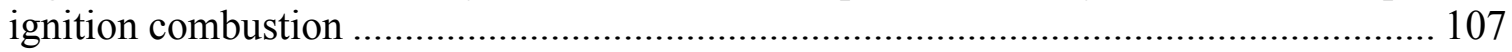

Figure 10.5 Net heat release rate comparison for CIBAI and spark ignition ................ 109

Figure 10.6 Mass fraction burned (MFB) for CIBAI and spark ignition combustion.... 110

Figure 11.1 Pressure history, net heat release rate, and mass fraction burned (MFB)

diagrams for compression ratios of 7.0, 7.5, and 8.0 ............................................... 116

Figure 11.2 Pressure history, net heat release rate, and mass fraction burned (MFB)

diagrams for intake temperatures of $70^{\circ} \mathrm{F}$, and $250^{\circ} \mathrm{F}$........................................... 117

Figure 11.3 Pressure history, net heat release rate, and mass fraction burned (MFB)

diagrams for air pre-heated charging pressures of 700, 800, and $900 \mathrm{psig}$................... 118

Figure 11.4 Pressure history, net heat release rate, and mass fraction burned (MFB)

diagrams for equivalence ratios of $0.45,0.50$, and 0.65 
Figure 11.5 Pressure history, net heat release rate, and mass fraction burned (MFB) diagrams for air injection timing of $85^{\circ}, 75^{\circ}$, and $65^{\circ} \mathrm{CA}$ bTDC ............................... 120 


\section{List of Tables}

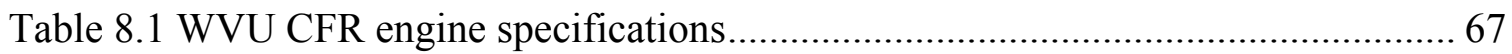

Table 8.2 CFR engine operating conditions under CIBAI combustion........................... 81

Table 8.3 Experimental matrix 1: effect of compression ratio in CIBAI combustion...... 84

Table 8.4 Experimental matrix 2: effect of intake temperature in CIBAI combustion .... 84

Table 8.5 Experimental matrix 3: effect of air charged pressure in CIBAI combustion.. 84

Table 8.6 Experimental matrix 4: effect of equivalence ratio in CIBAI combustion....... 85

Table 8.7 Experimental matrix 5: effect of air injection timing in CIBAI combustion.... 85

Table 10.1 CFR engine operating conditions during knock testing................................. 96

Table 10.2 CFR engine operating conditions during firing testing ……....................... 100

Table 10.3 Change in spark timing with compression ratio .......................................... 100

Table 10.4 Experimental results summary table for a compression ratio of 8.0:1 ......... 101

Table 11.1 The effect of compression ratio on CIBAI combustion................................ 113

Table 11.2 The effect of intake temperature on CIBAI combustion ............................. 114

Table 11.3 The effect of air pre-heater charging pressure on CIBAI combustion ......... 114

Table 11.4 The effect of equivalence ratio on CIBAI combustion.................................. 115

Table 11.5 The effect of air injection timing on CIBAI combustion.............................. 116

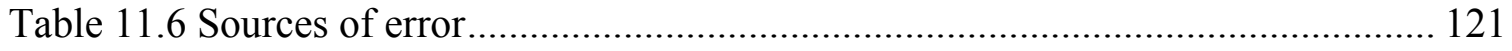

Table 11.7 Effects of input data on modeling results ............................................... 122

Table A1.1 WVU CFR engine specifications........................................................ 154

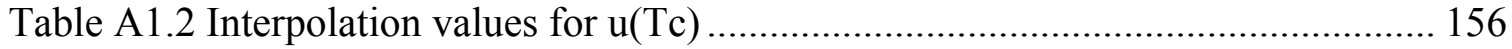

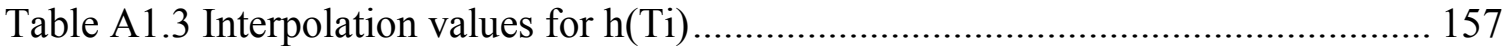

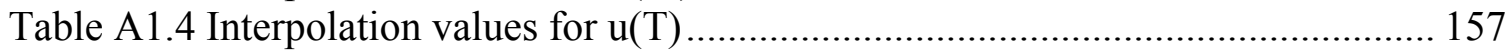

Table A1.5 Summary of air-injection calculations ……............................................ 158

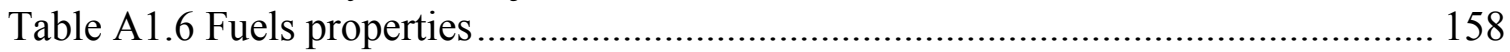




\section{Nomenclature and Symbols}

\begin{tabular}{|c|c|c|}
\hline $\mathrm{A}^{*}$ & $=$ & Effective choked flow area \\
\hline$A_{e}$ & $=$ & Orifice area \\
\hline AKI & $=$ & Anti-knock index \\
\hline $\mathrm{A}_{\mathrm{o}}$ & $=$ & Orifice cross-sectional area \\
\hline$A_{p}$ & $=$ & Area piston \\
\hline AR & $=$ & Activated radical \\
\hline ATAC & $=$ & Active thermo-atmosphere combustion \\
\hline aTDC & $=$ & After top dead center \\
\hline ASTM & $=$ & American society for testing and materials \\
\hline $\mathrm{b}$ & $=$ & Cylinder bore diameter \\
\hline $\mathrm{BDC}$ & $=$ & Bottom dead center \\
\hline BSFC & & Brake specific fuel consumption \\
\hline bTDC & $=$ & Before top dead center \\
\hline CAI & $=$ & Controlled auto-ignition \\
\hline CAS & $=$ & Crank angle sensor \\
\hline $\mathrm{cc}$ & $=$ & Cubic centimeter \\
\hline $\mathrm{CCV}$ & $=$ & Cylinder-connecting valve \\
\hline CFR & $=$ & Cooperative fuel research \\
\hline $\mathrm{CI}$ & $=$ & Compression ignition \\
\hline CIBAI & $=$ & Compression ignition by air injection \\
\hline CIHC & $=$ & Compression ignited homogeneous charge \\
\hline $\mathrm{CN}$ & $=$ & Cetane number \\
\hline $\mathrm{CO}$ & $=$ & Carbon monoxide \\
\hline C.R & $=$ & Compression ratio \\
\hline DAQ & $=$ & Data Acquisition \\
\hline DME & $=$ & Dimethyl-ether \\
\hline EGR & $=$ & Exhaust gas recirculation \\
\hline E.R & $=$ & Equivalence Ratio \\
\hline $\mathrm{EVC}$ & $=$ & Exhaust valve closing \\
\hline
\end{tabular}




\begin{tabular}{|c|c|c|}
\hline $\mathrm{f}$ & $=$ & Actual fuel-air ratio \\
\hline $\mathrm{F}$ & $=$ & Fuel-air ratio \\
\hline FD-LI & $=$ & Photon detonation laser ignition \\
\hline FFT & $=$ & Fast Fourier Transform \\
\hline F.L & $=$ & Fuel level \\
\hline FS & $=$ & Fuel sensitivity \\
\hline$f_{s}$ & $=$ & Stoichiometric fuel-air ratio \\
\hline$g_{c}$ & $=$ & Conversion factor \\
\hline GDI & $=$ & Gasoline direct injection \\
\hline $\mathrm{h}$ & $=$ & Specific enthalpy (absolute) \\
\hline $\mathrm{H}_{2}$ & $=$ & Hydrogen \\
\hline $\mathrm{HC}$ & $=$ & Hydrocarbon \\
\hline $\mathrm{HCCI}$ & $=$ & Homogeneous charge compression ignition \\
\hline IAPAC & $=$ & Injection assistee par air comprime (French) \\
\hline IC & $=$ & Internal combustion \\
\hline ICADE & $=$ & Isolated combustion and diluted expansion \\
\hline ID & $=$ & Ignition delay \\
\hline IMEP & $=$ & Indicated mean effective pressure \\
\hline IVO & $=$ & Intake valve opening \\
\hline $\mathrm{J}$ & $=$ & Joule \\
\hline 1 & $=$ & Connecting rod length \\
\hline M & $=$ & Total mass \\
\hline MAE & $=$ & Mechanical and Aerospace Engineering \\
\hline $\mathrm{M}_{\mathrm{a}}$ & $=$ & Mass of air \\
\hline $\mathrm{M}_{\mathrm{f}}$ & $=$ & Mass of fuel \\
\hline MFB & $=$ & Mass fraction burned \\
\hline MIE & $=$ & Minimum ignition energy \\
\hline $\mathrm{M}_{\mathrm{i}}$ & $=$ & Cylinder mass before injection \\
\hline MON & $=$ & Motor octane number \\
\hline $\mathrm{n}$ & $=$ & Revolutions per engine cycle (rev/cycle) \\
\hline $\mathrm{N}$ & $=$ & Engine speed \\
\hline
\end{tabular}




\begin{tabular}{|c|c|c|}
\hline $\mathrm{NC}$ & $=$ & Normal closed contact \\
\hline NETL & $=$ & National Energy Technology Laboratory \\
\hline NG & $=$ & Natural gas \\
\hline NO & $=$ & Normal open contact \\
\hline $\mathrm{NO}_{\mathrm{x}}$ & $=$ & Oxides of nitrogen \\
\hline NPT & $=$ & National pipe thread \\
\hline ON & $=$ & Octane number \\
\hline $\mathrm{P}$ & $=$ & Pressure (absolute) \\
\hline $\mathrm{P}_{1}$ & $=$ & Initial Pressure \\
\hline $\mathrm{P}_{\mathrm{a}}$ & $=$ & Air cylinder pressure \\
\hline$P_{a f}$ & $=$ & Air-fuel cylinder pressure \\
\hline PCCI & $=$ & Premixed charge compression ignition \\
\hline PM & $=$ & Particular matter \\
\hline $\mathrm{P}_{\text {prod }}$ & $=$ & Products pressure \\
\hline PRF & $=$ & Primary reference fuels \\
\hline PT & $=$ & Pressure transducer \\
\hline q & $=$ & Specific heat transfer \\
\hline Q & $=$ & Heat transfer \\
\hline $\mathrm{r}$ & $=$ & Crank radius \\
\hline $\mathrm{R}$ & $=$ & Gas constant \\
\hline$r_{c}$ & $=$ & Combustion induced temperature ratio \\
\hline $\mathrm{r}_{\mathrm{m}}$ & $=$ & Air-fuel mixture mass ratio \\
\hline RON & $=$ & Research octane number \\
\hline$r_{p}$ & $=$ & Instantaneous pressure ratio \\
\hline$r_{\text {pritical }}$ & $=$ & Critical pressure \\
\hline RPM & $=$ & Revolutions per minute \\
\hline $\mathrm{r}_{\mathrm{va}}$ & $=$ & Air compression ratio \\
\hline$r_{\mathrm{vaf}}$ & $=$ & Fuel-air compression ratio \\
\hline $\mathrm{t}$ & $=$ & Time \\
\hline $\mathrm{T}$ & $=$ & Temperature (absolute) \\
\hline $\mathrm{T}_{1}$ & $=$ & Initial Temperature \\
\hline
\end{tabular}




\begin{tabular}{|c|c|c|}
\hline $\mathrm{T}_{\mathrm{a}}$ & $=$ & Air cylinder temperature \\
\hline $\mathrm{T}_{\mathrm{af}}$ & $=$ & Air-fuel cylinder temperature \\
\hline TDC & $=$ & Top dead center \\
\hline $\mathrm{T}_{\text {prod }}$ & $=$ & Products temperature \\
\hline $\mathrm{s}$ & $=$ & Stroke \\
\hline $\mathrm{SC}$ & $=$ & Solenoid close \\
\hline SCFM & $=$ & Standard cubic feet per minute \\
\hline SI & $=$ & Spark ignition \\
\hline SO & $=$ & Solenoid opening time \\
\hline $\mathrm{u}$ & $=$ & Specific internal energy (absolute) \\
\hline $\mathrm{U}$ & $=$ & Total internal energy (absolute) \\
\hline UAV & $=$ & Unmanned aerial vehicles \\
\hline V & $=$ & Total volume \\
\hline $\mathrm{V}_{\mathrm{a}}$ & $=$ & Air cylinder volume \\
\hline$V_{\text {af }}$ & $=$ & Air-fuel cylinder volume \\
\hline $\mathrm{V}_{\mathrm{c}}$ & $=$ & Clearance volume \\
\hline $\mathrm{V}_{\mathrm{d}}$ & $=$ & Displacement volume \\
\hline $\mathrm{V}_{\text {dact }}$ & $=$ & Actual displacement volume \\
\hline VCT & $=$ & Variable camshaft timing \\
\hline$V_{\text {heater }}$ & $=$ & Volume heater \\
\hline $\mathrm{V}_{\mathrm{n}}$ & $=$ & Laminar burning velocity \\
\hline VVT & $=$ & Variable valve timing \\
\hline $\mathrm{V}_{\mathrm{s}}$ & $=$ & Flame speed \\
\hline $\mathrm{X}_{\text {stroke }}$ & $=$ & Distance traveled by the piston (at $\theta)$ measured from $\operatorname{TDC}(\theta=0)$ \\
\hline W & $=$ & Work \\
\hline WVU & $=$ & West Virginia University \\
\hline$\beta$ & $=$ & Cut-off ratio \\
\hline$\gamma$ & $=$ & Specific heat ratio \\
\hline$\eta_{\text {Cibai }}$ & $=$ & CIBAI thermal efficiency \\
\hline$\eta_{\text {Diesel }}$ & $=$ & Diesel thermal efficiency \\
\hline
\end{tabular}




$\begin{array}{lll}\eta_{\text {Otto }} & =\text { Otto thermal efficiency } \\ \eta_{\mathrm{v}} & =\text { Volumetric efficiency } \\ \theta & =\text { Engine crank angle (radians measured from TDC) } \\ \Phi & =\text { Equivalence ratio } \\ { }^{3 \mathrm{D}} & =\text { Three dimensions } \\ \Delta \mathrm{U} & =\text { Change in internal energy } \\ \Delta \mathrm{H} & =\text { Change in internal enthalpy } \\ \Delta \mathrm{t} & =\text { Injection duration } \\ { }^{\circ} \mathrm{CA} & =\text { Crank angle degree } \\ { }^{\circ} \mathrm{CA} \mathrm{bTDC} & =\text { Crank angle degree before top dead center } \\ \mathrm{dm} / \mathrm{dt} & =\text { Rate of air injection } \\ { }^{\circ} \mathrm{F} & =\text { Degree Fahrenheit } \\ { }^{\circ} \mathrm{R} & =\text { Degree Rankine }\end{array}$




\section{Chapter 1: Introduction}

Intensive research to increase engine fuel efficiency and reduce emissions is driven by the increase in worldwide oil demand and stringent emissions control regulations. As a result, a wide range of internal combustion (IC) engine cycle modifications have being developed and implemented to achieve complete combustion of lean fuel-air mixtures for low $\mathrm{NO}_{\mathrm{X}}$, while maximizing combustion compression for high thermal efficiency.

This research effort has resulted in the application of new emission control techniques (i.e. exhaust gas recirculation (EGR), variable valve timing, and $\mathrm{NO}_{\mathrm{x}}$ dilution), the use of new alternative fuels in internal combustion engines (i.e. natural gas (NG), alcohols, and hydrogen), the design of new power train configurations (i.e. fuel cells technology and hybrid vehicles), and the use of new ignition and combustion strategies (i.e. compression ignition by air injection (CIBAI), gasoline direct injection (GDI), photon detonation laser ignition (FD-LI), controlled auto-ignition (CAI), homogeneous charge compression ignition ( $\mathrm{HCCI}$ ), and stratified charge engines).

Internal combustion engines (IC) are primarily classified into spark ignition (SI) and combustion ignition (CI) engines. SI engines start the combustion process by using a high-voltage electrical discharge from a spark plug in each combustion cycle. CI engines start the combustion process when the fuel-air mixture self-ignites due to high temperature in the combustion chamber, caused by high compression. SI engines have higher power density, but are less efficient at part load because of losses associated with throttling [1]. CI engines avoid throttling and thus are more efficient at part load; 
however $\mathrm{CI}$ engines usually produce high particulate matter and oxides of nitrogen $\left(\mathrm{NO}_{\mathrm{x}}\right)$ emissions under high load.

Modern SI and CI engines have reached significant improvements in emissions reduction, and performance. However, their indicated thermal efficiencies are still in the range of $40 \%$ to $50 \%$ [2]. The thermal efficiency of spark ignition (SI) engines is limited by compression ratio, fuel octane number $(\mathrm{ON})$, and knock, while the thermal efficiency of compression ignition (CI) engines is limited by fuel cetane number $(\mathrm{CN})$, and exhaust emissions. In addition, an important factor limiting the thermal efficiency is the low flame speed associated with combustion, initiated by a spark or by a spray of diesel fuel [3].

In recent years controlled auto-ignition (CAI) has been extensively studied as an alternative to traditional spark ignition (SI) and compression ignition (CI) engines [4]. Controlled auto-ignition (CAI) is defined in the literature as a combustion process, which involves the auto-ignition and simultaneous combustion of a homogeneous air-fuel mixture. This ignition system allows burning very lean mixtures for more efficient operation at reduced power levels. Some additional benefits of CAI ignition over SI and $\mathrm{CI}$ ignition are: lower $\mathrm{NO}_{\mathrm{x}}$ emissions at part load, leaner mixture operation, reduced cycle-to-cycle variation, and lower soot emissions. However, its application in a production engine has been limited due to high peak pressures, high $\mathrm{HC}$ and $\mathrm{CO}$ emissions, the difficulty in timing of the auto-ignition, and heat release rate over the entire engine operational range.

Loth and Morris [3,5] patented a new thermodynamic cycle for piston type internal combustion (IC) engines called "Compression Ignition by Air Injection 
(CIBAI)." The CIBAI cycle offers an IC engine capable of an increased thermal efficiency, operating over a wide range of fuels, rapid ignition of very lean fuel-air mixtures, and reduced $\mathrm{NO}_{\mathrm{x}}$. The researchers indicated that CIBAI cycle could be more efficient than the Otto or Diesel cycle, and simpler, since it does not require high maintenance items like spark plug ignition systems, or high pressure diesel type fuel pump and fuel injectors.

Recently, researchers at the National Energy Technology Lab (NETL) reported obtaining laser-spark ignition of an ultra lean mixture using a Ricardo Proteous, singlecylinder, four-stroke, spark-ignited natural gas engine [6]. CIBAI and laser-spark ignition offer an alternative to traditional spark and compression ignited engines with their aboveaverage ignition energy achieving faster combustion of lean fuel-air mixtures for low $\mathrm{NO}_{\mathrm{x}}$, while maximizing combustion compression for high thermal efficiency.

The objective of this dissertation was to demonstrate experimentally the viability of achieving ignition by air injection (CIBAI) for controlled auto-ignition using a CFR engine. This experimental work mainly involved the development of an air injection model, the construction of specialized air injection and timing equipment, the collection of experimental data, the implementation of a numerical modeling program code, and the execution of a parametric study to determine the effect of operating parameters on CIBAI combustion. The specific tasks accomplished during this dissertation are presented next. 


\section{Chapter 2: Objectives}

The objective of this dissertation was to demonstrate experimentally the viability of achieving ignition by air injection (CIBAI) for controlled auto-ignition in a CFR engine. This concept was originally proposed by Professor Loth and Professor Gary Morris [3,5] and is based on theoretical concepts related to combustion, auto-ignition, and chemical kinetics. This objective was accomplished through the following tasks:

- A literature review was conducted to determine the combustion characteristics and engine operating parameters for controlled auto-ignition (CAI).

- Existing auto-ignition modeling techniques were reviewed.

- A simple, yet reliable, numerical model was developed and implemented to theoretically predict the influence of air injection, design parameters and operation variables in the compression ignition by air-injection (CIBAI) combustion.

- Multiple air-injection systems were designed, assembled, and tested to determine the optimal air-injection strategy.

- A microcontroller was designed, assembled, and tested to control the air-injection timing and operate the CFR engine safely during the air injection. Specialized control systems were needed to assure that the air injection occurred at the desired crank angle and the desired amount of air was injected all at once without additional air transfer after ignition occurred.

- Several cylinder-connecting valves (CCV) were designed, built, and tested to simulate the CIBAI combustion process using the CFR engine. 
- A suitable data acquisition system was assembled to be able to compare the CFR engine performance with spark ignition and with air-injection ignition.

- Multiple tests were carried out and recorded for different engine operating conditions while the CFR was motored, fired, and operated under the CIBAI cycle to determine experimentally the optimal operating conditions for CIBAI combustion.

- Experimental CIBAI combustion testing was performed to collect the empirical input data necessary to complete the numerical, parametric study, and to evaluate the effects of operating parameters on CIBAI combustion.

- A parametric study was conducted to study the effect of compression ratio, intake temperature, air-charged pressure, air-fuel ratio, and air-injection timing on CIBAI combustion.

- A computer code (Appendix A) was developed and integrated within a graphical user interface (GUI) to analyze the CIBAI cycle, implement the numerical model, and perform the parametric study.

- Model results were compared with experimental data to validate the ability of the numerical model to predict the effect of operating parameters on CIBAI combustion.

- Air-injection design recommendations, and conclusions were provided based on the results obtained through CIBAI experimentation and modeling. 


\section{Chapter 3: Literature Review}

\section{Auto-Ignition}

In SI engines auto-ignition is defined as the ignition of the air-fuel mixture during the compression stroke before the spark plug fires. Auto-ignition increases the combustion chamber temperature and under certain conditions leads to a knock or detonation reducing the power output and efficiency. The knock appears as a spontaneous and excessive pressure rise rate within the cylinder chamber. It has been found to be related to octane number, degree of mixing, and compression ratio. Fuels with low octane number have more propensity to the knock. SI Engines operating with high compression ratios need to use high octane number fuel to prevent the knock.

The mechanisms of auto-ignition and subsequent knock phenomena have been the subject of intensive research since the beginning of the automotive industry. Studies in the auto-ignition of hydrocarbons are normally done using constant-volume bombs, rapid compression machines, shock tubes, and cooperative fuel research CFR engines. Ricardo [7] and Erren and Campbell [8] indicated the importance of detecting and eliminating abnormal combustion phenomenon for a smooth operation of an IC engine. Experiments carried out by King [9], and King and Rand [10] indicated that "hot spots," such as spark plugs, exhaust valves, and the formation of deposits in the combustion chamber as the result of pyrolysis of lubricating oil could cause auto-ignition.

Obert [11] stated that the factors controlling auto-ignition or spontaneous chemical reaction are: temperature, pressure, ignition delay (ID), air-fuel ratio, the presence of inert gases, and in some cases turbulence. He used the auto-ignition model illustrated in Figure 3.1 to explain the correlation among those factors. Line AB'C 
represents a homogeneous air-fuel mixture with a particular condition of pressure, temperature, and air-fuel ratio. This mixture has been rapidly compressed at a certain compression ratio and held at high pressure and temperature, but has not been able to self-ignite; it rather cooled down after a short period of time. Lines $A \mathrm{~B}^{\prime \prime} \mathrm{C}^{\prime} \mathrm{D}$ ' and $A B$ "' $C$ "D" represent the same mixture, but compressed at a higher compression ratio. This mixture is held at higher pressure and above its self-ignition temperature, reaching self-ignition after a short induction time (ignition delay). The ignition delay is shown to be shorter for mixtures compressed at higher temperature.

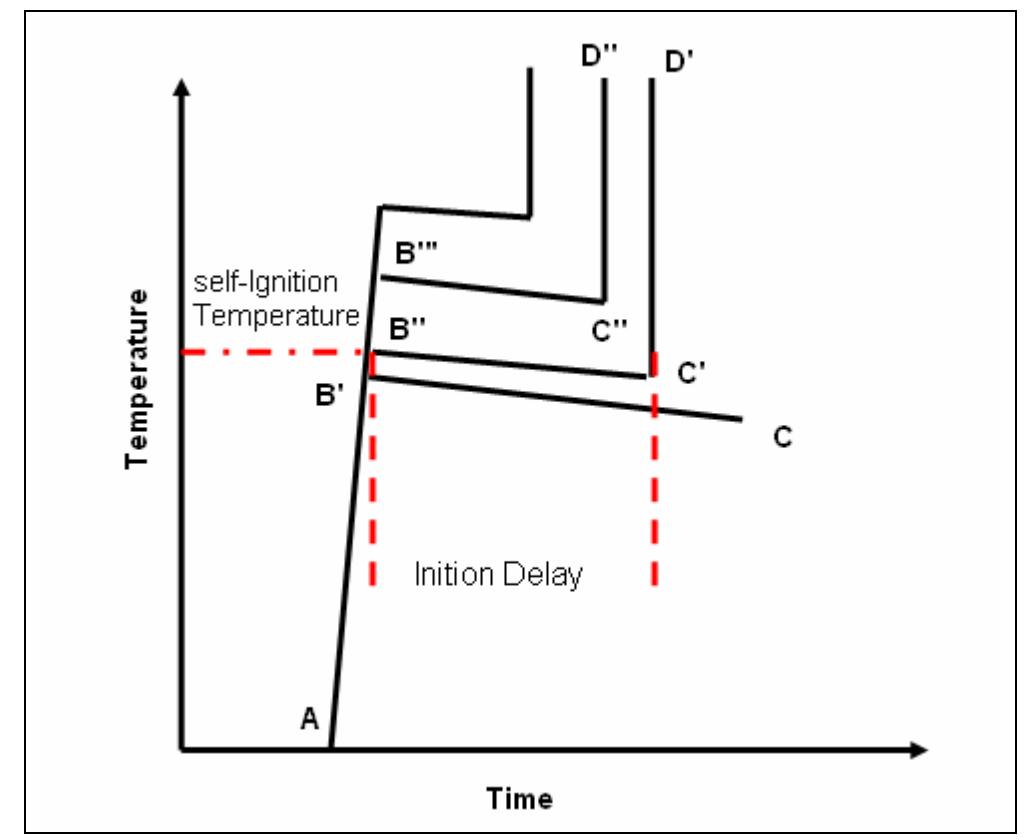

Figure 3.1 Ignition delay and the self-ignition temperature [11]

Miller [12], and Haskell and Bame [13] have proposed a detonation wave as a mechanism for auto-ignition. This shock wave is assumed to travel through the combustion chamber at supersonic velocity, compressing the unburned mixture at pressures and temperatures where auto-ignition occurs almost instantaneously [11]. 


\section{Controlled Auto-Ignition (CAI) \\ Overview}

Controlled auto-ignition (CAI) is defined in the literature as a combustion process which involves the auto-ignition and simultaneous combustion of a homogeneous air-fuel mixture [4]. This chemical kinetics process is characterized by the absence of flame propagation, the near simultaneous oxidation of the entire cylinder charge, rapid heat release rates, small cyclic pressure variations, and very low $\mathrm{NO}_{\mathrm{x}}$ emissions [14]. CAI combustion combines features of both SI and CI combustion since the fuel is exposed to conditions of compression heating suitable for auto-ignition, yet the air-fuel mixture is homogeneous.

In recent years, CAI combustion has emerged as an alternative to SI and CI combustion due to the decrease in exhaust emissions and improvement in fuel economy. CAI produces extremely low $\mathrm{NO}_{\mathrm{x}}$ emissions and almost zero $\mathrm{PM}$ emissions due to the absence of high temperature regions and nonexistence of localized fuel-rich regions [15]. Its fuel economy can approach the level of conventional diesel engines due to the fast burning rate, lean combustion, absence of throttling, and the removal of knock tendency [14].

However, its application in a production engine has been limited due to highpeak pressures, high $\mathrm{HC}$ and $\mathrm{CO}$ emissions, and the difficulty in timing of the autoignition and heat release rate over the entire engine operational range [16].

Researchers have given different names to controlled auto-ignition (CAI), including: active thermo-atmosphere combustion (ATAC) [14], activated radical (AR) combustion [17], injection assistee par air comprime (IAPAC) [18], homogeneous charge 
compression ignition (HCCI) [19], compression-ignited homogeneous charge (CIHC) combustion [20], premixed charge compression ignition (PCCI) [21], and compression by air injection (CIBAI) $[3,5]$. The most relevant of those CAI combustion processes are described next.

\section{Earlier Research}

One of the first reported works in CAI is attributed to Onishi et al. [14]. They developed a new technique, called "Active Thermo-Atmosphere Combustion (ATAC)." They studied lean combustion of two-stroke spark-ignition engines and found that abnormal combustion and auto-ignition could be used effectively to control combustion of lean mixtures without a need of an initial ignition source such as an electrical spark. ATAC combustion ignites a homogeneous air-fuel mixture by controlled auto-ignition relatively early in the compression stroke $\left(30^{\circ} \mathrm{CA}\right.$ bTDC $-70^{\circ} \mathrm{CA}$ bTDC), as compared to conventional two-stroke engines $\left(20^{\circ} \mathrm{CA}\right.$ bTDC $-45^{\circ} \mathrm{CA}$ bTDC). They reported significant reduction of $\mathrm{NO}_{\mathrm{x}}$ emissions, stable combustion using lean mixtures at partthrottle operation, smooth combustion with a little cycle-to-cycle variation, and improvement in thermal efficiency. Onishi et al. [14] stated that the conditions to achieve stable auto-ignition include uniform air-fuel mixture from cycle to cycle, highcombustion chamber temperature, and the proper ratio of a new mixture to residual gases.

Najt and Foster [20] from the University of Wisconsin-Madison conducted extensive research in a CAI technique, termed "Compression Ignited Homogeneous Charge (CIHC)." The objective of this research was to evaluate the impact of changes in the operating parameters in the ignition and energy-release processes. The experiments were conducted using a single-cylinder four-stroke cycle Waukesha CFR engine with a 
pressurized fuel intake and exhaust systems. These systems allowed control of the intake temperature and the mixing of fresh air and exhaust products. Their experimental results indicated high-compression-ratios advanced ignition and drastically increased energyrelease rates. Satisfactory ignition and a smooth energy release were obtained with a compression ratio of 7.5:1. They also observed that variations in the air-fuel ratio from the fuel-lean limit to stoichiometric advanced the point of ignition and produced a rapid increase in the energy-release rate. Suitable ignition and smooth-combustion operation were obtained with an air-fuel ratio of 0.8 . On the other hand, they stated that increase in the engine speed reduces the time available for the low-temperature (below $1200{ }^{\circ} \mathrm{F}$ ) oxidation kinetics which lead to spontaneous ignition to occur, and thus ignition becomes delayed or unattainable. Exhaust-gas recirculation (EGR) was used to increase the temperature of the intake mixture, but it was found that the chemical species in the exhaust gas did not have any significant role in the ignition process. This is due to the increase in the mass of inert gases in the combustion chamber and the subsequent decrease in the combustion temperature. Finally, the authors concluded that variations in the type of the fuel used modifies the CIHC combustion process by changing the lowtemperature (below $1200{ }^{\circ} \mathrm{F}$ ) oxidation kinetics, but it did not affect the high-temperature (above $1300{ }^{\circ} \mathrm{F}$ ) heat-release process since similar $\mathrm{CO}$ and $\mathrm{H}_{2}$ oxidation reactions prevail for all fuel types.

\section{Fundamentals of CAI Combustion}

Controlled auto-ignition (CAI) combustion is considered a pure, chemicalkinetics process marked by a homogeneous oxidation of an air-fuel mixture and gas, residual products. This statement has been supported by earlier research conducted by 
Onishi et al. [14], Najt and Foster [20], Haskell [22], and Noguchi et al. [23]. Flow visualization techniques such as Schlieren photographs used on some of those experiments have not shown any evidence of passing flame fronts, hot-spot ignition sources or particle-induced ignition.

Most of the literature on chemical kinetics agreed to classify the reaction route for alkene fuels into three distinct chain-branching regimes: low $\left(<900{ }^{\circ} \mathrm{F}\right)$, intermediate $\left(1000-1200{ }^{\circ} \mathrm{F}\right)$, and high $\left(>1300{ }^{\circ} \mathrm{F}\right)$. For the low regime, the leading fuel reactions are chain-propagating steps, pertaining to oxygen molecules and producing a series of complex partial oxidized species [24]. For the intermediate regime, the main fuel reactions are still chain-propagating steps, pertaining to oxygen molecules, but producing conjugate alkenes and $\mathrm{HO}_{2}$ radicals [25]. For the high regime, the principal fuel reactions included thermal decomposition by C-C bond-breakage, forming alkenes and smaller radicals [26].

Similarly, Najt and Foster [20] indicated that CAI combustion is controlled by two distinct kinetics mechanisms: a low-temperature (below $1200{ }^{\circ} \mathrm{F}$ ) kinetics mechanism, which controls the first stage of ignition, and a high-temperature (above $1300{ }^{\circ} \mathrm{F}$ ) mechanism, which controls the start of the main ignition and the energy-release process. Their findings have been supported by numerous experimental studies including the work of Westbrook [27,28], and Halstead and Kirsch Kelly [29].

This research focuses on producing an overall understanding of the basic mechanisms involved in compression ignition by air injection (CIBAI) in a CFR engine and does not concentrate on providing a detailed evaluation of the specific chemical species and reactions involved. 


\section{Modeling CAI Combustion}

Until recently, the majority of the studies on CAI combustion have been limited to experimental work due to the complexity of the chemical reactions. However, with the advent of high-speed computers and with a better understanding of the hydrocarbon chemistry, new theoretical formulations have been presented to describe the CAI combustion. CAI combustion models are mainly divided into single-zone models and multi-zone models.

Single-zone models have been used by Fiveland and Assanis [30] to simulate a four-stroke natural gas HCCI engine, Goldsborough and Van Blarigan [31] to model a hydrogen HCCI engine, Xu et al. [32] to study the characteristics of HCCI combustion in a four-stroke automotive engine, and by Dec [33] to investigate combustion emission in a HCCI engine. These models can predict ignition timing, heat release rates, and exhaust emissions.

In a multi-zone model the combustion chamber is divided into a specific number of zones that have particular mixture composition and initial pressure and temperature prescribed. Multi-zone models have been used by Najt and Foster [20] to evaluate the response of a CIHC engine to changes in operating parameters, Aceves et al. [34] to predict HCCI combustion and emissions, and by Easley et al. [35] to explore the effects of temperature stratification, heat loss and crevice volume on the HCCI combustion process and exhaust emissions.

\section{Recent Research in CAI Combustion}

During the last decade research in CAI Combustion has moved from research institutes and universities to the automotive industry. This new research effort has been 
focused on achieving stable CAI combustion and controllable heat-release rate over the entire engine operational range. This research has been primarily conducted in two areas: variations in the thermo-chemical properties of the mixture and changes in the engine operation parameters.

The first area of research includes modification of the reactivity of the air-fuel mixture by altering its thermo-chemical properties. To this aim, several techniques have been used. These include changes in the intake temperature, variation of the air-fuel mixture, exhaust gas recirculation (EGR), and the use of additives and fuel modifications. Aceves et al. [34], Griffiths et al. [36], and Curran et al. [37] have indicated that higher intake temperature increases the heat release rate, advances the start of the first stage of ignition, and reduces the ignition delay.

Christensen et al. [38] studied the characteristics of CAI combustion using isooctane, ethanol, and natural gas (NG), and compared their results with SI operation. Experiments were carried out using a 1.6 liter single cylinder engine with a fixed compression ratio of 21:1 in CAI operation and 12:1 in SI operation. Stable CAI combustion was achieved for all three fuels with the same compression ratio. CAI combustion was obtained for isooctane ran unthrottled without heating. The intake temperatures of $170{ }^{\circ} \mathrm{F}$ and $250{ }^{\circ} \mathrm{F}$ were required to achieve CAI combustion for Ethanol and natural gas $(\mathrm{NG})$ respectively.

Ishibashi [39], Christensen et al. [40,41], and Flowers et al. [42] have demonstrated the influence of the mixture composition in the CAI timing. They reported that rich mixtures tend to increase the ignition delay while lean mixtures tend to decrease 
the ignition delay. This may be explained by the changes in the specific heat ratios $(\gamma)$ that directly affect the quantity of disposable compression heating in the charge [4].

Law and Allen [43] and Law et al. [44] investigated the effects of exhaust gas recirculation (EGR) and/or trapped residuals in CAI combustion. They developed and implemented a two-exhaust valve control strategy in a single cylinder four-stroke engine. Their objective was to separate the thermal and chemical effect of EGR by injecting nitrogen and oxygen as a substitution. Nitrogen was heated to the same temperature of the exhaust residual gas and injected in the intake manifold. They found that nitrogen, due to its chemical inert nature, has the ability to delay combustion and smooth the heatrelease rate. Oxygen injection was found to have a direct effect on the start of the ignition for intake temperatures greater than $250{ }^{\circ} \mathrm{F}$ and produce unmanageably high pressures similar to the knock phenomena. This was attributed to the oxygen's chemical nature.

Fuel modifications and additives have been used to accelerate or reduce the start of the ignition and control the heat-release rate. Flowers et al. [42] added dimethyl-ether (DME) while conducting experiments with a CFR engine running with methane fuel. They improved CAI combustion and heat-release rate by adding 15\% DME (by volume). Ryan III et al. [45], and Jeuland et al. [46] carried out experiments to determine the fuel requirements for CAI combustion. They concluded that the fuel formulation plays a very important role in determining the operation range of CAI combustion and engine efficiency.

Water injection, a dilution technique normally used in hydrogen IC engines to reduce backfire and pre-ignition problems, was used by Christensen et al. [47] to affect 
the start of the ignition and heat release rate. They observed an increase in the ignition delay, a reduction of the heat-release rate, and an increase in $\mathrm{HC}$ and $\mathrm{CO}$ emissions.

The second area of research includes changes in the engine-operation parameters. The objective of this approach is to control auto-ignition (CAI) and obtain smooth heatrelease rate by affecting the time-temperature history of the mixture, for several engineoperation conditions. Changes in compression ratio, engine speed, variable valve timing (VVT), and supercharging have been extensively studied.

The effect of compression ratio on CAI combustion has been widely discussed in the literature. A higher compression ratio increases the thermal efficiency, and the temperature of the air-fuel mixture, and thus advances the start of the ignition $[3,5,40,41,45,48,49,50]$. Najt and Foster [20] earlier indicated that the engine speed did not affect the CAI combustion.

Variable valve timing (VVT) technique has been implemented by Law and Allen [43] and Law et al. [44]. They designed a special engine with a digitally-controlled, electro-hydraulic variable train system, which allowed changes in the valves opening profiles. Researchers indicated that this new technology has the potential for controlling CAI combustion and reducing $\mathrm{NO}_{\mathrm{x}}$ emissions.

Kontarakis et al. [51] demonstrated the HCCI concept using a single cylinder four-stroke SI engine with modified valve timing. They obtained stable CAI combustion for a compression ratio of 10.3:1 by applying a late inlet opening, early exhaust valve, closing valve-timing strategy.

Ogura et al. [52] used an intake and exhaust continuous variable valve timing mechanism in a premixed gasoline engine to control HCCI combustion. They concluded 
that it is possible to control the temperature in the cylinder during ignition timing by controlling early exhaust valve closing timing.

Supercharging has been used as a technique to increase the indicated mean effective pressure (IMEP) by increasing the mixture intake pressure. Christensen et al. $[40,41]$ experimented with different compression ratios and boost pressures. They reported an increase in the IMEP and a broader CAI combustion operation range.

Yap et al. [53] used hydrogen addition on a natural gas HCCI combustion engine to lower the minimum intake temperature required for auto-ignition of natural gas. Authors reported a significant reduction on the intake temperature at part load due to hydrogen's lower auto-ignition temperature and minimum ignition energy (MIE), and wider flammability limits (4-75\% by volume).

Recently, a number of studies have been done on controlled auto-ignition (CAI) combustion of gasoline engines. Oakley et al. [54] experimented with a four-stroke gasoline engine operating at $900 \mathrm{rpm}$ with a compression ratio of 11.5:1 and using unleaded gasoline with an anti knock index (AKI) of 90. They obtained stable CAI combustion for an intake temperature of $600^{\circ} \mathrm{F}$, and air-fuel ratio in excess of 80:1 with a maximum EGR rate of $60 \%$. They obtained very low $\mathrm{NO}_{\mathrm{x}}$ emissions at full load, and very high levels of $\mathrm{HC}$ and $\mathrm{CO}$ emissions at part load.

Zhao et al. [55] obtained stable CAI combustion at part load without intake charge heating or increasing compression ratio in a production 1.7 Liter Zetec SE 16 valve fourstroke, four-cylinder port fuel injection gasoline engine, with a compression ratio of 10.3:1. They used a mechanical variable camshaft timing (VCT) system as presented by Lavy et al. [15]. They increased the amount of the residue through the extended valve 
overlap by a combination of the early intake valve opening (IVO) and the retarded exhaust valve closing (EVC). They reported a reduction of almost $99 \%$ in $\mathrm{NO}_{\mathrm{x}}$ emissions and a significant improvement in brake specific fuel consumption (BSFC) and CO emissions.

Hiraya et al. [56] conducted studies on a gasoline-fueled, compression-ignition, single-cylinder engine under various compression ratios, intake temperatures, and intakegas compositions. They found a strong correlation between the timing for the onset of HCCI combustion and the intake-air temperature, and between the combustion duration and the air-fuel mixture composition. For compression ratio of 15:1 and an engine speed of $1200 \mathrm{rpm}$, researchers obtained stable and moderate CAI combustion for air-fuel ratios between $40: 1$ to $80: 1$ (by volume) and intake temperature between 350 and $550{ }^{\circ} \mathrm{F}$.

Yamaoka et al. [57] studied the influence of fuel injection timing on the stability of CAI combustion. Researchers experimented with a four-stroke, four-cylinder gasoline engine with a compression ratio of 12:1 and an intake temperature of $90^{\circ} \mathrm{F}$. The engine was equipped with a controller and an electric variable valve actuator to control the valve events and timing, and with an in-cylinder direction system. They observed reduced torque variance that occurred due to combustion instability, and significant reduction of $\mathrm{NO}_{\mathrm{x}}$ and $\mathrm{HC}$ emissions.

CAI combustion has been demonstrated to achieve stable heat release rate and reduced $\mathrm{NO}_{\mathrm{x}}$ emissions at part load. However, the main challenge remains to obtain stable combustion and a smooth heat-release rate at full load. Olsson et al. [58] proposed the use of turbo-charging or a mechanically-driven compressor to force more mass into an HCCI engine to recover some of the power loss due to EGR dilution. Experiments 
were conducted using a modified six-cylinder, turbo-charged diesel engine. The fuel selected for this study was a combination of heptane and ethanol because of the high octane number of the ethanol. After multiple boosting strategies, authors concluded that it is not possible to boost a HCCI engine to the maximum load of a present-day diesel engine.

Zhao et al. [55] proposed to adopt a hybrid engine operation of SI and CAI combustion in order to implement CAI technology in a production vehicle. They suggested using CAI combustion at part load to obtain maximum benefit of low $\mathrm{NO}_{\mathrm{x}}$ emissions and lean combustion, and using SI combustion at full load to sustain its maximum power and torque output.

Leach et al. [59] carried out experiments intended to control CAI combustion through injection timing in a gasoline direct injection (GDI) engine with an air-assisted injector. These experiments were done using a four-stroke, single-cylinder, Ricardoresearch engine, with a compression ratio of 9:1. This engine operated under CAI combustion by residual gas recirculation (EGR). Small quantities of compressed air were injected together with the fuel at approximately 100 psig. Air was injected at exhaust valve closure (EVC), intake valve opening (IVO) and BDC of the intake and compression strokes. Unleaded gasoline with a research octane number (RON) of 95 was used for all tests. The results of this study indicated that a proper air injection strategy has the potential to increase the operability range of CAI combustion, improve the fuel ignitability, advance the ignition timing, and reduce $\mathrm{HC}$ and $\mathrm{CO}$ emissions. 


\section{Chapter 4: Compression Ignition by Air Injection (CIBAI)}

\section{Overview}

Loth and Morris [3,5] patented a new thermodynamic cycle for piston type internal combustion, which Loth named "Compression Ignition by Air Injection (CIBAI)." The CIBAI cycle offers an IC engine capability to increase thermal efficiency, operate with a wide range of fuels, ignite rapidly very lean, fuel-air mixtures, and reduce $\mathrm{NO}_{\mathrm{x}}$. They indicated that the CIBAI cycle can be more efficient than the Otto or Diesel cycle, and be simpler as it does not require high maintenance items like spark-plug ignition systems, or high-pressure, diesel-type fuel pump and fuel injectors. The CIBAI cycle offers an alternative to spark- and compression-ignited engines, with auto-ignition timing, controlled by a cylinder-connecting valve. When it opens, hot-high-pressure air is injected into the adjacent cylinder, which contains pre-mixed air and fuel.

\section{Earlier Research}

In 1993, Loth et al. [60] patented a new IC combustion engine, called "Isolated Combustion and Diluted Expansion (ICADE) piston engine. The ICADE engine is a piston-cylinder assembly, used for the compression of air and expansion of diluted combustion products. The authors indicate that improvement in thermal efficiency and exhaust-pollution reduction can be obtained in the ICADE engine because the piston motion is used as a valve to isolate a small-cylinder volume, in which fuel injection and combustion are induced by auto-ignition.

In the ICADE engine combustion products are injected tangentially into a doughnut-shaped chamber, formed by the piston-cylinder clearance. The vortex produced in this compartment, induced by the combustion pressure, creates rapid mixing and fast 
cooling, preventing the $\mathrm{NO}_{\mathrm{x}}$ formation reactions, and the generation of vortex kinetic energy reduces the combustion pressure peak acting on the piston surface. Other benefits reported include the rapid burning of lean mixtures, allowing low octane fuel, and the elimination of the engine throttle valve to control engine power output, which otherwise reduces the compression ratio, and thereby thermal efficiency.

\section{CIBAI Concept}

Loth and Morris [3, 5] explained the CIBAI cycle concept as follows:

"The CIBAI cycle requires two or more adjacent cylinders to work in tandem. Typically one of the cylinders contains a conventional fuel-air mixture, except with double the usual fuel-air ratio and uses a conventional compression ratio in accordance to the fuel octane rating. The adjacent cylinder compresses only air, but to a much higher compression ratio, at least double, that in the air-fuel cylinder. At top dead center its compression volume is less than half that of the adjacent air-fuel cylinder. Only during the compression stroke are the two adjacent cylinder volumes separated from oneanother by a valve. Near top-dead center, when this valve opens, most of the highpressure air transfers into the other cylinder, thereby compressing, heating and producing controlled auto-ignition in the leaned fuel-air mixture. This allows complete combustion, even with very lean mixtures, while both pistons are near top dead center. The cylinder-connecting valve (CCV) remains open during the entire power stroke to equalize the pressure in both cylinders. The expansion ratio is then the mean value of the compression ratio in both cylinder pair. Both the high combustion compression by autoignition and high expansion ratio is what renders the CIBAI cycle more efficient than 
either the limited compression ratio spark ignition Otto cycle or the low combustion compression of the Diesel cycle with its ignition delay by fuel injection.”

A four-stroke configuration of an engine operating on the CIBAI cycle is shown in Figure 4.1. Its only additionally component is a cylinder-connecting valve (CCV), required to first transfer hot, high-pressure air for ignition, and subsequently combustion products in the other direction. Auto-ignition timing is controlled by the opening of the CCV valve.

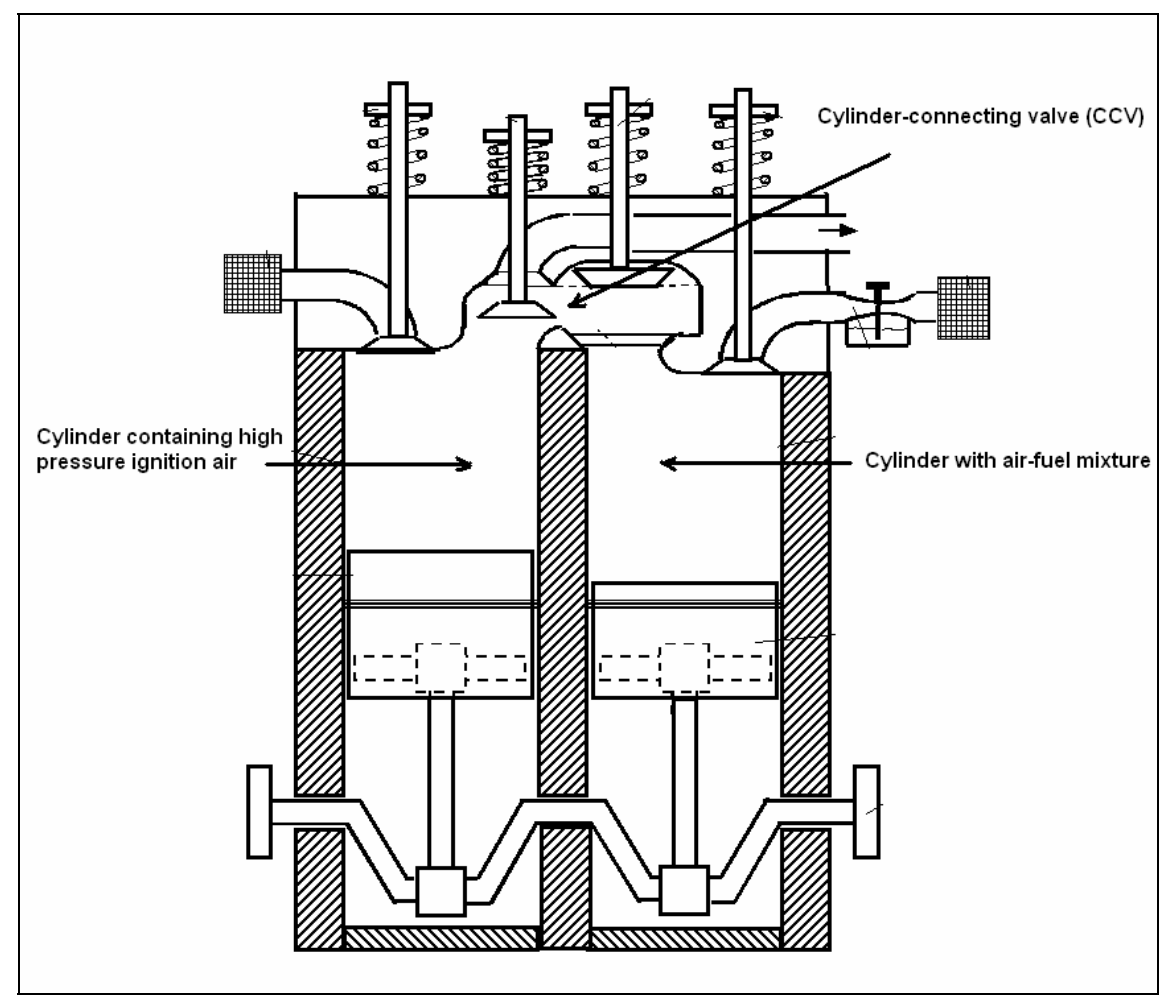

Figure 4.1 Four-stroke engine operating on the CIBAI cycle [3,5]

\section{CIBAI Benefits and Applications}

In addition to the high thermal efficiency, and the elimination of the need for a throttle valve, spark ignition, or high-pressure fuel injectors, Loth and Morris [3, 5] indicate that the CIBAI cycle has the potential to decrease $\mathrm{NO}_{\mathrm{X}}$ emissions and exhaust 
pipe loss due to the overall increase in expansion ratio in both cylinders. They pointed out five additional advantages of the CIBAI cycle:

1. Lower cost and increased reliability by reducing the components.

2. Avoiding the cold starting problem of the diesel engine because in CIBAI fuel-air mixture is fully mixed and pre-evaporated just like in the Otto cycle.

3. Applicable to any size engine, ranging from large ship engines to small engines such that of UAV's and lawn mowers, unlike the diesel engine, which requires a minimum displacement for accurate flow-metering during high-pressure fuel injection.

4. Capable of operating with low emissions in two-stroke engines by having two different cylinders, one only for air and fuel intake, while the other is only used for air intake and combustion product exhaust. This eliminates the possibility for unburned fuel to escape out of the exhaust port.

5. Increased safety is realized in a hydrogen engine as one cylinder compresses only hydrogen while the other only air, and these two gases only get to mix at the desired time of ignition when the CCV valve opens. Thus producing shaft power with hydrogen fuel in a CIBAI cycle is much safer than compressing a hydrogen-air mixture in a spark ignition engine because of its flammability limit (4-75\% volume). Also the use of hydrogen is problematic in a fuel injected engine. Its low density increases the time required to inject sufficient fuel and also requires significant power to compress the hydrogen gas for cylinder injection.

In the second (CIBAI) patent Loth and Morris [5] listed the advantages of preheating and pressurizing a solid-oxide fuel cell with a CIBAI cycle engine. This allows extracting shaft power both during heating and pressurization, and also by using fuel cell 
exhaust gas which still contains up to $20 \%$ hydrogen. Figure 4.2 shows a schematic diagram of the use of a CIBAI cycle engine in combination with a high temperature solid-oxide fuel cell to boost the overall conversion efficiency.

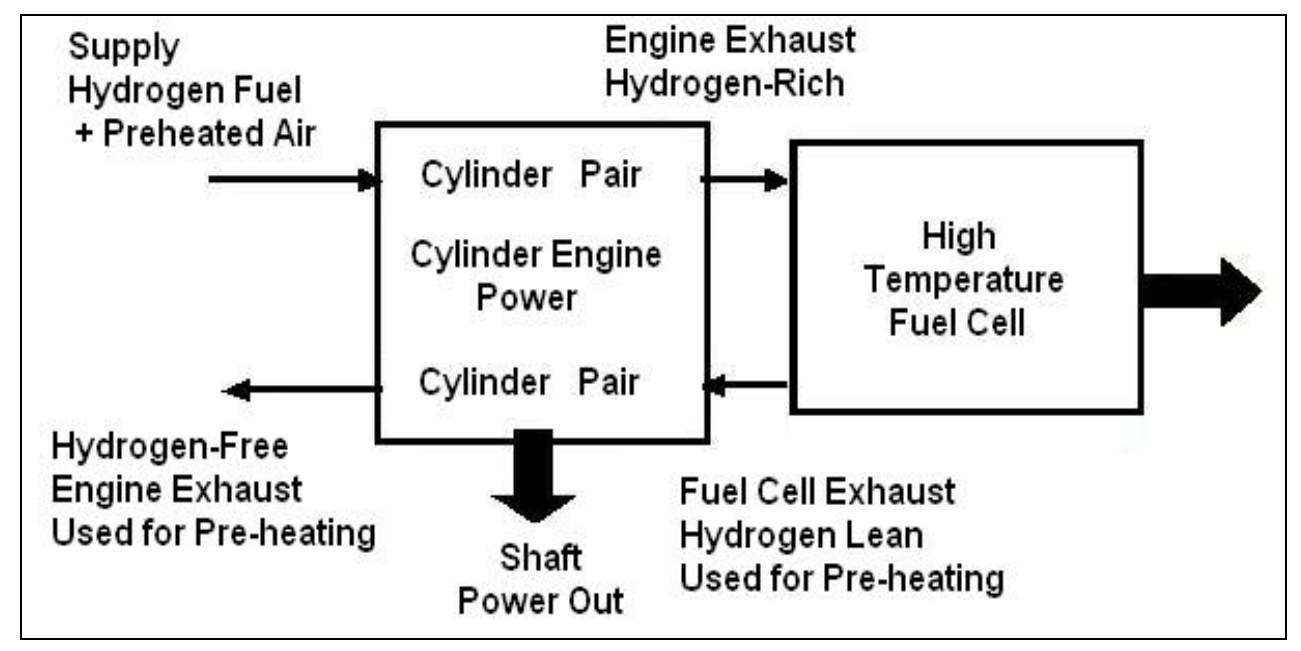

Figure 4.2 CIBAI engine in combination with a fuel cell [3,5]

\section{Thermal Efficiencies Comparison}

The cold-air standard thermodynamic theoretical efficiency for the three cycles:

Otto, Diesel, and CIBAI cycles are shown for comparison in both the equation and graphical form (Figure 4.3)

Otto Cycle Thermal Efficiency:

$$
\eta_{\text {Oto }}=1-\frac{1}{(C . R)^{\gamma-1}}
$$

Diesel Cycle Thermal Efficiency:

$$
\eta_{\text {Diesel }}=1-\frac{1 *\left(\beta^{\gamma}-1\right)}{(C . R)^{k-1} * \gamma^{*}(\beta-1)}
$$

CIBAI Cycle Thermal Efficiency:

$$
\eta_{\text {Cibai }}=\left[\frac{W_{\text {out }}}{Q_{\text {in }}}=\frac{r_{\text {vaf }}^{(\gamma-1)}-1+\left(r_{v a}^{(\gamma-1)}-1\right) * r_{m}}{\left.\left(r_{\text {vaf }}^{(\gamma-1)}+r_{\text {va }}^{(\gamma-1)} * r_{m}\right) * r_{c}-1\right)}\right]
$$


Thermal efficiency of the Otto cycle is only function of the compression ratio (C.R). As the compression ratio goes up, the thermal efficiency goes up. Thermal efficiency of the Diesel cycle is the function of the compression ratio (C.R) and cut-off ratio $(\beta)$. Cut-off ratio is defined as the change in volume that occurs during combustion. Thermal efficiency of the CIBAI cycle is the function of the air compression ratio $\left(\mathrm{r}_{\mathrm{va}}\right)$, fuel air compression ratio ( $\mathrm{r}_{\mathrm{vaf}}$ ), air-fuel mixture mass ratio $\left(\mathrm{r}_{\mathrm{m}}\right)$, and combustion induced temperature ratio $\left(\mathrm{r}_{\mathrm{c}}\right)$. A complete derivation of the thermal efficiency of the CIBAI cycle is presented in references [3,5]. Theoretically, CIBAI cycle has a higher thermal efficiency than Otto and Diesel cycle due to its second stage compression, prior to autoignition (Figure 4.3).

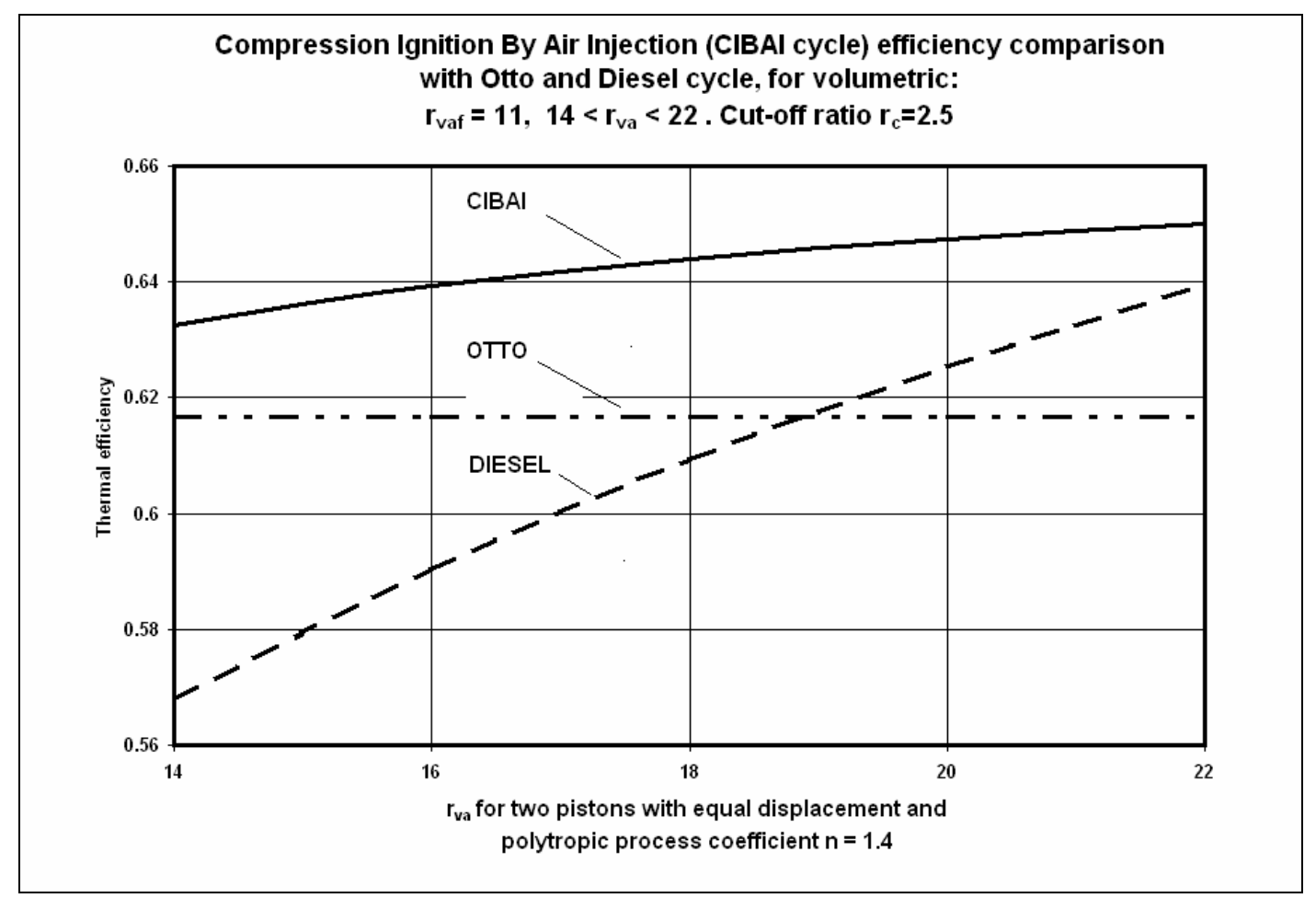

Figure 4.3 CIBAI cycle efficiency comparison with Otto and Diesel cycles [3,5] 


\section{Cold Air Standard CIBAI Cycle Analysis}

The cold air-standard CIBAI cycle is an ideal cycle, which assumes that heat addition occurs instantaneously at constant volume while both pistons are at TDC. Such a CIBAI cycle is shown on the pressure ratio $\left(\mathrm{P} / \mathrm{P}_{1}\right)$ and temperature ratio $\left(\mathrm{T} / \mathrm{T}_{1}\right)$ vs. crank-angle diagrams of Figures 4.4 and 4.5 respectively. The following assumptions were made to evaluate the cold air-standard CIBAI cycle.

- The fuel-air mixture and combustion product properties are the same as air for the entire cycle.

- The combustion process was replaced with a heat addition term $\mathrm{Q}_{\text {in }}$ of equal energy value.

- Compression strokes and expansion strokes were approximated by isentropic processes $(\mathrm{n}=1.4)$.

- The exhaust process was replaced with a closed system heat rejection process Qout of equal energy value.

- The combustion process was idealized by a constant-volume process.

- Air was treated as an ideal gas.

The CIBAI cycle consists of five processes in series. Process 1 is an isentropic compression process of the air as both pistons move from bottom dead center (BDC) to TDC (compression stroke). Process 2 is a constant volume process (combustion) which follows the opening of the cylinder-connecting valve (CCV). This valve allows the highpressure air to enter the-low-compression-ratio cylinder to compress heat, and ignite its fuel-air mixture. This valve remains open during the power stroke. 


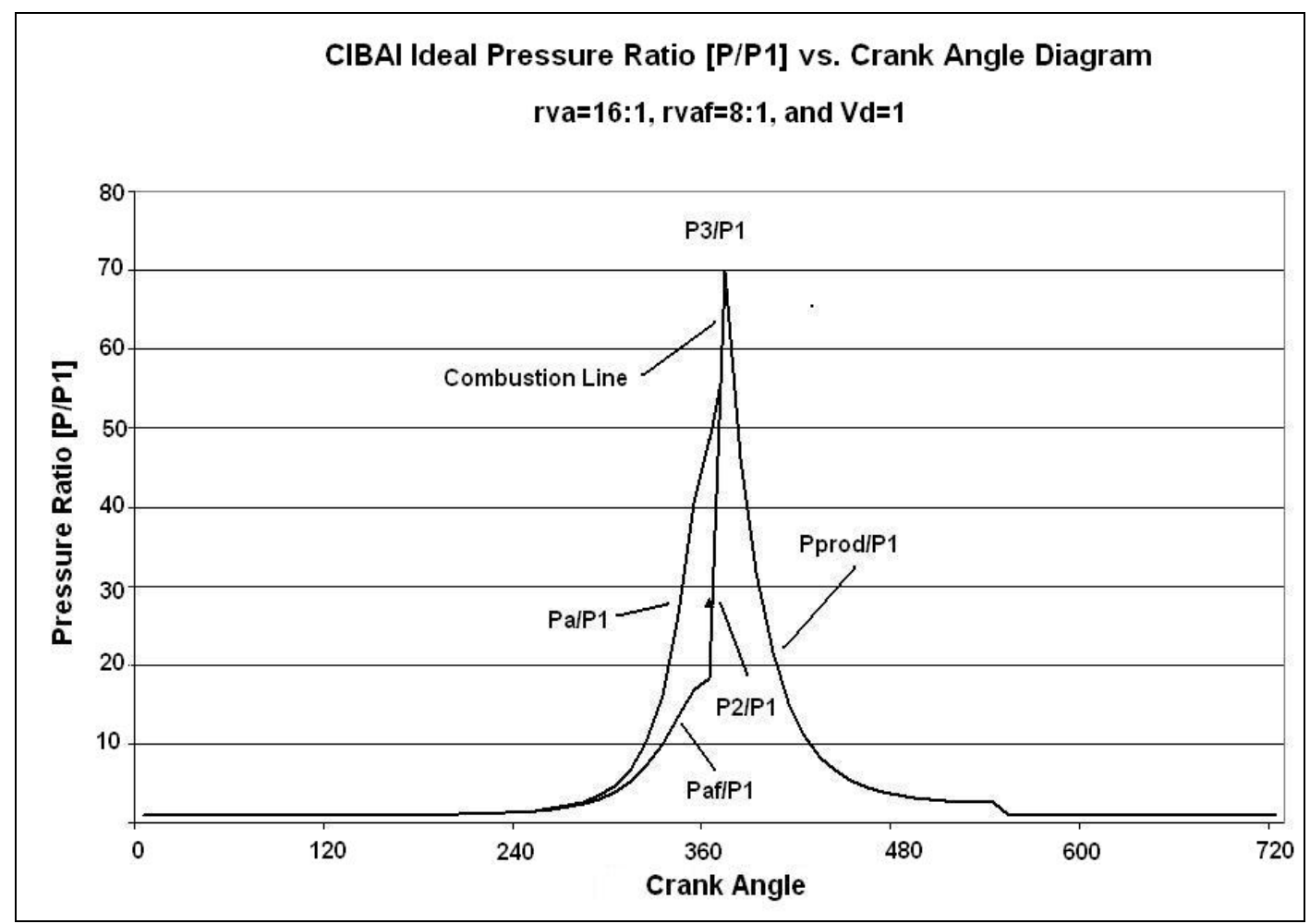

Figure 4.4 CIBAI cycle ideal pressure ratio $\left(\mathrm{P} / \mathrm{P}_{1}\right)$ vs. crank angle

The vertical line represents constant-volume heat addition indicating the instantaneous auto-ignition of the fuel-air mixture at the top dead center (TDC). This is followed by an isentropic expansion (power stroke). The cycle is completed by a constant-volume process, in which heat is rejected from the air while the piston is at BDC. The exhaust and intake strokes are represented by horizontal lines on scale $\mathrm{P} / \mathrm{P}_{1}=$ 1.0.

The set of equations for calculating the temperature and pressure ratios inside both cylinders (air-fuel and air-only) at any position during the expansion stroke are presented in references $[3,5]$. 


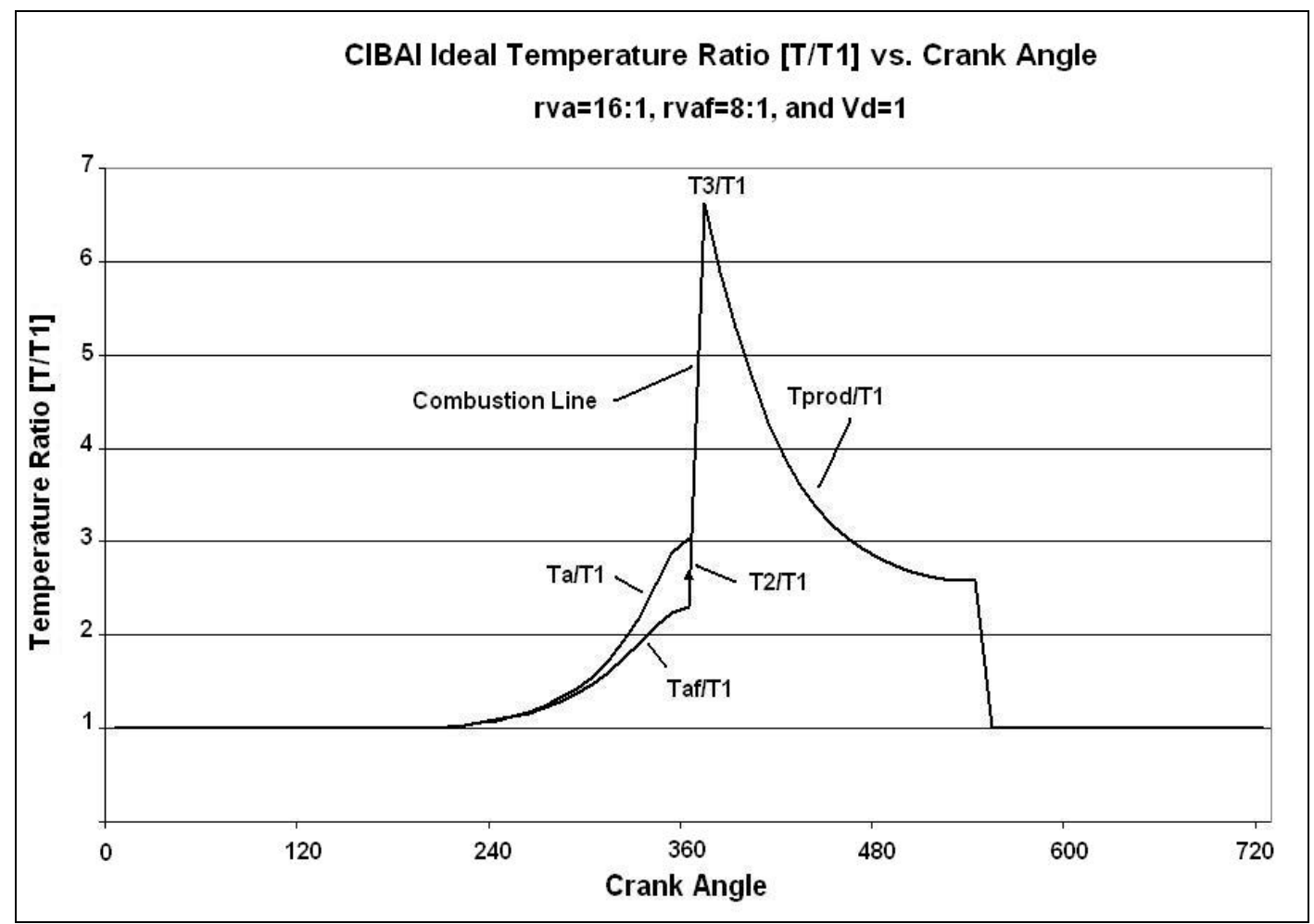

Figure 4.5 CIBAI cycle temperature ratio $\left(\mathrm{T} / \mathrm{T}_{1}\right)$ vs. crank angle 


\section{Chapter 5: The Analytical Model}

\section{Overview}

The objective of the analytical model presented here is the theoretical prediction of the influence of air-injection design parameters and operation variables in the compression ignition by the air-injection process. A cold-air-injection model is presented in chapter 6.

The thermodynamic cycle for controlled auto-ignition in a CFR engine is different from the CIBAI cycle above. The cold air from a bottle is pre-heated inside a pipe, placed inside the CFR engine exhaust. Its analytical model consists of two subsystems, a variable volume CFR engine combustion chamber and a fixed volume, containing hot, high-pressure air. These two compartments are normally isolated by a solenoid valve and a ball check valve, with an equivalent orifice-type, cross-sectional area $A_{0}$.

The combustion chamber and the air heater are modeled as separate thermodynamic systems with the outflow from the one, equal to the inflow into the other. This model is an extension of a model originally developed by El-Messiri [61], using a mathematical model developed by Borman [62], and thermodynamic properties obtained by Newhall and Starkman [63], using the data from the JANAF tables [64].

The solution to the model was used to generate the time histories of the air heater and combustion chamber thermodynamic properties throughout the cycle. Special attention is given to the combustion chamber pressure-time-volume history, which represents useful work produced per cycle. The schematic diagrams of the generalized thermodynamic model and the compression ignition by air injection model are shown in Figures 5.1, and 5.2 respectively. 


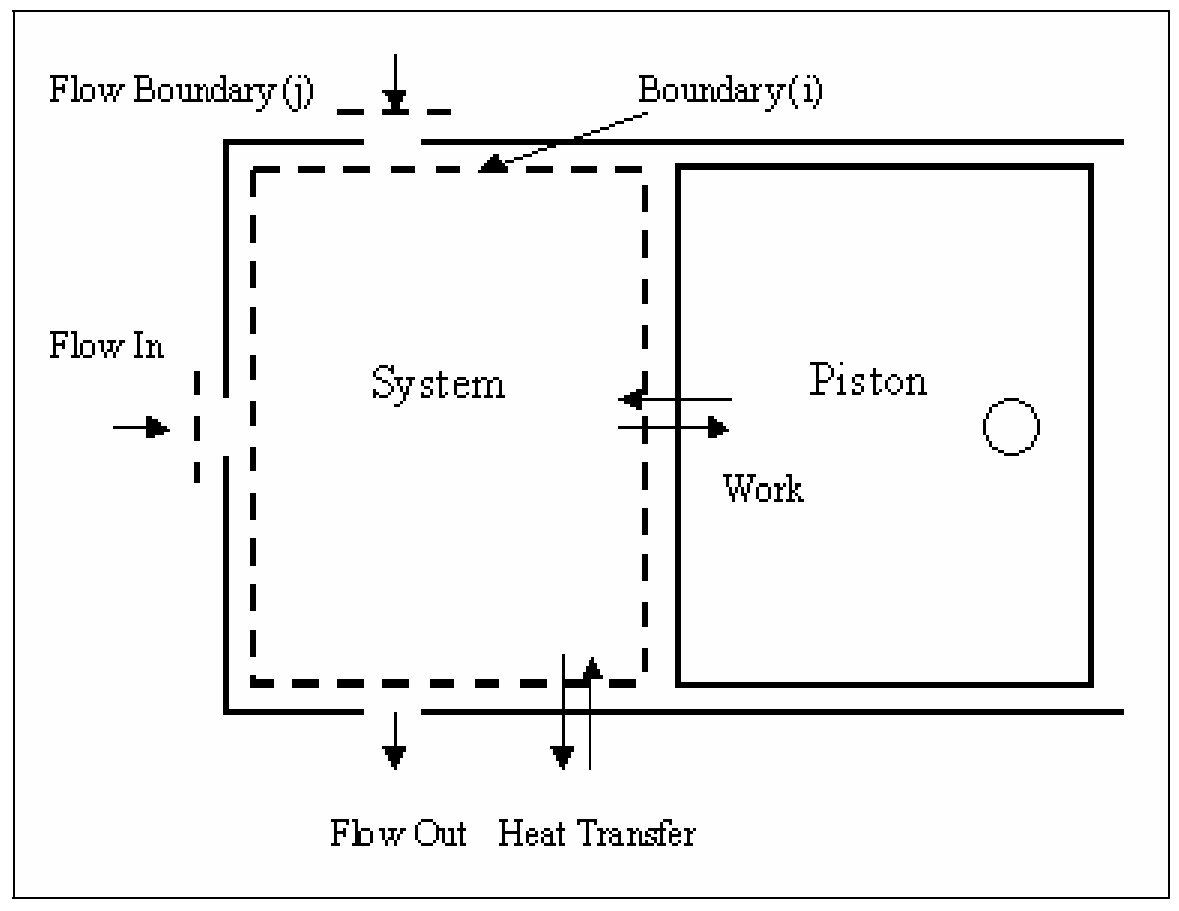

Figure 5.1 Generalized thermodynamic model [61]

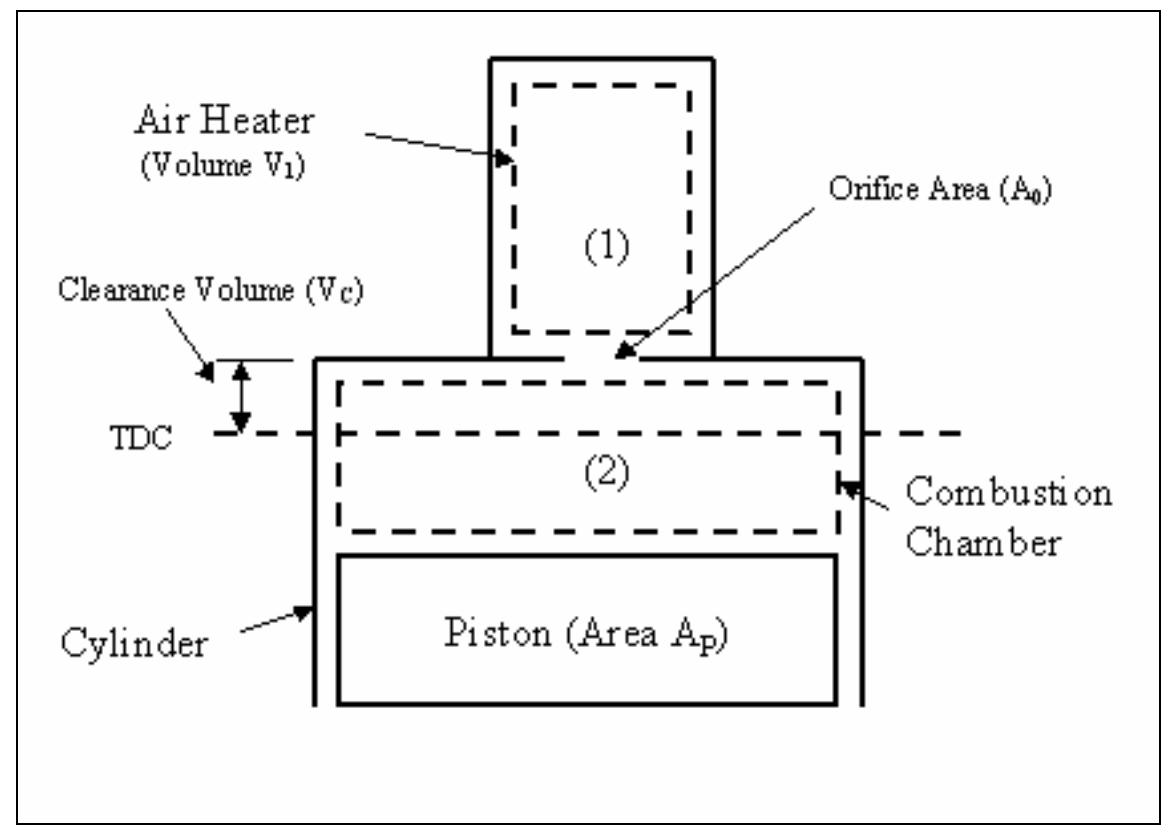

Figure 5.2 The compression ignition by air-injection (CIBAI) model 


\section{Assumptions}

The ideal cycle analysis is based on the following assumptions:

1. The first stage of combustion is assumed to occur instantly at a constant volume, leading to formation of equilibrated combustion products.

2. The high-temperature air flowing from the air heater into the combustion chamber mixes instantly and completely with the contents of the combustion chamber (fuel-air mixture).

3. Each subsystem is considered as a homogeneous system of uniform temperature, pressure, and composition.

4. Combustion products are assumed to behave as the cold-air standard.

5. Heat transfer from the gases to cylinder walls is neglected.

\section{Model Analysis and Governing Equations}

The generalized model has been solved using the first law of thermodynamics (conservation of energy), the equation of mass continuity (conservation of mass), and the equation of state, together with the thermodynamic property equations relating equilibrium combustion product properties to time dependent values of temperature (T), pressure (P), and effective fuel-air ratio (F), as proposed by Borman [62]. The solution obtained for the generalized model will be applied to the combustion chamber and air heater systems. 


\section{Governing Equations}

For the generalized thermodynamic system presented in Figure 5.1, the first law of thermodynamics (conservation of energy), the equation of mass continuity (conservation of mass), the equation of state, and the equilibrium combustion product equations are written as follows:

Conservation of Energy:

$$
\dot{\overline{M u}}=-P \dot{V}+\sum_{i} \dot{Q} i+\sum_{j} h_{j} \dot{M}_{j}
$$

Equation (5.1) is the time derivative version of the open-system energy balance. The left-hand side is the rate of change of the total energy of the system with time. The right-hand side consists of the work done due to the piston motion, the sum of the heat transfer rates across the boundaries of the system, and the sum of all energy flowing in and out of the system because of the mass transfer.

Conservation of Mass:

$$
\dot{M}=\sum_{j} \dot{M}_{j}
$$

The Equation of State:

$$
P V=M R T
$$

Equilibrium Combustion Products:

Borman [62] developed mathematical formulations to obtain the absolute internal energy $(\mathrm{u})$ and gas constant $(\mathrm{R})$ as a function of pressure, temperature, and fuel-air ratio. These formulations have the following forms:

$$
\begin{gathered}
u=u(T, P, F) \\
R=R(T, P, F)
\end{gathered}
$$




\section{Differential Equations for Temperature and Pressure:}

The differential equations for temperature and pressure are obtained from equations (5.1) to (5.5). The approach is to derive the equations in terms of the dependent variables $\mathrm{P}, \mathrm{T}, \mathrm{F}$, or related quantities that can be expressed in terms of these variables to facilitate the numerical solution. Time, $\mathrm{t}$, will be treated as the only independent variable. The resulting differential equations are coupled and non-linear; therefore, a numerical integration technique needs to be used to obtain a reasonable solution. The mathematical procedure is described next.

Applying the product rule to the left-hand side of equation (5.1) gives

$$
\stackrel{\bullet}{M u}=M \dot{u}+u \dot{M}
$$

Using the chain rule of differentiation for equation (5.4) yields

$$
\dot{u}=\frac{d u}{d T} \dot{T}+\frac{d u}{d P} \dot{P}+\frac{d u}{d F} \dot{F}
$$

Replacing (5.7) into (5.6), and the result equation into (5.1), and dividing equation (5.1) by mass $(\mathrm{M})$, the following differential equation is obtained:

$$
\frac{d u}{d T} \dot{T}+\frac{d u}{d P} \dot{P}+\frac{d u}{d F} \dot{F}+U \frac{\dot{M}}{M}=-R T \frac{\dot{V}}{V}+\sum_{j} h j \frac{\dot{M} j}{M}
$$

Equation (5.8) gives a relation between the pressure and temperature derivatives of the system. All other derivatives in equation (5.8) can be obtained in terms of the thermodynamic state variables, system geometry, and time. Another independent relation between the pressure and temperature derivatives is obtained by differentiating the equation of state (5.3) with respect to time as follows:

$$
P \dot{V}+V \dot{P}=\dot{M} R T+M \dot{R} T+M R \dot{T}
$$


Dividing equation 5.9 by PV yields the following equation

$$
\frac{\dot{V}}{V}+\frac{\dot{P}}{P}=\frac{\dot{M}}{M}+\frac{\dot{R}}{R}+\frac{\dot{T}}{T}
$$

Using the chain rule of differentiation for equation (5.5) yields

$$
\dot{R}=\frac{d R}{d T} \dot{T}+\frac{d R}{d P} \dot{P}+\frac{d R}{d F} \dot{F}
$$

Replacing (5.11) into (5.10) and rearranging terms gives the following differential equation

$$
\frac{\dot{V}}{V}-\frac{\dot{M}}{M}-\frac{1}{R} \frac{d R}{d F} \dot{F}=\frac{\dot{T}}{T}\left(\frac{T}{R} \frac{d R}{d T}+1\right)+\frac{\dot{P}}{P}\left(\frac{P}{R} \frac{d R}{d P}-1\right)
$$

Equation (5.12) gives a second relation between the pressure and temperature derivatives of the system. All other values, different from $\dot{T}$ and $\dot{P}$ in equation (5.12) can be obtained in terms of the thermodynamic state variables, system geometry, and time (t).

Equations (5.8) and (5.12) form a system of two independent, simultaneous, linear equations that can be solved together with the appropriate air-fuel ratio $(\dot{F})$, mass flow $(\dot{M})$, and volume change $(\dot{V})$ equations. The equilibrium thermodynamic properties of the products of combustion of $\mathrm{C}_{\mathrm{n}} \mathrm{H}_{2 \mathrm{~N}}$ and air ( $\mathrm{u}$, and $\mathrm{R}$ and the six partial derivatives) can be calculated as proposed by [62].

\section{Differential Equation for Air-fuel ratio (F):}

By definition the fuel-air ratio (F) is the ratio of the actual fuel-air ratio (f) to the stoichiometric, or chemically correct, fuel-air ratio $\left(\mathrm{f}_{\mathrm{s}}\right)$. The total mass at time $(\mathrm{t})$ is equal to the sum of the mass of fuel $\left(\mathrm{M}_{\mathrm{f}}\right)$ and the mass of air $\left(\mathrm{M}_{\mathrm{a}}\right)$. These relations are shown in equations (5.13), (5.14), and (5.15) respectively. 


$$
\begin{gathered}
F=\frac{f}{f_{s}} \\
f=\frac{M_{f}}{M_{a}} \\
M=M_{f}+M_{a}
\end{gathered}
$$

where:

$$
\begin{aligned}
& F=\text { Fuel-air air-fuel ratio } \\
& \mathrm{f}=\text { Actual fuel-air ratio } \\
& \mathrm{f}_{\mathrm{s}}=\text { Stoichiometric fuel-air ratio } \\
& \mathrm{M}=\text { Total mass } \\
& \mathrm{M}_{\mathrm{f}}=\text { Mass of fuel } \\
& \mathrm{M}_{\mathrm{a}}=\text { Mass of air. }
\end{aligned}
$$

Since the air-fuel ratio of the combustion chamber will be continuously changing during the air injection through the flow boundary $\mathrm{j}$, an "effective" air-fuel ratio for the mixture needs to be calculated. Following the same methodology presented by Borman, [62] the differential equation for $F$ was obtained.

$$
\dot{F}=\frac{1}{M_{a}}\left(\sum_{j} \frac{\dot{M}_{j} F_{j}}{1+f_{j}}\right)-\frac{M_{f}}{M_{a}^{2}}\left(\sum_{j} \frac{\dot{M}_{j}}{1+f_{j}}\right)
$$

\section{Mass Flow Rate Through the Orifice:}

Since the mass flow must enter through a restricted area, called here an orifice, the conservation of mass can be written as

$$
\dot{M}_{1}=-\dot{M}=-\dot{M}_{2}
$$

The mass flow rate, $\dot{M}$, through the orifice connecting the combustion chamber and the air heater system can be calculated from the quasi-steady compressible flow equation as follows: 


$$
\dot{M}=A e P_{1}\left[\frac{2 \gamma}{\gamma-1} \frac{g_{c}}{R_{1} T_{1}}\left(\left(r_{p}\right)^{\frac{2}{\gamma}}-\left(r_{p}\right)^{\frac{\gamma+1}{\gamma}}\right)\right]^{\frac{1}{2}}
$$

where:

$$
\begin{aligned}
& r_{p}=\frac{P_{2}}{P_{1}}(\text { Instantaneous pressure ratio }) \\
& A_{e}=\text { Orifice Area } \\
& g_{c}=\text { Dimensional constant } \\
& \gamma=\text { Specific heat ratio. }
\end{aligned}
$$

During the initial stages of injection and/or expansion, the flow through the orifice is likely to be the choked flow. In this case the pressure ratio $\left(r_{p}\right)$ in equation (5.18) should be replaced by the critical pressure

$$
\left.r_{p}\right|_{\text {critical }}=\left(\frac{2}{\gamma+1}\right)^{\frac{\gamma}{\gamma-1}}
$$

Therefore, for the calculation of the mass flow rate using equation (5.18), the instantaneous pressure ratio $\left(r_{p}\right)$ needs to be compared to the critical pressure ratio $\left(\left.r_{p}\right|_{\text {critical }}\right)$. If $\mathrm{r}_{\mathrm{p}}$ is less than then the critical pressure ratio, then $\left.r_{p}\right|_{\text {critical }}$ is used in equation (5.17) since then the pressure ratio and the calculated mass flow rate correspond to the choked flow.

The expression $\dot{M} / M$ appearing in equations (5.8) and (5.12) can be replaced by the following expression

$$
\frac{\dot{M}}{M}=A_{e} \frac{P_{1}}{M_{1}}\left[\frac{2 \gamma}{\gamma-1} \frac{g_{c}}{R_{1} T_{1}}\left(\left(r_{p}\right)^{\frac{2}{\gamma}}-\left(r_{p}\right)^{\frac{\gamma+1}{\gamma}}\right)\right]^{\frac{1}{2}}
$$


Volume and Rate of Change of Volume for the Cylinder:

The volume $(\mathrm{V})$ and the rate of change of volume $(\dot{V})$ for the cylinder is given by Lichty [65] in terms of engine geometry as follows:

$$
V=V C+\pi B^{2} X / 4
$$

in which

$$
X=r[1-\cos \theta+(L / r)(1-Z)]
$$

and

$$
\begin{gathered}
Z=\left[1-(r / L)^{2} \sin ^{2} \theta\right]^{\frac{1}{2}} \\
\dot{V}=\frac{\pi}{4} B^{2} r\left[\sin \theta+\frac{r}{2 L Z} \sin 2 \theta\right] \dot{\theta} \\
\dot{\theta}=2 \pi(N) / 60
\end{gathered}
$$

The only independent variable in the system of equations is time $(\mathrm{t})$. Therefore, an expression of $\theta$ (in radians) in terms of time $(\mathrm{t})$ is required for the derivation of the differential equations of the system. This is obtained by integrating equation (5.25) between $\mathrm{t}=0$ and $\mathrm{t}$ to give

$$
\theta=\theta_{0}+\frac{2 \pi(N)}{60} t
$$

The expression $\dot{V} / V$ appearing in equations (5.8) and (5.12) can be obtained at any instant of time (t) from equations (5.21) and (5.24).

Equations (5.8), (5.12), (5.16), (5.20), (5.21) and (5.24) completely characterize the generalized thermodynamic model. These equations constitute a system of coupled non-linear ordinary differential equations that need to be solved using numerical methods. 


\section{Application to the Air-Injection System}

The equations derived in the previous section for the generalized thermodynamic model are applied to each subsystem (combustion chamber and air heater) to theoretically predict the influence of air-injection, design parameters and operation variables on the process of compression ignition by air injection. Denoting the air heater by subscript 1 and the combustion chamber by subscript 2, the equations for each subsystem are obtained as follows.

\section{Air Heater}

For the air-heater subsystem, the volume is constant. Therefore, the equations for this subsystem are obtained from equations (5.8), and (5.12) by replacing $\dot{V}_{1}=0$ and $\dot{F}_{1}=0$. Equation (5.8) is reduced to the following normalized form by dividing both sides by $R_{1} T_{1}$, making use of the equation of state (PV=MRT) and the definition of enthalpy $(\mathrm{h}=\mathrm{u}+\mathrm{PV})$

$$
\frac{1}{R_{1}}\left(\frac{d u}{d T}\right)_{1} \frac{\dot{T}_{1}}{T_{1}}-\frac{\dot{M}_{1}}{M_{1}}+\left(\frac{P_{1}}{R_{1} T_{1}}\left(\frac{d u}{d P}\right)_{1} \frac{\dot{P}_{1}}{P_{1}}\right)=0
$$

Equation (5.12) is reduced to:

$$
\left[\frac{T_{1}}{R_{1}}\left(\frac{d R}{d T}\right)_{1}-1\right] \frac{\dot{T}_{1}}{T_{1}}+\frac{\dot{M}_{1}}{M_{1}}+\left[\frac{P_{1}}{R_{1}}\left(\frac{d R}{d P}\right)_{1}-1\right] \frac{\dot{P}_{1}}{P_{1}}=0
$$

\section{Combustion Chamber}

For this subsystem, the volume as well as the fuel-air ratio are changing. The generalized equations (5.8), (5.12), (5.16), (5.20), (5.21), and (5.24) will be applied to 
this subsystem and the expressions $\frac{\dot{M}_{2}}{M_{2}}$ and $\dot{F}$ will be expressed in terms of $\frac{\dot{M}_{1}}{M_{1}}$ to facilitate the solution by numerical methods.

From conservation of mass

$$
M_{1}+M_{2}=M=\text { Constant }
$$

differentiating both sides with respect to time $(\mathrm{t})$

$$
\dot{M}_{2}=-\dot{M}_{1}
$$

and in terms of $\frac{\dot{M}_{1}}{M_{1}}$, the quantity $\frac{\dot{M}_{2}}{M_{2}}$ is expressed as

$$
\frac{\dot{M}_{2}}{M_{2}}=-\frac{\dot{M}_{1}}{M-M_{1}}=\frac{1}{1-\left(\frac{M}{M_{1}}\right)} \frac{\dot{M}_{1}}{M_{1}}
$$

Using equation (5.29) and dividing both sides of equation (5.8) by $\mathrm{R}_{2} \mathrm{~T}_{2}$ yields

$$
\left[\frac{1}{R_{2}}\left(\frac{d u}{d T}\right)_{2}\right] \frac{\dot{T}_{2}}{T_{2}}+\left[\frac{P_{2}}{R_{2} T_{2}}\left(\frac{d u}{d P}\right)_{2}\right] \frac{\dot{P}_{2}}{P_{2}}+\left[\frac{1}{R_{2} T_{2}}\left(\frac{d u}{d F}\right)_{2}\right] \dot{F}_{2}+\left[\frac{u_{2}-u_{1}-R_{1} T_{1}}{R_{2} T_{2}} * \frac{1}{1-\left(\frac{M}{M_{1}}\right)}\right] \frac{M_{1}}{M_{1}}=-\frac{\dot{V}_{2}}{V_{2}}
$$

Applying equation (5.12) to the subsystem and by using equation (5.30), the following expression is obtained

$$
\left[\frac{T_{2}}{R_{2}}\left(\frac{d R}{d T}\right)_{2}+1\right] \frac{\dot{T}_{2}}{T_{2}}+\left[\frac{P_{2}}{R_{2}}\left(\frac{d R}{d P}\right)_{2}-1\right] \frac{\dot{P}_{2}}{P_{2}}+\left[\frac{1}{R_{2}}\left(\frac{d R}{d F}\right)_{2}\right] \dot{F}_{2}+\left[\frac{1}{1-\left(\frac{M}{M_{1}}\right)}\right] \frac{M_{1}}{M_{1}}=\frac{\dot{V}_{2}}{V_{2}}
$$

Finally, an expression for the air-fuel ratio $F_{2}$ and its time derivative $\dot{F}_{2}$ is obtained from equations (5.13) through (5.16) and equation (5.31) as follows 


$$
\dot{F}_{2}=\frac{\left(F_{2}-F_{1}\right) M_{1}}{F_{1} f_{S} M_{02}+M-M_{1}} * \frac{\dot{M}_{1}}{M_{1}}
$$

In summary, equations (5.27) through (5.32) together with the properties given by equations (5.4) and (5.5) completely describe the thermodynamics of the compression by the air-injection model. The volume terms $V_{2}$ and $\dot{V}_{2}$ are prescribed by the geometry and operating speed of the engine mechanism and the mass flow term $\dot{M}_{1}$ by the appropriate fluid dynamic expressions. These equations constitute a system of coupled non-linear ordinary differential equations that need to be solved using numerical methods. A coldair-injection model was used to determine the air-injection, initial conditions and the airheater design parameters (see chapter 6). 


\section{Chapter 6: The-Cold-Air Injection and Thermodynamic Models}

\section{Overview}

The cold-air-injection model proposed in this chapter uses thermodynamic concepts and fuel properties to determine the ideal operating conditions needed to reach auto-ignition by hot ,high-pressure air injection during one single CFR engine event. High-pressure air injection into the CFR is modeled by using a fixed container, connected by a solenoid valve and an injector ball-check valve to the cylinder-piston arrangement shown in Figure 6.1. The fixed container delivers a precise, controlled amount of hothigh-pressure air into the cylinder during one single engine cycle. The analysis of the model is done by using the conservation of mass and energy principles, the ideal gas law, and the CIBAI concept.

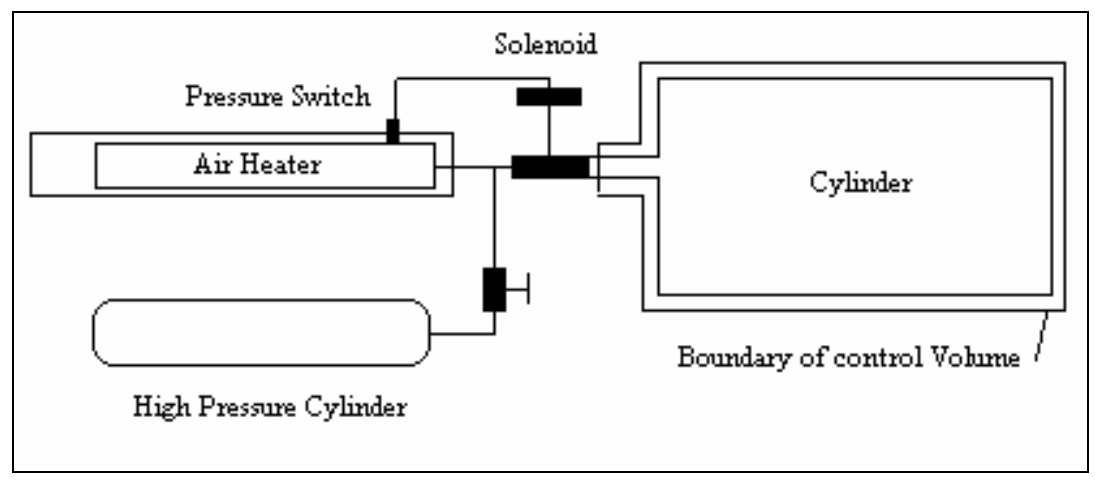

Figure 6.1 Air injection schematic model

As mentioned earlier, the new thermodynamic cycle for IC engines, CIBAI cycle, patented by Loth and Morris [3,5], indicates that it is possible to obtain a higher thermal efficiency than with the Otto or Diesel cycle by simply injecting compressed air into an air-fuel mixture cylinder. The higher thermal efficiency may be explained by the increase in combustion compression due to the use of a high energy ignition source in the form of hot-high-pressure air injection. However, this research is based on using a CFR engine 
and therefore differs significantly from the CIBAI cycle. The conservation of mass and energy principles, and the ideal gas model are used to determine the final equilibrium temperature and pressure of the air in the cylinder after all the injected air has entered prior to auto-ignition. The second law of thermodynamics is used to determine the heat rejection during the combustion process. The derivation of the CFR engine air-injection process resulted in two models: the air-injection model, and the thermodynamic model. These models are described next.

\section{Air-Injection Model}

The schematic diagram shown on Figure 6.1 is used to simulate the hot highpressure air injection into the CFR engine. High-pressure air from a compressed bottle is injected into the air heater at a known temperature and pressure. The air heater is located inside the flexible exhaust pipe of the CFR engine. Air is injected into the cylinder through an injector ball-check valve in series with a normally closed solenoid valve. This valve is operated by a microcontroller that receives and processes input signals from sensors added to the engine. The solenoid valve is closed at the moment that the pressure inside the heater reaches a pre-selected cut-off pressure. A detailed description of the instrumentation, data acquisition system, and the control system is included in the

experimental set-up and procedure section of this paper (Chapter 8). The following assumption are needed for the analysis of the air injection model

\section{$\underline{\text { Assumptions }}$}

1. Air injection occurs at TDC.

2. The ideal gas model for air is applied.

3. The $\mathrm{P}$ and $\mathrm{T}$ of the injected air remain constant prior to entering the cylinder. 
4. The amount of air injected into the cylinder is limited to the actual displacement volume, $\mathrm{Vd}_{\mathrm{act}}$.

$\underline{\text { Analysis }}$

The analysis of this model involves the steps needed to calculate the amount of air in the air heater and the amount of air injected into the CFR engine in one single cycle event. An analysis of the air-injection model is shown below.

The displacement volume $\left(\mathrm{V}_{\mathrm{d}}\right)$ at sea level can be represented as a function of the engine bore (b) and stroke (s) values

$$
V_{d}=\frac{\pi^{*} b^{2} * s}{4}
$$

The actual volume displacement, $\mathrm{V}_{\text {dact }}$, is a function of the CFR engine operating conditions

$$
V_{\text {dact }}=\frac{\dot{V}}{\frac{N}{n}}
$$

where:

$$
\begin{aligned}
& \dot{V}=\text { Volumetric air flow rate } \\
& \mathrm{N}=\text { Revolutions per minute (RPM) } \\
& \mathrm{n}=\text { Revolutions per engine cycle (Rev/cycle). }
\end{aligned}
$$

The associated volumetric efficiency $\left(\eta_{\mathrm{vol}}\right)$ is given by

$$
\eta_{\text {vol }}=V_{\text {dact }} / V_{d}
$$

The required heater volume, $\mathrm{V}_{\text {heater }}$, can be obtained from the conservation of mass principle

$$
m_{c}-m_{p}=m_{i}
$$


where:

$\mathrm{m}_{\mathrm{c}}=$ Mass initially inside the heater at the maximum pressure and temperature

$\mathrm{m}_{\mathrm{p}}=$ Mass remaining in the heater after the cut-off pressure

$\mathrm{m}_{\mathrm{i}}=$ Mass injected into the cylinder.

$\mathrm{V}_{\text {heater }}$ and $\mathrm{P}_{\text {cutoff }}$ are designed in such a way that $\mathrm{m}_{\mathrm{i}}$ equals the mass already present

inside the CFR engine cylinder, prior to injection. Substituting into Eq. 6.4

$$
\frac{P_{\max } * V_{\text {heater }}}{R^{*} T_{\max }}-\frac{P_{\text {cutoff }} * V_{\text {heater }}}{R^{*} T_{\max }}=\frac{P_{\text {ref }} * V_{\text {dact }}}{R^{*} T_{\text {ref }}}
$$

where:

$\mathrm{P}_{\max }=$ Maximum pressure at which gas is injected into the air heater

$\mathrm{P}_{\text {ref }} \quad=$ Pressure reference at sea level

$\mathrm{P}_{\text {cutoff }}=$ Cut-off pressure. This is the pressure value inside the air heater at which the solenoid valve is closed.

$\mathrm{R}=$ Gas constant

$\mathrm{T}_{\max }=$ Maximum temperature air heater

$\mathrm{T}_{\text {ref }}=$ Temperature reference at sea level.

and solving the equation for $\mathrm{V}_{\text {heater }}$ results in:

$$
V_{\text {heater }}=\frac{P_{\text {ref }} * V_{\text {dact }} * T_{\max }}{\left[p_{\max }-P_{\text {cutoff }}\right]^{*} T_{\text {ref }}}
$$

Finally, the hot, high-pressure air injected into the cylinder will have a volume at sea

level conditions $\mathrm{V}_{\mathrm{i}}$, as calculated from the ideal gas law equation

$$
V_{i}=\frac{m_{i}^{*} R^{*} T_{r e f}}{P_{r e f}}
$$




\section{Thermodynamic Model}

The conservation of mass and energy principles is used to calculate the temperature and pressure in the cylinder at TDC before and after air injection for several compression ratios.

\section{Derivation of the Temperature and Pressure Before Air Injection}

The temperature and pressure inside the cylinder before the air injection are calculated using the air-standard, Otto-cycle analysis introduced previously, under the following assumptions.

Assumptions

1. The air in the piston-cylinder assembly is the closed system.

2. The compression and expansion processes are adiabatic.

3. All processes are internally reversible.

4. Air injection occurs at TDC.

5. The air-fuel mixture is modeled as an ideal gas.

6. Kinetic and potential energy effects are negligible.

7. Process 1-2 (adiabatic compression) of the air-standard Otto cycle is considered for the calculation of the temperature and pressure at TDC before the air injection.

\section{$\underline{\text { Analysis }}$}

For an isentropic process:

$\mathrm{pv}^{\mathrm{k}}=$ Constant with $\mathrm{k}=\mathrm{c}_{\mathrm{p}} / \mathrm{c}_{\mathrm{v}}$

For process 1-2

$\mathrm{p}_{1} \mathrm{v}_{1}{ }^{\mathrm{k}}=\mathrm{p}_{2} \mathrm{v}_{2}{ }^{\mathrm{k}}, \mathrm{m}=$ constant 
Therefore, the pressure $\mathrm{p}_{2}$ before the air injection at TDC is given by the following equation:

$$
\begin{aligned}
& p_{2}=p_{1} *\left(\frac{V_{1}}{V_{2}}\right)^{K} \\
& p_{2}=p_{1} *(C . R)^{k}
\end{aligned}
$$

where $C . R=$ Compression ratio.

In the similar manner, the temperature $T_{2}$ before the air injection at TDC is obtained as follows:

$$
\begin{gathered}
\frac{v_{1}{ }^{k}}{v_{2}{ }^{k}}=\frac{p_{2}}{p_{1}}=\frac{\frac{R T_{2}}{v_{2}}}{\frac{R T_{1}}{V_{1}}}=\frac{T_{2} * v_{1}}{T_{1} * v_{2}} \\
\frac{v_{1}{ }^{k} * v_{2}}{v_{2}{ }^{k} * v_{1}}=\frac{T_{2}}{T_{1}} \\
\frac{T_{2}}{T_{1}}=\frac{v_{1}{ }^{k-1}}{v_{2}{ }^{k-1}}=\left(\frac{v_{1}}{v_{2}}\right)^{k-1}
\end{gathered}
$$

Since $\mathrm{m}=$ constant, then

$$
\frac{T_{2}}{T_{1}}=\left(\frac{V_{1}}{v_{2}}\right)^{k-1}=\left(\frac{V_{1}}{V_{2}}\right)^{k-1}=\left(\frac{V_{B D C}}{V_{T D C}}\right)^{K-1}=(C \cdot R)^{k-1}
$$

Thus, the temperature before the air injection in the cylinder at TDC is given by:

$$
T_{2}=T_{1} *(C . R)^{(k-1)}
$$

\section{Derivation of the Temperature and Pressure After Air Injection}

The following assumptions are considered to determine the final temperature and pressure after the air injection and prior to detonation. 


\section{$\underline{\text { Assumptions }}$}

1. Injection occurs at TDC.

2. The state of the injected air remains constant until it enters the cylinder.

3. There is no heat transfer with the surrounding, $\dot{W}_{c v}=0$, and all kinetic and potential energy effects are ignored.

4. The ideal gas model applies assuming air.

\section{$\underline{\text { Analysis }}$}

The control volume shown in Figure 6.1 has a single inlet and no exit. Therefore the mass rate balance takes the form

$$
\frac{\partial m_{c v}}{d t}=\dot{m}_{i}
$$

Similarly, the energy rate balance is

$$
\frac{\partial E_{c v}}{d t}=\dot{Q}_{c v}-\dot{W}_{c v}+\dot{m}_{i} *\left(h_{i}+\frac{V i^{2}}{2}+g * z_{i}\right)
$$

With assumption $3, \dot{Q}_{c v}=\dot{W}_{c v}=0$, and all kinetic and potential energy effects can be neglected. Thus

$$
\frac{\partial U_{c v}}{d t}=\dot{m}_{i} * h_{i}
$$

Combining the mass and energy rate balances give

$$
\frac{\partial U_{c v}}{d t}=h_{i} * \frac{d m_{c v}}{d t}
$$

In accordance with assumption 2, the specific enthalpy of the air entering the control volume is constant: $h i=h\left(T_{i}\right)$, where $T_{i}$ is the temperature of the air within the air heater. Thus, on integration, the above equation becomes 


$$
\Delta U_{c v}=h\left(T_{i}\right) * \Delta m_{c v}
$$

where $\Delta U_{c v}$ and $\Delta m_{c v}$ denote, respectively, the changes in the internal energy and mass of the control volume. The change in the mass contained within the control volume equals the mass injected into the cylinder

$$
\Delta m_{c v}=m_{i}
$$

The change in internal energy is

$$
\Delta U_{c v}=\left(m_{c}+m_{i}\right) * u(T)-m_{c} * u\left(T_{c}\right)
$$

where:

$$
\begin{array}{ll}
\mathrm{m}_{\mathrm{c}} & =\text { Mass of the air initially in the cylinder } \\
\mathrm{m}_{\mathrm{i}} & =\text { Mass of the air injected into the cylinder } \\
\mathrm{T}_{\mathrm{c}} & =\text { Temperature of the air initially in the cylinder at TDC } \\
\mathrm{T} & =\text { Final temperature of the air within the cylinder after the air injection and } \\
& \text { prior to detonation } \\
\mathrm{u}\left(\mathrm{T}_{\mathrm{c}}\right)= & \text { Specific internal energy as a function of } \mathrm{T}_{\mathrm{c}} \\
\mathrm{u}(\mathrm{T}) \quad= & \text { Specific internal energy as a function of } \mathrm{T} .
\end{array}
$$

Grouping equations (6.13), (6.14), and (6.15) and solving them gives the specific internal energy at $\mathrm{T}$ temperature

$$
u(T)=\frac{m_{c} * u\left(T_{c}\right)+m_{i} * h\left(T_{i}\right)}{m_{c}+m_{i}}
$$

Using the ideal gas properties of air tables from Moran and Shapiro [66], and interpolating with the value of the specific internal energy obtained from equation (6.16), the final temperature $\mathrm{T}$ of the air in the cylinder after the air injection and prior to autoignition is obtained.

The final pressure $\mathrm{P}$ of the cylinder at TDC after the air injection and prior to autoignition is found by using the ideal gas equation of state

$$
P=\left(m_{c}+m_{i}\right) * R * T / V
$$


The volume (V) of the cylinder at TDC can be obtained from the ideal gas equation of state, and it is equal to the clearance volume $\left(\mathrm{V}_{\mathrm{c}}\right)$. It can be calculated using equation 6.18 . $\mathrm{V}=\mathrm{V}_{\mathrm{c}}$

$$
V=m_{c} * R * T_{c} / P_{c}
$$

where $\mathrm{P}_{\mathrm{c}}$ and $\mathrm{T}_{\mathrm{c}}$ are the pressure and temperature of the air initially in the cylinder before the air injection. Combining equations 6.17 and 6.18 the final pressure $\mathrm{p}$ after the air injection and prior to auto-ignition is found.

$$
P=\frac{\left(m_{c}+m_{i}\right) * R * T}{\left(m_{c} * R^{*} T_{c} / P_{c}\right)}=P_{c} * \frac{T}{T_{c}} *\left(\frac{m_{c}+m_{i}}{m_{c}}\right)
$$

The air-injection model developed in this section was used to quantitatively evaluate the benefits of ignition by hot, high-pressure air injection on a CFR engine during one single engine cycle (Appendix B). The results of this analysis were used as the primary design criteria for the design of the air-injection system presented in Chapter 8 of this dissertation. 


\section{Chapter 7: Preliminary Designs}

\section{Overview}

The air-injection model developed in Chapter 6 was used to quantitatively evaluate the benefits of ignition by hot, high-pressure air injection on a CFR engine during one single engine cycle. The results of this analysis were used as the primary design criteria for the design of the air-injection system. Safety considerations were also important in the selection of materials, equipment, and operating procedures.

Based on the results obtained through the implementation of the air-injection model presented in the previous chapter, and the CIBAI fundamentals proposed by Loth [3], the following design criteria were chosen for the air-injection system:

1) The amount of hot, high-pressure air injection was limited to $437 \mathrm{cc}$ of standard air.

2) A maximum air-charge pressure of 1000 psig and minimum of 700 psig were chosen.

3) A maximum exhaust temperature of $1100{ }^{\circ} \mathrm{F}$ and a minimum of $600{ }^{\circ} \mathrm{F}$ were selected to pre-heat the air charge prior to injection.

4) The injector ball type check valve, downstream of the solenoid valve was set to open at 500 psig. This means that this valve would open for a charging pressure greater than or equal to 500 psig.

5) A compression ratio (C.R) limit of 8:1 was selected for the initial CIBAI combustion test. However, the system would allow working with higher compression ratios if needed.

6) An intake mixture temperature of $70^{\circ} \mathrm{F}$ was chosen for the first set of experiments.

7) A maximum air-injection time of $20 \mathrm{~ms}$ was chosen to assure that most of the air injected would have entered the cylinder prior to reaching TDC. 
8) Test repeatability was determined to be paramount.

9) Digitalized data acquisition was chosen to store the large amount of data.

10) Synchronization between air-injection timing, data acquisition, and engine operation was essential in the data acquisition phase.

In order to fulfill the design requirements presented above for the air-injection system, several conceptual and physical designs were proposed, and analyzed during the course of this research. These designs are discussed next.

\section{Conceptual Designs}

Conceptual designs are defined as those that were proposed, and evaluated, but never built. However, they provided valuable information about the functionality and feasibility of the CIBAI engine. Conceptual designs included 3D models of a four-stroke and two-stroke CIBAI engines, a CIBAI combustion bomb, and an air-gun rapidcompression machine.

\section{$\underline{\text { 3D Models }}$}

Two four-stroke CIBAI engines were modeled using a 3D software package. A $1000 \mathrm{cc}$ two-cylinder engine (Figures 7.1) and a $2000 \mathrm{cc}$ four-cylinder engine (Figure 7.2) were evaluated. The aim of this modeling was to gain understanding of the challenges to implement the CIBAI concept in a commercial engine. It demonstrated the importance of the correct location and size of the cylinder-connecting valve (CCV), as described by Loth and Morris [3,5], to make an engine operate on the CIBAI cycle. 


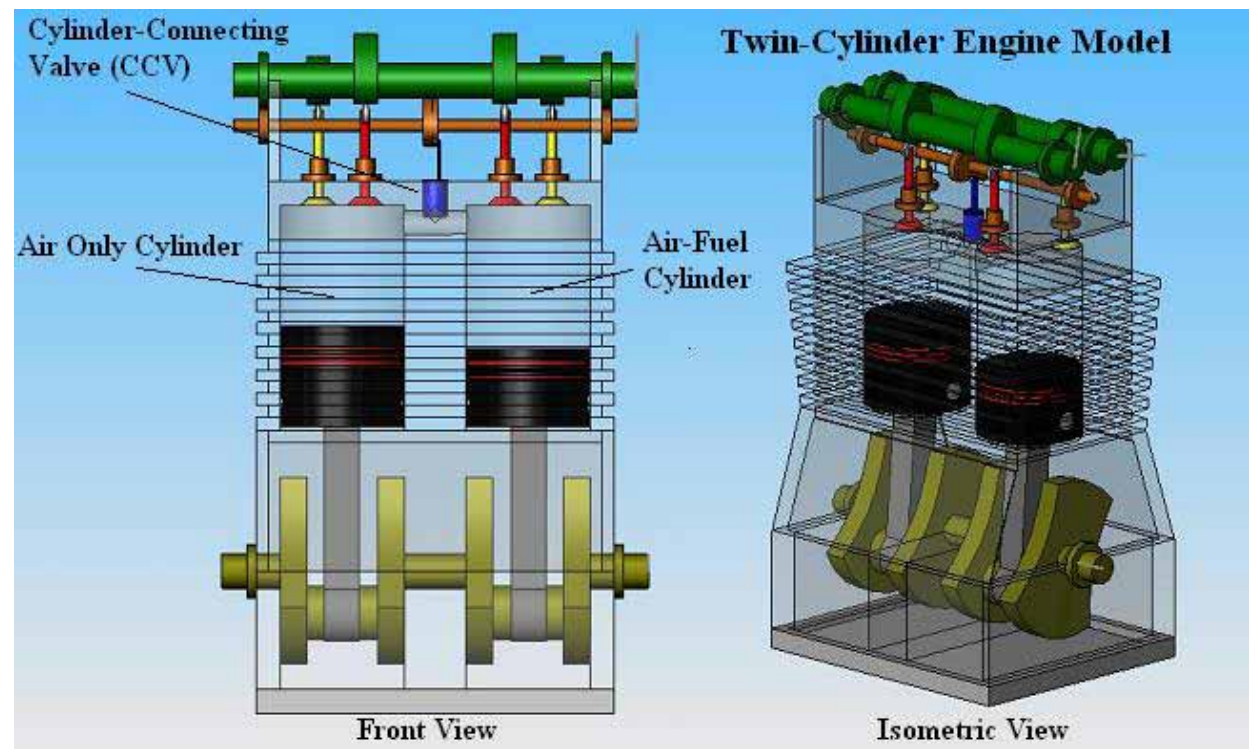

Figure 7.1 Twin-cylinder CIBAI engine 3D model

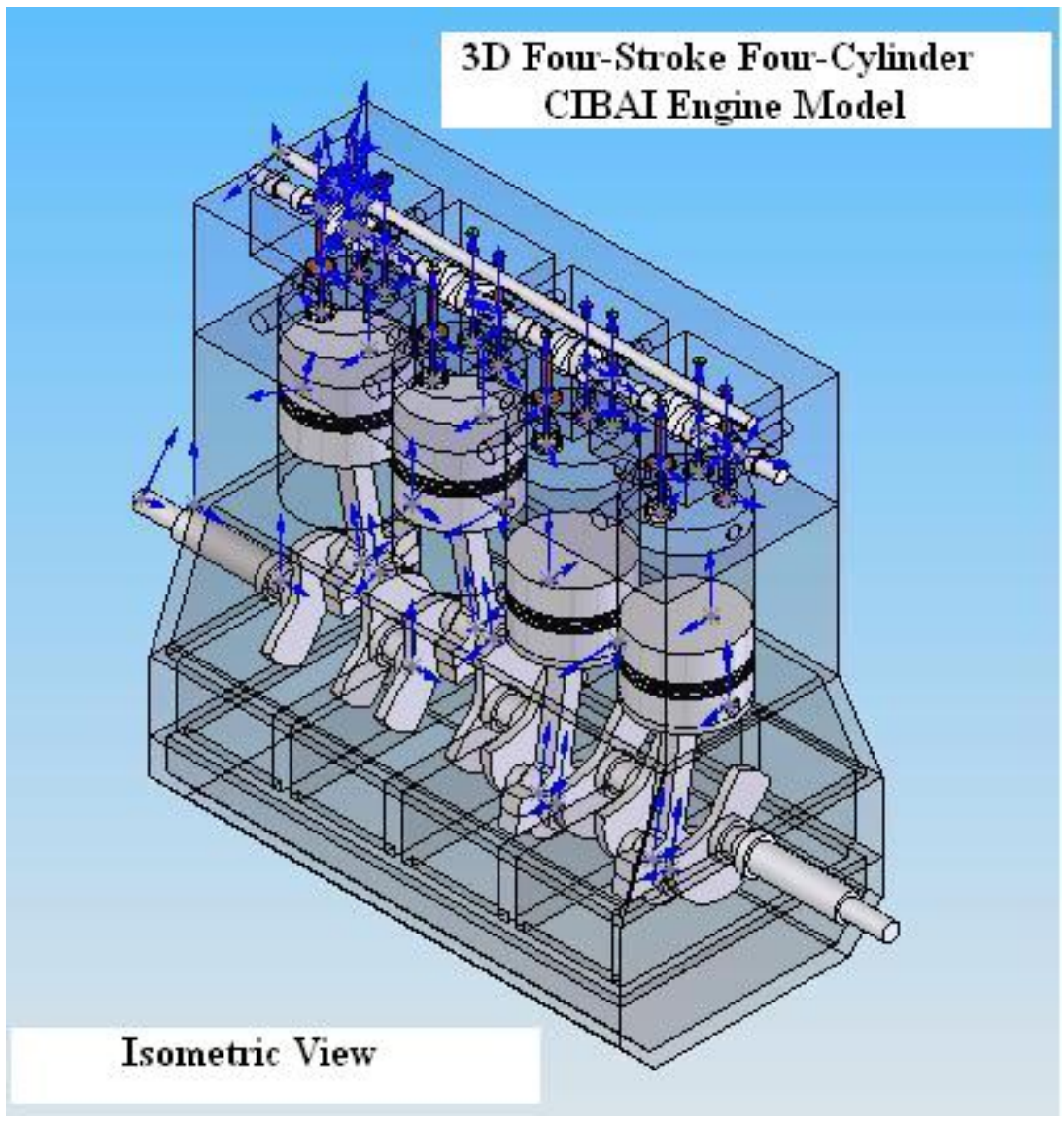

Figure 7.2 Four-stroke four-cylinder CIBAI engine 3D model 
The need for the modification of the crankshaft, cylinder head, and camshaft are clearly evident in these 3D models. This is the reason why the concept of Compression Ignition By Air Injection (CIBAI) was studied in an available CFR engine, which was easily converted to ignition-by-air injection to prove the concept.

\section{CIBAI Combustion Bomb}

Most of the earlier studies done on auto-ignition were carried out using rapid compression machines, pulse combustors, shock tubes, and combustion bombs. Combustion bombs have been a very useful tool to understand the phenomena occurring in the combustion chamber, and allowed advanced engine concepts to be explored in search of higher efficiency, lower emissions, and greater fuel flexibility. This type of device is relatively simple in concept, although, in order to reach auto-ignition conditions, it is necessary to use high pressures and temperatures. A single-event, constant-volume combustion bomb could have been used to simulate the CIBAI combustion process, without the need of the moving parts of traditional reciprocating engines.

The design of the CIBAI combustion bomb was completed with several major objectives in mind. The design strategy for the CIBAI combustion bomb was to produce a simple and flexible research apparatus that would be inexpensive to build and operate. Therefore, off-the shelf components were proposed to be used. For example, a solenoid activated valve could be used to simulate the cylinder-connecting valve (CCV), and the container could be welded together using standard pipes and flanges. As a research device, it was deemed necessary to make adequate provisions for the CIBAI combustion bomb to be highly instrumented. Therefore, sensor ports, and optical observation 
windows would be needed in the bomb design. Additional design considerations would be needed to assure the safe operation of the combustion bomb, due to the unique hazards of this type of device. For example, a reliable pressure relief valve would be needed, and test procedures would have to be specified. The bomb was designed for a temperature and pressure before ignition of $500^{\circ} \mathrm{F}$ and $700 \mathrm{psig}$, respectively.

Figure 7.3 shows a cross-sectional diagram of the CIBAI combustion bomb proposed for this study. It was designed particularly for gaseous fuel experiments, but could be used for gasoline and diesel fuel combustion with minor changes in the fuel supply system. The gaseous fuel and compressed air are supplied to the combustion bomb from high-pressure cylinders through a system of control valves and meters.

The CIBAI combustion bomb consists of an outer casing, incorporates a 1" stainless steel ball valve (4000 psi $\left.150^{\circ} \mathrm{F}\right)$ to simulate the cylinder-connecting valve (CCV), two tubes of 1" diameter schedule 40 stainless steel pipe of 12 " and 40 " long sections act as dual combustion chambers for the air and fuel respectively, a heating element, insulation materials, two 1" quartz windows, different fittings for air and fuel filling, a pressure transducer, a thermocouple probe, and exhaust and relief valves. The outer casing consists of a 1 " stainless steel box of a 10 " x 10 " x 4 " with a 1 " base plate of 10 " x 6", and a 1" removable top cover. The volumes of the air and fuel chambers are 35 $\mathrm{cc}$ and $70 \mathrm{cc}$ respectively for a volume ratio of 2. 


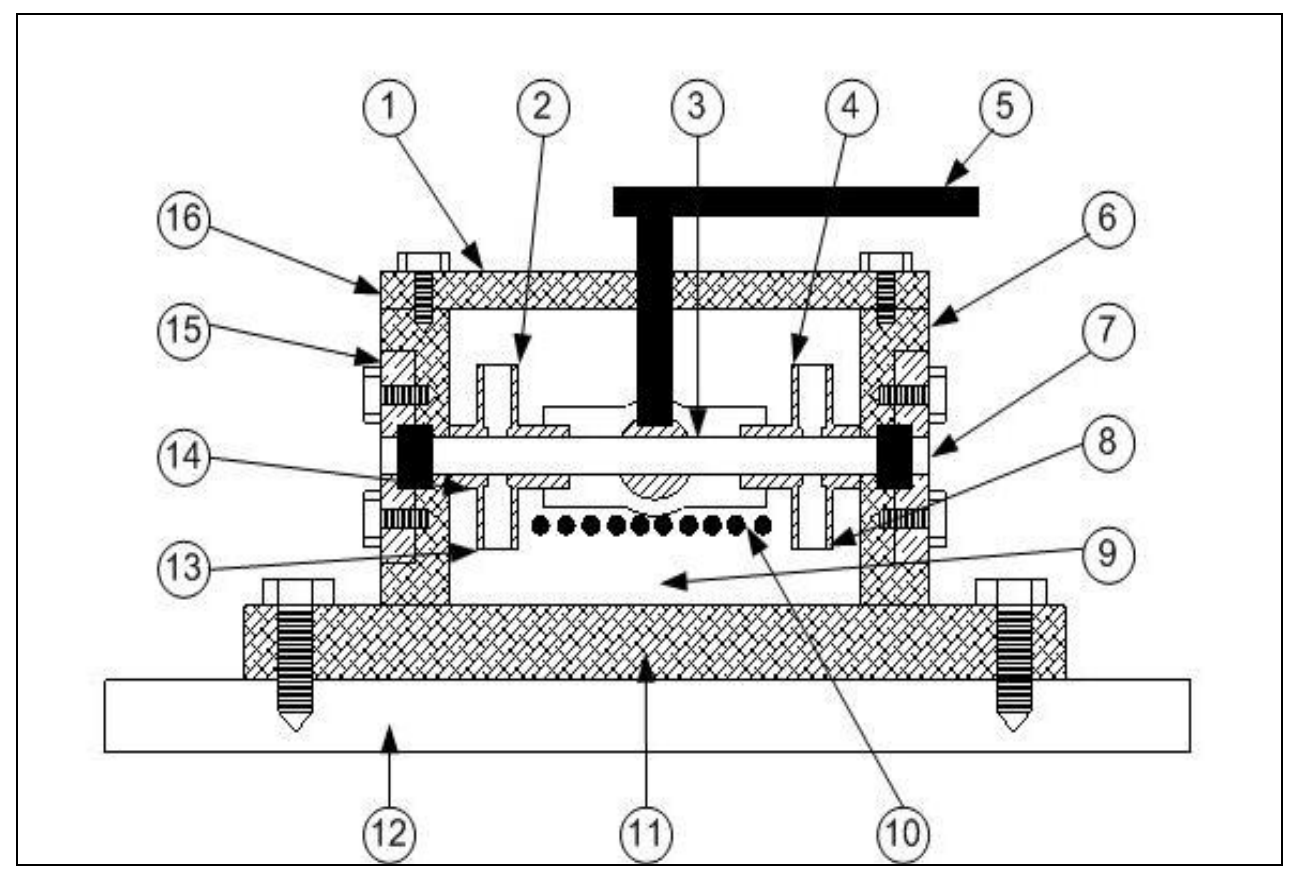

Figure 7.3 Cross-sectional diagram of the CIBAI combustion bomb

1. CIBAI Combustion bomb. 2. Pressure Transducer Port. 3. Cylinder-connecting valve (CCV). 4. Thermocouple Port. 5. Valve Actuator. 6. Lateral Outer Casing. 7. Quartz Observation Window. 8. Air Intake Port. 9. Insulation Blanket. 10. Electrical Resistance Heater. 11. Bottom Outer Casing. 12. Concrete Pad. 13. Fuel Intake Port. 14. Stainless Steel Pipe. 15. Observation Window Flange. 16. Top Outer Casing. 17. Relief Valve (Back). 18. Exhaust Valve (Back). 19. Injector Port (Front - Optional). 20. Spark Plug Port (Front- Optional).

Since the CIBAI combustion bomb has no moving parts, such as the piston of the internal combustion engine, used to compress the inlet cold air and fuel to auto-ignition, an electrical resistance heater located at the bottom of the chamber was proposed in order to raise the temperature of the air and fuel to the required level. To achieve the preignition pressure conditions, the combustion chamber is pressurized with air and filled with an air-fuel mixture fuel to theoretical pressures normally obtained during the compression stroke in a reciprocating engine. To minimize the heat loss through the walls, the combustion bomb and the outer casing are wrapped with ceramic fiber blankets, which can withstand continuous usage at very high temperatures. The CIBAI 
combustion bomb design is fully instrumented and equipped with a trigger system to provide the proper synchronization between the start of the combustion event, and the beginning of the data acquisition.

Even though, a CIBAI combustion bomb as described here was never built, it provided valuable insights in the design necessary to obtain auto-ignition under a controllable environment.

\section{Air-Gun Rapid Compression Machine}

An air-gun rapid compression machine was proposed to simulate the CIBAI combustion process in a single cylinder four-stroke CFR engine. The air gun consists of a $1 / 2$ " inside diameter glass tube with a Teflon piston, a 2000 psig 1/4" NPT carbon steel check valve, a 2000 psig 1/4” NPT stainless steel three-way ball valve, and a 2000 psig 1/8" NPT 115VAC brass solenoid valve. Four hundred and thirty seven (437) cc of sea level air at an average of 700 psig would be injected into the glass tube cylinder-piston assembly from a 2000 psig compressed bottle. This air is injected into the CFR engine through the normally closed solenoid valve at a mass flow rate of $0.0404 \mathrm{~kg} / \mathrm{s}$, for a discharged time of $6.72 \mathrm{~ms}$ or $36 \mathrm{crank}$ angle degree at $900 \mathrm{rpm}$.

This design indicated the importance of a rapid response mechanism to inject the air into the CFR engine. This design did not provide a way to pre-heat the air before injection into the CFR engine, which is a critical factor to obtain auto-ignition for the CIBAI concept.

\section{Physical Designs}

The designs discussed in this section were built and tested under different operating conditions. The objective at this stage was to build a simple air-injection 
system capable to simulate the combustion process in a CIBAI engine. Special attention was given to the safety of the system and operator, time response of the system, accuracy of the data, and repeatability of the results. In order to achieve these objectives a pistoncylinder assembly, air injectors, and cylinder-connecting valves (CCV) were designed, built, and extensively tested. In addition, some complementary components were built to support some of the preliminary experiments. These designs are discussed next.

\section{Piston-Cylinder Assembly Design}

One of the objectives of this piston-cylinder assembly was to simulate the initial conditions occurring in a CIBAI engine prior to combustion. Another objective was to determine the time response of the solenoid valve to changes in the amount of air injected, charged pressure, amplified pressure, and back pressure. Finally, the purpose was to incorporate the piston-cylinder assembly in a more complex experimental set-up to study the compression ignition by air injection (CIBAI) in a CFR engine for a single cycle event as proposed by Loth and Morris [3,5].

The piston-cylinder assembly is shown in Figure 7.4. It consisted of a CFR simulator, pressure amplifier, and a pressure charger. The CFR simulator resembled the air-fuel cylinder of the CIBAI engine. Physically, it simulated a clearance volume of 77 cc of a 500 cc single-cylinder four stroke CFR engine with a compression ratio (C.R) of 8:1 at TDC in the compression stroke. Back pressure was adjusted by way of a pressure regulator connected to either a 200 psig pressurized air tank or a 2000 psig compressed air bottle (Appendix C). A 1000 psig Omega pressure transducer (Appendix D) installed in the upper right side of the CFR simulator was used to obtain the time-pressure history inside the clearance chamber. 


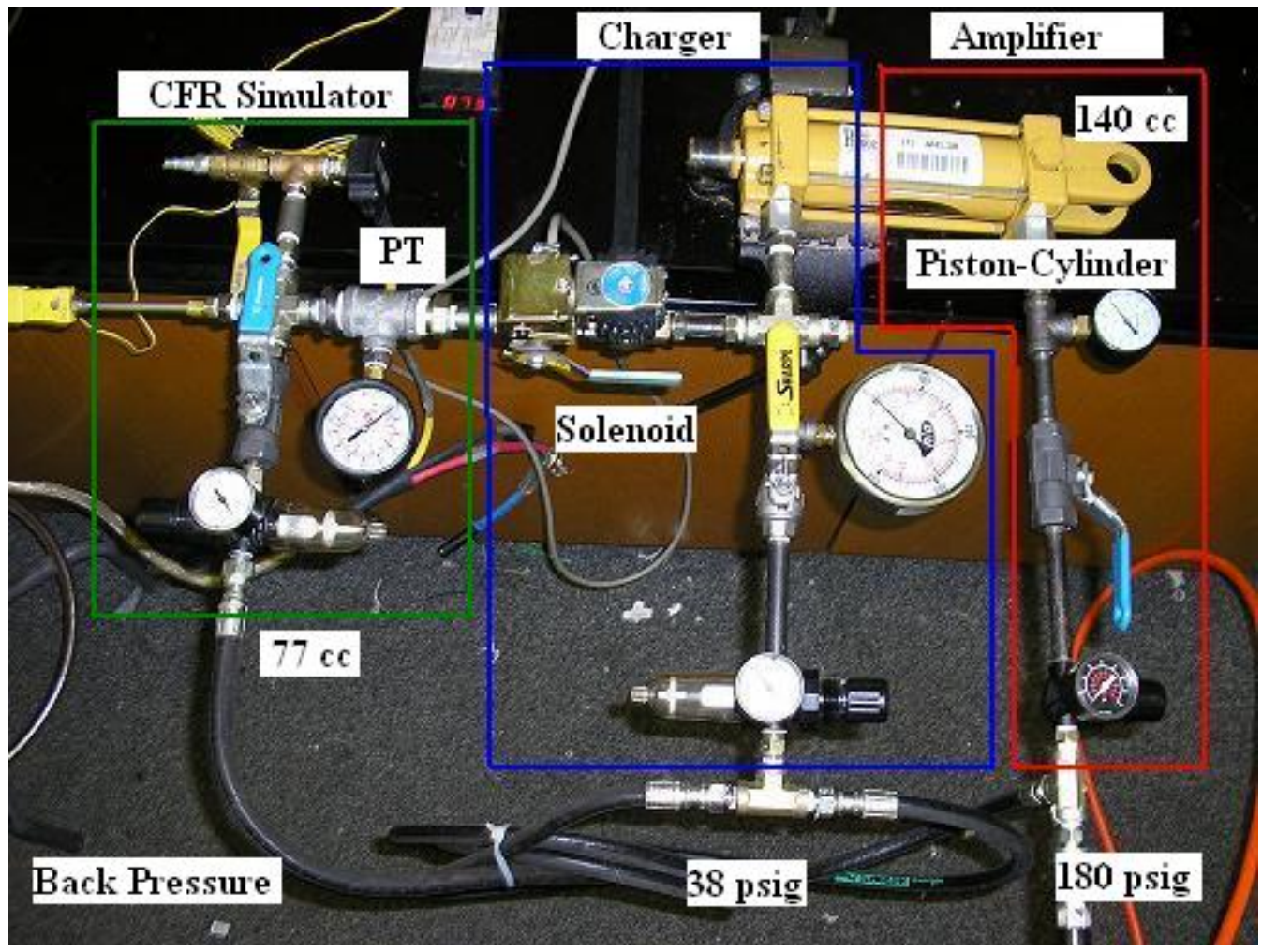

Figure 7.4 Piston-cylinder assembly

The pressure charger and pressure amplifier simulated the air-only cylinder paralleled to the air-fuel cylinder of the CIBAI engine. The pressure charger controlled the amount of air injected into the CFR simulator by isothermally compressing the air, at 38 psig into a volume of $140 \mathrm{cc}$, located in the piston-cylinder rod compartment, which is equivalent to $500 \mathrm{cc}$ of the standard air. By actuating the $1 / 8$ " brass 115 VAC solenoid valve (Appendix E), located between the CFR simulator and piston-cylinder assembly, the mass of air was then injected into the CFR simulator, at a pressure of 600 psig by the action of the pressure amplifier. The solenoid valve simulated the cylinder-connecting valve $(\mathrm{CCV})$, which joins the air-fuel mixture cylinder together with the air only cylinder at nearly constant volume at TDC in the CIBAI engine. Charging pressure was supplied from a 200 psig pressurized air tank. 
The pressure amplifier consisted of a 2500 psig double acting tie-rod hydraulic cylinder (Appendix F), an air pressure regulator, a bleed valve, a pressure gauge, and plumbing. Pressure amplification up to 3.16 can be obtained from the area ratio between the piston and the piston rod areas. Amplified pressure was supplied from either a 200 psig-pressurized air tank or a 2000 psig-compressed air bottle. To prevent damage to the cylinder-piston assembly during air injection, a 1/8" rubber O-ring was installed to cushion the impact of the piston with the plug at the end of the cylinder.

By injecting an additional $500 \mathrm{cc}$ of standard air into the CFR engine, the incylinder pressure is increased to an approximate value of $500 \mathrm{psig}$, which is equivalent to polytropic compressed air $(\gamma=1.35)$ from an initial intake pressure of 12.2 psig at a compression ratio (C.R) of 16:1. If auto-ignition conditions are met (temperature, pressure, and air-fuel ratio), then suddenly doubling the CFR engine air mass will cause the homogeneous air-fuel mixture to auto-ignite, or CIBAI combustion to occur, as proposed by Loth and Morris [3,5].

The piston-cylinder assembly was tested over a wide range of pressures ranging from 0 to $100 \mathrm{psig}$. Charging pressures ranged from 30 to $100 \mathrm{psig}$, and amplified pressures ranged from 0 to $400 \mathrm{psig}$. The time-pressure history of the clearance chamber and the corresponding volumetric values were collected and verified.

Several important findings were obtained from this experimental work. The discharged time ranged between $40 \mathrm{~ms}$ for high pressure charged to $150 \mathrm{~ms}$ for low pressure charged. The piston movement was slow due to friction and the cylinder-piston assembly was considered unsuitable for experiments with ignition by air injection (CIBAI) in a CFR engine running at $900 \mathrm{rpm}$, and completing a thermodynamic cycle in 
133 ms. The low response time of the cylinder-piston assembly was attributed to high friction between the cylinder and piston surface, and to large masses of the piston, and solenoid valve actuator, which required a minimum of $20 \mathrm{~ms}$ to open fully.

Lower than expected pressures in the clearance chamber were observed for most of the tests. This was attributed to additional plumbing volume outside the cylinderpiston assembly, which could not be pressurized by the piston during air injection.

Finally, the pressure amplification was not consistent for most of the tests, possibly because of leakages in the system.

\section{Air-Injector Design}

After the decision was made to use the CFR engine as the main apparatus for experiments with controlled auto-ignition by air injection, the design of an air injector was initiated taking under consideration the engine space constraints and the need for access ports for the pressure transducer (PT), solenoid valve, and pressure relief valve. The first design (Figure 7.5) was a multifunctional air injector that operated partially as a CCV while air injection was controlled by a solenoid valve and pressure relief configuration.

This design consisted of a two-piece element: a 7/8" OD diameter by 2-47/64" long carbon steel rod with two 3/16" diameter holes and two 1/8" NPT ports for the pressure transducer (PT), an air injection access port, and a 1-3/8" OD by 7/8" ID carbon steel bushing by $7 / 8$ " long with two lateral $1 / 8$ " NTP ports 90 degrees apart to connect the pressure-relief valve and the solenoid valve connections. The steel bushing had two $1 / 8$ " by $3 / 16$ " grooves for two high temperature rubber O-rings to prevent leakage from 
inside the combustion chamber. The air injector was flush-mounted on the cylinder head in place of the original CFR engine 7/8" detonation pick-up.

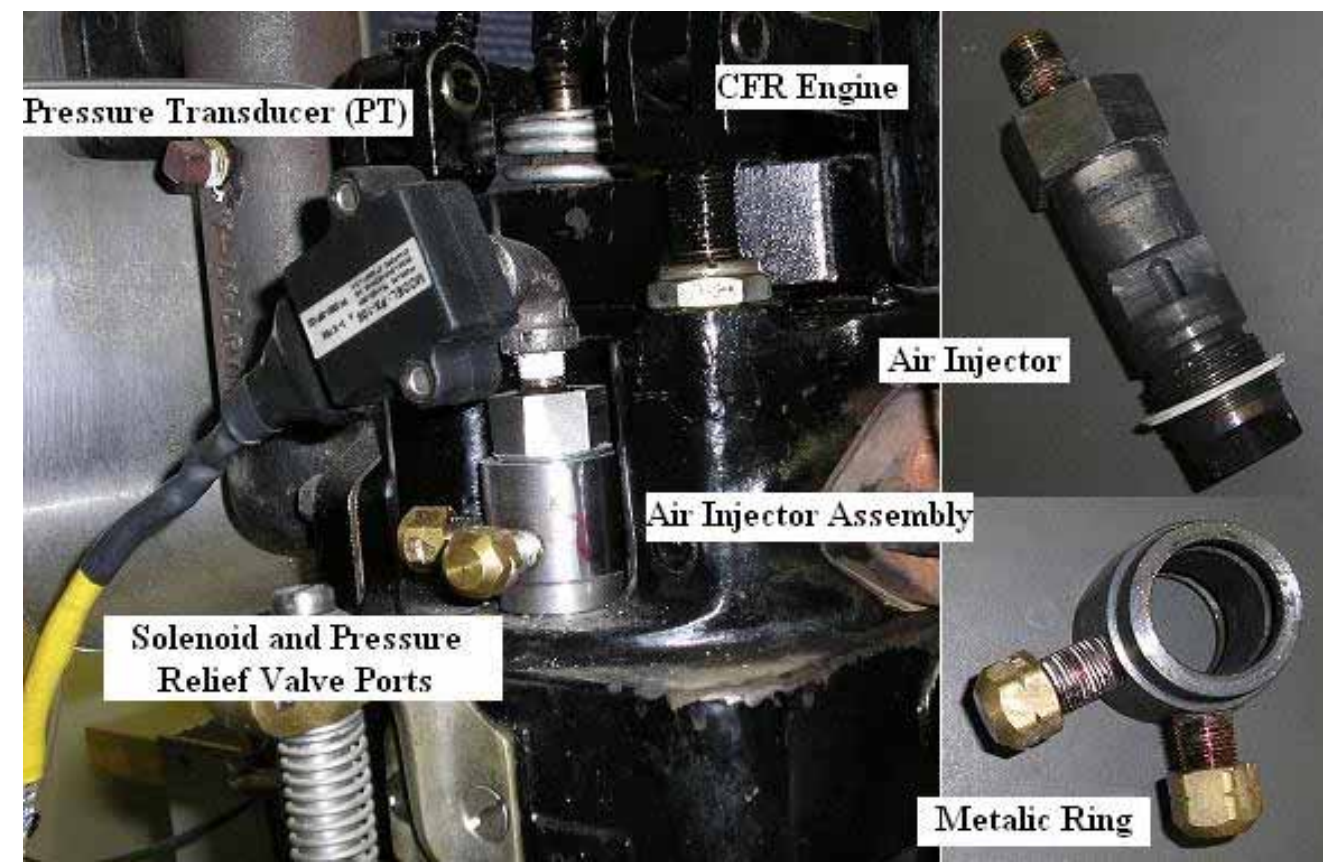

Figure 7.5 Air injector assembly installed in the CFR engine

This configuration allowed minimum modification of the CFR engine while providing secure and flexible access for air injection and data acquisition. This design was tested with the CFR engine, motored and fired for compression ratios ranging from 5:1 to $16: 1$ and under different operating conditions. The results of these tests indicated the need to incorporate a cooling system into the design of the air injector to prevent the pressure transducer (PT), solenoid valve, and pressure-relief valve from overheating. The air-injector design drawing is displayed in Appendix G.

The first air injector was modified (Figure 7.6) by adding a 1/8" copper watercooling system and removing the pressure transducer (PT), solenoid valve and pressure- 
relief valve NPT ports from the main body of the injector. This was accomplished by eliminating the external steel bushing.

The solenoid and pressure-relief valve were installed in series, and the air was discharged into the CFR combustion chamber through a 1/8"-1000 psig stainless steel tee installed between the air injector and pressure transducer (PT). This new design increased the engine clearance volume by $12 \mathrm{cc}$. The CFR engine was motored and fired under different operation conditions using the new air injector and air injection system, but it failed to produce auto-ignition. This was attributed to injecting cold compressed air from a bottle instead of high- pressure air, heated by compression as in patent disclosures.

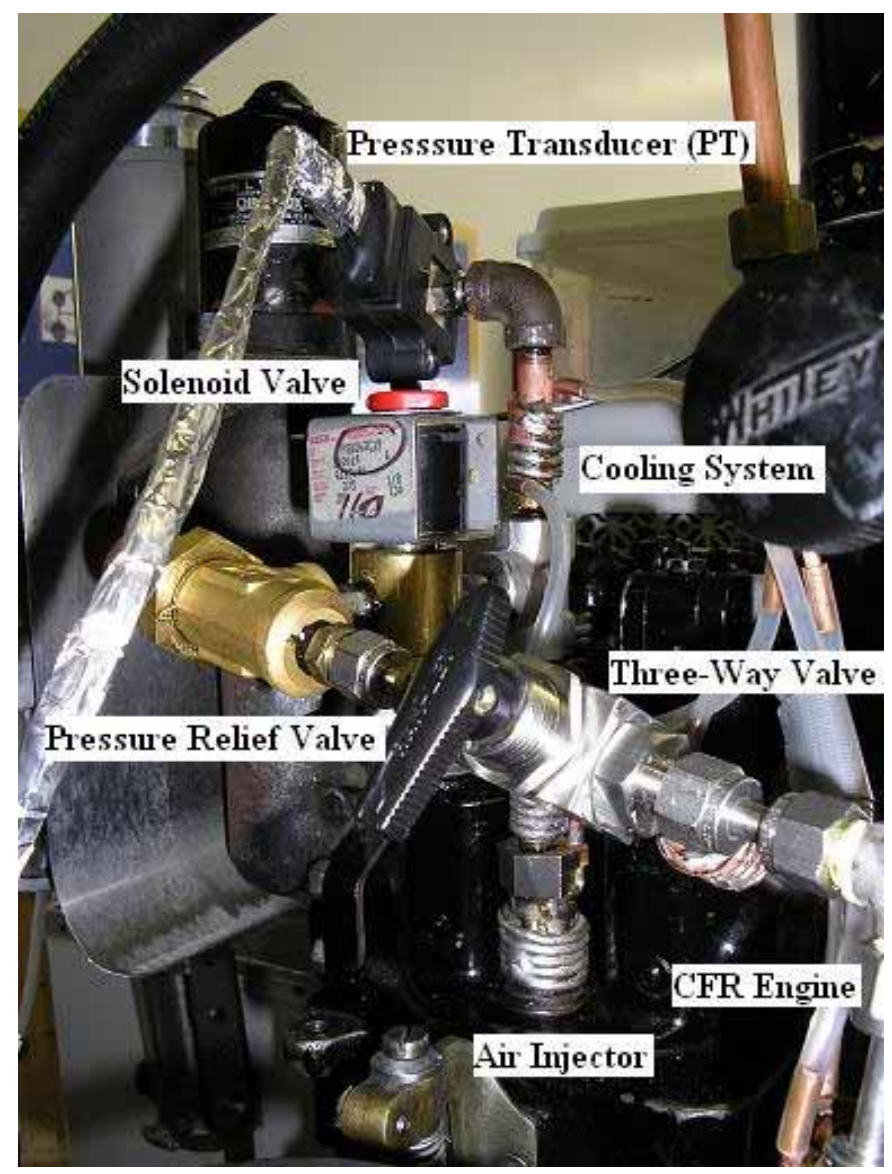

Figure 7.6 Modified air injector with cooling system 


\section{Injector Ball-Check Valve}

The injector ball-check valve is an important component in the air-injection system. It prevents air from leaking into the cylinder after the air injection. This ballcheck valve operates in a difficult environment since it is exposed to extremely high average temperatures (greater than $\left.1000{ }^{\circ} \mathrm{F}\right)$ and high-pressure variations $(0-1000 \mathrm{psig})$; thus its design requirement is tolerate these conditions.

The ball-check valve consists of a 5/8" NF adjusting screw, a 1-1/8" diameter steel rod of 4" long, a 9/16" OD by 1-5/32" long carbon steel helical spring of 5 windings of $1 / 8$ " diameter wire, a 3/8" diameter steel ball, and a 7/8" ID x 1-1/8" OD brass bushing of 3/8" long (Figure 7.7). The steel rod had a centered hole of 3/16" diameter to allow air flow from the solenoid valve to the combustion chamber, and a $1 / 8$ " diameter hole centered at $1 / 4 "$ from the center, and with a $1 / 8$ " NPT connection located in its lateral side for the assembly of the water-cooled pressure adapter. The relief-pressure setting can be increased by turning the adjusting screw clockwise.

The adjusting screw has on one end a $1 / 8$ " NPT connection to attach the airinjection system, and a machined steel seat to press the steel ball against the helical spring on the other end. The adjusting screw has a 3/16" diameter hole to allow highpressure hot air to flow from the air heater into the combustion chamber through the steel ball and helical spring when the solenoid has been actuated by the microcontroller, and the opening pressure has been reached.

The function of the brass bushing is to prevent leakage from the combustion chamber into the atmosphere and provide flexibility in assembling the air injection system. The air injection ball-valve check was tested using cold-air injection, while the 
engine was motored and fired using different compression ratios. Minor leakage was detected at a 500 psig relief-pressure setting, therefore this was increased to 600 psig at which leakage was almost completely eliminated. The air injector ball-check valve met all the operation requirements during the first set of experiments.

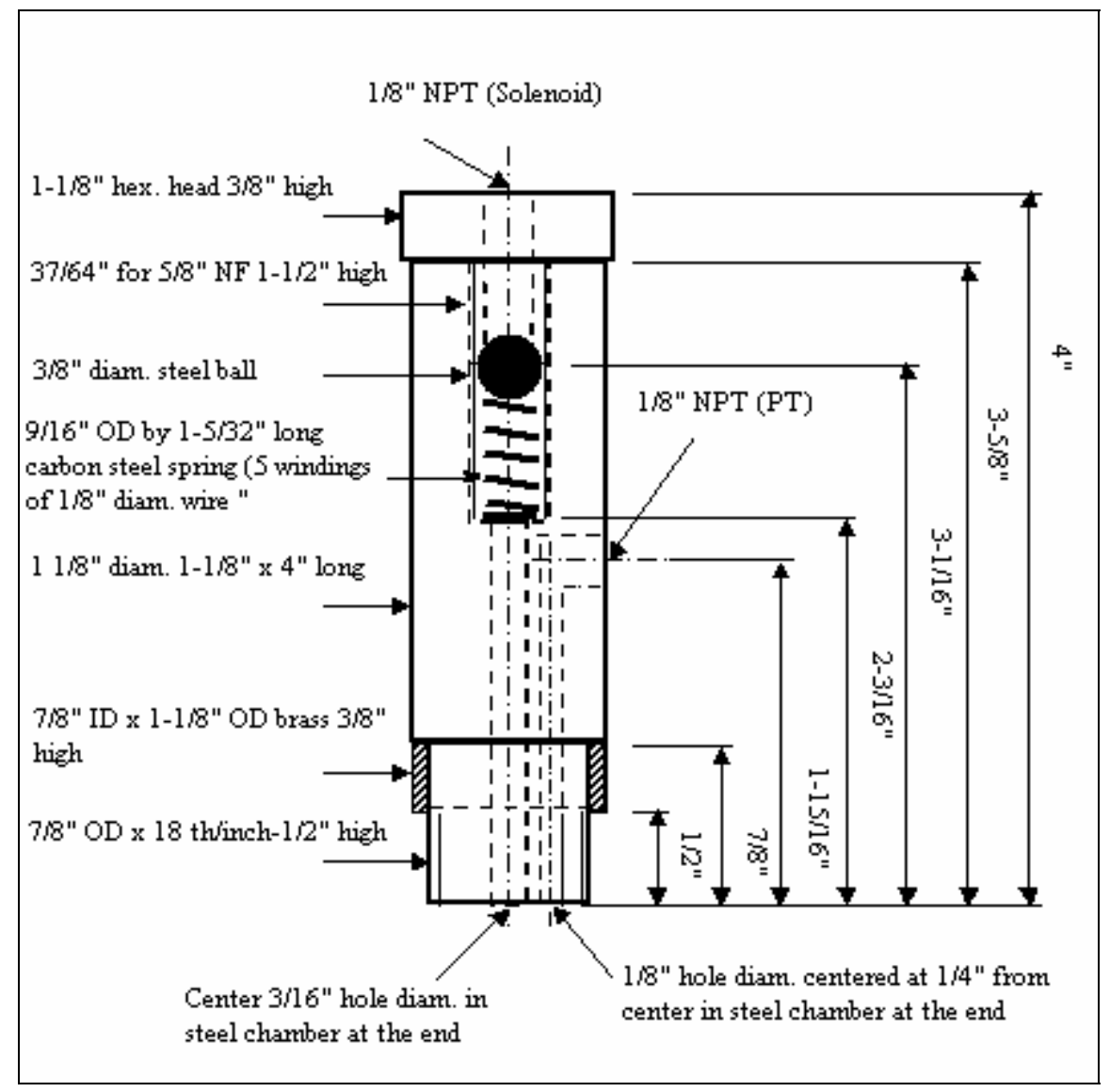

Figure 7.7 Injector ball check valve drawing

Additional details about the design of the cylinder air-injection valve are presented under the experimental set-up and procedures of this dissertation (Chapter 8).

Other mechanical designs done during the course of this research included a spark adapter (Appendix H) used for cold-air-injection tests, and a water-cooled, pressuretransducer adapter (Appendix I) to prevent the pressure transducer (PT) from overheating. 


\section{Chapter 8: Experimental Set-Up and Procedures}

\section{Overview}

The main objective of the experimental work done during the course of this research was to closely simulate a CIBAI engine working under different operation conditions. After designing, building, and evaluating several air-injection systems as presented in Chapter 7, the experimental set-up displayed in Figure 8.1 was selected, and implemented for this study. The engine used for this research was a Cooperative Fuel Research (CFR) engine equipped with a high-pressure air-injection system, and fully instrumented for data acquisition purposes. The engine in-cylinder pressure history with its corresponding crank angle position was recorded while the engine was motored, fired, and operated under the CIBAI principle. The data collected is analyzed in Chapter 9 to provide a better understanding of the CIBAI combustion process. A detailed description of the experimental set-up and procedures are presented next.

\section{Experimental Set-Up}

The schematic diagram of the experimental set-up is illustrated in Figure 8.1. The experimental set-up for this research is shown in Figure 8.2. It consisted of five interrelated components: CFR engine, air-injection system, instrumentation, data acquisition system, and microcontroller unit. Each of these components was either modified, designed, built, or assembled during the course of this dissertation and are explained in detail in the following section. 


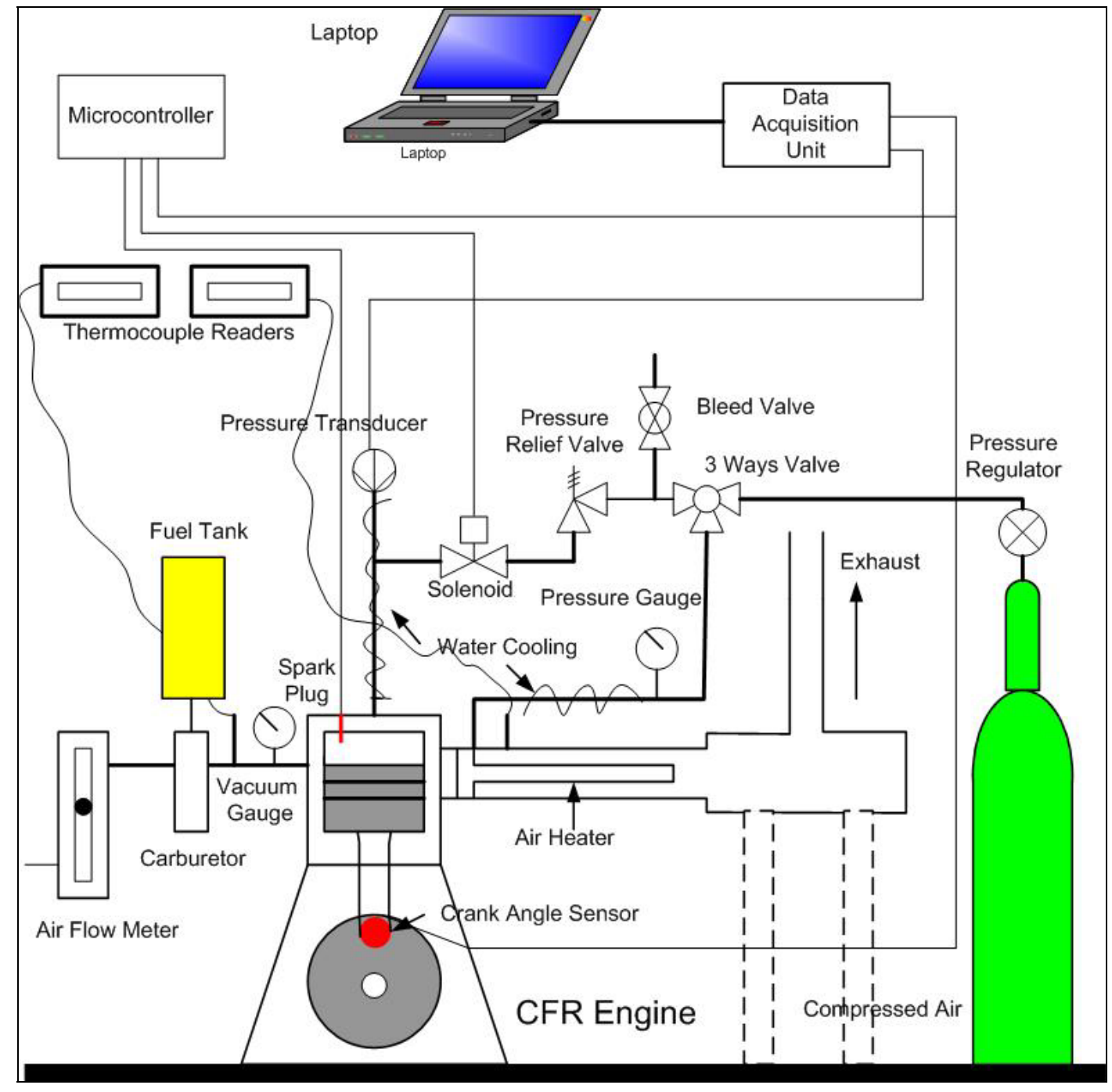

Figure 8.1 Schematic diagram of the experimental set-up 


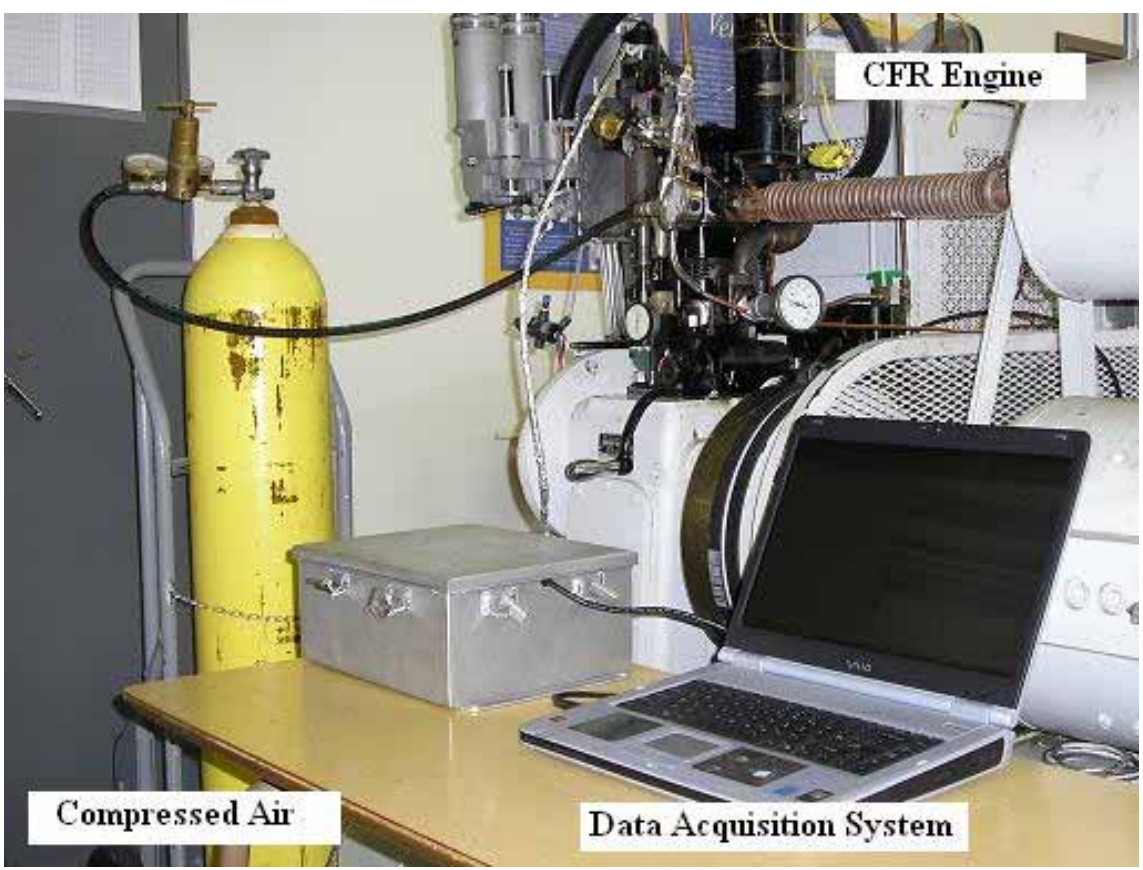

Figure 8.2 Experimental set-up

\section{CFR Engine}

The engine used in this project is a standard four-stroke, single-cylinder CFR

F-2 (motor method octane rating unit) spark-ignition engine with variable compression ratio, manufactured by Waukesha Motor Company in 1957. The engine flywheel was connected by belt to a special power absorption motor. This motor starts the engine (motoring), absorbs the power output of the engine when the combustion takes place (firing), and maintains a constant engine speed of $900+/-9 \mathrm{rpm}$. During firing the absorption motor operates as an alternator and the energy generated is introduced to the AC power system. The engine specifications are given in Table 8.1. 
Table 8.1 WVU CFR engine specifications

\begin{tabular}{|l|r|r|}
\hline \multicolumn{1}{|c|}{ Specification } & English Units & \multicolumn{1}{c|}{ International Units } \\
\hline Model & CFR-48 Crankcase & CFR-48 Crankcase \\
\hline Octane Method Rating & Motor & Motor \\
\hline Type & CFR F-2 Rating Unit & CFR F-2 Rating Unit \\
\hline Engine Speed & $900 \mathrm{rpm}$ & $900 \mathrm{rpm}$ \\
\hline Bore & $3.25 ”$ & $82.55 \mathrm{~mm}$ \\
\hline Stroke & $4.5 ”$ & $114.2 \mathrm{~mm}$ \\
\hline Displacement & 37.33 cubic inches & $612.5 \mathrm{~cm}^{3}$ \\
\hline Compression Ratio (C.R.) & $4: 1$ to $18: 1$ & $4: 1$ to $18: 1$ \\
\hline Ignition Timing & Variable & Variable \\
\hline
\end{tabular}

The main components of the CFR engine are shown in Figure 8.3.

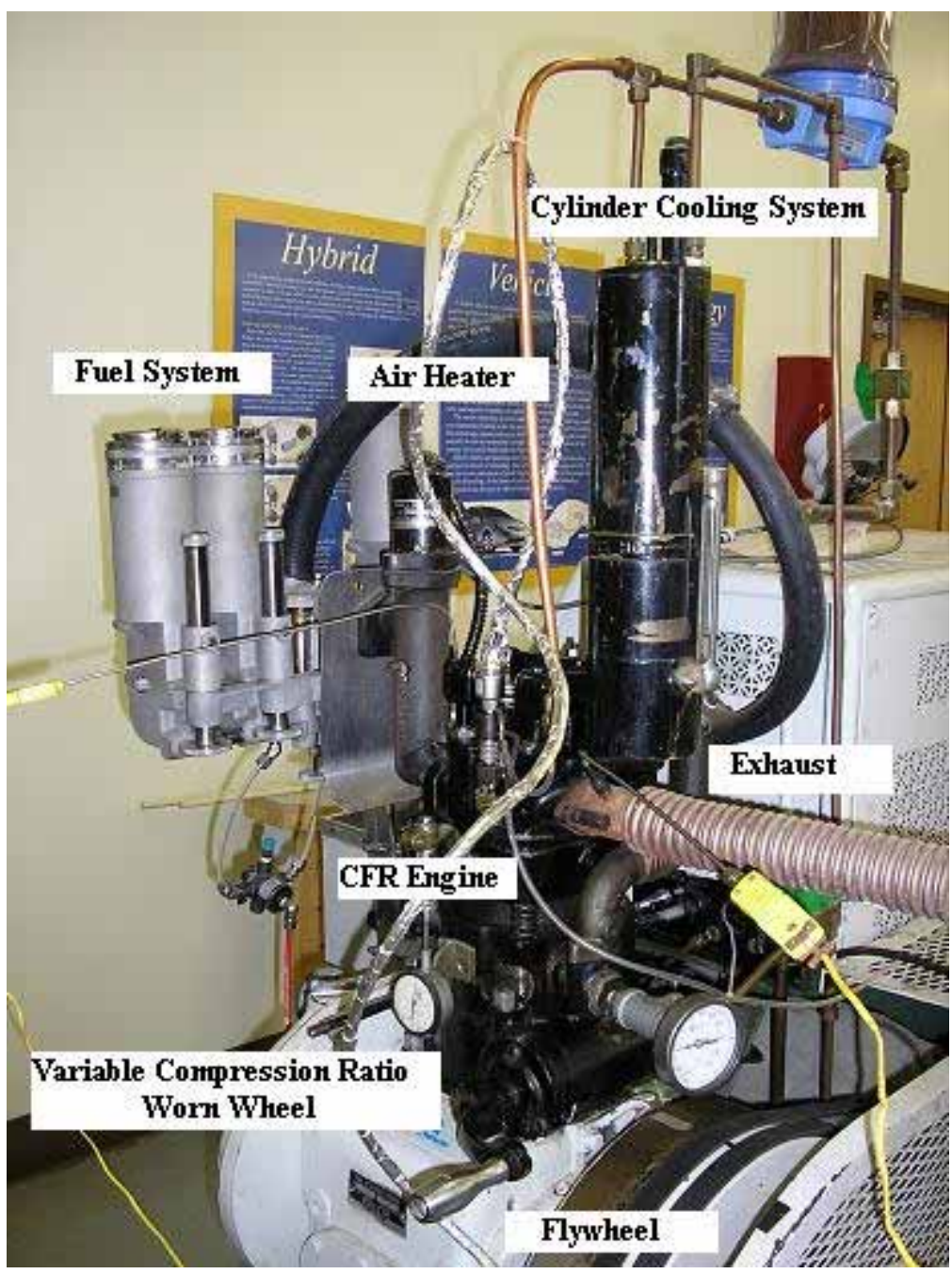

Figure 8.3 CFR engine main components 
The CFR engine was equipped with a 1000 watt, 115 VAC, two-element mixture heater that was installed between the carburetor and the engine intake port. The mixture temperature was controlled through the CFR engine temperature controller.

The fuel supply system (Figure 8.4) consisted of three carburetor bowl/float chamber assemblies, mounted on an adjustment screw to increase or reduce the fuel level and thus change the air-fuel ratio. The carburetor assembly consisted of the carburetor body, a 9/16" throat diameter venturi jet, fuel selector, and fuel level sight glasses. The fuel used for all experiments was unleaded gasoline with an anti knock index (AKI) of 87.

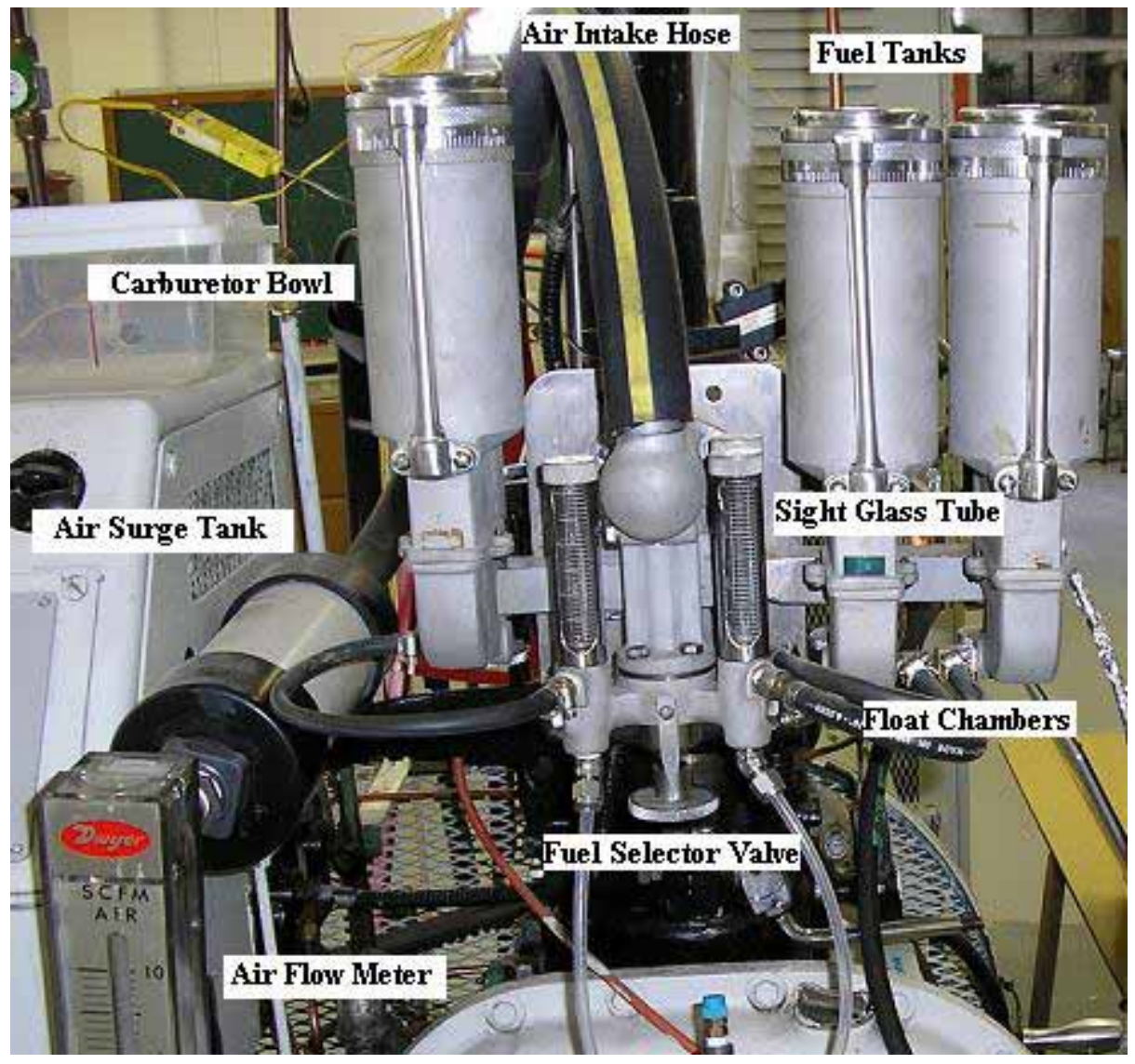

Figure 8.4 Air intake and fuel systems 
The CFR cylinder cooling system was of the thermal-syphon, ebullient, recirculating jacket-cooling type. It consisted of a condenser body, condensing coil, coolant baffle, sight glass assembly, return pipe, cooling jacket, and coolant thermometer. Boiling coolant recirculates through the cooling jacket, and when contacted with the condensing coil, condensates and returns to the cylinder jacket creating a continuous loop. During firing operations the cylinder jacket coolant temperature was maintained around $212{ }^{\circ} \mathrm{F}$.

Several modifications were made to the CFR engine to facilitate air injection into the combustion chamber and allow recording the in-cylinder pressure history. An air surge tank (Figure 8.4) was built using a standard 3" PVC pipe, installed upstream of the carburetor to make the intake-flow rate, steady enough to allow the use of an air-flow meter. The $7 / 8$ " diameter detonation pick-up transducer mounted on the top of the cylinder was removed and replaced by a $7 / 8$ " diameter, carbon steel, ball-type check valve as shown in Figure 8.5.
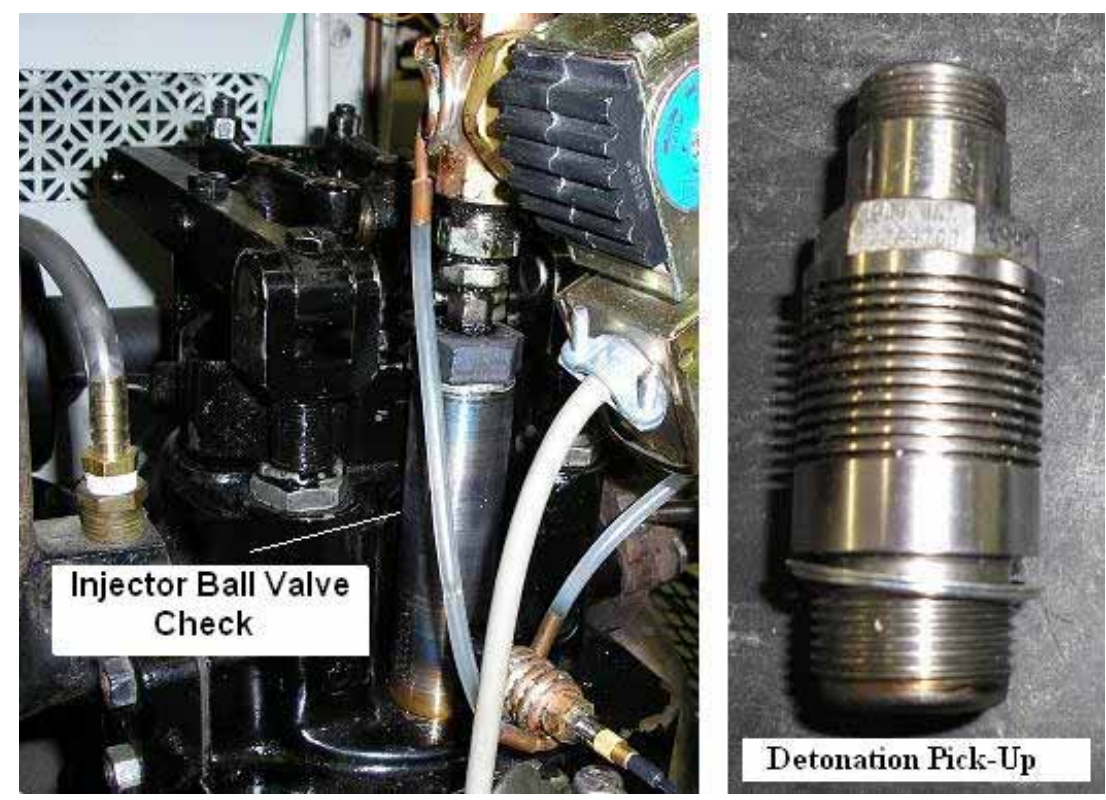

Figure 8.5 Injector ball-check valve and detonation pick-up sensor 
Between the exhaust port and the flexible exhaust pipe an air heater was installed to heat the air charge prior to air injection into the cylinder. The air heater was built with a 1/4" by $1 \mathrm{ft}$ long stainless steel schedule 40 pipe as illustrated in Figure 8.6.
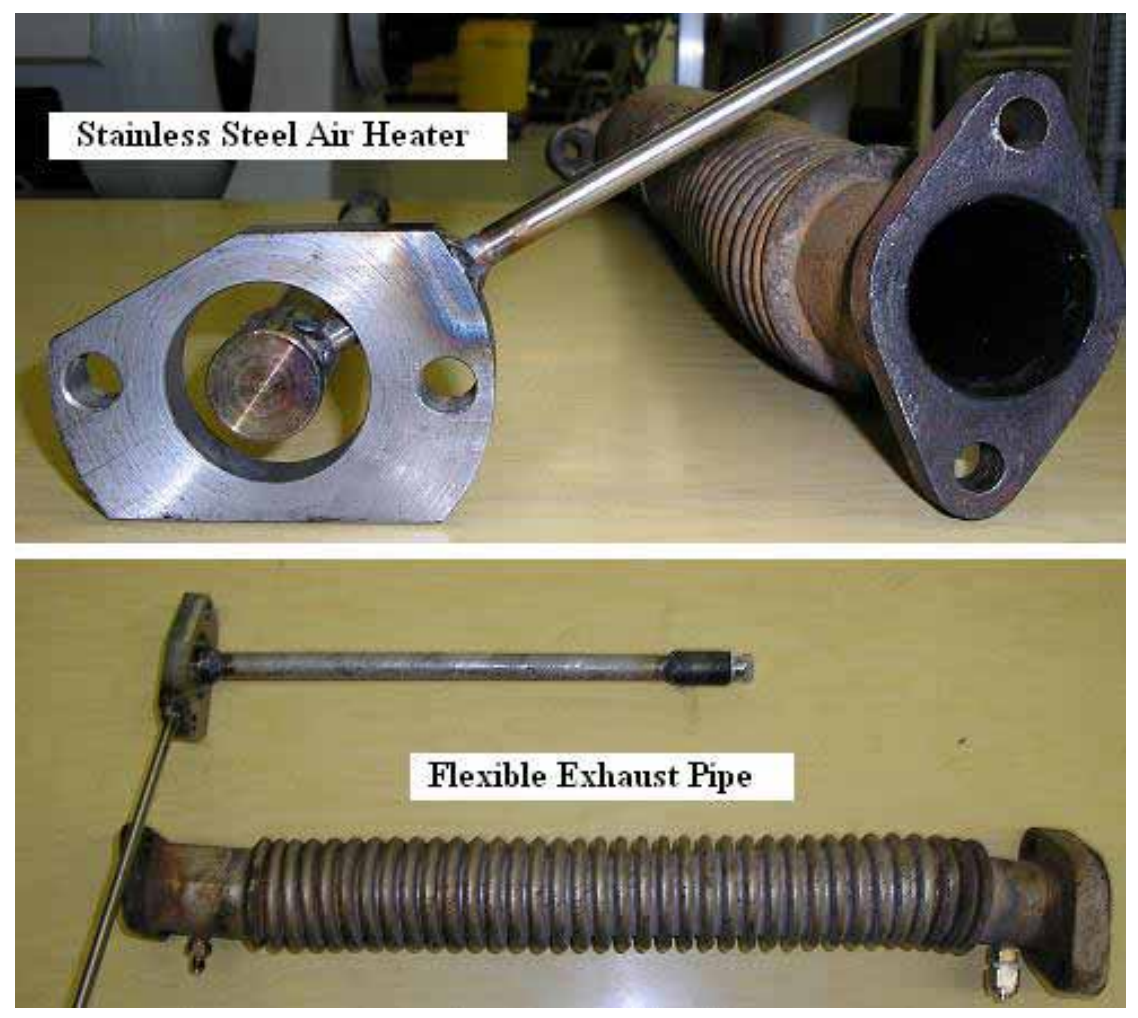

Figure 8.6 Air heater and flexible exhaust pipe

\section{Air-Injection System}

The objective of the air-injection system was to simulate the operating conditions of the second parallel cylinder containing air only, which was needed to run the engine under the CIBAI cycle as proposed by Loth and Morris [3,5]. In this research, the air-fuel cylinder was simulated by the CFR engine single cylinder while the air only cylinder was simulated by the air-injection system and its components.

The air-injection system consisted of the following main components: A 2000 psig compressed air bottle (Appendix C) that supplied the high pressure air into the air 
heater; A $1 / 4$ " by $1 \mathrm{ft}$ long stainless steel air heater which contained the correct amount of air mass for injection at high pressure. A water-cooled 1/4"-115V brass solenoid valve (Appendix E) allows high pressure and temperature air to enter the combustion chamber when activated by a microcontroller. A 1/4"- 2500 psig stainless steel three (3) way ball valve (Appendix J) directed the air between the compressed air supply, air heater, and solenoid valve. A 1/8" copper pipe water-cooling system protected all three: ball valve, solenoid valve, and pressure transducer from overheating. A 7/8" carbon steel injector ball-check valve allowed the heated high pressure air to be injected into combustion chamber. The solenoid valve opening timing was controlled by the microcontroller. It was considered to add a $1 / 8$ " brass air-pressure-relief valve (Appendix K) with a pressure range $235-450$ psig to prevent excess air from entering later in the cycle into the combustion chamber. The air-injection system is shown in Figure 8.7.

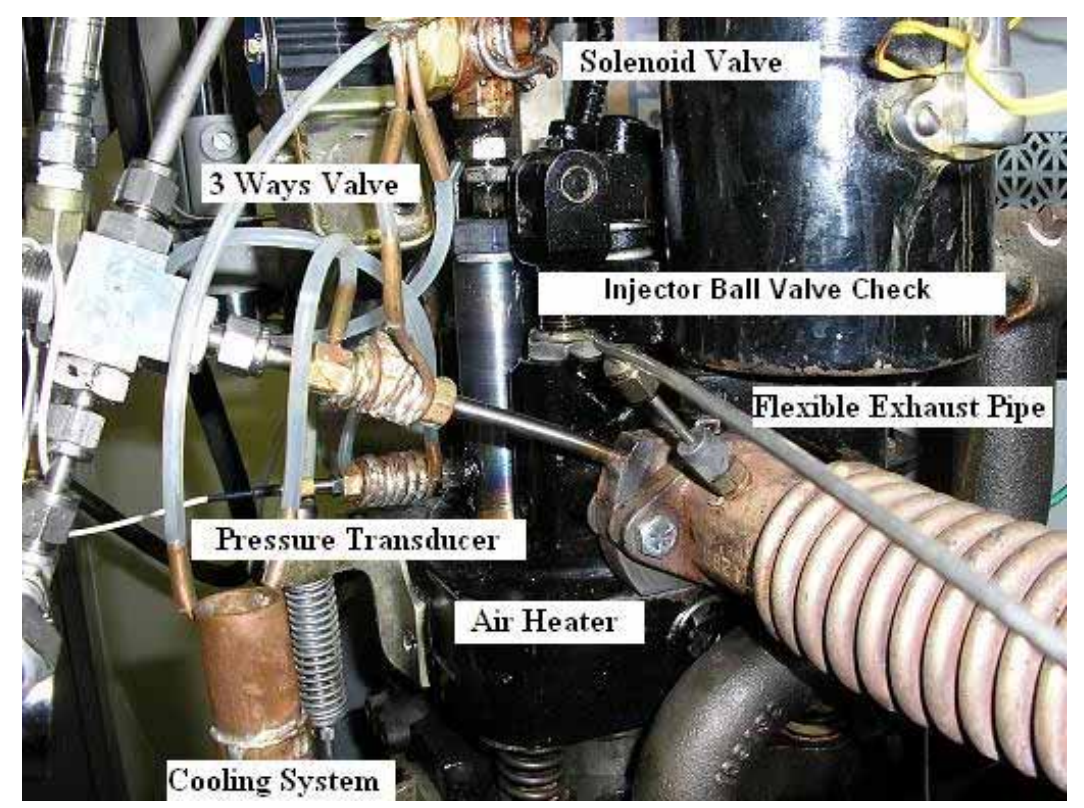

Figure 8.7 Air-injection system 


\section{Instrumentation}

The CFR engine was fully instrumented so that the engine operating conditions could be monitored, as well as in-cylinder pressure history and crank angle, before and after air injection could be measured. It was essential during the experiments to have repeatability of the engine operations from test to test. Calibration information from all instruments was obtained either from the manufacturer of the particular instrument or generated in the laboratory. Figure 8.8 illustrates the schematic diagram of CFR engine instrumentation used in this research.

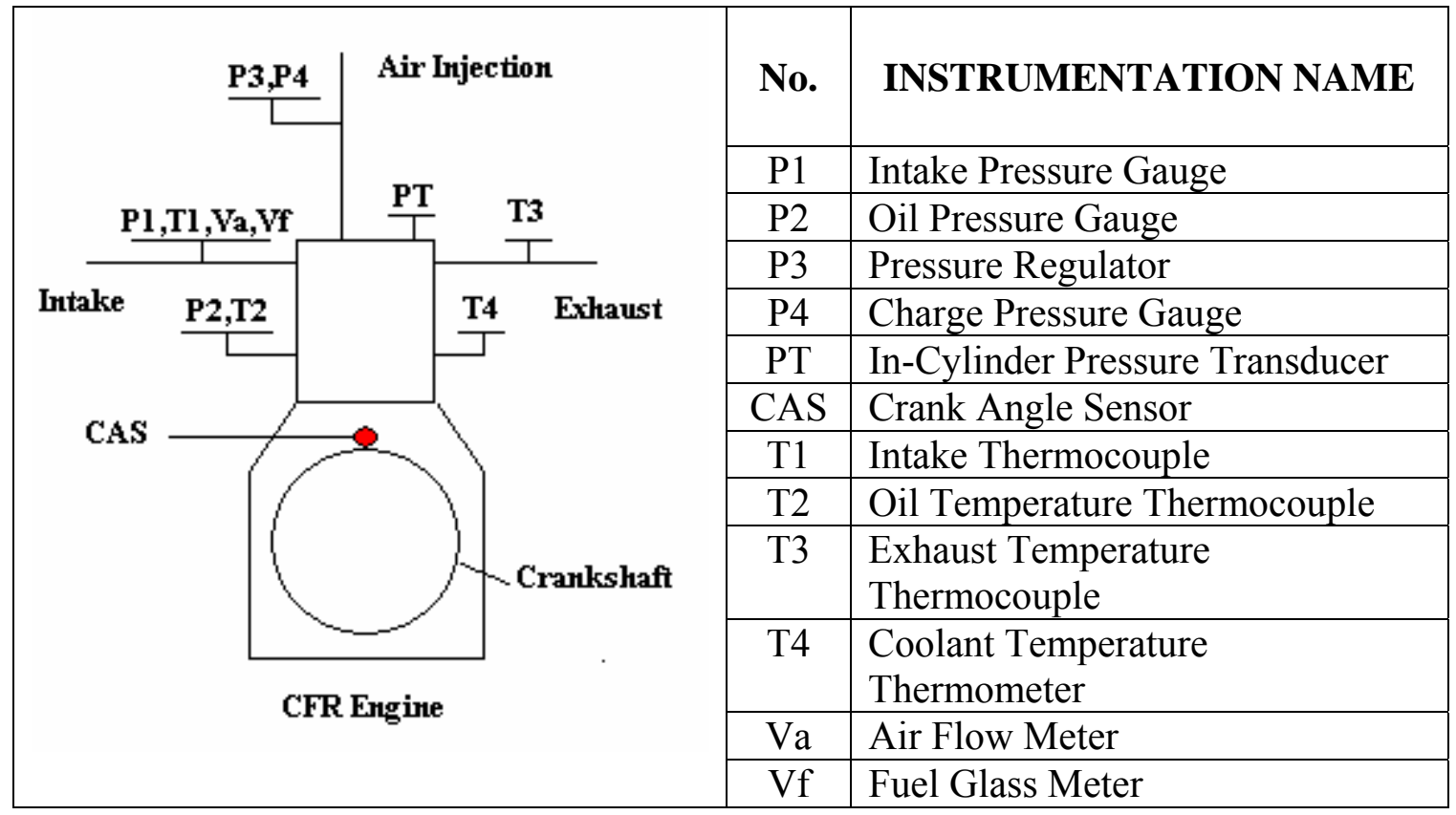

Figure 8.8 Schematic diagram CFR engine instrumentation

\section{Pressure Transducer (PT)}

The engine in-cylinder pressure data were obtained with a water-cooled Dytran piezoelectric pressure transducer, mounted on the injector ball-check valve (Figure 8.5). The transducer preparation and calibration procedures described by Lancaster et al. (1975) were followed in this study. The pressure transducer (PT) required a $20 \mathrm{~V}$ 
excitation, and output $0 \mathrm{~V}$ at 0 psig and $5 \mathrm{~V}$ at 1000 psig with a minimum rise time of input pressure pulse of 2 microseconds. The pressure transducer (PT) datasheet and calibration certificate are shown in Appendix L. The pressure signal was conditioned using a Kistler Piezotron coupler charge amplifier (Appendix M). The pressure data were acquired with a data acquisition system at a sampling rate of $10 \mathrm{KHz}$. Significant noise was present in the acquired pressure data despite extensive effort to eliminate it. These included battery power for all sensors, shielding wires, and metallic boxes for the data acquisition unit and microcontroller. Post-processing activities included low pass filters, smoothing techniques, and Fast Fourier Transform (FFT) spectral analysis.

\section{Crank Angle Sensor (CAS)}

The instantaneous volume of the cylinder as the piston moves from TDC to BDC was determined with the crank angle data obtained from a 5VDC magnetic switch. The CAS was installed on the left side of the CFR engine and above the ignition-timing shaft as shown in Figure 8.9. The magnetic bar was located at $410^{\circ} \mathrm{CA}$ bTDC of the compression stroke.

TDC was determined using a dial indicator to indicate the highest point the piston traveled. This was verified with the TDC mark on the flywheel when the piston was at the highest position. The CAS rotated together with the ignition timing shaft, and sent an analog output to the data acquisition system by actuating the normally open (NO) contact when passing in front of the magnetic switch. The CAS required a 5VDC excitation and delivered a square wave with a lower limit of $0 \mathrm{~V}$ and an upper limit of $5 \mathrm{~V}$ at a rate of 1 pulse per $720^{\circ} \mathrm{CA}$ degree of rotation. In addition, to determine the crank angle position 
with respect to the TDC, the output of the CAS was also used for triggering the data acquisition system and microcontroller unit.

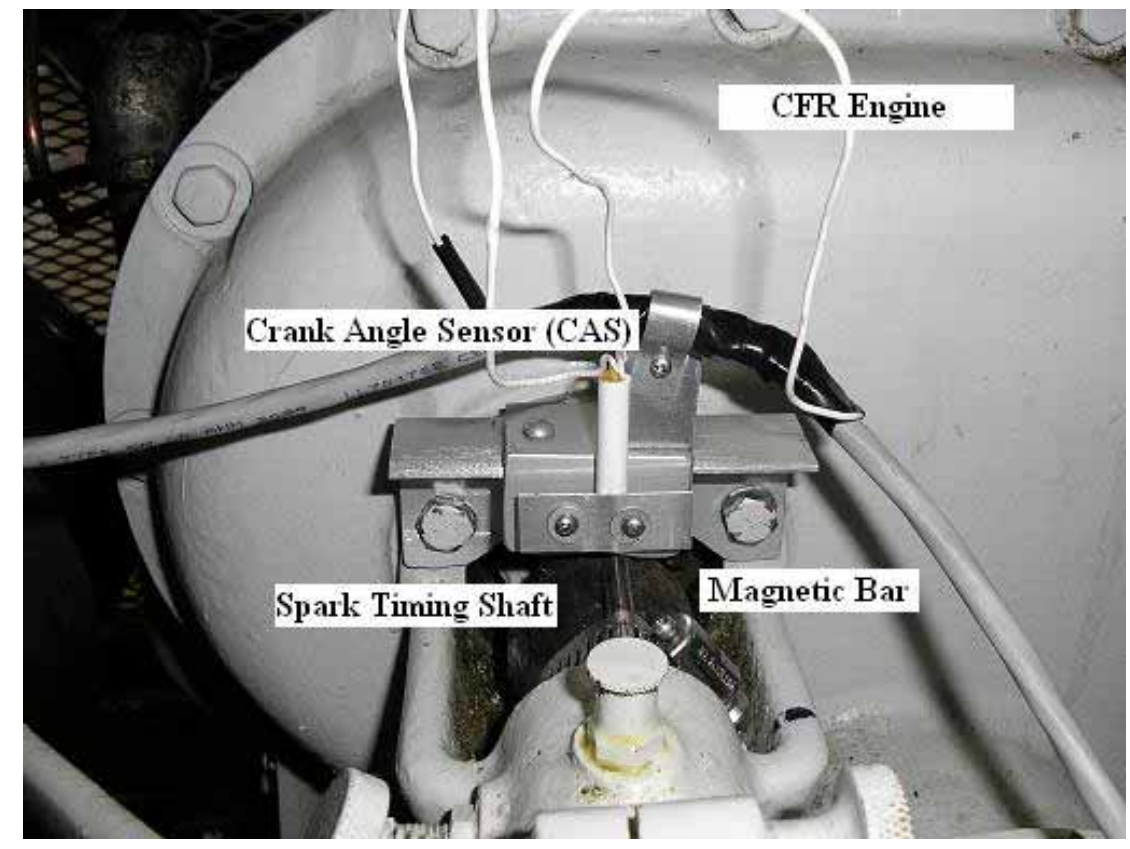

Figure 8.9 Crank angle sensor mounted on CFR engine

\section{Intake Air Flow Rate, Pressure and Temperature}

Intake air volumetric flow rate was monitored via a Dwyer float rotameter with a range of $0-10+/-0.1$ SCFM that was attached to the air surge tank (Figure 8.4). The engine operated at a volumetric air flow rate of 7.0 SCFM. Simultaneously, the pressure and the temperature of the intake were monitored to determine the actual mass flow rate of the intake air using the ideal gas law equation of state.

Intake pressure was displayed on an analog USG vacuum with a range of 0-60 psig +/- 0.1 psig. Intake mixture temperature was monitored with a type $\mathrm{K}$ Omega thermocouple with a range of -208 to $2552{ }^{\circ} \mathrm{F}+/-1{ }^{\circ} \mathrm{F}$. The temperature signal was conditioned and displayed with an Omega 400B thermocouple reader. 


\section{Fuel Flow Rate}

The fuel flow was measured volumetrically by marking known volumes on the sight glass located in the carburetor bowl (fuel tank). Time was measured using a stopwatch for the consumption of the known volume of fuel. With the known time and volume of the fuel, the volumetric flow rate was calculated.

\section{Coolant and Exhaust Temperature}

Exhaust temperature was monitored with a type K Omega thermocouple with a range of -208 to $2552{ }^{\circ} \mathrm{F}+/-1{ }^{\circ} \mathrm{F}$. The Signal was conditioned and displayed with an Omega 400B thermocouple reader. Cylinder jacket coolant temperature was monitored with a $82 \mathrm{~F}$ ASTM thermometer with a range of $0-220{ }^{\circ} \mathrm{F}+/-3^{\circ} \mathrm{F}$. Coolant temperature varied between $160^{\circ} \mathrm{F}$ and $200{ }^{\circ} \mathrm{F}$ during the course of this research.

\section{Oil Temperature and Pressure}

Crankcase oil temperature and pressure were displayed on analog gauges mounted on the front of the CFR engine console instrument panel. Crankcase oil temperature was maintained at $135{ }^{\circ} \mathrm{F}$ through the engine temperature controller. Oil pressure was observed at 30 psig during all tests.

\section{Ignition Timing}

Ignition timing was monitored using a 12VDC strobe timing light with an inductive pick-up manufactured by Sears Roebuck and Co. The inductive pick-up was wrapped around the spark plug and the strobe light, oriented in front of a scaled plate, mounted on the top of the flywheel. The scaled plate was marked with crank angle degrees with respect to the TDC, and thus the match between the strobe light and the 
scaled plate indicated the location of the spark timing when the spark plug was fired. The spark timing varied with the compression ratio.

The basic setting for the CFR engine was $26^{\circ} \mathrm{CA}$ bTDC at a compression ratio of 5.0. A Champion D-16 spark plug with a 0.020 " gap was used for gasoline and spark plug test. The ignition timing of the engine running under normal conditions was employed as a reference to determine the optimal air-injection timing while the engine was running under the CIBAI mode.

\section{Data Acquisition System}

A data acquisition system was assembled to acquire and store the air-injection test data. The data acquisition system consisted of hardware and software components. The hardware components included the pressure transducer (PT) sensor, and the crank angle sensor (CAS), the data acquisition (DAQ) unit, the laptop, and data acquisition card. The software components included the DAQ-EZ Professional, V 1.17, and the Signal View, V 1.91 for data collection, and data post-processing techniques, such as signal filtering, smoothing, and FFT spectral analysis. The electric diagram of the data acquisition, and the data acquisition card datasheet are shown in Appendixes $\mathrm{N}$ and $\mathrm{O}$ respectively.

\section{Microprocessor Unit}

A microcontroller unit was developed in order to control the spark timing, injection timing, and injection duration of the CIBAI operation. The schematic diagram of the microcontroller unit is shown in Figure 8.10. The system consists of a Microchip Pic16F72 chip (Appendix P), electric source circuit, the trigger circuit, the air-injection circuit, and the circuit for controlling the spark ignition. The microcontroller unit program (Appendix Q) was written using the PicBasic Pro language. The process in the 
microcontroller is described as follows: once the unit is triggered by a push button, it reads the delay time and injection duration signals from a pair of potentiometers installed within the unit and enters into a loop until the spark ignition signal is detected from a normally open (NO) magnetic sensor mounted on the spark-ignition distributor shaft.

Having sensed the spark ignition, the microcontroller outputs the spark-ignition control signal to actuate an external 110VAD/6VDC, normally open (NO) relay, installed between the spark-ignition distributor contact points and ground wire. This relay, when energized, grounds the spark to prevent the air-fuel mixture from igniting by spark ignition. After a programmed time delay has passed, the microcontroller sends an output signal to actuate a second external 110VAD/6VDC, normally open (NO) relay, to energize the normally closed solenoid valve and proceed with the air injection. Once the solenoid is energized, it remains open until the selected injection duration has expired. After this period, the microcontroller outputs a signal to restore the spark ignition and resets itself to wait for a new trigger signal to start the next air-injection cycle.

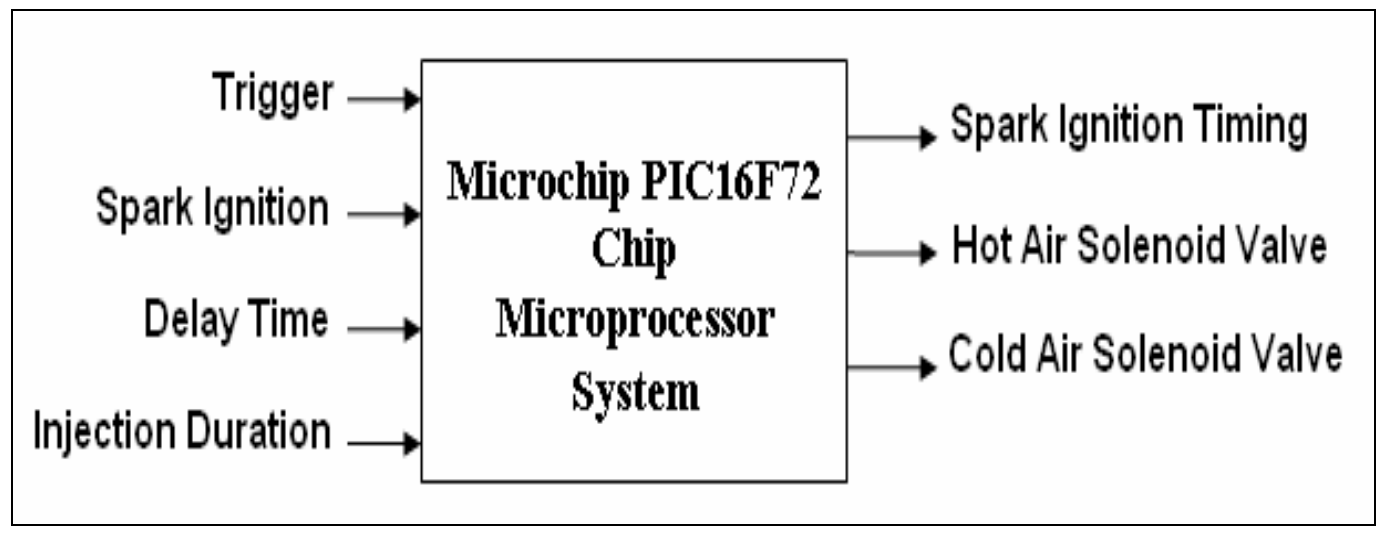

Figure 8.10 Schematic diagram of the microcontroller unit

The air injection strategy discuss above is shown in Figures 8.11, and 8.12. 


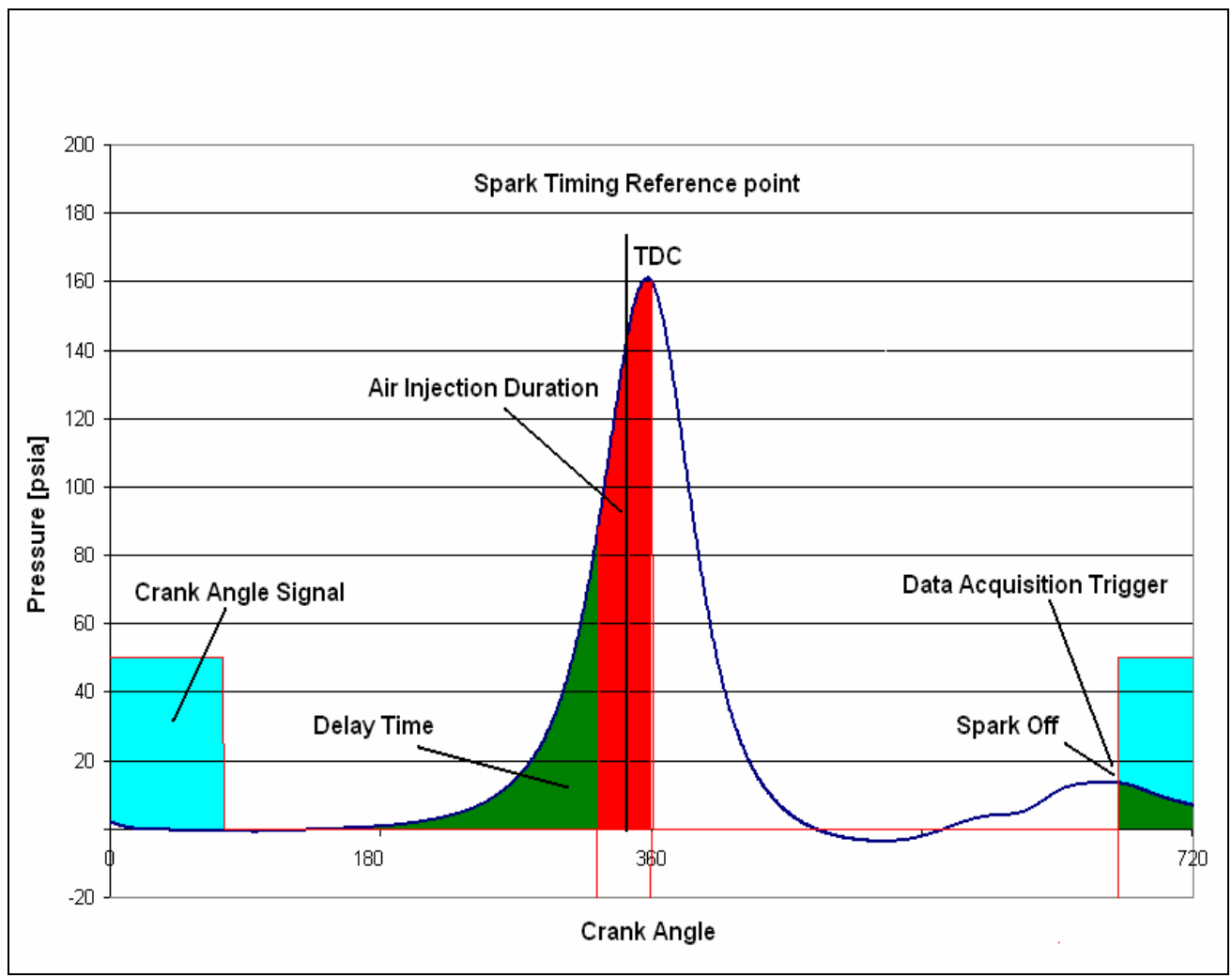

Figure 8.11 Air injection strategy controlled by a microcontroller unit

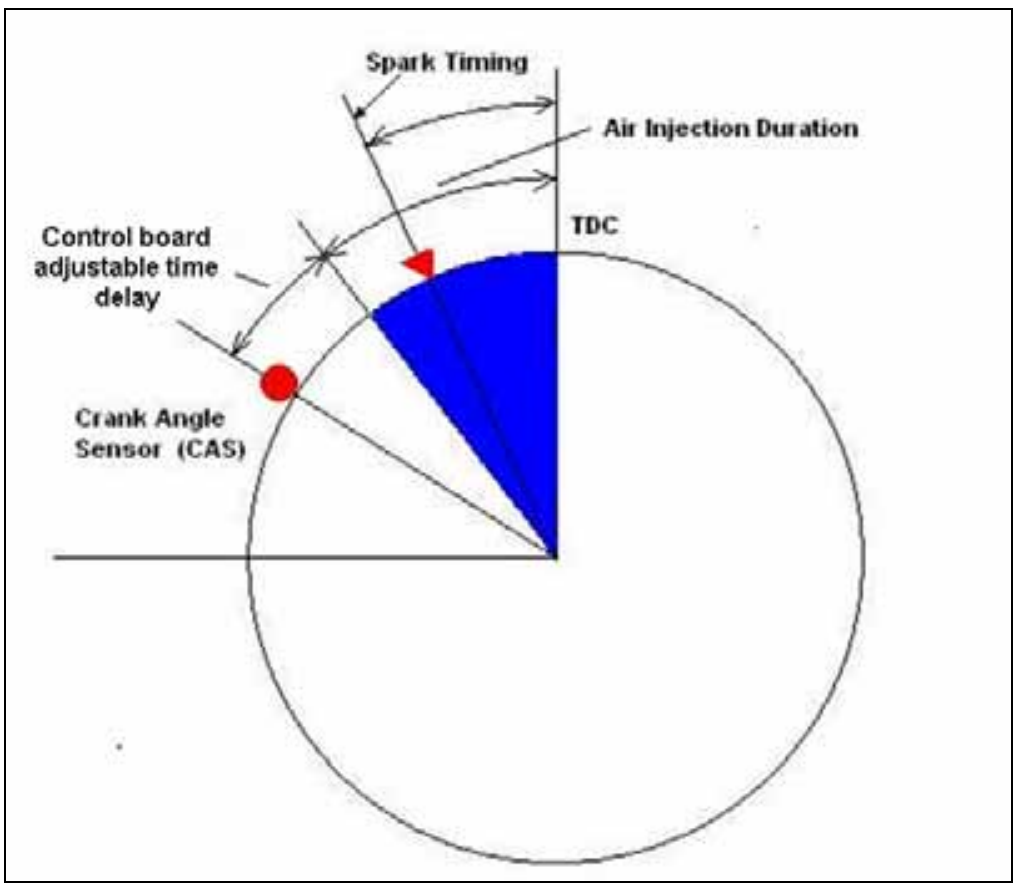

Figure 8.12 Air injection timing crank angle diagram 


\section{Engine Preparation}

Before the start of the experimental work, the engine was given a complete overhaul, including a thorough cleaning of the carburetor, cylinder head, intake and exhaust manifolds, spark plug, etc. The pressure transducer (PT) and crank angle sensor (CAS) were calibrated, and the TDC was determined following the steps outlined before. A dial indicator was used to find the height between the piston and cylinder head for a given compression ratio. The cylinder-connecting valve $(\mathrm{CCV})$ and pressure transducer (PT) were flush-mounted to the cylinder head (Figure 8.5). The flexible exhaust pipe was removed, and the air heater was inserted between the engine exhaust manifold and the exhaust flexible pipe (Figure 8.6). The solenoid valve, three-way ball valve, cooling system, and their corresponding plumbing were assembled (Figure 8.7), and a hydraulic test was taken to detect possible leakages. Liquid displacement was used to measure the added clearance volume due to the cylinder-connecting valve and pressure-transducer (PT) connection, and consequently the CFR engine variable compression ratio was adjusted to include the new clearance volume.

To conclude the engine preparation, the engine was motored, the pressure transducer (PT) was zeroed, and the in-cylinder pressure taken for compression ratios, ranging between 4.56:1 and 16:1. The intake manifold pressure, specific heat ratio $(\gamma)$, and P-V diagram were obtained from the motored data.

\section{Experimental Procedures}

The experimental procedure is outlined next and corresponds to the actual CIBAI process while the engine was motored with a homogeneous air-fuel mixture. However, extensive experimental work was done prior to it, in which procedures differed 
significantly from those presented here. Initial experiments included: Piston-cylinder assembly tests, knock tests, pressure tests without air injection while the engine was motored and fired, cold-air-injection tests with zero back pressure, and cold-air-injection tests while the engine was motored. These initial test results are discussed in the results and discussion section of this paper (Chapter 10).

The experimental procedures for the CIBAI auto-ignition testing are outlined as follows: after the engine preparation and instrumentation calibration were done, the microcontroller unit had been programmed, and the data acquisition system had been properly connected and tested, the CFR engine was motored and fired using the standard procedures outlined by ASTM [67]. While the engine was motored, the compression ratio (C.R) was adjusted to the one selected for the particular test. The carburetor bowl was filled with regular unleaded gasoline with an average knock index (AKI) of 87 . The three-way valve was turned to allow regulated air to flow from the 2000 psig compressed air bottle into the air heater. The injection air pre-heater was filled with high-pressure cold air to a predetermined pressure.

The engine was fired by turning the ignition switch on and turning the fuel valve selector to the on-position of the carburetor being used. The fuel sight glass was kept at the level selected for the particular test, and the air flow rate was maintained at 7.0 SCFM. The engine was run at the operating conditions specified in Table 8.2 until the exhaust temperature achieved a steady state.

At this point, the three-way valve was turned to allow pre-heated high-pressure air to become connected to the solenoid valve. The ignition was then shut off and the microcontroller unit and data acquisition triggered. At this moment, the microcontroller 
unit had complete control over the engine operation, data acquisition and air-injection processes. With the engine motored with the same operating conditions, a predetermined number of cycles of motored pressures were collected. The microcontroller then used the input data processed from the set of potentiometers installed in its unit to determine the ignition delay and air-injection timing, and proceeded to actuate the solenoid valve to allow high-pressure hot air into the cylinder through the injector ball-check valve.

Table 8.2 CFR engine operating conditions under CIBAI combustion

\begin{tabular}{|l|l|}
\hline Fuel & Unleaded Gasoline AKI 87 \\
\hline Fuel Level (in) & $0.5,1.0,1.5+/-0.1$ \\
\hline Intake Temperature $\left({ }^{\circ} \mathrm{F}\right)$ & $70,150,250+/-5$ \\
\hline Oil Temperature $\left({ }^{\circ} \mathrm{F}\right)$ & $135+/-5$ \\
\hline Oil Pressure $(\mathrm{psia})$ & $30+/-5$ \\
\hline Coolant Temperature $\left({ }^{\circ} \mathrm{F}\right)$ & $180+/-10$ \\
\hline Exhaust Temperature $\left({ }^{\circ} \mathrm{F}\right)$ & $600+/-15$ \\
\hline Compression Ratio & $7.0,7.5,8.0$ \\
\hline RPM & $900+/-9$ \\
\hline Air Pre-heater Charging Pressure (psig) & $700,800,900,1000+/-20$ \\
\hline Spark Plug Gap (in.) & $0.020-0.025$ \\
\hline Spark Timing (Fired) & Variable \\
\hline
\end{tabular}

If the conditions for self-ignition (e.g. temperature, pressure, and air-fuel ratio, turbulence, density) were met, the air-fuel mixture would auto-ignite, and CIBAI ignition and combustion would take place. After, the auto-ignition was completed, spark ignition was turned back on, and the engine continued to fire at the previous operation conditions. Data from a predetermined number of cycles before and after auto-ignition were collected. Finally, the standard stopping procedures suggested by ASTM [67] were followed to stop the engine. After the experimental work was concluded, the digitized pressure data were scaled, averaged, and analyzed.

This procedure was repeated for air-fuel mixture intake temperatures of $70^{\circ} \mathrm{F}$, and $250^{\circ} \mathrm{F}$, at compression ratios of 7.0:1, 7.5:1 and 8.0:1, fuel levels of 0.5 in, 1.0 in, and 1.5 
in, air pre-heater charging pressure varied from 700 psig to 900 psig, and air-injection timing from $85^{\circ}, 75^{\circ}$, and $65^{\circ} \mathrm{CA}$ bTDC. The experimental matrices for this study are presented next.

\section{Experimental Matrices}

The experiments for this research were divided into five matrices. These matrices described the experiments carried out to determine the effect of compression ratio, intake temperature, air pre-heater charging pressure, equivalence ratio, and air-injection timing with CIBAI combustion.

\section{Matrix 1: The Effect of Compression Ratio on CIBAI Combustion}

The effect of compression ratio on CIBAI combustion was experimentally studied by increasing the compression ratio from 7.0:1 to $8.0: 1$ in increments of 0.5 , while the engine speed, intake temperature, exhaust temperature, equivalence ratio, air flow rate, and air pre-heater charging pressure were maintained constant. In-cylinder pressure data were recorded and analyzed for motored, fired, and CIBAI combustion. Matrix 1 is shown in Table 8.3.

\section{Matrix 2: The Effect of Intake Temperature on CIBAI Combustion}

The effect of intake temperature on CIBAI combustion was experimentally studied by increasing the air-fuel mixture intake temperature from 70 to $250^{\circ} \mathrm{F}$, while the engine speed, compression ratio, exhaust temperature, air flow rate, air pre-heater charging pressure, equivalence ratio, and air-injection timing were maintained constant. In-cylinder pressure data were recorded and analyzed for motored, fired, and CIBAI combustion. Matrix 2 is shown in Table 8.4. 


\section{Matrix 3: The Effect of Air Pre-heater Charging Pressure on CIBAI Combustion}

The effect of air pre-heater charging pressure on CIBAI combustion was experimentally studied by varying the charging pressure from 700 to 900 psig in increments of $100 \mathrm{psig}$, while the engine speed, compression ratio, intake temperature, exhaust temperature, fuel level, air flow rate, equivalence ratio, and air-injection timing were maintained constant. In-cylinder pressure data were recorded and analyzed for motored, fired, and CIBAI combustion. Matrix 3 is shown in Table 8.5.

\section{Matrix 4: The Effect of Equivalence Ratio on CIBAI Combustion}

The effect of equivalence ratio on CIBAI combustion was experimentally studied by changing the equivalence ratio $(\Phi)$ from 0.45 to 0.65 in increments of 0.15 , while the engine speed, compression ratio, intake temperature, exhaust temperature, air flow rate, air pre-heater charging pressure, and air-injection timing were maintained constant. Incylinder pressure data were recorded and analyzed for motored, fired, and CIBAI combustion. Matrix 4 is shown in Table 8.6. A sample calculation for air-fuel and equivalence ratios is shown in Appendix R.

\section{Matrix 5: The Effect of Air-Injection Timing on CIBAI Combustion}

The effect of air-injection timing on CIBAI combustion was experimentally studied by changing the air-injection timing from 85 to $65^{\circ} \mathrm{CA}$ bTDC in decrements of $10^{\circ}$, while the engine speed, compression ratio, intake temperature, exhaust temperature, air flow rate, air pre-heater charging pressure, equivalence ratio, and air-fuel ratio were maintained constant. In-cylinder pressure data were recorded and analyzed for motored, fired, and CIBAI combustion. Matrix 5 is shown in Table 8.7. 
Table 8.3 Experimental matrix 1: effect of compression ratio in CIBAI combustion

\begin{tabular}{|l|l|l|l|}
\hline & Test 1 & Test 2 & Test 3 \\
\hline $\begin{array}{l}\text { Variable Parameter } \\
\text { Compression Ratio }\end{array}$ & C.R $=7.0$ & C.R $=7.5$ & C.R. $=8.0$ \\
\hline $\begin{array}{l}\text { Fixed Parameters } \\
\text { RPM }\end{array}$ & $900+/-9$ & $900+/-9$ & $900+/-9$ \\
\hline Intake Temperature $\left({ }^{\circ} \mathrm{F}\right)$ & $70+/-5$ & $70+/-5$ & $70+/-5$ \\
\hline Exhaust Temperature $\left({ }^{\circ} \mathrm{F}\right)$ & $600+/-15$ & $600+/-15$ & $600+/-15$ \\
\hline Equivalence Ratio $(\Phi)$ & $0.50+/-0.01$ & $0.50+/-0.01$ & $0.50+/-0.01$ \\
\hline Air Flow Rate $(\mathrm{SCFM})$ & $7+/-0.1$ & $7+/-0.1$ & $7+/-0.1$ \\
\hline Air Pre-heater Charging Pressure (psig) & $800+/-10$ & $800+/-10$ & $800+/-10$ \\
\hline $\begin{array}{l}\text { Air Injection Timing } \\
\left({ }^{\circ} \text { CA bTDC) }\right.\end{array}$ & $75+/-0.5$ & $75+/-0.5$ & $75+/-0.5$ \\
\hline
\end{tabular}

Table 8.4 Experimental matrix 2: effect of intake temperature in CIBAI combustion

\begin{tabular}{|l|c|c|}
\hline & Test 4 & Test 5 \\
\hline $\begin{array}{l}\text { Variable Parameter } \\
\text { Intake Temperature }\left({ }^{\circ} \mathrm{F}\right)\end{array}$ & $70+/-5$ & $150+/-5$ \\
\hline $\begin{array}{l}\text { Fixed Parameters } \\
\text { RPM }\end{array}$ & $900+/-9$ & $900+/-9$ \\
\hline Compression Ratio & C.R $=8$ & C.R $=8$ \\
\hline Exhaust Temperature $\left({ }^{\circ} \mathrm{F}\right)$ & $600+/-15$ & $600+/-15$ \\
\hline Equivalence Ratio $(\Phi)$ & $0.50+/-0.01$ & $0.50+/-0.01$ \\
\hline Air Flow Rate $(\mathrm{SCFM})$ & $7+/-0.1$ & $7+/-0.1$ \\
\hline Air Pre-heater Charging Pressure $(\mathrm{psig})$ & $800+/-10$ & $800+/-10$ \\
\hline $\begin{array}{l}\text { Air Injection Timing } \\
\left({ }^{\circ} \mathrm{CA} \text { bTDC) }\right.\end{array}$ & $75+/-0.5$ & $75+/-0.5$ \\
\hline
\end{tabular}

Table 8.5 Experimental matrix 3: effect of air charged pressure in CIBAI combustion

\begin{tabular}{|l|c|c|c|}
\hline & Test 6 & Test 7 & Test 8 \\
\hline $\begin{array}{l}\text { Variable Parameter } \\
\text { Air Pre-Heater Charging Pressure }(\mathrm{psig})\end{array}$ & $700+/-10$ & $800+/-10$ & $900+/-10$ \\
\hline $\begin{array}{l}\text { Fixed Parameters } \\
\text { Compression Ratio }\end{array}$ & $\mathrm{C} . \mathrm{R}=8$ & C.R $=8$ & C.R $=8$ \\
\hline RPM & $900+/-9$ & $900+/-9$ & $900+/-9$ \\
\hline Intake Temperature $\left({ }^{\circ} \mathrm{F}\right)$ & $70+/-5$ & $70+/-5$ & $70+/-5$ \\
\hline Exhaust Temperature $\left({ }^{\circ} \mathrm{F}\right)$ & $600+/-15$ & $600+/-15$ & $600+/-15$ \\
\hline Equivalence Ratio $(\Phi)$ & $0.50+/-0.01$ & $0.50+/-0.01$ & $0.50+/-0.01$ \\
\hline Air Flow Rate $(\mathrm{SCFM})$ & $7+/-0.1$ & $7+/-0.1$ & $7+/-0.1$ \\
\hline Air Injection Timing $\left({ }^{\circ} \mathrm{CA}\right.$ bTDC) & $75+/-0.5$ & $75+/-0.5$ & $75+/-0.5$ \\
\hline
\end{tabular}


Table 8.6 Experimental matrix 4: effect of equivalence ratio in CIBAI combustion

\begin{tabular}{|c|c|c|c|}
\hline & Test 9 & Test 10 & Test 11 \\
\hline $\begin{array}{l}\text { Variable Parameter } \\
\text { Equivalence Ratio }(\Phi)\end{array}$ & $0.65+/-0.01$ & $0.50+/-0.01$ & $0.45+/-0.01$ \\
\hline $\begin{array}{l}\text { Fixed Parameters } \\
\text { Compression Ratio }\end{array}$ & C. $\mathrm{R}=8$ & C. $\mathrm{R}=8$ & $\mathrm{C} . \mathrm{R}=8$ \\
\hline RPM & $900+/-9$ & $900+/-9$ & $900+/-9$ \\
\hline Intake Temperature $\left({ }^{\circ} \mathrm{F}\right)$ & $70+/-5$ & $70+/-5$ & $70+/-5$ \\
\hline Exhaust Temperature $\left({ }^{\circ} \mathrm{F}\right)$ & $600+/-15$ & $600+/-15$ & $600+/-15$ \\
\hline Air Pre-heater Charging Pressure (psig) & $800+/-10$ & $900+/-10$ & $1000+/-10$ \\
\hline Air Flow Rate (SCFM) & $7+/-0.1$ & $7+/-0.1$ & $7+/-0.1$ \\
\hline $\begin{array}{l}\text { Air Injection Timing } \\
\left({ }^{\circ} \mathrm{CA} \text { bTDC) }\right.\end{array}$ & $75+/-0.5$ & $75+/-0.5$ & $75+/-0.5$ \\
\hline
\end{tabular}

Table 8.7 Experimental matrix 5: effect of air injection timing in CIBAI combustion

\begin{tabular}{|l|c|c|c|}
\hline & Test 12 & Test 13 & Test 14 \\
\hline $\begin{array}{l}\text { Variable Parameter } \\
\text { Air Injection Timing } \\
\left({ }^{\circ} \text { CA bTDC) }\right.\end{array}$ & & & \\
\hline $\begin{array}{l}\text { Fixed Parameters } \\
\text { Compression Ratio }\end{array}$ & $85+/-1.0$ & $75+/-1.0$ & $65+/-1.0$ \\
\hline RPM & C.R $=8$ & C.R $=8$ & C.R $=8$ \\
\hline Intake Temperature $\left({ }^{\circ} \mathrm{F}\right)$ & $900+/-9$ & $900+/-9$ & $900+/-9$ \\
\hline Exhaust Temperature $\left({ }^{\circ} \mathrm{F}\right)$ & $70+/-5$ & $70+/-5$ & $70+/-5$ \\
\hline Equivalence Ratio $(\Phi)$ & $600+/-15$ & $600+/-15$ & $600+/-15$ \\
\hline Air Flow Rate $(\mathrm{SCFM})$ & $0.50+/-0.01$ & $0.50+/-0.01$ & $0.50+/-0.01$ \\
\hline Air Pre-Heater Charging Pressure $(\mathrm{psig})$ & $7+/-0.1$ & $7+/-0.1$ & $7+/-0.1$ \\
\hline
\end{tabular}




\section{Chapter 9: Data Analysis}

\section{Overview}

Engine in-cylinder pressure and volume data in combination with thermodynamic principles and ideal gas law are fundamental for a combustion study. In-cylinder pressure data are used to study ignition, auto-ignition, knock phenomena, and cycle-to-cycle variations among others. Pressure measurement data are also used to determine peak pressure, indicated work, engine friction, pumping losses, and to compare experimental pressures with the pressures calculated by combustion models.

In this study, the CFR engine in-cylinder pressure was used to calculate the following parameters: indicated work, indicated mean effective pressure (IMEP), temperature history, heat release rate, mass fraction burned (MFB), ignition delay (ID), and combustion interval. A computer program was developed to carry out the necessary calculations. This computer program used numerical integration methods, thermodynamic principles, and the ideal gas law in order to compute these parameters.

The preparation and calibration of the piezoelectric system used in these experiments were done using the procedure outlined by Lancaster et al. [68]. The combustion characterization of engine pressure data was done using the heat release model, developed by Gatowski et al. [69], and Woschni [70], and the mass fraction burned (MFB) equation, presented by Rassweiler and Withrow [71].

\section{In-Cylinder Pressure History}

Most of the pressure data in this research were taken with a water-cooled Dytran pressure transducer Model 2201V1 (Appendix L), and the signal was amplified using a Kistler Piezotron charge amplifier (Appendix M). The correlation between the time- 
pressures history with the cylinder volumes was done using an electromagnetic crankangle sensor (Figure 8.10), as described in the experimental set-up section of this paper. The total cylinder volume associated with each crank angle was calculated by adding the volume, associated with the displacement of the piston, and the clearance volume, associated with the selected compression ratio. The volume generated by the piston motion was calculated from the physical dimensions of the engine, and the crank angle was calculated using Equation 9.1 [72]

$$
V=V_{c}+\frac{\pi b^{2}}{4}\left[\frac{s}{2}(1-\cos \theta)+l-\sqrt{l^{2}-\frac{s^{2}}{4} \sin ^{2} \theta}\right]
$$

where:

$$
\begin{array}{ll}
\mathrm{V} & =\text { Total volume inside the cylinder } \\
\mathrm{V}_{\mathrm{c}} & =\text { Clearance volume } \\
\mathrm{B} & =\text { Engine bore } \\
\mathrm{S} & =\text { Engine stroke } \\
\mathrm{L} & =\text { Connecting rod length } \\
\theta & =\text { Crank angle measured from TDC. }
\end{array}
$$

\section{Work}

In an internal combustion (IC) engine work is produced by the gas pressure in the combustion chamber, acting on the face of the piston as the engine moves through the entire cycle. The work produced by an IC engine is represented by the following equation:

$$
W=\int P d V
$$

where:

$\mathrm{P}=$ Pressure in combustion chamber $\mathrm{dV}=$ Differential volume displaced by the piston . 
The net work done by the fluid on the piston (net indicated work) is greater than the work done at the output shaft (brake work). This difference is due to the mechanical friction and parasitic loads, which are not included in the calculation of the net indicated work. The brake work is given by:

$$
W_{b}=W i-W_{f}
$$

where:

$$
\begin{aligned}
& \mathrm{W}_{\mathrm{b}}=\text { Brake work } \\
& \mathrm{W}_{\mathrm{i}}=\text { Net indicated work } \\
& \mathrm{W}_{\mathrm{f}}=\text { Work lost due to friction and parasitic load. }
\end{aligned}
$$

Figure 9.1 shows a typical P-V diagram for the Otto cycle. The upper loop represents the gross indicated work, produced during the compression and expansion strokes while the lower loop represents the pump work, absorbed from the engine during the intake and exhaust strokes. The net indicated work is calculated as follows:

$$
W i=W_{\text {gross }}+W_{\text {pumping }}
$$

where:

$$
\begin{aligned}
& \mathrm{W}_{\mathrm{i}}=\text { Net indicated work } \\
& \mathrm{W}_{\text {gross }}=\text { Gross indicated work } \\
& \mathrm{W}_{\text {pump }}=\text { Pump work. }
\end{aligned}
$$

The pump work is positive when the intake pressure is greater than the exhaust pressure (i.e. supercharged or turbocharged engines), and is negative when the intake pressure is less than the exhaust pressure.

The net indicated work can be obtained through numerical integration using the engine in-cylinder pressure data and its corresponding volume data given by the crank angle during the piston motion. 


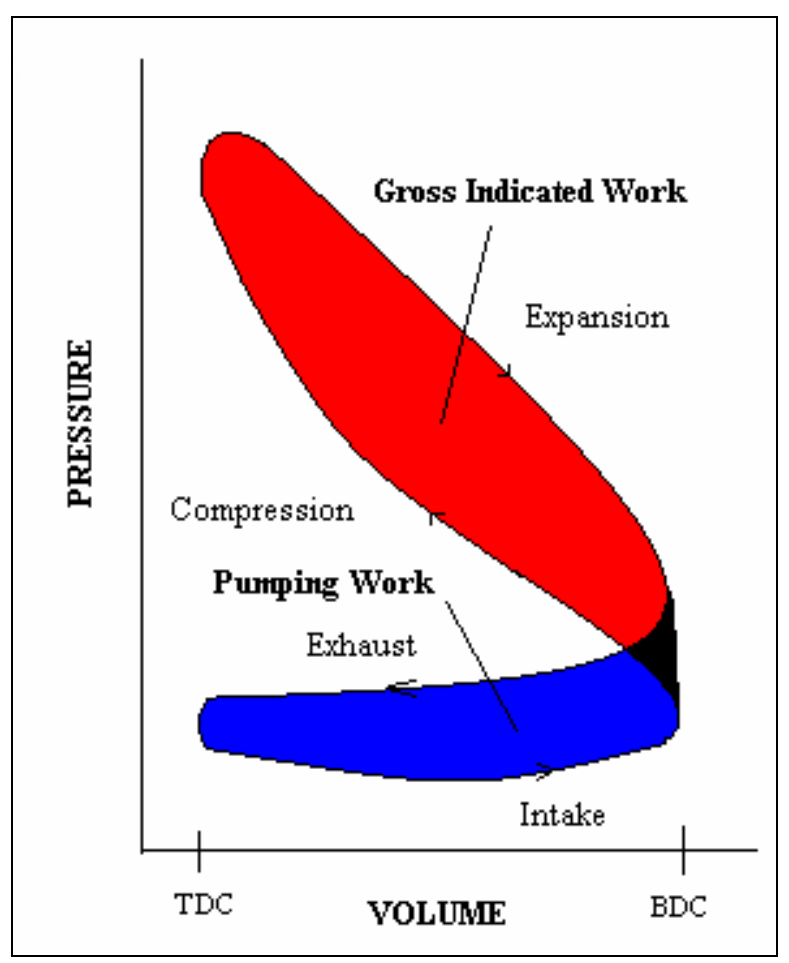

Figure 9.1 Otto cycle p-v diagram

For this study the numerical integration method proposed by Lancaster et al. [68] was used.

By definition:

$$
\text { Work }=\int_{\theta 1}^{\theta 2} P d V=\int_{\theta 1}^{\theta 2} P \frac{d V}{d \theta} d \theta
$$

Equation 9.5 can be closely approximated by:

$$
\text { Work }=\sum_{\theta 1=\theta 1}^{\theta 2} P(\theta)_{i} \frac{d V}{d \theta}(\theta)_{i} \Delta \theta
$$

where:

$$
\begin{array}{ll}
\mathrm{P}(\theta) \mathrm{I} & =\text { Instantaneous pressure at a given crank angle }(\theta) \\
\mathrm{dV}(\theta) \mathrm{i} / \mathrm{d}(\theta) & =\text { Instantaneous differential volume with respect to } \\
& \text { the crank angle }(\theta) \\
\Delta \theta & \text { Crank angle sampling variation. }
\end{array}
$$




\section{Mean Effective Pressure}

The mean effective pressure (MEP) is defined as the theoretical pressure needed to produce a work equal to the type of work done by the gas pressure on the piston per unit, volume per cycle. The MEP is independent of engine size and speed, and thus it is a good parameter to compare engines of different size. The MEP is calculated by integrating the pressure-volume curve inside the cylinder and dividing by the cylinder volume displacement:

$$
W=\frac{1}{\pi b^{2} s} \int P d V
$$

or

$$
M E P=W / V d
$$

where:

$$
\begin{array}{ll}
\mathrm{MEP} & =\text { Mean effective pressure } \\
\mathrm{W} & =\text { Work of one cycle } \\
\mathrm{Vd} & =\text { Volume displacement. }
\end{array}
$$

The mean effective pressure is calculated according to the work segment considered. This gives indicated pumping, brake, and friction mean effective pressures among others. The indicated mean effective pressure (IMEP) was of particular interest for this study. The IMEP represents the net result between the work done by the gases on the piston motion during the expansion stroke and the work absorbed during the compression stroke. The IMEP can be calculated from the in-cylinder pressure data using numerical integration and is given by:

$$
I M E P=\frac{1}{\pi B^{2} S} \sum_{i}^{j} \frac{1}{2}\left(P(\theta)_{i+1}+P(\theta)_{i}\right)\left(V(\theta)_{i+1}-V(\theta)_{i}\right)
$$


where:

$\mathrm{i}=$ Start at BDC before the compression stroke

$\mathrm{j}=$ End at BDC after the expansion stroke

$\mathrm{P}(\theta)_{\mathrm{i}+1}=$ Instantaneous pressure at a crank angle $(\theta)_{\mathrm{i}+1}$

$\mathrm{P}(\theta)_{\mathrm{i}} \quad=$ Instantaneous pressure at a crank angle $(\theta)_{\mathrm{i}}$

$\mathrm{V}(\theta)_{\mathrm{i}+1}=$ Instantaneous volume at a crank angle $(\theta)_{\mathrm{i}+1}$

$\mathrm{V}(\theta)_{\mathrm{i}}=$ Instantaneous volume at a crank angle $(\theta)_{\mathrm{I}}$

\section{Heat Release Rate}

The heat release is defined in the literature as the amount of heat that would have to be added to the cylinder contents to produce the measured pressure variations due to combustion of the air-fuel mixture. The heat release rate provides a way to characterize the combustion process within the engine combustion chamber. The heat release rate is obtained using the in-cylinder pressure and crank angle data in combination with the ideal law gas and thermodynamic principles.

The heat release rate is approximated by treating the combustion chamber as a closed system of varying volume and neglecting heat transfer effects to the walls and flows into and out of crevices volumes in the combustion chamber. These assumptions provide significant margin of errors in the final calculation of the heat release rate, and thus analysis based on these results has to be examined in that context. The heat-release rate equation is developed as follows:

The change in pressure during the combustion process is assumed to be the sum of the pressure change due to the piston motion and the pressure change due to the combustion of the air-fuel mixture. This can be calculated using Equation 9.11.

$$
\Delta P=\Delta P_{M}+\Delta P_{C}
$$


where:

$\Delta P \quad=$ Total change in pressure during the combustion process

$\Delta P_{M} \quad=$ Change in pressure due to the piston motion

$\Delta P_{C} \quad=$ Change in pressure due to the combustion process.

Assuming a constant specific heat ratio $(\gamma)$ as proposed by Gatowski et al. [69], and using the polytropic process relations, the ideal gas law, the continuity equation, the conservation of energy principle for a closed system, and the in-cylinder pressure and crank angle data, the heat-release rate equation is obtained:

$$
\frac{d Q_{H R}}{d \theta}=\frac{V_{\theta}+\Delta \theta}{(\gamma-1) \Delta \theta}\left(P_{\theta+\Delta \theta}-P_{\theta}\left[\frac{V_{\theta}}{V_{\theta}+\Delta_{\theta}}\right]^{\gamma}\right)
$$

where:

$$
\begin{array}{ll}
\frac{d Q_{H R}}{d \theta} & =\text { The net heat release rate per crank angle degree }(\theta) \\
P_{\theta+\Delta \theta} & =\text { Pressure at crank angle }(\theta+\Delta \theta) \\
P_{\theta} & =\text { Pressure at crank angle }(\theta) \\
V_{\theta+\Delta \theta} & =\text { Volume at crank angle }(\theta+\Delta \theta) \\
V_{\theta} & =\text { Volume at crank angle }(\theta) \\
\gamma & =\text { Specific heat ratio } \approx 1.35[69] .
\end{array}
$$

In this study, the beginning of combustion was set to the crank angle, corresponding to the first negative or zero value for the heat release preceding the maximum release rate. In the same way, the end of combustion was set to the crank angle corresponding to the first negative or zero value for heat release following the maximum heat release. 


\section{Mass Fraction Burned (MFB)}

The mass fraction burned (MFB) is a measurement of how fast the charge is burned during the combustion process. MFB is obtained from the heat release data by assuming that the heat added to the combustion chamber is proportional to the amount burned. Numerically, it is calculated by integrating the heat release curve up to the point of interest and dividing the result by the total heat release [71], and it is given by:

$$
M F B=\frac{\sum_{i=B C}^{P}\left(\frac{d Q_{H R}}{d \theta}\right)}{\sum_{i=B C}^{E C}\left(\frac{d Q_{H R}}{d \theta}\right)}
$$

where:

$$
\begin{array}{ll}
\mathrm{BC} & =\text { Beginning of combustion } \\
\mathrm{EC} & =\text { End combustion } \\
\mathrm{P} & =\text { Point of calculation of the MFB. }
\end{array}
$$

Typical values for MFB will range from $0 \%$ to $100 \%$.

\section{Ignition Delay (ID)}

Normally, the ignition delay, $\Delta \theta_{\mathrm{ID}}$, for spark ignited (SI) engines is defined as the time between the spark discharge and the time a 10\% MFB. In compression ignited (CI) engines the ignition delay, $\Delta \theta_{\mathrm{ID}}$, is defined as the time between the start of injection and the onset of combustion. For CIBAI combustion, the ignition delay, $\Delta \theta_{\mathrm{ID}}$, has been defined as the crank angle interval between the opening of the cylinder-connecting valve (CCV) and 10\% MFB.

\section{Combustion Duration}

The combustion duration is an important parameter for the operation of internal combustion (IC) engines. The combustion duration, $\Delta \theta_{\mathrm{CI}}$, is defined as the crank angle 
required to burn the bulk of the engine charge, and it is usually taken as the difference between crank angles corresponding to $10 \%$ MFB and $90 \%$ MFB [1]. The ignition delay and combustion interval are also obtained from the heat release data. 


\section{Chapter 10: Results and Discussion}

\section{Overview}

Prior to the actual tests on ignition by air injection (CIBAI) using the CFR engine, preliminary experiments were conducted to create a profile of the operating conditions of the CFR engine, and determine the optimal design for the air-injection system. These experiments were divided into four groups: knock, volumetric, cold-air injection, and compression-pressure tests. These experiments were then followed by the actual ignition by air-injection (CIBAI) tests, using the experimental set-up and procedures outlined in Chapter 8 .

After that, the digitized in-cylinder pressure and its corresponding cylinder volume data were scaled to absolute level, and processed using spectral analytical tools. The processed data were then input into a computer program (Appendix A) to be integrated numerically to conduct a parametric study of the ignition by the air-injection (CIBAI) process. The computer program calculated the indicated work, indicated mean effective pressure (IMEP), net heat release, net-heat-release rate, mass fraction burned (MFB), ignition delay (ID), and combustion interval. The results of this experimental work are discussed next.

\section{Experimental Results}

\section{Knock Data}

The objective of these tests was to determine the onset of the knock to evaluate the incidence of the compression ratio, intake temperature, and spark timing on the appearance of the knock for a particular fuel type and air-fuel mixture. The onset of knock was checked for the CFR engine running under different compression ratios and 
operating conditions. The fuel used was unleaded gasoline with an average knock index (AKI) of 87. The engine was run at $900 \mathrm{rpm}$ until the exhaust temperature reached steady state (around $1000{ }^{\circ} \mathrm{F}$ ). At that point, the compression ratio gradually increased until audible knock was detected. Using an intake temperature of $120^{\circ} \mathrm{F}$ and a spark timing of $5^{\circ} \mathrm{CA}$ bTDC, the audible knock was perceived for compression ratios greater than or equal to $12.51: 1$. When the CFR engine was run with an intake temperature of $400{ }^{\circ} \mathrm{F}$ (using the intake heater) and a spark timing of $15^{\circ} \mathrm{CA}$ bTDC, the audible knock was detected at a compression ratio of 11:1.

The knock tests showed that increasing the temperature of the engine charge by raising the compression ratio, raising the inlet air temperature, and advancing the spark timing increased the possibility of the knock in the SI engine. The CFR engine operating conditions used during the knock tests are summarized in Table 10.1.

Table 10.1 CFR engine operating conditions during knock testing

\begin{tabular}{|l|r|}
\hline Engine Parameter & Specification \\
\hline Fuel & Unleaded Gasoline AKI 87 \\
\hline Fuel Level (in) & $1.0+/-0.1$ \\
\hline Intake Temperature $\left({ }^{\circ} \mathrm{F}\right)$ & $70,150,250,400+/-5$ \\
\hline Oil Temperature $\left({ }^{\circ} \mathrm{F}\right)$ & $135+/-5$ \\
\hline Oil Pressure $(\mathrm{psia})$ & $30+/-5$ \\
\hline Coolant Temperature $\left({ }^{\circ} \mathrm{F}\right)$ & $180+/-10$ \\
\hline Exhaust Temperature $\left({ }^{\circ} \mathrm{F}\right)$ & $900+/-15$ \\
\hline Compression Ratio & Variable from 7.0 to 16.0 in increments of 0.5 \\
\hline RPM & $900+/-15$ \\
\hline
\end{tabular}

\section{Volumetric Data}

Volumetric tests were conducted using the cylinder-piston arrangement discussed in Chapter 7. The main objectives were to determine the discharged time of the $1 / 8$ " solenoid valve and evaluate the mass, injected into the CFR simulator for different charged, amplified, and back pressures. The charged pressure was varied between $30 \mathrm{psig}$ 
and $100 \mathrm{psig}$, and the back pressure from 0 to $150 \mathrm{psig}$, while the amplified pressure value was kept constant. The amplified pressure was changed from 40 psig to 400 psig. Several important findings were obtained from this experimental work. The maximum pressures for high amplified pressures (200-400 psig) were obtained for a discharged time lasting approximately $40 \mathrm{~ms}$. For low amplified pressures $(<200 \mathrm{psig})$, the maximum pressures were obtained for a discharged time around $150 \mathrm{~ms}$. The discharged time reached with the cylinder-piston assembly was very slow, and thus the system was considered unsuitable to be used as the simulated-air-only cylinder of the CIBAI engine. During the ignition by air-injection (CIBAI) experiment, the CFR engine ran at $900 \mathrm{rpm}$, and completed a thermodynamic cycle in $133 \mathrm{~ms}$. Air injection was done around $75^{\circ} \mathrm{CA}$ $\mathrm{bTDC}$ for an injection time of $15 \mathrm{~ms}$ to achieve maximum compression heating near TDC, and therefore a fast air-injection system was required.

The low response time of the cylinder-piston assembly can be attributed to high friction between the cylinder and piston surface, and/or the large masses of the piston, and solenoid valve actuator.

The volumetric data also indicated the possibility of measuring and injecting a particular amount of air for predetermined initial conditions without affecting the integrity of the engine and/or operator. An average volume fluctuating between 500 and $600 \mathrm{cc}$ of standard air was injected into the measured device for amplified pressures ranging from 80 to 160 psig. These results closely agreed with the initial conditions predicted for the CIBAI combustion test as calculated in Chapter 7. 


\section{Cold Injection Data}

Cold injection tests were conducted to verify the time response of the actual airinjection system as explained in Chapter 8 . For these tests, the spark plug was removed and replaced by a spark plug adaptor (Appendix H), which was used to bleed air into the atmosphere after each test. The compression ratio was then selected, and the air-injection system pressurized for the predetermined air pre-heated charging pressure. After that, the pressure transducer was zeroed and the data acquisition triggered as explained in the experimental set-up (Chapter 8) of this dissertation.

Peak pressure after injection was obtained around $72 \mathrm{~ms}$ for all charged pressures tested. This may indicate that the time to reach the maximum pressure does not depend on the charging pressure, but on the response time of the solenoid valve. The information obtained with the cold-injection experiments was fundamental to define the air-injection strategy to control auto-ignition by air injection (CIBAI) using the CFR engine. The airinjection strategy will be discussed later in this chapter.

\section{Compression Pressure Data}

In-cylinder pressure data were taken while the CFR engine was motored for different compression ratios and operating conditions. The motored data were then used to check for leakages, verify the calibration of all instruments, determine the intake absolute pressure, estimate the polytropic exponent (n), and check the experimental procedures. The pressure data were also used to verify the phasing of pressure with respect to volume. This was done by verifying the curve pressure-crank near the peak pressure. Normally, the peak pressure occurs near the TDC $\left(1^{\circ}\right.$ or $2^{\circ} \mathrm{CA}$ bTDC) due to irreversibilities mainly by heat transfer [68]. 
No major leakages were observed during the compression tests. Minor leakages were present in the air-injection system, but they were corrected before the actual air injection. A polytropic exponent (n) between 1.23 and 1.35 was obtained using a logarithmic P-V diagram with the same set of motored data. The numbers obtained closely agreed with the data obtained by previous researchers $[68,69]$. For this work, a polytropic exponent (n) corresponding to a specific heat ratio $(\gamma)$ of 1.35 was used for all calculations.

The pressure data did not show a significant shifting with respect to the volume data $\left(<0.5^{\circ} \mathrm{CA}\right)$, which were assumed to be acceptable for the current experimental setup. The intake absolute pressure reading during the compression test was $10.1 \mathrm{psia}$ for the engine running with the flow meter and 11.1 psia without the flow meter. The pressure drop can be attributed to friction and minor losses (pumping losses) due to the flow meter, air surge tank, and intake pipe fittings.

\section{Fired Data}

The CFR engine in-cylinder pressure data were digitized and processed for a number of cycles during CIBAI test. This was done in order to compare both, spark ignition, and CIBAI ignition, combustion parameters for the same operating conditions,

and determine the net benefits of ignition by air-injection (CIBAI) combustion over sparked ignited combustion. The CFR engine operating conditions used in these experiments are summarized in Table 10.2.

During spark ignition (SI) testing, the CFR engine was fired using a Champion D16 spark plug, and the CFR engine conventional ignition system. This system consisted 
of an ignition power supply, an ignition switch, ignition coil, a housing containing the breaker, a spark plug, and high-tension spark wire.

Table 10.2 CFR engine operating conditions during firing testing

\begin{tabular}{|l|r|}
\hline Engine Parameter & Specification \\
\hline Fuel & Unleaded Gasoline AKI 87 \\
\hline Fuel Level (in) & $0.5,1.0,1.5+/-0.1$ \\
\hline Intake Temperature $\left({ }^{\circ} \mathrm{F}\right)$ & $70,150,250+/-5$ \\
\hline Oil Temperature $\left({ }^{\circ} \mathrm{F}\right)$ & $135+/-5$ \\
\hline Oil Pressure $(p s i a)$ & $30+/-5$ \\
\hline Coolant Temperature $\left({ }^{\circ} \mathrm{F}\right)$ & $180+/-10$ \\
\hline Exhaust Temperature $\left({ }^{\circ} \mathrm{F}\right)$ & $600+/-15$ \\
\hline Compression Ratio & 7.0 to 12.0 \\
\hline RPM & $900+/-15$ \\
\hline Spark Timing & Variable \\
\hline
\end{tabular}

The spark timing was automatically adjusted as the compression ratio changed from 4.54:1 to $16: 1$. The change in spark timing with compression ratio is shown in Table 10.3. These numbers were verified using a strobe light as described in the experimental set-up section of this paper (Chapter 8)

Table 10.3 Change in spark timing with compression ratio

\begin{tabular}{|c|c|c|}
\hline $\begin{array}{c}\text { Compression Ratio } \\
\text { (Uncompensated) }\end{array}$ & $\begin{array}{c}\text { Micrometer Reading } \\
(\mathbf{0 . 0 0 0})\end{array}$ & $\begin{array}{c}\text { Spark Timing } \\
\text { ( CA bTDC }\end{array}$ \\
\hline 5.00 & 0.825 & 26 \\
\hline 5.19 & 0.773 & 25 \\
\hline 5.41 & 0.721 & 24 \\
\hline 5.64 & 0.669 & 23 \\
\hline 5.91 & 0.617 & 22 \\
\hline 6.20 & 0.565 & 21 \\
\hline 6.54 & 0.513 & 20 \\
\hline 6.91 & 0.461 & 19 \\
\hline 7.36 & 0.408 & 18 \\
\hline 7.86 & 0.356 & 17 \\
\hline 8.45 & 0.304 & 16 \\
\hline 9.15 & 0.252 & 15 \\
\hline 10.00 & 0.200 & 14 \\
\hline & & \\
\hline
\end{tabular}

Using numerical integration techniques as presented in Chapter 9, the indicated net work, indicated mean effective pressure (IMEP), and combustion parameters (net- 
heat release, net-heat-release rate, mass fraction burned (MFB), ignition delay (ID), and combustion duration) were obtained from the in-cylinder pressure and crank angle data. These results were then compared with the same parameters obtained during CIBAI combustion to evaluate the benefits of ignition by air injection as a mechanism to control auto-ignition (CAI) and achieve smooth heat release. CIBAI experimental results are discussed next.

\section{CIBAI Experimental Results}

The general operating conditions of the CFR engine during the CIBAI Combustion were presented in Table 8.4. The summary of the results for this experimental work for motored, injected, fired, and CIBAI configurations while the CFR engine was run with a compression ratio of $8: 1$ are summarized in Table 10.4. The air injection strategy was defined in Chapter 8. The indicated net work, indicated mean effective pressure (IMEP), and heat release data were obtained through numerical integration of the pressure and volume data and its combination with thermodynamic principles as detailed in Chapter 9.

Table 10.4 Experimental results summary table for a compression ratio of 8.0:1

\begin{tabular}{|l|r|r|r|r|}
\hline & \multicolumn{1}{|c|}{ Motored } & \multicolumn{1}{c|}{ Injected } & \multicolumn{1}{c|}{ Fired } & \multicolumn{1}{c|}{ CIBAI } \\
\hline Indicated Net Work $(\mathrm{J})$ & -69.03 & 9.27 & 303.54 & 398.91 \\
\hline IMEP $(\mathrm{psia})$ & -16.37 & 2.20 & 71.96 & 94.58 \\
\hline Ignition Delay $(\mathrm{ms})$ & $\mathrm{N} / \mathrm{A}$ & $\mathrm{N} / \mathrm{A}$ & 5.00 & 5.68 \\
\hline Combustion Duration $(\mathrm{ms})$ & $\mathrm{N} / \mathrm{A}$ & $\mathrm{N} / \mathrm{A}$ & 5.30 & 4.40 \\
\hline Thermal Efficiency $(\%)$ & $\mathrm{N} / \mathrm{A}$ & $\mathrm{N} / \mathrm{A}$ & 34.97 & 38.29 \\
\hline Start Combustion $\left({ }^{\circ} \mathrm{CA}\right)$ & $\mathrm{N} / \mathrm{A}$ & $\mathrm{N} / \mathrm{A}$ & 342.65 & 344.85 \\
\hline End Combustion $\left({ }^{\circ} \mathrm{CA}\right)$ & $\mathrm{N} / \mathrm{A}$ & $\mathrm{N} / \mathrm{A}$ & 405.90 & 403.15 \\
\hline Peak Pressure $(\mathrm{psia})$ & 130.49 & 189.36 & 291.17 & 367.66 \\
\hline
\end{tabular}

\section{In-Cylinder Pressure History}

The in-cylinder pressure history for motored, cold injection, fired, and CIBAI combustion for a compression ratio of 8.0:1 is plotted in Figure 10.1. Figure 10.1 shows 
that the peak pressure obtained through CIBAI combustion was higher than the one obtained for spark ignition, and cold injection, and thus indicated that combustion occurred during air injection. This conclusion is collaborated by the net indicated work, IMEP, and heat release data, obtained through numerical integration as displayed in Table 10.4. The peak pressure for CIBAI combustion was on average twenty six percent higher than the one obtained for spark ignition.

\section{Indicated Net Work, IMEP}

The net gain in the indicated net work is calculated as the difference between the curve obtained during CIBAI combustion and the air injected without gasoline, minus the difference between the curve obtained during spark ignition and motored operation for the same compression ratio. An average of $6 \%$ net gain in the indicated net work and IMEP was obtained using CIBAI combustion as compared with spark ignition. This may indicate the benefit of using CIBAI combustion as an alternative to conventional sparkignited (SI) and compression-ignited engines as proposed by Loth and Morris [3,5]. Further research needs to be done to determine the effect of CIBAI combustion on engine power output at full load and the effect on exhaust emissions. Most of the research done on controlled-auto-ignition indicates the need to expand the operational range in which controlled auto-ignition occurs. This is due to difficulty in timing the onset of autoignition and combustion duration, and controlling heat-release rate over the entire operational range [56]. An example of an in-cylinder pressure-volume diagram for the CIBAI and spark ignition (SI) engines is shown in Figure 10.2. It clearly illustrates the gain in gross indicated work during CIBAI combustion as described above. 


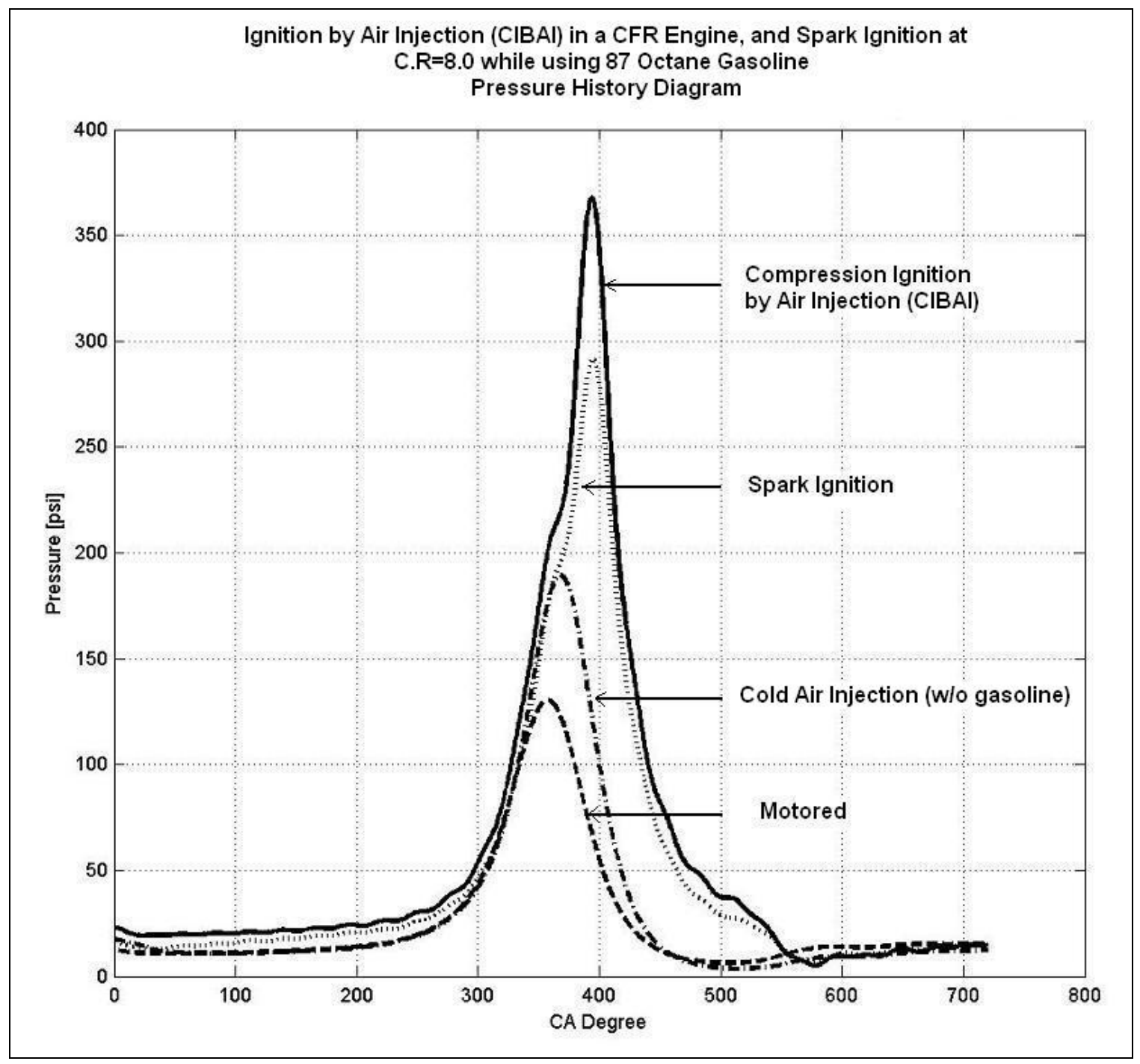

Figure 10.1 Pressure history diagram for motored, cold injection, spark ignition, and CIBAI combustion. 


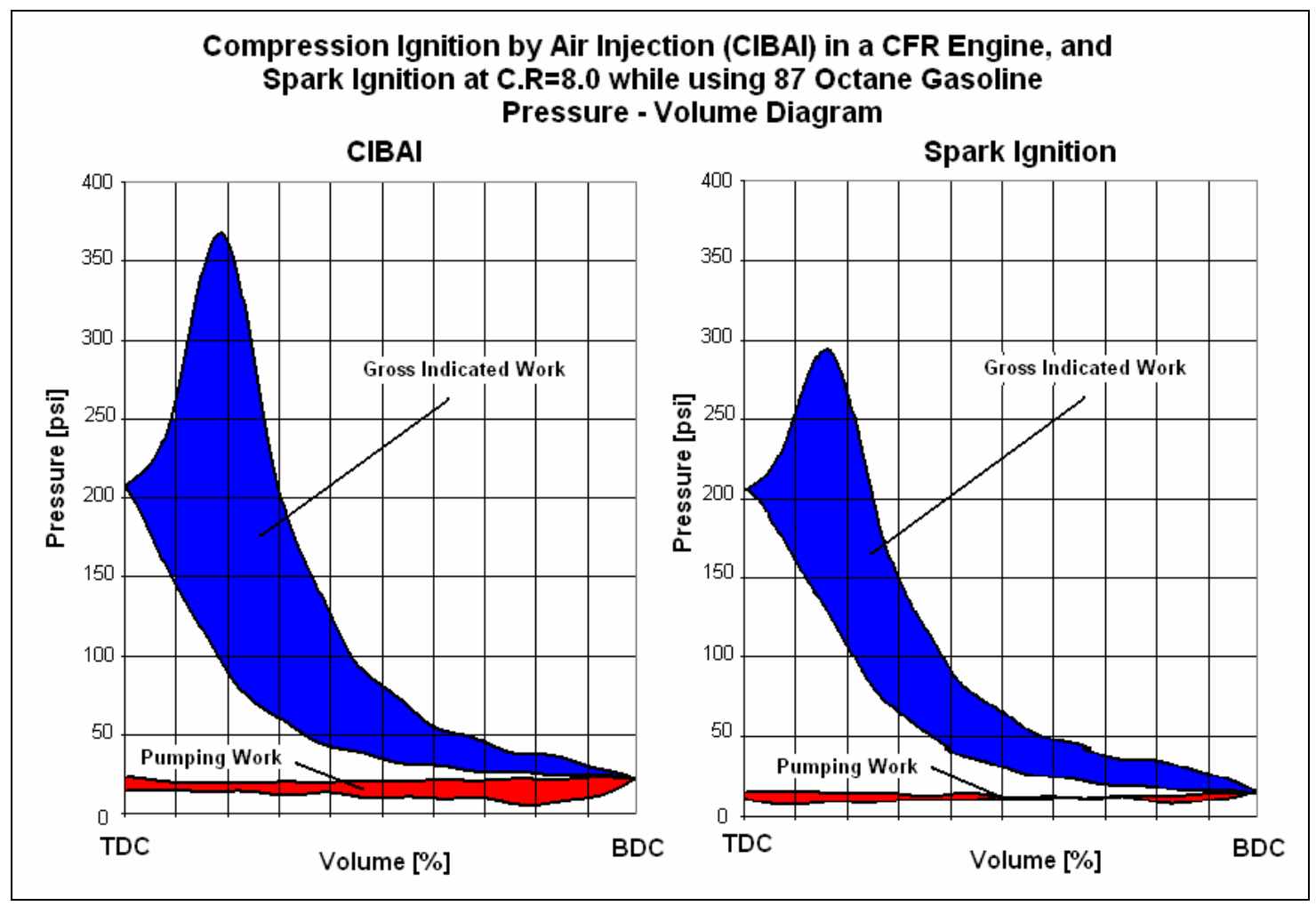

Figure 10.2 In-cylinder pressure-volume diagram for CIBAI and Spark Ignition

\section{In-Cylinder Bulk Mean Temperature History}

The in-cylinder bulk mean temperature history for the CIBAI and spark ignition (SI) engines was calculated by combining experimental pressure data, engine geometry, and thermodynamic principles. The air-fuel mixture in the cylinder was treated as air for the entire cycle, and properties values of air were used in the analysis. Air was considered an ideal gas so that the ideal gas relationships could be used to derive the instantaneous in-cylinder bulk mean temperature at each crank angle. During the compression stroke and prior to air injection, the bulk mean temperature (T) was calculated from the total mass air plus fuel (M), using measured data during the stroke intake, the pressure (P) from measured pressure transducer data, volume (V) from piston position. The mass in the cylinder was assumed constant between the intake valve closing (IVC) and the start of 
hot-high-pressure air injection. Pressure and volume values are functions of time and were obtained from the pressure and crank angle data, and engine geometry respectively. During air injection the mass inside the cylinder was increased by adding to the initial mass $\left(\mathrm{M}_{\mathrm{i}}\right)$ the amount of air injected. This is a function of the rate of air injection $(\mathrm{dm} / \mathrm{dt})_{\mathrm{i}}$ corresponding to each crank angle (CA) as follows:

$$
M=M_{i}+\sum_{n=S O}^{S C}\left(\frac{d m}{d t}\right) \Delta t
$$

where:

$$
\begin{aligned}
& M=\text { Cylinder total mass } \\
& \mathrm{M}_{\mathrm{i}}=\text { Cylinder mass before injection } \\
& \mathrm{SC}=\text { Solenoid Close } \\
& \mathrm{SO}=\text { Solenoid Opening time } \\
& \mathrm{dm} / \mathrm{dt}=\text { Rate of air injection. }
\end{aligned}
$$

The total mass injected was calculated as the difference between the initial mass of preheated air inside the heat exchanger and the mass remaining after air injection. This was presented in the air-injection model (Chapter 6). The rate of air injection was modeled as a function of time assuming isothermal choked flow independent of the back pressure inside the cylinder. Equation 10.2 was used to calculate the rate of air injection:

$$
\frac{d m}{d t}=\frac{0.0406^{*} P^{*} A^{*}}{\sqrt{T}}(\mathrm{Kg} / \mathrm{sec})
$$

where:

$$
\begin{aligned}
& \mathrm{A}^{*}=\text { Effective choked flow area } \\
& \mathrm{P}=\text { Pressure in Pascal } \\
& \mathrm{T}=\text { Temperature in degree } \mathrm{K} \\
& \mathrm{dm} / \mathrm{dt}=\text { Rate of air injection } \\
& \Delta \mathrm{t}=\text { Injection duration }
\end{aligned}
$$


The injection duration $(\Delta t)$ was assumed equal to the programmed solenoid open time. Initially, the effective orifice area $\left(\mathrm{A}^{*}\right)$ was obtained from equation 10.2 by assuming that the pressure $(\mathrm{P})$ drops at steady rate with an average value between the air pre-heater injection pressure and the pressure at which the injector ball-check valve opens, allowing hot-pressure air to flow into the combustion chamber. The exhaust temperature, total mass injected, and solenoid opening time were also used to calculate the effective orifice area $\left(\mathrm{A}^{*}\right)$. Finally, the in-cylinder temperature $(\mathrm{T})$ was obtained from equation 10.2 for each pressure reading, corresponding to the duration of the solenoid opening time. The rate of air injection $(\mathrm{dm} / \mathrm{dt})$ was integrated numerically to verify that it was equal to the total amount of the air injected into the cylinder. For the remaining part of the power stroke, between the solenoid closing and exhaust valve opening (EVO), the temperature was calculated using the equation of state for known values of pressure $(\mathrm{P})$, and volume $(\mathrm{V})$. In this case the total mass $(\mathrm{M})$ was equal to the initial mass in the cylinder plus the preheated air mass injected. For the first part of the cycle, the temperature (T) was assumed equal to the air inlet temperature. Similarly, the temperature (T) for the last part of the cycle was assumed equal to the exhaust temperature. The resulting in-cylinder bulk mean temperature history is shown in Figure 10.3 .

Peak bulk mean temperatures of $1871^{\circ} \mathrm{K}$ and $2287^{\circ} \mathrm{K}$ were obtained for CIBAI combustion and spark ignition (SI) respectively. The eighteen percent (18\%) decline in peak bulk mean temperature for CIBAI combustion is due to the mixture dilution by the injected air. Lean air-fuel mixtures have lower adiabatic flame temperatures. $\mathrm{NO}_{\mathrm{x}}$ formation is highly dependent on temperature and time. Significant amounts of $\mathrm{NO}_{\mathrm{x}}$ 
emission are generated in the $2500-3000^{\circ} \mathrm{K}$ temperature range [2]. A high expansion ratio produces fast expansion cooling, which also reduces the possibility of $\mathrm{NO}_{\mathrm{x}}$ formation $[3,5]$. Further research needs to be done to be able to evaluate the effect of CIBAI combustion on exhaust emissions. A sample calculation of the in-cylinder bulk mean temperature for both CIBAI and spark ignition (SI) combustion is shown in Appendix S.

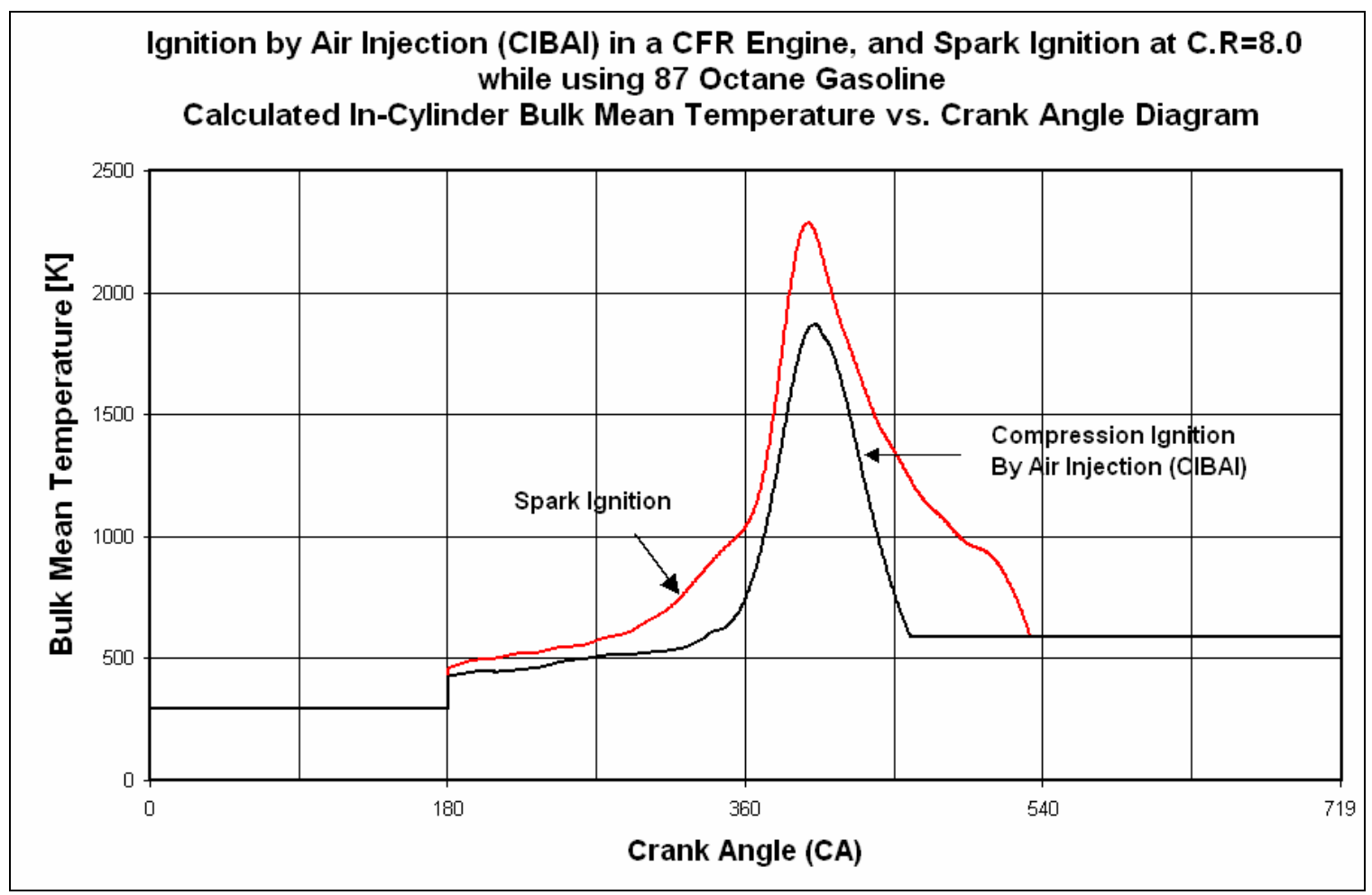

Figure 10.3 Calculated in-cylinder bulk mean temperature history for CIBAI and spark ignition combustion

\section{Heat Release, MFB, Combustion Duration, Ignition Delay (ID)}

The heat release data obtained from the methods discussed in Chapter 9 provided a way to determine the heat release rate, mass fraction burned, combustion duration and ignition delay (ID). The heat release is defined as the amount of heat that would have to 
be added to cylinder contents to produce the same pressure variations due to combustion of the air-fuel mixture [69].

The net heat release rate curve (Figure 10.4) shows that CIBAI combustion occurred at a faster rate than spark ignition (SI) combustion. This may be attributed to the high temperature achieved at the end of the compression stroke as a result of pre-heating the injected air, increasing the intake temperature, and doubling the compression ratio. The faster heat release rate obtained for CIBAI combustion agreed with earlier researchers who had indicated that auto-ignition occurs almost spontaneously without a presence of flame propagation [14, 20,23]. However, this result has to be taken in the context of the assumptions involved in the calculation of the net heat release as explained in Chapter 9.

The mass fraction burned (MFB) curves were obtained from the heat release data as described in Chapter 9. Figure 10.5 shows the MFB for both, CIBAI and spark ignition. The air-fuel mixture burned $17 \%$ faster for CIBAI combustion than during spark ignition. This may be attributed to the higher heat release rate after TDC.

Ignition delay and combustion duration data indicate how fast the combustion process occurs. The average ignition delay (ID) obtained for CIBAI combustion was approximately half millisecond longer than the values obtained for spark ignition (SI) combustion. Conversely, the average combustion duration obtained for CIBAI was approximately one millisecond faster than the values obtained for spark ignition. These differences can be attributed to the lower response of the solenoid valve $(\sim 20 \mathrm{~ms})$, pressure and crank angle signal shift $\left(<0.5^{\circ} \mathrm{CA}\right)$, spark noise in the pressure signal, and higher net heat release rate during CIBAI combustion. Computational fluid dynamics 
(CFD) and flow visualization techniques may be helpful in a future CIBAI research to verify or correct the values obtained in this research.

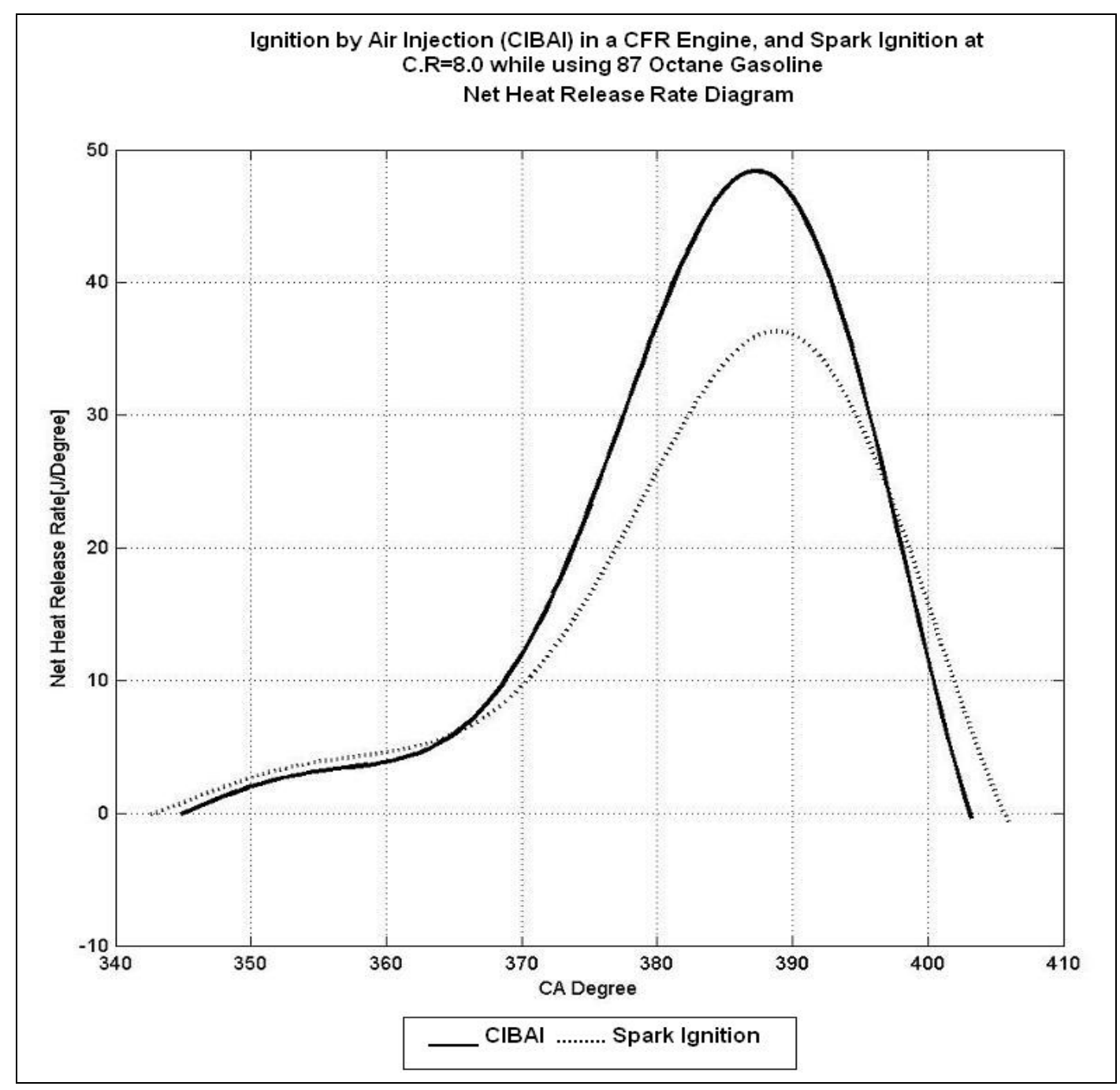

Figure 10.5 Net heat release rate comparison for CIBAI and spark ignition combustion 


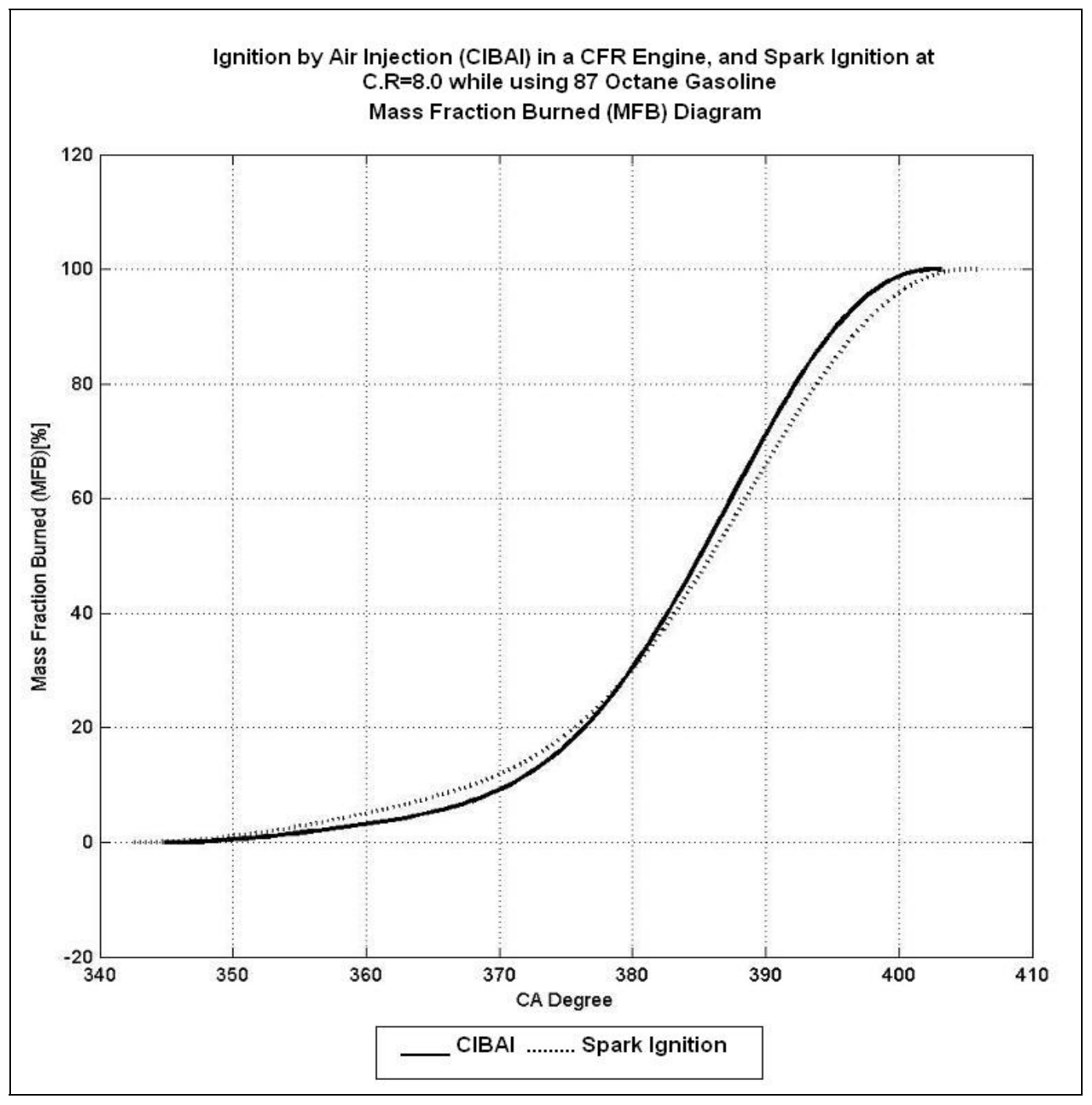

Figure 10.6 Mass fraction burned (MFB) for CIBAI and spark ignition combustion 


\section{Chapter 11: Parametric Study}

\section{Overview}

The objective of the parametric study discussed in this chapter was to determine the effect of the CFR engine operating parameters on CIBAI combustion. The parameters analyzed were the compression ratio, intake temperature, air preheat charging pressure, equivalence ratio, and air-injection timing. To this aim, the analytical, the cold air injection, and thermodynamic models presented in chapters 5 and 6 respectively were incorporated into a computer program written in Matlab version 6.5 (Appendix A).

The computer code contains two main programs. The first subroutine named, CIBAI cycle analysis program, performed a complete CIBAI cycle analysis for different engine configurations. The second subroutine named, CIBAI numerical modeling program, was used to conduct the parametric study for the selected engine parameters. The numerical modeling used the mathematical derivations presented in the data analysis section of this dissertation (Chapter 9). The computer program interacted with the user through a graphical user interface (GUI).

The experimental study conducted during the course of this dissertation provided the empirical data needed as inputs to the analytical model. Multiple experiments were taken for each of the fourteen (14) tests proposed in Chapter 8. Tests producing significant variations in results were repeated until a statistical analysis of their mean performance was accurately established. The sources of error and the experimental uncertainty are discussed at the end of this chapter. 


\section{Parametric Matrix}

The parametric study involved choosing a compression ratio, volume displacement, air pre-heater charging pressure, equivalence ratio, air flow rate, intake temperature, intake pressure, exhaust temperature, and air-injection timing combination, which offers acceptable CIBAI combustion performance.

The outputs generated by the numerical modeling code included the in-cylinder pressure, net heat release, net heat release rate, and mass fraction burned (MFB) history graphs for a single CIBAI combustion event, and for a particular set the parameters as stated in Chapter 8. In addition, the indicated net work, IMEP, ignition delay (ID), combustion duration, thermal efficiency, and the start and end of combustion were calculated for each simulation.

The parametric matrix for CIBAI combustion consisted of the following cases:

- Three (3) compression ratios:

- Three (3) intake temperatures:

- Three (3) air charged pressures:

- Three (3) equivalence ratios $(\Phi)$ :

- Three (3) air injection timing:
$7.0: 1,7.5: 1$, and $8.0: 1$

$70^{\circ} \mathrm{F}, 250^{\circ} \mathrm{F}$, and $450^{\circ} \mathrm{F}$

700,800, and 900 psig

$0.45,0.50$, and 0.65

$85^{\circ}, 75^{\circ}$, and $65^{\circ} \mathrm{CA}$ bTDC

The results of the parametric study are discussed next.

\section{Parametric Study Results}

The objective of the parametric study was to determine the effect of compression ratio, intake temperature, air pre-heated charging pressure, equivalence ratio, and airinjection timing on CIBAI combustion. The understanding of the effect of these engine parameters on the occurrence of CIBAI combustion is vital to specify a CIBAI engine 
configuration that would result in maximum power and efficiency. The parametric study results are summarized as follows:

\section{The Effect of Compression Ratio}

For the set of initial conditions given in Table 8.3, changes in the compression ratio altered the CIBAI combustion process by increasing the compression temperature. Higher compression ratios and thus expansion ratios significantly increase the net heat release rate, advancing the start of the ignition of the CIBAI combustion, all contributing to increased thermal efficiency. The combustion duration was slightly affected by changes in the compression ratio. The results of this simulation are summarized in Table 11.1, and illustrated in Figure 11.1.

Table 11.1 The effect of compression ratio on CIBAI combustion

\begin{tabular}{|l|r|r|r|}
\hline RESULTS: & Test 1(C.R=7.0) & Test 2 (C.R=7.5) & Test 3 (C.R=8.0) \\
\hline Indicated Net Work (J) & 283.98 & 307.55 & 398.91 \\
\hline IMEP (psia) & 67.33 & 72.92 & 94.58 \\
\hline Ignition Delay (ms) & 6.79 & 6.69 & 5.68 \\
\hline Combustion Duration $(\mathrm{ms})$ & 4.10 & 3.90 & 4.40 \\
\hline Thermal Efficiency $(\%)$ & 32.21 & 34.26 & 38.29 \\
\hline Start Combustion $\left({ }^{\circ} \mathrm{CA}\right)$ & 346.50 & 344.85 & 344.85 \\
\hline End Combustion $\left({ }^{\circ} \mathrm{CA}\right)$ & 402.05 & 399.85 & 403.15 \\
\hline
\end{tabular}

\section{The Effect of Intake Temperature}

For the set of initial conditions given in Table 8.4, changes in the intake temperature altered the CIBAI combustion process by changing the volumetric efficiency. Higher intake temperature severely increased the net-heat-release rate, considerably advanced the start of the ignition of the CIBAI combustion, significantly reduced the IMEP, and contributed to lower thermal efficiency due to the lower volumetric efficiency. The combustion duration were slightly affected by changes in the intake temperature. The results of this simulation are summarized in Table 11.2, and 
illustrated in Figure 11.2. It should be noted that the simulation of the CIBAI combustion using an intake temperature of $450{ }^{\circ} \mathrm{F}$ was not conducted due to significant presence of audible knock during the actual experiment.

Table 11.2 The effect of intake temperature on CIBAI combustion

\begin{tabular}{|l|r|r|}
\hline RESULTS: & Test $\mathbf{4}\left(\mathbf{T}=\mathbf{7 0}^{\circ} \mathbf{F}\right)$ & Test $\mathbf{5}\left(\mathbf{T}=\mathbf{2 5 0}{ }^{\circ} \mathbf{F}\right)$ \\
\hline Indicated Net Work $(\mathrm{J})$ & 398.91 & 375.49 \\
\hline IMEP $($ psia) & 94.58 & 89.02 \\
\hline Ignition Delay (ms) & 5.68 & 6.29 \\
\hline Combustion Duration $(\mathrm{ms})$ & 4.40 & 3.80 \\
\hline Thermal Efficiency $(\%)$ & 38.29 & 33.93 \\
\hline Start Combustion $\left({ }^{\circ} \mathrm{CA}\right)$ & 344.85 & 339.90 \\
\hline End Combustion $\left({ }^{\circ} \mathrm{CA}\right)$ & 403.15 & 397.65 \\
\hline
\end{tabular}

\section{The Effect of Air Pre-heater Charging Pressure}

For the set of initial conditions given in Table 8.3, changes in the air pre-heater charging pressure changed the CIBAI combustion process by changing the air-fuel ratio. Higher pressures drastically retarded the start of the ignition of the CIBAI combustion, significantly decreasing the net-heat-release rate, and considerably reducing the IMEP and combustion duration. This can be attributed to the additional amount of mass of air injected during high air pre-heated charging, which significantly leaned the air-fuel mixture. The results of this simulation are summarized in Table 11.3, and illustrated in Figure 11.3.

Table 11.3 The effect of air pre-heater charging pressure on CIBAI combustion

\begin{tabular}{|l|r|r|r|}
\hline RESULTS: & Test 6 (P=700 psig) & Test 7 (P=800 psig) & Test 8 (P=900 psig) \\
\hline Indicated Net Work $(\mathrm{J})$ & 355.82 & 398.91 & 310.35 \\
\hline IMEP $(\mathrm{psia})$ & 84.36 & 94.58 & 73.58 \\
\hline Ignition Delay $(\mathrm{ms})$ & 3.68 & 5.68 & 4.88 \\
\hline Combustion Duration $(\mathrm{ms})$ & 5.90 & 4.40 & 3.30 \\
\hline Thermal Efficiency $(\%)$ & 33.41 & 38.29 & 33.65 \\
\hline Start Combustion $\left({ }^{\circ} \mathrm{CA}\right)$ & 340.45 & 344.85 & 357.50 \\
\hline End Combustion $\left({ }^{\circ} \mathrm{CA}\right)$ & 404.25 & 403.15 & 391.05 \\
\hline
\end{tabular}




\section{The Effect of Equivalence Ratio}

For the set of initial conditions given in Table 8.4, changes in the equivalence ratio altered the CIBAI combustion process by varying the amount of compression heating in the charge. Enriching the mixture $(\Phi=0.65)$ considerably shortened the ignition delay (ID), retarded the start of the ignition of the CIBAI combustion, and drastically increased the net heat release rate. Leaning the mixture $(\Phi=0.45)$ greatly reduced the net heat release, IMEP, and combustion duration. The results of this simulation are summarized in Table 11.4, and illustrated in Figure 11.4.

Table 11.4 The effect of equivalence ratio on CIBAI combustion

\begin{tabular}{|l|r|r|r|}
\hline RESULTS: & Test 9 (E.R=0.65) & Test 10 (E.R=0.50) & Test 11 (E.R=0.45) \\
\hline Indicated Net Work $(\mathrm{J})$ & 423.04 & 398.91 & 244.40 \\
\hline IMEP $(\mathrm{psia})$ & 100.30 & 94.58 & 57.94 \\
\hline Ignition Delay $(\mathrm{ms})$ & 5.38 & 5.68 & 4.78 \\
\hline Combustion Duration $(\mathrm{ms})$ & 3.10 & 4.40 & 3.60 \\
\hline Thermal Efficiency $(\%)$ & 34.70 & 38.29 & 36.78 \\
\hline Start Combustion $\left({ }^{\circ} \mathrm{CA}\right)$ & 360.25 & 344.85 & 355.30 \\
\hline End Combustion $\left({ }^{\circ} \mathrm{CA}\right)$ & 392.70 & 403.15 & 393.80 \\
\hline
\end{tabular}

\section{The Effect of Air-Injection Timing}

For the set of initial conditions given in Table 8.5, changes in the air-injection timing altered the start of the CIBAI combustion process. Advancing the air-injection timing drastically advanced the start of the combustion process, increased the ignition delay (ID), and substantially, decreased the net-heat-release rate due to the lower compression heating. Conversely, retarding the air-injection timing drastically delayed the start of the combustion process, decreased the ignition delay (ID), increased the peak pressure, reduced the combustion duration, and substantially increased the net-heatrelease rate due to the higher compression heating. The results of this simulation are summarized in Table 11.5, and illustrated in Figure 11.5. 
Table 11.5 The effect of air injection timing on CIBAI combustion

\begin{tabular}{|l|r|r|r|}
\hline RESULTS: & Test 12 (100 ${ }^{\circ}$ CA bTDC) & Test 13 (75 ${ }^{\circ}$ CA bTDC) & Test 14 (50 $\mathbf{C A ~ b T D C ) ~}^{\circ}$ \\
\hline Indicated Net Work $(\mathrm{J})$ & 418.31 & 398.91 & 278.40 \\
\hline IMEP $(\mathrm{psia})$ & 99.18 & 94.58 & 66.00 \\
\hline Ignition Delay $(\mathrm{ms})$ & 8.22 & 5.68 & 4.07 \\
\hline Combustion Duration $(\mathrm{ms})$ & 7.40 & 4.40 & 3.30 \\
\hline Thermal Efficiency (\%) & 35.66 & 38.29 & 33.84 \\
\hline Start Combustion $\left({ }^{\circ} \mathrm{CA}\right)$ & 338.25 & 344.85 & 356.95 \\
\hline End Combustion $\left({ }^{\circ} \mathrm{CA}\right)$ & 419.10 & 403.15 & 392.15 \\
\hline
\end{tabular}

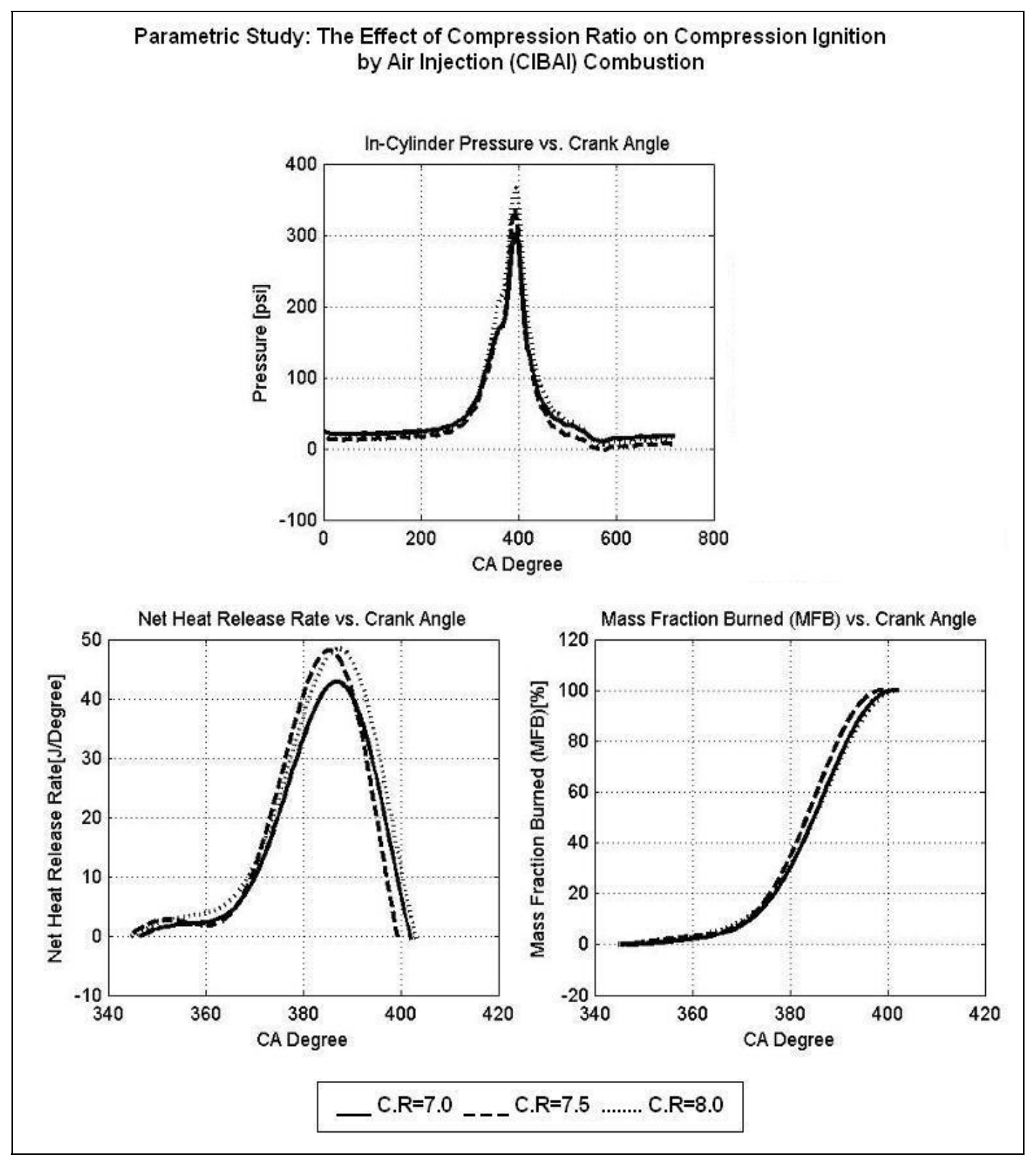

Figure 11.1 Pressure history, net heat release rate, and mass fraction burned (MFB) diagrams for compression ratios of 7.0, 7.5, and 8.0 


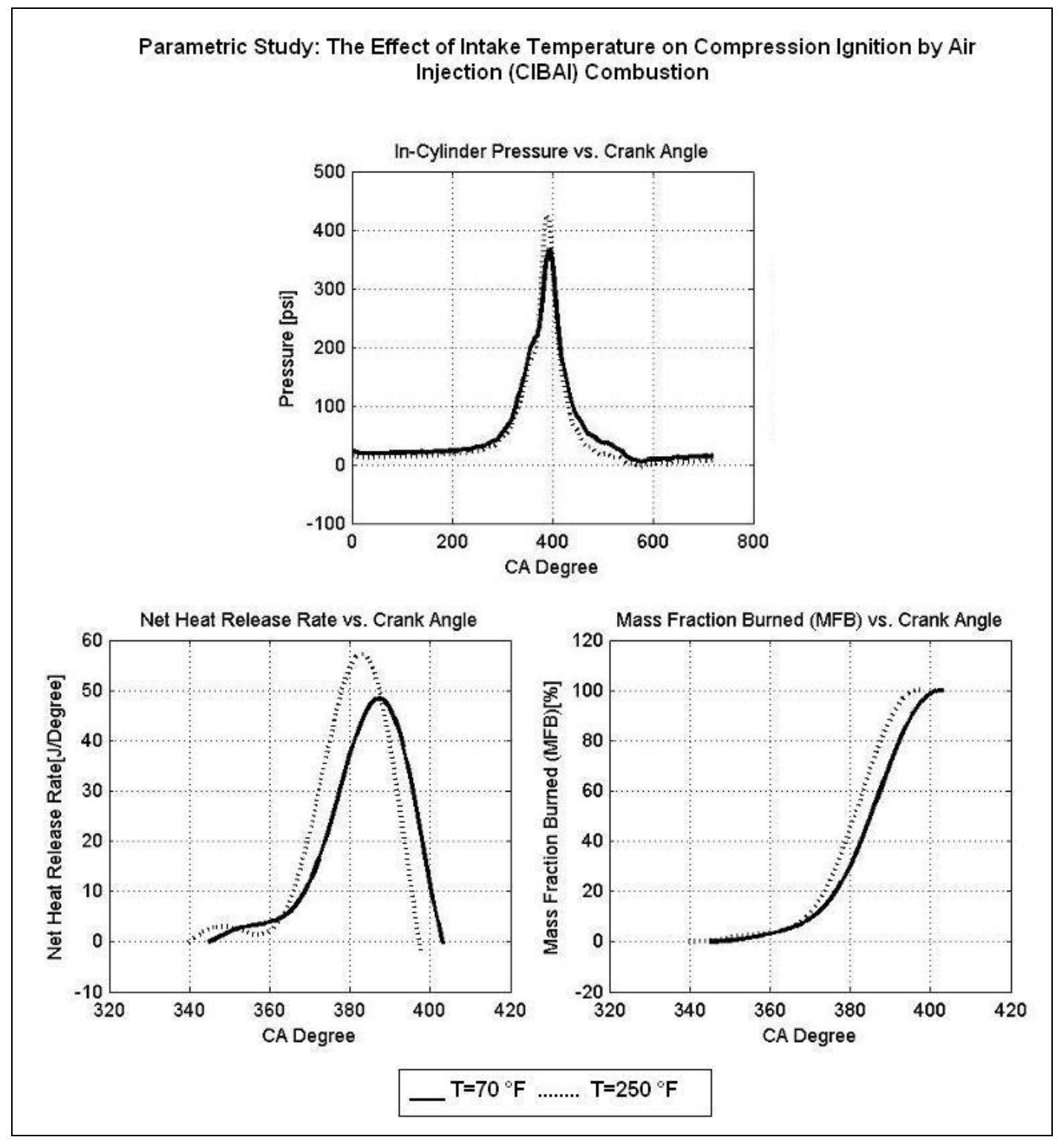

Figure 11.2 Pressure history, net heat release rate, and mass fraction burned (MFB) diagrams for intake temperatures of $70^{\circ} \mathrm{F}$, and $250{ }^{\circ} \mathrm{F}$ 
Parametric Study: The Effect of Air Pre-heated Charging Pressure on Compression Ignition by Air Injection (CIBAI) Combustion
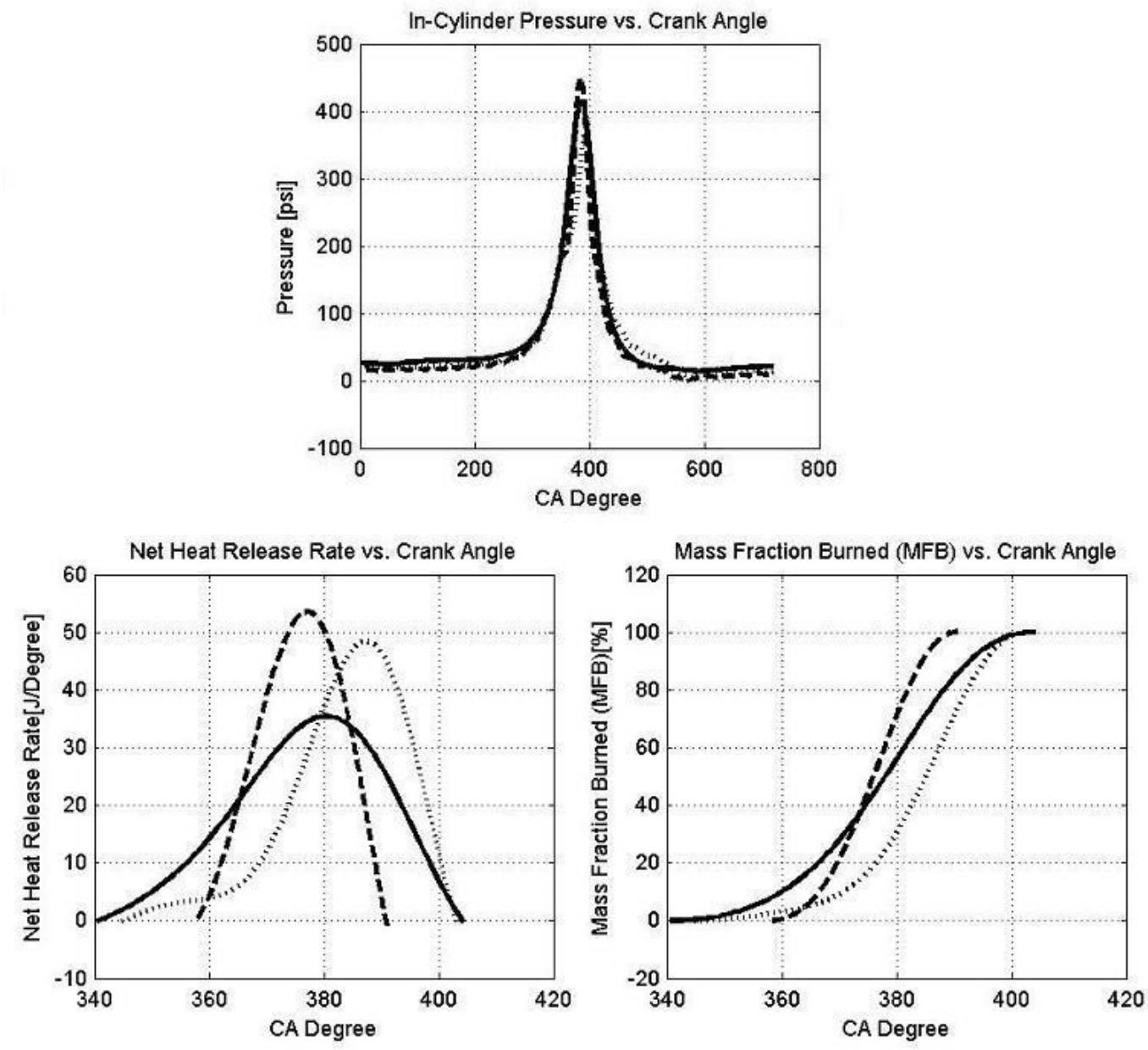

$P=700$ psig .......P=800 psig _ _ $P=900$ psig

Figure 11.3 Pressure history, net heat release rate, and mass fraction burned (MFB) diagrams for air pre-heated charging pressures of 700,800 , and 900 psig 


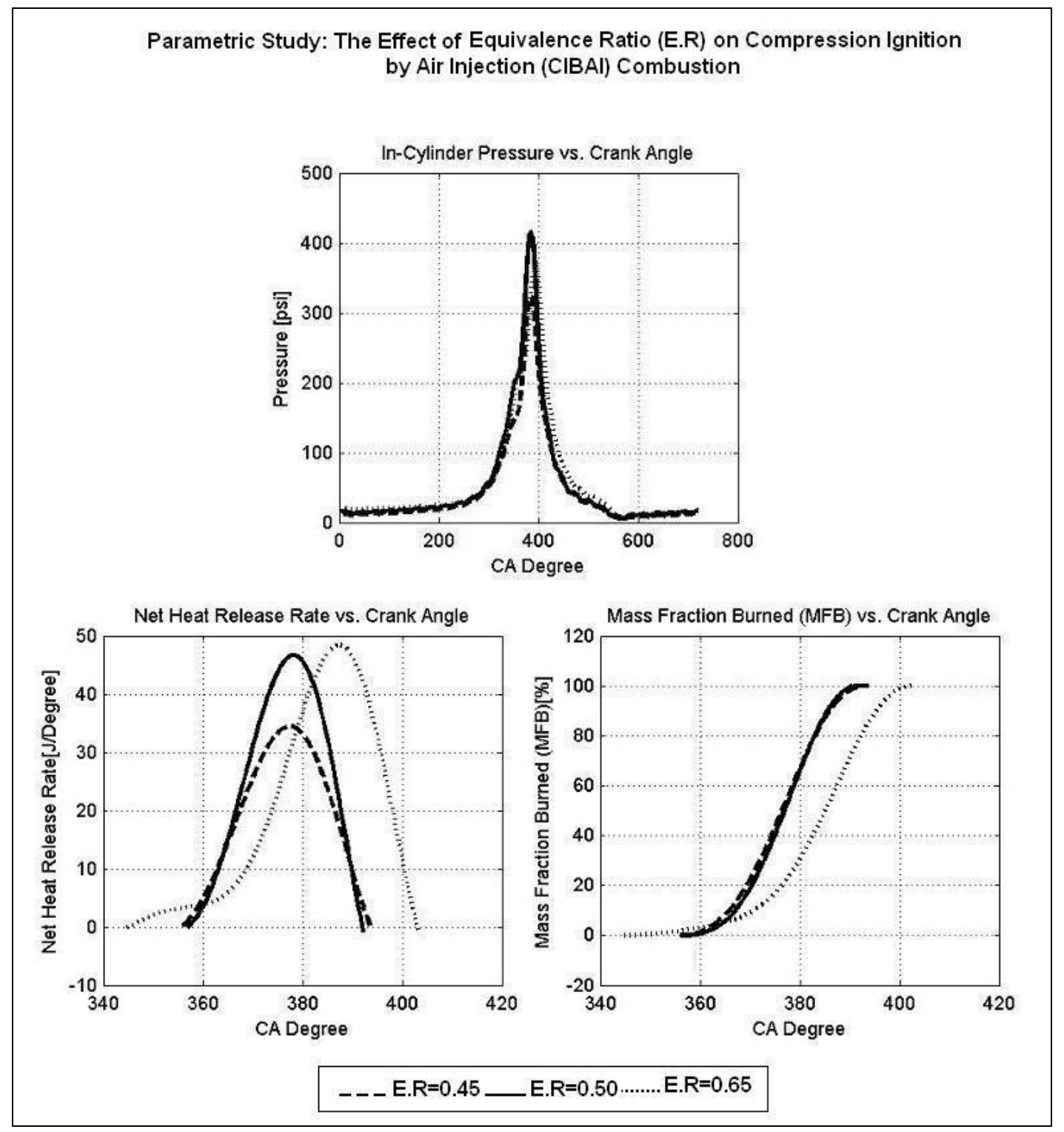

Figure 11.4 Pressure history, net heat release rate, and mass fraction burned (MFB) diagrams for equivalence ratios of $0.45,0.50$, and 0.65 


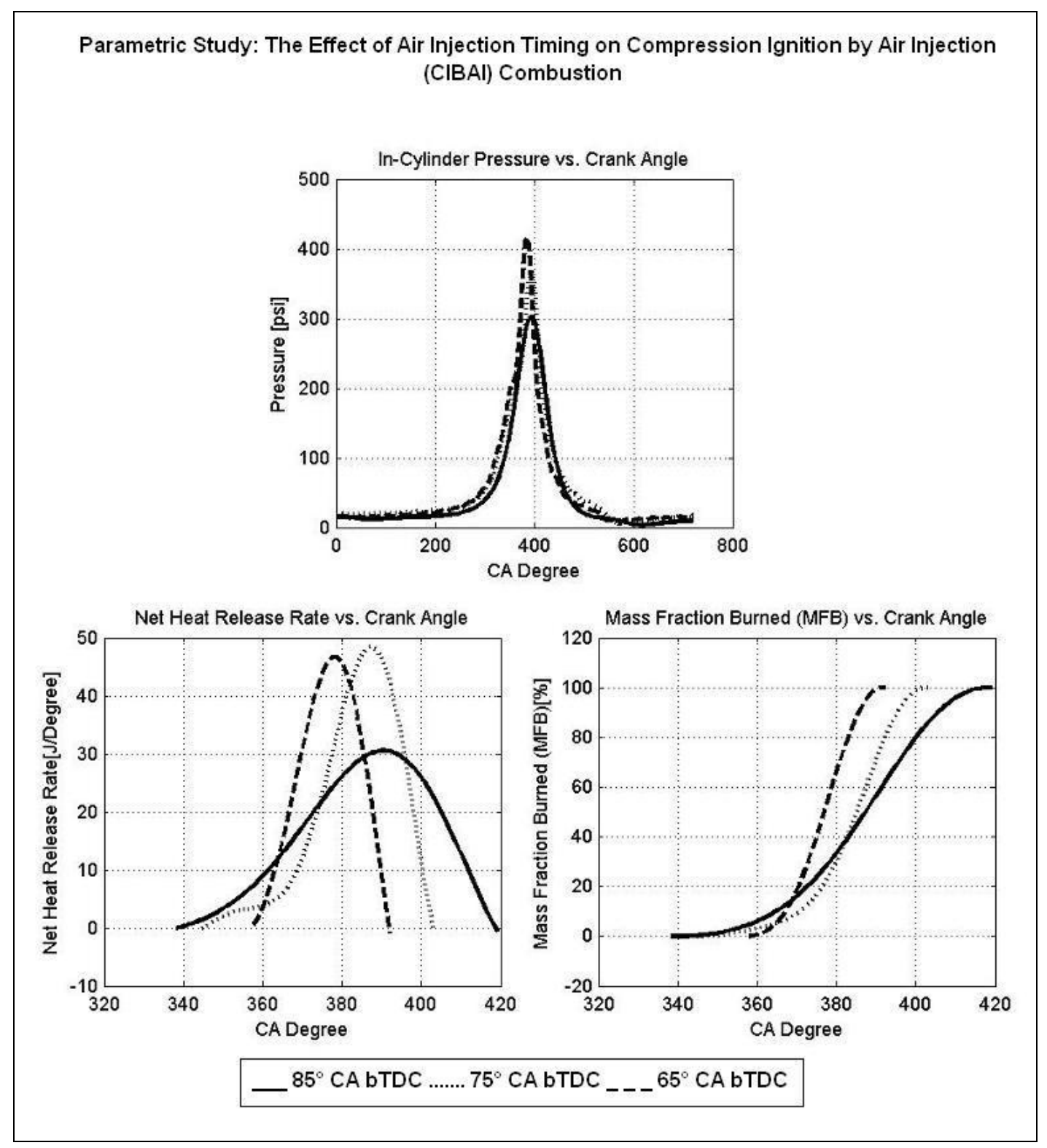

Figure 11.5 Pressure history, net heat release rate, and mass fraction burned (MFB) diagrams for air injection timing of $85^{\circ}, 75^{\circ}$, and $65^{\circ} \mathrm{CA}$ bTDC 


\section{Sources of Error}

Throughout the experimental work, every effort was made to reduce possible sources of error, but as with any experimental procedure, there were some uncertainties with experimental measurements. Possible sources of error and their relative magnitudes are given in Table 11.6.

Table 11.6 Sources of error

\begin{tabular}{|l|l|}
\hline \multicolumn{1}{|c|}{ Instrument } & \multicolumn{1}{c|}{ Error } \\
\hline Intake Pressure Gauge & $+/-0.1 \mathrm{psig}$ \\
\hline Oil Pressure Gauge & $+/-5 \mathrm{psig}$ \\
\hline Pressure Regulator & $+/-50 \mathrm{psig}$ \\
\hline Air Pre-heater Charging Pressure Gauge & $+/-10 \mathrm{psig}$ \\
\hline In-Cylinder Pressure Transducer & $+/-1 \%$ full scale \\
\hline Crank Angle Sensor & $+/-0.5^{\circ} \mathrm{CA}$ \\
\hline Intake Thermocouple & $+/-1^{\circ} \mathrm{F}$ \\
\hline Oil Temperature Thermocouple & $+/-5^{\circ} \mathrm{F}$ \\
\hline Exhaust Temperature Thermocouple & $+/-1^{\circ} \mathrm{F}$ \\
\hline Coolant Temperature Thermometer & $+/-1^{\circ} \mathrm{F}$ \\
\hline Air Flow Meter & $+/-0.1 \mathrm{SCFM}$ \\
\hline Fuel Glass Meter & $+/-0.1 \mathrm{in}$ \\
\hline A/D Converter Data Acquisition Board & $+/-0.0024 \mathrm{~V}$ \\
\hline Compression Ratio Micrometer & $+/-0.0001 \mathrm{in}$ \\
\hline
\end{tabular}

The results of the numerical model were affected by the experimental data, which were used as inputs into the analytical model. An evaluation of the sensitivity of the numerical results to these errors indicated that the compression ratio, air-injection timing, and scale factor were the mayor contributor to errors in the predicted results. The scale factor is a number used by the numerical code to zero the in-cylinder pressure data to obtain comparable absolute pressure data for multiple simulations. The effects of these three errors in the numerical results are listed in Table 11.7. The ignition delay (ID) was the output with the maximum margin of error $(1.31 \%)$. 
Table 11.7 Effects of input data on modeling results

\begin{tabular}{|l|c|c|c|c|}
\hline \multirow{2}{*}{} & \multicolumn{2}{|c|}{ Net Heat Release } & \multicolumn{2}{c|}{ Ignition Delay ( ID) } \\
\cline { 2 - 5 } & {$[\mathrm{J}]$} & Error (\%) & {$[\mathbf{m s}]$} & Error (\%) \\
\hline Case Without Input Errors & 844 & 0.00 & 6.89 & 0.00 \\
\hline Compression Ratio Error $(+/-0.1)$ & 841 & 0.35 & 6.89 & 0.00 \\
\hline Air Injection Timing (+/- $\left.0.5^{\circ} \mathrm{CA}\right)$ & 844 & 0.00 & 6.98 & 1.31 \\
\hline Scale Factor (+/- 25 psig) & 848 & 0.94 & 6.89 & 0.00 \\
\hline
\end{tabular}

\section{Uncertainty Analysis}

For each experiment the indicated net work was calculated and averaged for a certain number of cycles. The number of cycles used ranged from 20 to 50 depending on the type of operation. This was done for each engine configuration (motored, fired, air injected w/o gasoline, and CIBAI) in order to determine the net gain in the indicated net work as a result of CIBAI combustion. The objective of the uncertainty analysis was to determine the reliability of the average calculations, especially when the fluctuation levels were significant.

Assuming the data were normally distributed, the uncertainty in the mean value was calculated using the following equation [73].

$$
\Delta \bar{x}=t_{\alpha / 2 ; v} \frac{s}{\sqrt{N}}
$$

where the value $t_{\alpha / 2 ; v}$, comes from the t-distribution with 1- $\alpha$ confidence, $\mathrm{N}=$ number of samples, $\mathrm{v}=\mathrm{N}-1$, and $\mathrm{s}$ is the standard deviation of the data. The true sample mean is then $\mu=\bar{x} \pm \Delta \bar{x}$ with the specified level of confidence.

The uncertainty analysis was applied to the indicated net work value obtained during CIBAI Combustion. The true mean value of the indicated net work calculated was $398.91 \mathrm{~J}+/-2.14 \%$ with $95 \%$ confidence for the CFR engine using 87 octane gasoline at 
a compression ratio of $8: 1$, intake temperature of $70^{\circ} \mathrm{F}$, air preheated charging pressure of 800 psig, equivalence ratio $(\Phi)=0.5$, and air-injection timing of $75^{\circ} \mathrm{CA}$ bTDC. 


\section{Chapter 12: Conclusions}

The objective of this research was to demonstrate experimentally the viability of achieving ignition by air injection (CIBAI) for controlled auto-ignition in a CFR engine. Experimental work was done on a modified single cylinder, four-stroke, spark ignition cooperative fuel research (CFR) engine, fully instrumented and equipped with a highly specialized air injection and timing system to assure that air injection occurred at the desired crank angle, and the desired amount of air was injected in one step, without additional air entering after ignition started. An air injection model was developed, and a parametric study was conducted to determine the effect of operating parameters on CIBAI combustion. A numerical modeling code was developed and integrated into a graphical user interface (GUI) to analyze the CIBAI combustion process and perform the parametric study.

The following are the main conclusions of this experimental study, and the recommendations for future research work:

- It has been experimentally proven that it is possible to achieve auto-ignition by air injection (CIBAI) with controlled ignition time in a CFR engine by timing a solenoid valve, which simulates the operation of a cylinder-connecting-valve (CCV) in the CIBAI cycle.

- The numerical integration of the pressure- volume diagram of Figure 10.2 shows that the indicated net work and IMEP increased by $31 \%$ using CIBAI like combustion as compared with spark ignition (SI). After subtracting the work done to compress the bottle of air used to simulate CIBAI combustion, a net gain of $6 \%$ in the indicated net work was obtained. 
- This parametric study indicated that CIBAI combustion was influenced primarily by the compression ratio, intake temperature, and air-injection timing. Changes in the compression ratio altered the CIBAI combustion process by increasing the compression temperature. Figure 11.1 shows that higher compression ratios and thus expansion ratios significantly increased the net heat release rate, advanced the start of the ignition of the CIBAI combustion, and contributed to increase the indicated thermal efficiency. Changes in the intake temperature altered the CIBAI combustion process by changing the volumetric efficiency. Figure 11.2 shows that higher intake temperature severely increased the net heat release rate, considerably advanced the start of the ignition of the CIBAI combustion, significantly reduced the IMEP, and contributed to lower thermal efficiency due to the lower volumetric efficiency. Changes in the air-injection timing altered the start of the CIBAI combustion process. Figure 11.5 shows that, injecting in a larger volume, drastically slowed the start of the combustion process, increasing ignition delay (ID), and substantially, decreased the net heat release rate due to the reduced compression heating.

- CIBAI like combustion was obtained in a modified CFR engine using unleaded gasoline with an anti knock index (AKI) of 87, compression ratio of 16:1, intake temperature of $70^{\circ} \mathrm{F}$, air pre-heated charging pressure of 800 psig, equivalence ratio $(\Phi)=0.5$, and air-injection timing of $75^{\circ} \mathrm{CA}$ bTDC.

- The use of an injector ball-check-valve in line with the solenoid valve and electronic injection timing was important to achieve CIBAI cycle like ignition, inside a CFR engine. 


\section{Chapter 13: Recommendations for Future Work}

The development of a commercial CIBAI engine will be facilitated by the experimental work, numerical modeling, and parametric analysis presented in this dissertation. Future work on CIBAI combustion should include the following activities:

- The development of a detailed chemical kinetics model in order to understand the mechanism of auto-ignition during CIBAI combustion, and predict the composition of CIBAI combustion products.

- The implementation of a computational fluid dynamics (CFD) code in order to predict the effect of CIBAI combustion on $\mathrm{NO}_{\mathrm{X}}$ emissions.

- The use of flow visualization techniques such as laser pyrometry, schlieren and shadowgraph photography, and laser Raleigh scattering in order to obtain flow velocity distribution, and temperature and pressure profiles during air injection. This information can be helpful to accurately predict combustion interval and ignition (ID) during CIBAI combustion.

- The implementation and analysis of CIBAI combustion in a production engine. 


\section{References}

1. Heywood, J. B., Internal Combustion Engine Fundamentals, McGraw-Hill Inc., New York, NY 1988.

2. Pulkrabek, W. W., Engineering Fundamental of the Internal Combustion Engine

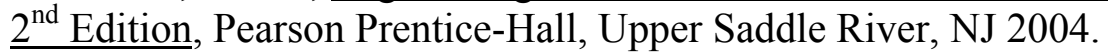

3. Loth, J. L., "Compression Ignition By Air Injection (CIBAI) Cycle and Engine," US Patent No.: 6.899.061, May 31, 2005.

4. Milovanovic, N., and Chen, R., "A Review of Experimental and Simulation Studies on Controlled Auto-Ignition Combustion," SAE Paper No. 2001-01-1890, Warrendale, PA 2001.

5. Loth, J. L., and Morris, G. J., “Compression Ignition Engine by Air Injection from Air-Only Cylinder to Adjacent Air-Fuel Cylinder," US Patent No.: 6.994.057, February 7, 2006.

6. McMillian, M. H., "Laser Spark Ignition for Lean-Burn Natural Gas Reciprocating Engines," National Energy Technology Laboratory (NETL). 2005. $<$ http://www.netl.doe.gov/newsroom/backgrounder/mb-0006.html> (7 Dec. 2005).

7. Ricardo, H. R., "Further Note on Fuel Research. Report of the Empire Motor Fuels Committee," Proceedings of the Institute of Automobile Engineers, London, 1923.

8. Erren, R. A., and Campbell, W. H. "Hydrogen: A Commercial Fuel for Internal Combustion Engines and other Purposes," Journal of the Institute of Fuel, VI, pp. 277-291, 1933.

9. King, R. O., "The Hydrogen Engine and the Nuclear Theory of Ignition," Canadian Journal Research, F.26, p 264, 1948.

10. King, R. O., and Rand, M., "The Oxidation, Decomposition, Ignition and Detonation of Fuel Vapors and Gases," Canadian Journal Technology, pp 445469, 1955.

11. Obert, E. F., Internal Combustion Engines $3^{\text {rd }}$ Edition, International Textbook Company, Scranton, PA 1968.

12. Miller, C. D., "Roles of Detonation Waves and Auto-Ignition in Spark Ignition Engine Knock," SAE Trans., Vol. 1(1), p. 98, 1947. 
13. Hanskell, W.W., "Fuel Ignition in a Rapid Compression Machine," SAE Paper No. 700059, Warrendale, PA 1970.

14. Onishi, S., Jo, S. H., Shoda, K., Jo, P. D., and Kato, S., “Active ThermoAtmosphere Combustion (ATAC): A New Combustion Process for Internal Combustion Engines," SAE Paper No. 790501, Warrendale, PA 1979.

15. Lavy, J., Dabadie, J. C., Angelberger, C., and Duret, P., "Innovative Ultra-Low $\mathrm{NO}_{\mathrm{x}}$ Controlled Auto-Ignition Combustion Process for Gasoline Engines: the 4SPACE Project," SAE Paper No. 2000-01-1837, Warrendale, PA 2000.

16. Stanglmairer, R. H., and Roberts, C. E., "Homogeneous Charge Compression Ignition (HCCI): Benefits, Compromises, and Future Engine Applications," SAE Paper No. 1999-01-3682, Warrendale, PA 1999.

17. Ishibashi, Y., and Asai, M., "Improving the Exhaust Emissions of Two-Stroke Engines by Applying the Radical Combustion," SAE Paper No. 960742, Warrendale, PA 1996.

18. Duret, P., and Venturi, S., "Automotive Calibration of the IAPAC Fluid Dynamically Controlled Two Stroke Combustion Process," SAE Paper No. 960363, Warrendale, PA 1996.

19. Thring, R. H., "Homogeneous Charge Compression Ignition (HCCI) Engines," SAE Paper No. 892068, Warrendale, PA 1989.

20. Najt, P. M., and Foster, D. E., "Compression-Ignited Homogeneous Charge Combustion," SAE Paper No. 830264, Warrendale, PA 1983.

21. Aoyama, T., Hattori, Y., Mizuta, J., and Sato, Y., "Premixed-Charge Compression Ignition Gasoline Engines," SAE Paper No. 960081, Warrendale, PA 1996.

22. Hanskell, W.W., and Bame, J., "Engine Knock - An End Gas Explosion," SAE Paper No. 650506, Warrendale, PA 1965.

23. Noguchi, M., Tanaka, Y., Tanaka, T., and Takeuchi, Y., "A Study on Gasoline Engine Combustion by Observation of Intermediate Reactive Products During Combustion," SAE Paper No. 790840, Warrendale, PA 1979.

24. Fish, A., "The Cool Flames of Hydrocarbons," Angewandte Chemie International Edition, Vol. 7, pp. 45-60, 1968.

25. Baldwin, R. R., and Walker, R. W., "Problems and Progress in Hydrocarbon Oxidation," $14^{\text {th }}$ Symposium (International) on Combustion. The Combustion Institute, Pittsburgh, PA, pp. 241-257, 1973. 
26. Dryer, F. L., and Glassman, I., "Combustion Chemistry of Chain Hydrocarbons," Progress in Astronautics and Aeronautics, Vol. 62, pp. 255-306, 1978.

27. Westbrook, K. C., Pitt, W. J., and Leppard, W. R., "The Auto-Ignition Chemistry of Paraffinic Fuels and Pro-Knock and Anti-Knock Additives: A Detailed Chemical Kinetic Study,” SAE Paper No. 912314, Warrendale, PA 1991.

28. Westbrook, K. C., "Chemical Kinetics of Hydrocarbons Ignition in Practical Combustion Systems," $28^{\text {th }}$ Internacional Combustion Symposium, Vol. 28, pp. 1563-1577, Edinburgh, 2000.

29. Halstead, M. P., Kirsch, L. J., and Quinn, C. P., "The Autoignition of Hydrocarbon Fuels at High Temperatures and Pressures, Fitting of a Mathematical Model," Combustion and Flame, Vol. 30, pp. 45-60, 1977.

30. Fiveland, S. B., and Assanis, D. N., "A Four-Stroke Homogeneous Charge Compression Ignition Engine Simulation for Combustion and Performance Studies," SAE Paper No. 2000-01-0332, Warrendale, PA 2000.

31. Goldsborough, S., and Van Blarigan, P., "A numerical Study of a Free Piston IC Engine Operating on Homogeneous Charge Compression Ignition Combustion," SAE Paper No. 1999-01-0609, Warrendale, PA 1999.

32. Xu, H., Fu, H., Williams, H., and Shilling, I., "Modeling Study of Combustion and Gas Exchange in a HCCI (CAI) Engine," SAE Paper No. 2002-01-0114, Warrendale, PA 2002.

33. Dec, J. E., "A Computational Study of the Effects of Low Fuel Loading and EGR on Heat Release Rates and Combustion Limits in HCCI Engines," SAE Paper No. 2002-01-1309, Warrendale, PA 2002.

34. Aceves, S. M., "A Multi-Zone Model for Prediction of HCCI Combustion and Emissions,” SAE Paper No. 2000-01-0327, Warrendale, PA 2000.

35. Easley, W. L., Agarwal, A., and Lavole, G., "Modeling of HCCI Combustion and Emissions Using Detailed Chemistry," SAE Paper No. 2001-01-1029, Warrendale, PA 2001.

36. Griffiths, J., Halford-Maw, P. A., and Mohamed, C., "Spontaneous Ignition Delays as a Diagnostic of the Propensity of Alkenes to Cause Engine Knock," Combustion and Flame, Vol. 111, pp.327-337, 1997.

37. Curran, H. J., Gaffuri, P., Pitz, W. J., and Westbrook, C. K., “A Comprehensive Modeling Study of n-Heptane Oxidation," Combustion and Flame, Vol. 114, pp. 149-177, 1998. 
38. Christensen, M., Einewall, P., and Johansson, B., "Homogeneous Charge Compression Ignition (HCCI) Using Isoctane, Etanol and Natural Gas: A Comparison with Spark Ignition Operation," SAE Paper No. 972874, Warrendale, PA 1997.

39. Ishibashi, Y., "Basic Understanding of Activated Radical Combustion and its Two-Stroke Engine Application and Benefits," SAE Paper No. 2000-01-1836, Warrendale, PA 2000.

40. Christensen, M., and Johansson, B., "Influence of Mixture Quality on Homogeneous Charge Compression Ignition," SAE Paper No. 982454, Warrendale, PA 1998.

41. Christensen, M., Johansson, B., Amneus, P. J., and Gauss, F., "Supercharged Homogenous Charge Compression Ignition", SAE Paper No. 980787, Warrendale, PA 1998.

42. Flowers, D., Aceves, S. M., Smith, J. R., Torres, J., Girard, J., and Dibble, R. W., "HCCI in a CFR Engine: Experiments and Detailed Kinetic Modeling," SAE Paper No. 2000-01-0328, Warrendale, PA 2000.

43. Law, D., and Allen, J., "On the Mechanism of Controlled Auto-Ignition," SAE Paper No. 2002-01-0421, Warrendale, PA 2002.

44. Law, D., Allen, J., Kemp, D., Kirkpatrick, G., and Copland, T., "Controlled Combustion in an IC Engine with a Fully Variable Valve Train," SAE Paper No. 2001-01-0251, Warrendale, PA 2001.

45. Ryan III, T. W., and Matheaus, A. C., "Fuel Requirements for HCCI Engine Operation," SAE Paper No. 2003-01-1813, Warrendale, PA 2003.

46. Jeuland, N. et al. "Engine and Fuel Related Issues of Gasoline CAI (Controlled Auto-Ignition) Combustion", SAE paper, 2003-01-1856, 2003.

47. Christensen, M., Hultquist, A., Johansson, B., Franke, A., Richter, M., and Alden, M., "A Study of the Homogenous Charge Compression Ignition with Water Injection,” SAE Paper No. 1999-01-3680, Warrendale, PA 1999.

48. Lida, N. Y., "Auto-Ignition and Combustion of n-Butane and DME/Air Mixtures in a Homogenous Charge Compression Engine," SAE Paper No. 2000-01-1832, Warrendale, PA 2000.

49. Ryan III, T. W., and Callahan, T. J., "Homogenous Charge Compression Ignition (HCCI) of Diesel Fuel,” SAE Paper No. 961160, Warrendale, PA 1996. 
50. Chen, Z., and Mitsuru, K., "How to Put the HCCI Engine to Practical Use: Control the Ignition Timing By Compression Ratio and Increase the Power Output by Supercharge," SAE Paper No. 2003-01-1832, Warrendale, PA 2003.

51. Kontarakis. G., Collings, N., and Ma, T. H, "Demonstration of HCCI Using a Single Cylinder Four-Stroke SI Engine with Modified Valve Timing," SAE Paper No. 2000-01-2870, Warrendale, PA 2000.

52. Ogura, M., Sasaki, T., and Kawaguchi, Y., "HCCI Combustion Control by Intake and Exhaust Continuous Variable Valve Timing Mechanism in Premixed Gasoline Engine," SAE Paper No. 2004-32-0096, Warrendale, PA 2004.

53. Yap, D., Wyszynski, M. L., Megaritis, A., Peucheret, S. M., and Xu, H., "Effect of Hydrogen Addition on Natural Gas HCCI Combustion," SAE Paper No. 200401-1972, Warrendale, PA 2004.

54. Oakley, A., Zhao, H., Ladommatos, N., and Ma, T., "Experimental Studies on Controlled Auto-Ignition (CAI) Combustión of Gasolina in a 4-Stroke Engine," SAE Paper No. 2001-01-1030, Warrendale, PA 2001.

55. Zhao, H., Li, J., and Ladommatos, N., "Performance and Analysis of a FourStroke Multi-Cylinder Gasoline Engine with CAI Combustion," SAE Paper No. 2002-01-0420, Warrendale, PA 2002.

56. Hiraya, K., Hasegawa, K., Urushihara, T., Liyama, A., and Itoh, T., "A Study on Gasoline Fueled Compression Ignition Engine: A Trial of Operation Region Expansion," SAE Paper No. 2002-01-0416, Warrendale, PA 2002.

57. Yamaoka, S., Shimada, A., Kihara, Y., Kakuya, H., Nakagawa, S., and Nogi, T., "A Study of Controlling the Auto-Ignition and Combustion in a Gasoline HCCI Engine," SAE Paper No. 2004-01-0942, Warrendale, PA 2004.

58. Olsson, J. O., Tunestal, P., and Johansson, B, "Boosting for High Load HCCI," SAE Paper No. 2004-01-0940, Warrendale, PA 2004.

59. Leach, B., Zhao, H., and Li, Y., "Control of CAI Combustion Through Injection Timing in a GDI Engine with an Air-Assisted Injector," SAE Paper No. 2005-010134, Warrendale, PA 2005.

60. Loth, J. L., Loth, E., and Loth, F., "Isolated Combustion and Diluted Expansion (ICADE) Piston Engine," United States Patent 5.239.959, Alexandria, VA 1993.

61. El-Messiri, I. A., "The Divided Combustion Chamber Concept and Design For Control of SI Engine Exhaust Air Pollutant Emissions," Ph.D. Dissertation, University of Wisconsin, 1973. 
62. Borman, G. L., "Mathematical Simulation of Internal Combustion Engine Processes and Performance Including Comparison with Experiment," Ph.D. Thesis, University of Wisconsin, 1964.

63. Newhall, H. K., and Starkman, E. S., "Thermodynamic Properties of Octane and Air for Engine Performance Calculations," SAE Paper 633G, Warrendale, PA 1963.

64. JANAF Thermochemical Tables", $2^{\text {nd }}$ Edition., National Bureau of Standards Publications, NSRDS-N35 37, Washington D. C., 1971.

65. Lichty, L. C., Internal Combustion Engines, McGraw Hill Book Company, New York, NY 1951.

66. Moran, M. J., and Shapiro, H. N., Fundamentals of Engineering Thermodynamics $4^{\text {th }}$ Edition, John Wiley \& Sons, Inc, New York, NY 2000.

67. ASTM Manual for Rating Motor Fuels by Research and Motor Methods $6^{\text {th }}$ Edition, American Society for Testing and Materials (ASTM), Rahway, NJ 1969.

68. Lancaster, D. R., Krieger, R. B., and Lienesch, J. H., "Measurement and Analysis of Engine Pressure Data," SAE Paper No. 750026, Warrendale, PA 1975.

69. Gatowski, J. A., Balles, E. N., Chun, K. M., Nelson, F. E., Ekchian, J. A., and Heywood, J. B., "Heat Release Analysis of Engine Pressure Data," SAE paper, 841359, Warrendale, PA 1984.

70. Woschni, G., "A Universally Applicable Equation for the Instantaneous Heat Transfer Coefficient in the Internal Combustion Engine," SAE Paper No. 670931, Warrendale, PA 1967.

71. Rassweiler, G. M., and Withrow, L., "Motion Pictures of Engine Frames Correlated with Pressure Cards," SAE Paper No. 970037, Warrendale, PA 1997.

72. Stone, R., Introduction to Internal Combustion Engines, SAE Book, Warrendale, PA, 1994.

73. Lipson, C., and Sheth, N. J., Statistical Design and Analysis of Engineering Experiments, McGraw Hill Book Company, New York, NY 1973. 


\section{Appendixes}

\section{Appendix A: CIBAI Analytical and Numerical Modeling Program Code}

\section{CIBAI Cycle Analysis Code}

\%Name: CIBAI Numerical Model Code

\%Institution:West Virginia University

\%Developed by: Fernando Echavarria Hidalgo

\%Date: February 14, 2006

$\%$ Objectives:

\%Perform a complete thermodynamic analysis of the CIBAI

$\%$ cycle,and compare the results with the ones obtained for the Otto and

$\%$ Diesel cycles under comparable parameters.

$\%$--- Executes on button press in clear.

function clear_Callback(hObject, eventdata, handles)

$\%$ hObject handle to clear (see GCBO)

$\%$ eventdata reserved - to be defined in a future version of MATLAB

$\%$ handles structure with handles and user data (see GUIDATA)

set(handles.cibaieff,'string',");\%Empty fields

set(handles.ottoeff,'string',"); \%Empty fields

set(handles.dieseleff,'string',");\%Empty fields

cla reset \%resets the properties of the current axes.

$\%$--- Executes on button press in plotpressure.

function plotpressure_Callback(hObject, eventdata, handles)

$\%$ hObject handle to plotpressure (see GCBO)

$\%$ eventdata reserved - to be defined in a future version of MATLAB

$\%$ handles structure with handles and user data (see GUIDATA)

\% Variable definition

set(gcf, 'name','CIBAI Cycle');

grid; \%add grids to current axes

rvastring=get(handles.rva,'string');\%get rva string value from screen rva $=$ str2num(rvastring); $\%$ convert rva string value to numeric value

rvafstring=get(handles.rvaf,'string'); \%get rvaf string value from screen rvaf=str2num(rvafstring);\%convert rvaf string value to numeric value

nstring=get(handles.n,'string'); \%convert $\mathrm{n}$ string value to numeric value 
$\mathrm{n}=\operatorname{str} 2$ num(nstring); \%convert $\mathrm{n}$ string value to numeric value

rcstring=get(handles.rc,'string'); \%convert rc string value to numeric value $\mathrm{rc}=\mathrm{str} 2$ num(rcstring); \%convert $\mathrm{rc}$ string value to numeric value

stob=1; \%input('Stroke-to-Bore Ratio:');

vdo=1; \%input('Volume Displacement:');

crtoca $=5$; \%input('Connecting Rod Length to Crank Angle Offset Ratio:');

\section{\%Initial Calculations}

vcaftovdo=vdo/(rvaf-1);

$\%$ Volume clearance air fuel cylinder to volume displacement

vcatovdo=vdo/(rva-1);

$\%$ Volume clearance air only cylinder to volume displacement

bore $=\left(\mathrm{vdo}^{*} 4 /\left(\mathrm{pi}^{*} \text { stob }\right)\right)^{\wedge}(1 / 3) ; \%$ Bore

stroke $=$ bore* $v$ do; $\%$ Stroke

co=stroke $/ 2 ; \%$ Crank offset

$\mathrm{crl}=\mathrm{co} *$ crtoca; \%Connecting rod length

$\mathrm{rm}=(\mathrm{vdo}+\mathrm{vcatovdo}) /(\mathrm{vdo}+\mathrm{vcaftovdo}) ; \%$ Mass ratio

taft $1=\mathrm{rvaf}^{\wedge}(\mathrm{n}-1) ; \% \mathrm{Taf} / \mathrm{T} 1$

tat $1=$ rva $^{\wedge}(\mathrm{n}-1) ; \% \mathrm{Taf} / \mathrm{T} 1$

t2tot $1=(1 /(1+\mathrm{rm})) *(\operatorname{taft} 1+\operatorname{tat} 1 * \mathrm{rm}) ; \% \mathrm{~T} 2 / \mathrm{T} 1$

t3tot $1=$ t2tot $1 *$ rc; \% $3 / \mathrm{T} 1$

p2afp1=rvaf $($ n); \%P2af/P1

p2ap1 $=\mathrm{rva}^{\wedge}(\mathrm{n}) ; \% \mathrm{P} 2 \mathrm{a} / \mathrm{P} 1$

v2tovdo $=$ vcaftovdo + vcatovdo; $\% \mathrm{~V} 2 / \mathrm{Vdo}$

$\mathrm{p} 2 \mathrm{p} 1=(\mathrm{t} 2 \mathrm{tot} 1) /(\mathrm{v} 2$ tovdo/(v2tovdo $+2 * \mathrm{vdo})) ; \% \mathrm{P} 2 / \mathrm{P} 1$

$\mathrm{p} 3 \mathrm{p} 1=\mathrm{p} 2 \mathrm{p} 1{ }^{*} \mathrm{rc} ; \% \mathrm{P} 3 / \mathrm{P} 1$

\section{\%Overall Efficiency Comparison}

wintomocvt $1=\operatorname{rvaf}^{\wedge}(\mathrm{n}-1)-1+\left(\mathrm{rva}^{\wedge}(\mathrm{n}-1)-1\right) * \mathrm{rm} ; \%$ Work in wouttomocvt $1=\mathrm{rc}^{*}\left(\mathrm{rvaf}^{\wedge}(\mathrm{n}-1)+\mathrm{rva}^{\wedge}(\mathrm{n}-1) * \mathrm{rm}\right)^{*}\left(1-(\mathrm{v} 2 \text { tovdo } /(\mathrm{v} 2 \operatorname{tovdo}+2))^{\wedge}(\mathrm{n}-1)\right)$;

$\%$ Work out qintomocvt $1=\left(\operatorname{rvaf}^{\wedge}(\mathrm{n}-1)+\mathrm{rva}^{\wedge}(\mathrm{n}-1) * \mathrm{rm}\right) *(\mathrm{rc}-1) ; \%$ Heat in woutoqin=wouttomocvt1/qintomocvt $1 ; \%$ Work out over heat in wintoqin=wintomocvt1/qintomocvt $1 \% \%$ Work in over heat in cibaieff $=($ woutoqin-wintoqin $) * 100 ; \%$ CIBAI thermal efficiency ottoeff $=\left(1-1 / \text { rvaf }^{\wedge}(\mathrm{n}-1)\right)^{*} 100 ; \%$ OTTO thermal efficiency dieseleff $=\left(1-1 / \mathrm{rva}^{\wedge}(\mathrm{n}-1) *\left(\mathrm{rc}^{\wedge} \mathrm{n}-1\right) /(\mathrm{n} *(\mathrm{rc}-1))\right)^{*} 100 ; \%$ DIESEL thermal efficiency 


\section{$\%$ Vector to store $\mathbf{P} / \mathbf{P 1}$ ratio}

paftop $1=(0: 720) ; \%$ Instantaneous Taf/T1

patop $1=(0: 720) ; \%$ Instantaneous $\mathrm{Ta} / \mathrm{T} 1$

p4top $1=(0: 720) ; \%$ Instantaneous T4/T1

detonationlinepressure $=(0: 720) ; \%$ Detonation line temperature diagram

for $\mathrm{i}=1$ :length(ca)

$\operatorname{cpdi}=\mathrm{co}^{*} \cos (\mathrm{ca}(\mathrm{i}) * \mathrm{pi} / 180)+\left(\mathrm{crl}^{\wedge} 2-\mathrm{co}^{\wedge} 2^{*} \sin \left(\mathrm{ca}(\mathrm{i})^{*} \mathrm{pi} / 180\right)^{\wedge}(2)\right)^{\wedge}(1 / 2) ;$

$\%$ Distance between crank axis and wrist pin axis

vdoi $=\left(\left(\text { pi }^{*} \text { bore }^{\wedge}(2)\right) / 4\right)^{*}(\operatorname{crl}+$ co-cpdi $) ; \%$ Instantaneous volume displacement

if $\mathrm{ca}(\mathrm{i})>=0 \quad \& \mathrm{ca}(\mathrm{i})<180$

$\operatorname{paftop} 1(\mathrm{i})=1$;

patop1(i) $=1$;

p4top1(i) $=0$;

detonationlinepressure $(\mathrm{i})=0$;

elseif ca(i) $>=180 \& \mathrm{ca}(\mathrm{i})<359$

paftop1 $(\mathrm{i})=\left(\left((\text { vcaftovdo }) /\left(\text { vcaftovdo }^{\prime} \text { vdoi }\right)\right)^{\wedge}(\mathrm{n})\right)^{*} \operatorname{rvaf}^{\wedge}(\mathrm{n})$;

patop $1(\mathrm{i})=\left(((\text { vcatovdo }) /(\text { vcatovdo }+ \text { vdoi }))^{\wedge}(\mathrm{n})\right)^{*} \mathrm{rva}^{\wedge}(\mathrm{n})$;

p4top1(i) $=0$;

detonationlinepressure $(\mathrm{i})=0$;

elseif $\mathrm{ca}(\mathrm{i})==359$

detonationlinepressure $(\mathrm{i})=\left(\left((\operatorname{vcaftovdo}) /\left(\operatorname{vcaftovdo}^{\prime}+\operatorname{vdoi}\right)\right)^{\wedge}(\mathrm{n})\right)^{*} \operatorname{rvaf}^{\wedge}(\mathrm{n})$;

paftop1(i) $=0$;

patop $1(i)=0$;

p4top1(i) $=0$;

elseif ca $(\mathrm{i})==360$

detonationlinepressure $(\mathrm{i})=(\mathrm{p} 3 \mathrm{p} 1) *(($ vcaftovdo + vcatovdo $) /($ vcaftovdo + vcatovdo $+2 *$ vdoi $))$

$\wedge(n)$;

$\operatorname{paftop} 1(\mathrm{i})=0$;

patop1(i) $=0$;

p4top1(i) $=0$;

elseif ca(i) $>360 \& \mathrm{ca}(\mathrm{i})<=540$

$\operatorname{paftop} 1(\mathrm{i})=0$;

patop1(i) $=0$;

p4top1 $(\mathrm{i})=(\mathrm{p} 3 \mathrm{p} 1) *((\mathrm{vcaftovdo}+\mathrm{vcatovdo}) /(\mathrm{vcaftovdo}+\mathrm{vcatovdo}+2 * \mathrm{vdoi}))^{\wedge}(\mathrm{n})$;

detonationlinepressure $(\mathrm{i})=0$; 
elseif ca(i) $>540 \&$ ca(i) $<=720$

paftop $1(\mathrm{i})=0$;

patop $1(\mathrm{i})=0$;

p4top1(i) $=1$;

detonationlinepressure $(\mathrm{i})=0$;

else

disp('Crank Angle is between 0 and 720 ca degree');

end

end

\section{\%Plot pressure ratio diagram}

handle10=plot(ca(1:359),paftop1(1:359),'g-');

set(handle10,'LineWidth',2);

hold on

handle11=plot(ca(1:359),patop1(1:359),'k-');

set(handle11,'LineWidth',2);

hold on

handle12=plot(ca(360:361), detonationlinepressure(360:361),'r-');

set(handle12,'LineWidth',2);

hold on

handle13=plot(ca(362:540),p4top1(362:540),'b-');

set(handle13,'LineWidth',2);

hold on

handle14=plot(ca(541:721),p4top1(541:721),'b-');

set(handle14,'LineWidth',2);

grid \%draws a grid over the plot

set(gca,'FontWeight','bold');

title('P/P1 vs. Crank Angle');

xlabel('Crank Angle');

ylabel('P/P1');

legend('Paf/P1', 'Pa/P1', 'Denotation', 'Pprod/P1')

\section{\%Display results}

set(handles.cibaieff,'string', cibaieff); \%Cibai efficiency set(handles.ottoeff,'string', ottoeff); \%Otto efficiency set(handles.dieseleff,'string', dieseleff); \%Diesel efficiency 
$\%$--- Executes on button press in plottemperature.

\section{function plottemperature_Callback(hObject, eventdata, handles)}

$\%$ hObject handle to plottemperature (see GCBO)

$\%$ eventdata reserved - to be defined in a future version of MATLAB

$\%$ handles structure with handles and user data (see GUIDATA)

\section{\%Variable definition}

set(gcf, 'name','CIBAI Cycle');

grid; \%add grids to current axes

rvastring=get(handles.rva,'string'); \%get rva string value from screen rva $=$ str2num(rvastring); \%convert rva string value to numeric value

rvafstring=get(handles.rvaf,'string'); \%get rvaf string value from screen rvaf=str2num(rvafstring); \%convert rvaf string value to numeric value

nstring=get(handles.n,'string'); \%convert $\mathrm{n}$ string value to numeric value $\mathrm{n}=\operatorname{str} 2$ num(nstring); \%convert $\mathrm{n}$ string value to numeric value

rcstring=get(handles.rc,'string'); \%convert rc string value to numeric value $\mathrm{rc}=\mathrm{str} 2$ num(rcstring); \%convert $\mathrm{rc}$ string value to numeric value

stob=1; \%input('Stroke-to-Bore Ratio:');

$\mathrm{vdo}=1 ; \%$ input('Volume Displacement:');

crtoca $=5$; \%input('Connecting Rod Length to Crank Angle Offset Ratio:');

\section{\%Initial Calculations}

vcaftovdo=vdo/(rvaf-1); \%Volume clearance air fuel cylinder to volume displacement vcatovdo $=\mathrm{vdo} /(\mathrm{rva}-1) ; \%$ Volume clearance air only cylinder to volume displacement

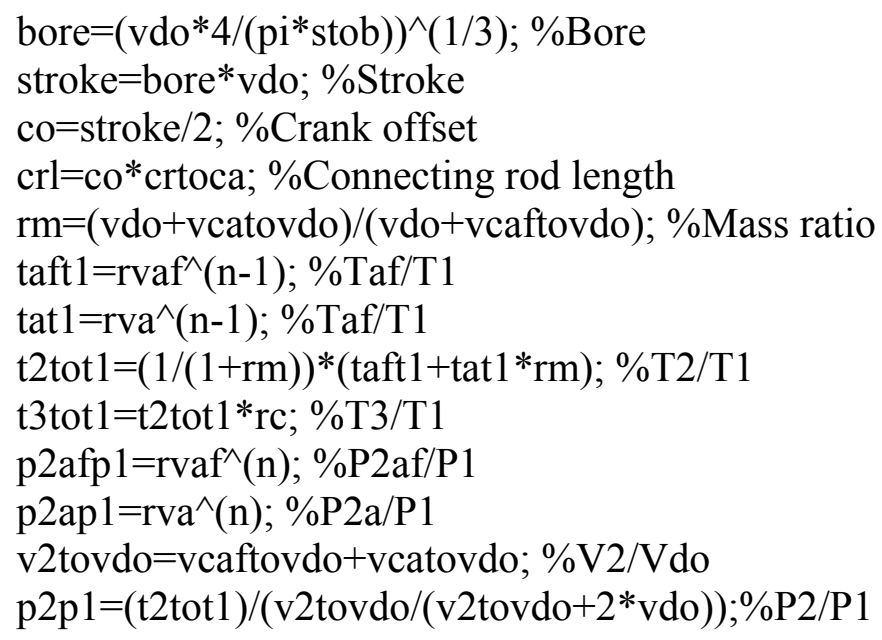


$\mathrm{p} 3 \mathrm{p} 1=\mathrm{p} 2 \mathrm{p} 1 *_{\mathrm{rc}} ; \% \mathrm{P} 3 / \mathrm{P} 1$

\section{\%Overall Efficiency Comparison}

wintomocvt $1=\operatorname{rvaf}^{\wedge}(\mathrm{n}-1)-1+\left(\mathrm{rva}^{\wedge}(\mathrm{n}-1)-1\right)^{*} \mathrm{rm} ; \%$ Work in wouttomocvt $1=\operatorname{rc}^{*}\left(\operatorname{rvaf}^{\wedge}(n-1)+\operatorname{rva}^{\wedge}(n-1) * \operatorname{rm}\right) *\left(1-(\operatorname{vitovdo} /(\operatorname{vitovdo}+2))^{\wedge}(n-1)\right)$; $\%$ Work out qintomocvt $1=\left(\operatorname{rvaf}^{\wedge}(\mathrm{n}-1)+\mathrm{rva}^{\wedge}(\mathrm{n}-1) * \mathrm{rm}\right) *(\mathrm{rc}-1) ; \%$ Heat in woutoqin=wouttomocvt $1 /$ qintomocvt $1 ; \%$ Work out over heat in wintoqin=wintomocvt1/qintomocvt1; \%Work in over heat in cibaieff $=$ (woutoqin-wintoqin $) * 100 ; \%$ CIBAI thermal efficiency ottoeff $=\left(1-1 / \text { rvaf }^{\wedge}(n-1)\right)^{*} 100 ; \%$ OTTO thermal efficiency dieseleff $=\left(1-1 / \mathrm{rva}^{\wedge}(\mathrm{n}-1) *\left(\mathrm{rc}^{\wedge} \mathrm{n}-1\right) /(\mathrm{n} *(\mathrm{rc}-1))\right)^{*} 100 ; \%$ DIESEL thermal efficiency

\section{$\%$ Vector to store $\mathrm{T} / \mathrm{T} 1$ ratio}

$\mathrm{ca}=(0: 720) ; \%$ Crank angle vector

length(ca); \%Length crank angle vector

taftot $1=(0: 720) ; \%$ Instantaneous Taf $/ \mathrm{T} 1$

tatot $1=(0: 720) ; \%$ Instantaneous Ta/T1

t4tot1 $=(0: 720) ; \%$ Instantaneous T4/T1

detonationlinetemperature $=(0: 720) ; \%$ Detonation line temperature diagram

for $\mathrm{i}=1$ :length(ca)

$\mathrm{cpdi}=\mathrm{co}^{*} \cos (\mathrm{ca}(\mathrm{i}) * \mathrm{pi} / 180)+\left(\mathrm{crl}^{\wedge} 2-\mathrm{co}^{\wedge} 2^{*} \sin (\mathrm{ca}(\mathrm{i}) * \mathrm{pi} / 180)^{\wedge}(2)\right)^{\wedge}(1 / 2)$;

$\%$ Distance between crank axis and wrist pin axis

vdoi $=\left(\left(\text { pi }^{*} \operatorname{bore}^{\wedge}(2)\right) / 4\right)^{*}(\operatorname{crl}+$ co-cpdi $) ; \%$ Instantaneous volume displacement

if $\mathrm{ca}(\mathrm{i})>=0 \quad \& \mathrm{ca}(\mathrm{i})<180$

taftot $1(\mathrm{i})=1$;

$\operatorname{tatot} 1(\mathrm{i})=1$;

$\mathrm{t} 4 \operatorname{tot} 1(\mathrm{i})=0$;

detonationlinetemperature $(\mathrm{i})=0$;

elseif ca(i) $>=180 \&$ ca(i) $<359$

taftot $1(\mathrm{i})=\left(((\text { vcaftovdo }) /(\text { vcaftovdo }+ \text { vdoi }))^{\wedge}(\mathrm{n}-1)\right) * \mathrm{rvaf}^{\wedge}(\mathrm{n}-1)$;

tatot $1(\mathrm{i})=\left(((\text { vcatovdo }) /(\text { vcatovdo }+ \text { vdoi }))^{\wedge}(\mathrm{n}-1)\right) * \mathrm{rva}^{\wedge}(\mathrm{n}-1)$;

$\mathrm{t} 4 \operatorname{tot} 1(\mathrm{i})=0$;

detonationlinetemperature $(\mathrm{i})=0$;

elseif $\mathrm{ca}(\mathrm{i})==359$

detonationlinetemperature $(\mathrm{i})=\left(((\text { vcaftovdo }) /(\text { vcaftovdo }+ \text { vdoi }))^{\wedge}(n-1)\right) *^{*} \operatorname{rvaf}^{\wedge}(n-1)$;

$\operatorname{taftot} 1(\mathrm{i})=0$; 


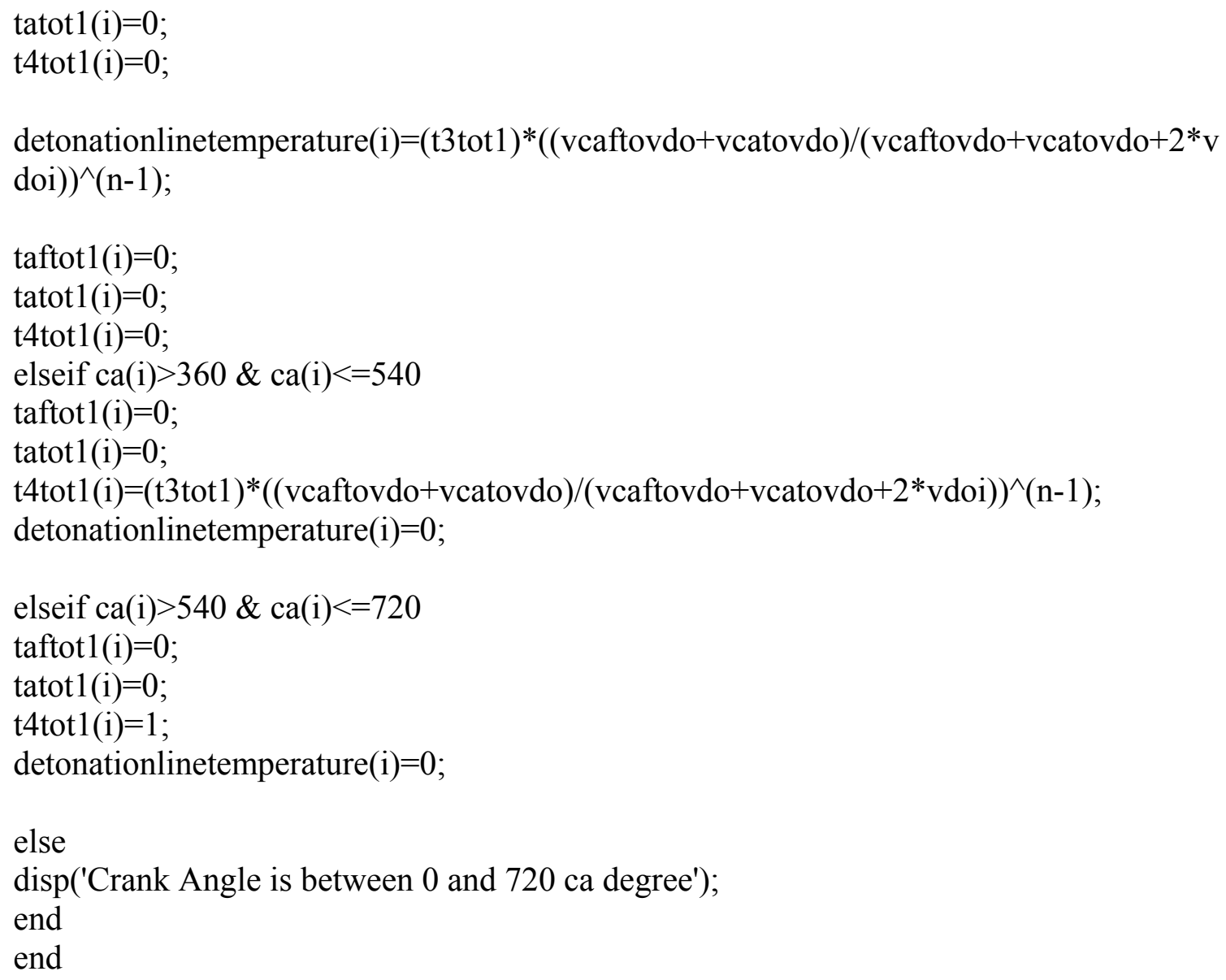


xlabel('Crank Angle');

ylabel('T/T1');

legend('Taf/T1', 'Ta/T1', 'Detonation', 'Tprod/T1')

\%Display Results

set(handles.cibaieff,'string', cibaieff); \%Cibai efficiency

set(handles.ottoeff,'string', ottoeff); \%Otto efficiency

set(handles.dieseleff,'string', dieseleff); \%Diesel efficiency

$\%$

function Analysis_Callback(hObject, eventdata, handles)

$\%$ hObject handle to Analysis (see GCBO)

$\%$ eventdata reserved - to be defined in a future version of MATLAB

$\%$ handles structure with handles and user data (see GUIDATA)

gui;\%Call cycle analysis program

$\%$

function Numerical_modeling_Callback(hObject, eventdata, handles)

$\%$ hObject handle to Numerical_modeling (see GCBO)

$\%$ eventdata reserved - to be defined in a future version of MATLAB

$\%$ handles structure with handles and user data (see GUIDATA)

gui2;\%Call numerical modeling program

$\%$

function raw_data_Callback(hObject, eventdata, handles)

$\%$ hObject handle to raw_data (see GCBO)

$\%$ eventdata reserved - to be defined in a future version of MATLAB

$\%$ handles structure with handles and user data (see GUIDATA)

raw; \%Open raw data screen 


\section{CIBAI Numerical Modeling Code}

\%Institution:West Virginia University

\%Developed by: Fernando Echavarria Hidalgo

$\%$ Date: February 14, 2006

$\%$ Objectives:

\%1)Perform numerical integration using in-cylinder pressure

$\%$ data to calculate engine power and combustion parameters such as, indicated net work, \%indicated mean effective pressure (IMEP),thermal efficiency, net heat release,

\%heat release rate, mass fraction burned (MFB),ignition delay, and combustion duration.

$\% 2$ )Conduct a parametric study using experimental data as an input to

$\%$ predict the effect of compression ratio, air injection pressure, intake

\%temperature, air-fuel ratio, and air injection timing on CIBAI combustion.

$\%$--- Executes on button press in pushbutton 1.

function pushbutton1_Callback(hObject, eventdata, handles)

$\%$ hObject handle to pushbutton 1 (see GCBO)

$\%$ eventdata reserved - to be defined in a future version of MATLAB

$\%$ handles structure with handles and user data (see GUIDATA)

set(gcf, 'name','CIBAI Numerical Modeling');

$\%$ Create a get file box

[filename, pathname]=uigetfile('*.m;*.xls',...

'Open File');

if isequal(filename,0) | isequal(pathname,0)

else

set(gcf, 'name',filename);

\%Download test data from excel

\%filename=input('Enter File Name: ','fl');\%Enter file name

test $=x l s r e a d(f i l e n a m e) ; \%$ Downloading in-cylinder pressure data

\section{\%Input variables}

crstring=get(handles.cr,'string');\%get cr string value from screen $\mathrm{cr}=\operatorname{str} 2$ num(crstring);\%convert cr string value to numeric value

acpstring=get(handles.acp,'string');\%get acp string value from screen 
acp $=\operatorname{str} 2$ num(acpstring);\%convert acp string value to numeric value

gammastring=get(handles.n,'string');\% $\%$ convert $\mathrm{n}$ string value to numeric value gamma $=$ str2num(gammastring); $\%$ convert $n$ string value to numeric value

flstring=get(handles.fl,'string');\%convert fl string value to numeric value $\mathrm{fl}=$ str2num(flstring);\%convert fl string value to numeric value

afrstring=get(handles.afr,'string');\%convert afr string value to numeric value afr=str2num(afrstring);\%convert afr string value to numeric value exhtempstring=get(handles.exhtemp,'string'); \%convert exhtemp string value to numeric value exhtemp=str2num(exhtempstring);\%convert exhtemp string value to numeric value itempstring=get(handles.itemp,'string');\%convert itemp string value to numeric value intemp=str2num(itempstring);\%convert itemp string value to numeric value

ipresstring=get(handles.intpre,'string');\%convert intpre string value to numeric value inpres $=$ str2num(ipresstring);\% $\%$ convert intpre string value to numeric value

\section{\%Calculate combustion duration and injection delay}

intimstring=get(handles.intim,'string');

$\%$ convert air injection timing string value to numeric value injection_delaystring=get(handles.injection_delay,'string');

$\%$ convert spark timing string value to numeric value

if get(handles.checkbox 2, Value'$\left.^{\prime}\right)==1$

injtiming=360-str2num(injection_delaystring);

$\%$ convert spark timing string value to numeric value

else

injtiming $=360$-str2num(intimstring) +50 ;

$\%$ convert re string value to numeric value

end

sfstring=get(handles.sf,'string');\%convert sf string value to numeric value scalefactor=str2num(sfstring); \%convert sf string value to numeric value

\section{\%Fixed Variables}

$\mathrm{vd}=612.5 ; \%$ Volume displacement

stroke $=4.5 ; \%$ Stroke

bore $=3.25 \% \%$ Bore

crlength $=10 ; \%$ Connecting Rod Lenght(in) 


\section{\% Initial Calculations}

tcycle $=0.1309 ; \%$ Duration combustion cycle disptft $=3 / 12 ; \%$ Distance pressure transducer dtheta $=0.55 ; \%$ delta theta $\mathrm{vcin}=\mathrm{vd} /(\mathrm{cr}-1) /(2.54)^{\wedge} 3 ; \%$ Volume clearance in^3 coff $=$ stroke $/ 2 ; \%$ Crank Offset crlovercoff $=$ crlength $/$ coff; $\%$ Coonecting rod length to crank offset ratio vdin $=0.25 *$ pi $^{*}$ bore ${ }^{\wedge}{ }^{*}$ stroke; $\%$ Volume displacement in^3 vtotal $=$ vcin + vdin; $\%$ Total volume intempr $=$ intemp $+460 ; \%$ Initial temperature in Ranking temp $2=$ intempr* $\mathrm{cr}^{\wedge}(($ gamma-1)/gamma $) ; \%$ Isentropic temperature 2 gasconst $=1716 ; \%$ Gas constant speedsound $=$ sqrt (gamma* gasconst*temp 2$) ; \%$ speed of sound inprespsig=(inpres/29.92)*14.7;\%intake pressure in psig tlag=disptft/speedsound;\%Time lag due to the distance to the PT as a function of speed of sound

$\mathrm{dthetadt}=720 /$ tcycle $\%$ Variation of angle with respect time $\mathrm{rpm}=\mathrm{dthetadt} / 6 ; \% \mathrm{RMP}$

\section{\%Vector to store pressure and crank angle data}

global ca2;

global abspressure; global rawnheatrel; global rawnheatrat;

ca2 $=(0: 0.55: 720) ; \%$ Crank angle vector length(ca2);\%Length crank angle vector

count $=0$

\section{\%Adjusted in-cylinder pressure data}

sigviewfactor $=0.3062 ; \%$ sigview factor 1 sigview unit $=0.0003062$ volts ptsens $=5 ; \%$ pressure transducer sensitivity $5 \mathrm{mv}=1 \mathrm{psig}$ scaletest $=$ test + scalefactor; $\%$ Scale pressure abspressure $=$ inprespsig + scaletest* sigviewfactor/ptsens;\%In-cylinder absolute pressure

\section{\%Change color and line type for the plot}

value_color=get(handles.listbox1,'value'); value_line=get(handles.listbox2,'value');

\section{\%Set graph color}




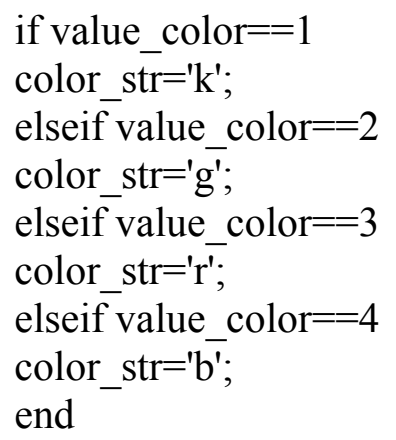

end

for $\mathrm{i}=1:$ length(ca2)

if $\operatorname{ca} 2 \operatorname{rad}(\mathrm{i})==0$

dvinst $(\mathrm{i})=0 ; \%$ Instantaneous change in volume workftlb(i) $=0 ; \%$ Indicated work $(\mathrm{ft}-\mathrm{lb})$

powerhp(i) $=0 ; \%$ Power $(\mathrm{hp})$

else

$\mathrm{p}=\mathrm{i}-1$; 
dvinst $(\mathrm{i})=\operatorname{vcinst}(\mathrm{i})-\mathrm{vcinst}(\mathrm{p}) ; \%$ Instantaneous change in volume workftlb(i)=dvinst(i)*abspressure(i)/12;\%Indicated work (ft-lb)

end

end

\section{\%Plot in-cylinder pressure diagram}

axes(handles.axes4);

set(handles.axes4,'xgrid','on','ygrid','on');

handle1=plot(ca2,abspressure, style);

set(handle1,'LineWidth',2);

hold on

grid on

\section{\%Indicated Net Work and IMEP Calculations}

inetwork $=$ sum (workftlb)*1.35582;\%Indicated net work (J)

imep $=(\operatorname{sum}($ workftlb)/vdin)*12; \%IMEP(psi)

\section{\%Display Results}

set(handles.inw,'string', inetwork);\%Cibai efficiency

set(handles.imep,'string', imep);\%Otto efficiency

set(handles.nhr,'string', 0);\%Diesel efficiency

set(handles.id,'string', 0);\%Cibai efficiency

set(handles.cd,'string', 0);\%Otto efficiency

set(handles.eff,'string', 0);\%Diesel efficiency

set(handles.start_combustion,'string', 0);\%Otto efficiency

set(handles.end_combustion,'string', 0);\%Diesel efficiency

else

\section{\%Fill instantaneous vectors}

for $\mathrm{i}=1$ :length(ca2)

ca2rad(i) $=$ ca2(i) $*$ pi $/ 180 ; \%$ Crank angle vector in radians

$\operatorname{vcinst}(i)=\operatorname{vdin} /(\operatorname{cr}-1)+(\operatorname{vdin} / 2) *(1+$ crlovercoff-cos(ca2rad(i) $)-\operatorname{sqrt}\left(\operatorname{crlovercoff}{ }^{\wedge} 2-\right.$

$\left.\left.(\sin (\mathrm{ca} 2 \operatorname{rad}(\mathrm{i})))^{\wedge} 2\right)\right) ; \%$ Instantaneous volume displacement

crinst $(i)=+(v \operatorname{cinst}(i)+v d i n) / v \operatorname{vinst}(i) ; \%$ Instantaneous compression ratio

end

for $\mathrm{i}=1$ :length(ca2) 


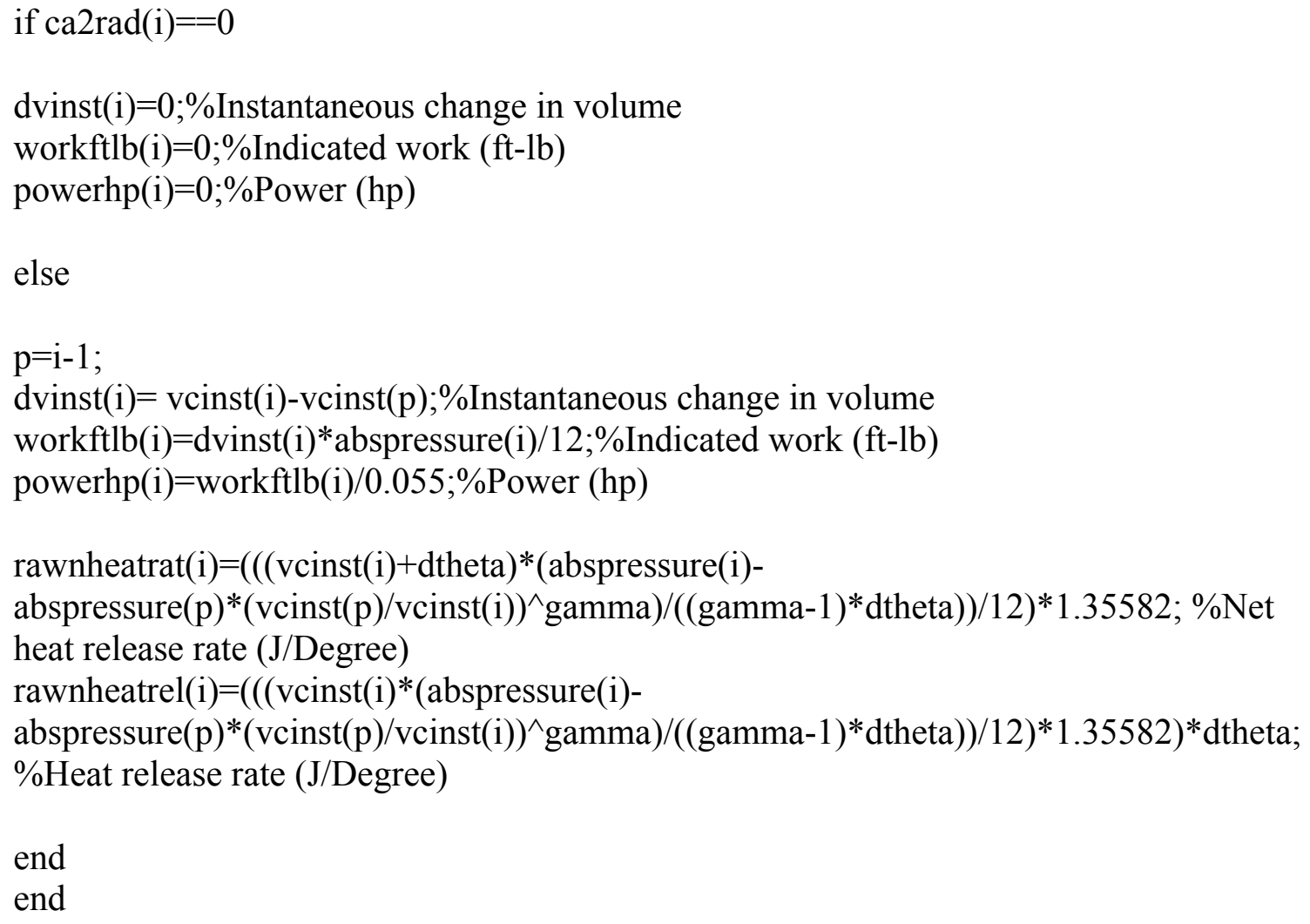

\section{\%Determine beginning and end of combustion}

$[$ maxnheatrel,locmaxnheatrel $]=\max ($ rawnheatrel $) ; \%$ Maximum point of heat release

startcomb $=0 ; \%$ Start combustion

endcomb $=0 ; \%$ End combustion

$\mathrm{W}=0 ; \%$ Counter

for $\mathrm{v}=1$ :length(rawnheatrel)

$\mathrm{w}=$ locmaxnheatrel-v;

if $\mathrm{w}>0$

if rawnheatrel $(\mathrm{w})<=0$

startcomb $=\mathrm{w} ; \%$ determine start combustion

break

end

end

end

for $\mathrm{f}=1$ :length(rawnheatrel)

if $\mathrm{f}>$ locmaxnheatrel

if rawnheatrel $(\mathrm{f})<=0$ 
endcomb $=\mathrm{f} ; \%$ determine end combustion

break

end

end

end

\section{$\%$ Fill actual heat release and heat release rate vectors}

sumheatrel $=0 ; \%$ Summation heat release

count $1=0 ; \%$ Counter for heat release vectors

for $\mathrm{i}=1$ :length(rawnheatrel)

if $\mathrm{i}>=$ startcomb \& $\mathrm{i}<=$ endcomb

count $1=$ count $1+1 ; \%$ Counter for heat release vectors

nheatrel(count 1$)=$ rawnheatrel(i);\%Net heat release

nheatrat (count 1$)=$ rawnheatrat $(\mathrm{i}) ; \%$ Net heat release

xheat $($ count 1$)=\mathrm{ca} 2(\mathrm{i}) ; \% \mathrm{X}$ axis for heat release graph

sumheatrel $=$ sumheatrel + nheatrel(count1);\%Summation heat release scalar sumheatrelvec $($ count 1$)=$ sumheatrel;\%Summation heat release vector

end

end

\%Calculation mass fraction burned (MFB)

for $\mathrm{k}=1$ :length(sumheatrelvec)

$\mathrm{mfb}(\mathrm{k})=($ sumheatrelvec $(\mathrm{k}) /$ sumheatrel $) * 100$;

end

\section{\%Indicated net work and IMEP}

inetwork $=\operatorname{sum}($ workftlb $) * 1.35582 ; \%$ Indicated net work $(\mathrm{J})$

imep $=(\operatorname{sum}($ workftlb $) /$ vdin $) * 12 ; \% \mathrm{IMEP}(\mathrm{psi})$

thermaleff=(inetwork/sumheatrel)*100;\%Thermal efficiency

\section{\%Calculation ignition delay}

ignitiondelay $=0$;

for $\mathrm{g}=1$ :length $(\mathrm{mfb})$

if $\mathrm{mfb}(\mathrm{g})>=10 \% 10$ percent MFB

tenpercentmark $=x$ heat $(\mathrm{g}) ; \%$ Crank angle degree at 10 percent MFB

if ca2(startcomb)>injtiming

ignitiondelay $=(($ tcycle $*(\operatorname{xheat}(\mathrm{g})$-injtiming $)) / 720) * 1000 ; \%$ Ignition delay

else

disp('Warning: Review Spark-Injection Timing'); 


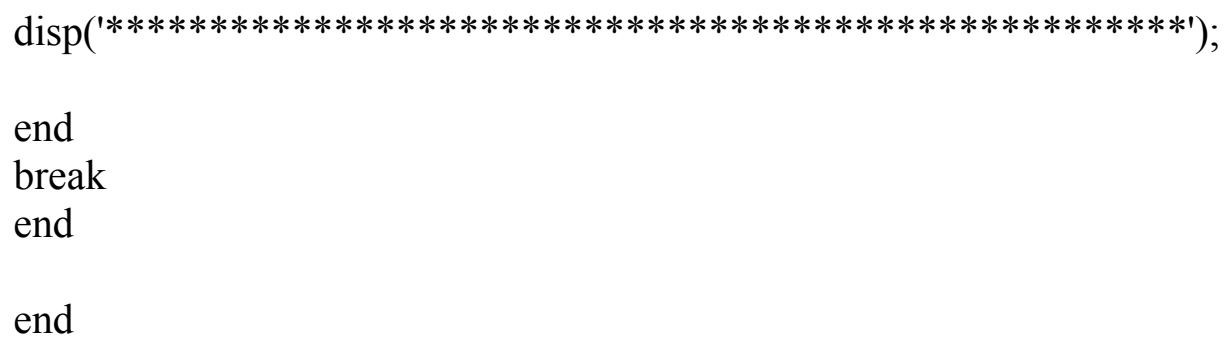

\section{\%Calculation combustion duration}

for $\mathrm{g}=1:$ length $(\mathrm{mfb})$

if $\mathrm{mfb}(\mathrm{g})>=90 \% 90$ percent MFB

ninetypercentmark $=$ xheat $(\mathrm{g}) ; \%$ Crank angle degree at 10 percent MFB break

end

end

combustionduration $=(($ tcycle $*($ ninetypercentmark-tenpercentmark $)) / 720) * 1000$;

\section{\%Display Results}

set(handles.inw,'string', inetwork); \%Cibai efficiency set(handles.imep,'string', imep); \%Otto efficiency set(handles.nhr,'string', sumheatrel); \%Diesel efficiency set(handles.id,'string', ignitiondelay); \%Cibai efficiency set(handles.cd,'string', combustionduration); \%Otto efficiency set(handles.eff,'string', thermaleff); \%Diesel efficiency set(handles.start_combustion,'string',ca2(startcomb));\%Start combustion set(handles.end_combustion,'string',ca2(endcomb));\%End combustion

\section{\%Plotting}

global handle1 handle2 handle3 handle4

\%Plot in-cylinder pressure diagram

axes(handles.axes4);

set(handles.axes4,'xgrid','on','ygrid','on'); handle $1=\operatorname{plot}(\mathrm{ca} 2$, abspressure, style);

hold on

grid on

set(handle1,'LineWidth',2);

title('In-Cylinder Pressure vs. Crank Angle');

xlabel('CA Degree');

ylabel('Pressure [psi]'); 


\section{\%Plot net heat release}

axes(handles.axes2);

handle $2=$ plot(xheat, sumheatrelvec, style);

hold on

grid on

set(handle2,'LineWidth',2);

title('Net Heat Release vs. Crank Angle');

xlabel('CA Degree');

ylabel('Net Heat Release [J]');

\section{\%Plot net heat release rate}

axes(handles.axes3);

handle $3=$ plot(xheat,nheatrat, style);

hold on

grid on

set(handle3,'LineWidth',2);

title('Net Heat Release Rate vs. Crank Angle');

xlabel('CA Degree');

ylabel('Net Heat Release Rate[J/Degree]');

\%Plot mass fraction burned

axes(handles.axes1);

handle4=plot(xheat,mfb, style);

hold on

grid on

set(handle4,'LineWidth',2);

title('Mass Fraction Burned (MFB) vs. Crank Angle');

xlabel('CA Degree');

ylabel('Mass Fraction Burned (MFB)[\%]');

end

end

function pushbutton7_Callback(hObject, eventdata, handles)

$\%$ hObject handle to pushbutton7 (see GCBO)

$\%$ eventdata reserved - to be defined in a future version of MATLAB

$\%$ handles structure with handles and user data (see GUIDATA)

global handle1

$\%$ Reset axes

reset(handles.axes1); 


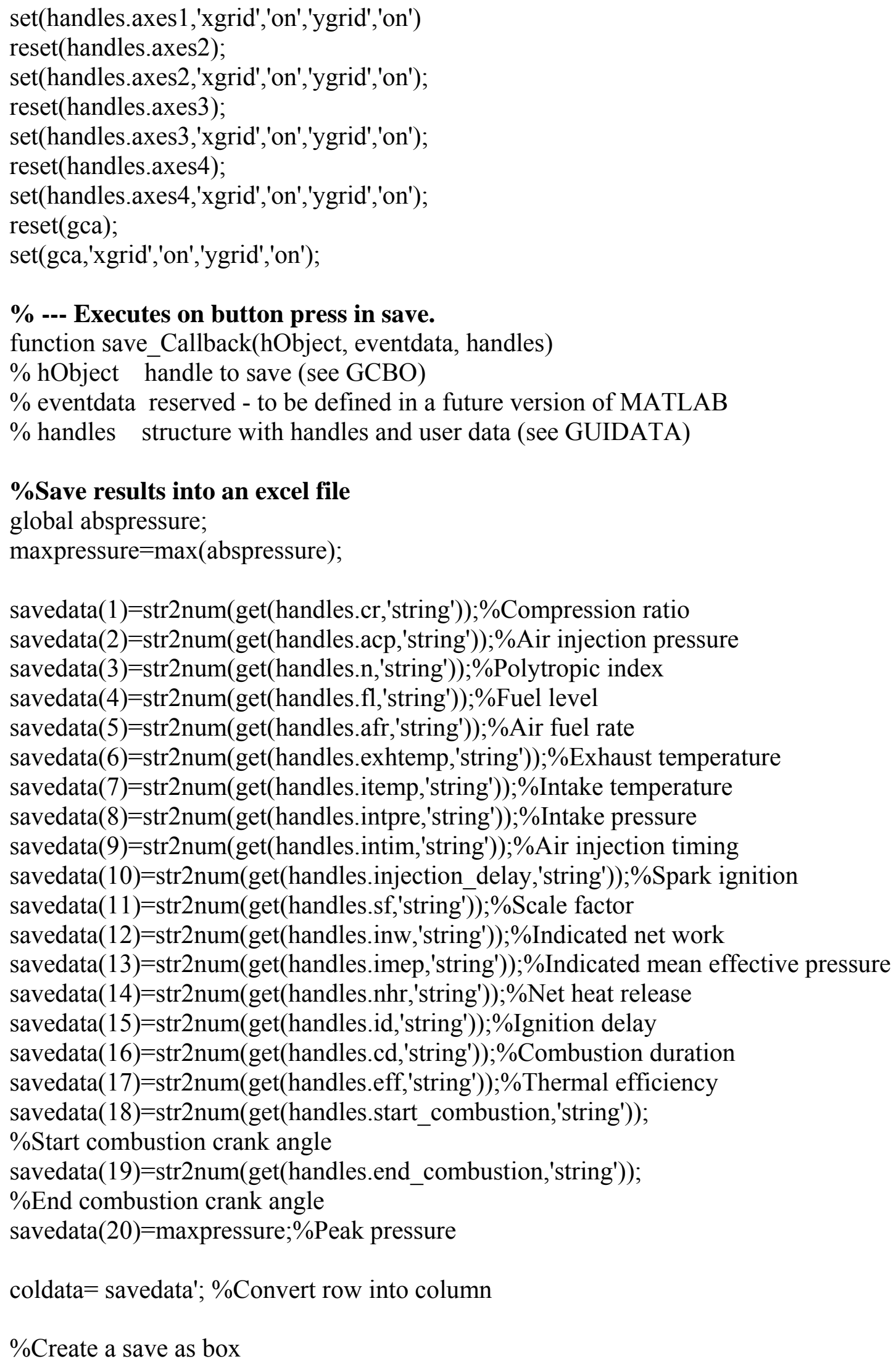


[filename, pathname] $=$ uiputfile $(\ldots$

\{'*.m;*.fig;*.mat;*.mdl', 'All MATLAB Files (*.m, *.fig, *.mat, *.mdl)'; ...

'*.xls; ${ }^{*} . w k 1 ; * .{ }^{*}$.csv', $\quad$ 'Spreadsheet Files(*.xls, *.wk1, *..csv)';...

'*.*', 'All Files $\left.(* *)^{*}\right\}, \ldots$

'Save as');

if isequal(filename,0) | isequal(pathname,0)

else

$\mathrm{f}=$ '.';

$\mathrm{g}=$ 'xls';

string $=$ strcat(filename, $\mathrm{f}, \mathrm{g})$;

wk1write(string,coldata);\%Save records into root directory

end

$\%$--- Executes on button press in pushbutton 10.

function pushbutton10_Callback(hObject, eventdata, handles)

$\%$ hObject handle to pushbutton10 (see GCBO)

$\%$ eventdata reserved - to be defined in a future version of MATLAB

$\%$ handles structure with handles and user data (see GUIDATA)

global ca2;

global abspressure;

global rawnheatrel;

global rawnheatrat;

global records_plots;

if get(handles.checkbox 1,'value') $==0$

$\mathrm{a}=\mathrm{ca} 2^{\prime}$;

$\mathrm{b}=\mathrm{abspressure;}$

$\mathrm{c}=$ rawnheatrel';

$\mathrm{d}=$ rawnheatrat';

records_plots $=[\mathrm{a}$ b c d]; $\%$ Get records into a matrix

\section{\%Open save dialog box}

[filename, pathname] $=$ uiputfile $(\ldots$

\{'*.m;*.fig;*.mat;*.mdl', 'All MATLAB Files (*.m, *.fig, *.mat, *.mdl)'; ...

'*.xls; ${ }^{*}$. wk1;*.csv', 'Spreadsheet Files(*.xls, *.wk1, *.csv)';...

'*.*', 'All Files $\left.(* *)^{\prime}\right\}, \ldots$ 
'Save as');

if isequal(filename,0) $\mid$ isequal(pathname,0)

else

$\mathrm{f}=$ '.';

$\mathrm{g}=$ 'xls';

string $=$ strcat(filename, $f, g)$;

wk1write(string,records_plots);\%Save records into root directory

set(gcf, 'PaperOrientation', 'landscape');\%Set landscape orientation

Print(gcf,'-djpeg',filename); \% Print Figure with results table

end

else

$\mathrm{a}=\mathrm{ca} 2$;

$\mathrm{b}=\mathrm{abspressure;}$

records_plots $=[\mathrm{a} b] ; \% \mathrm{Get}$ records into a matrix

\section{\%Open save dialog box}

[filename, pathname] $=$ uiputfile $(\ldots$

$\left\{{ }^{*} . \mathrm{m} ;{ }^{*}\right.$. fig; ${ }^{*} . \mathrm{mat} ;{ }^{*} . \mathrm{mdl}$ ', 'All MATLAB Files (*.m, *.fig, *.mat, *.mdl)'; ...

'*.xls; ;.wk1;*.csv', $\quad$ 'Spreadsheet Files(*.xls, *.wk1, *.csv)';...

'*.*', 'All Files $\left.(* *)^{*}\right\}, \ldots$

'Save as');

if isequal(filename,0) $\mid$ isequal(pathname,0)

else

$\mathrm{f}=$ '.';

$\mathrm{g}=$ 'xls';

string $=$ strcat(filename, $\mathrm{f}, \mathrm{g})$;

wk1write(string,records_plots);\%Save records into root directory

set(gcf, 'PaperOrientation', 'landscape');\%Set landscape orientation

Print(gcf,'-djpeg',filename); \% Print Figure with results table

end

end 
$\%$--- Executes on button press in print.

function print_Callback(hObject, eventdata, handles)

$\%$ hObject handle to print (see GCBO)

$\%$ eventdata reserved - to be defined in a future version of MATLAB

$\%$ handles structure with handles and user data (see GUIDATA)

\%global handle1 handle2 handle3 handle4

set(gcf, 'PaperOrientation', 'landscape');\%Set landscape orientation

Print(gcf); \% Print Figure 


\section{Appendix B: Cold-Air-Injection-Model Calculations}

\section{$\underline{\text { Calculations }}$}

The main specification of the CFR engine used on this experiment is shown in Table A1.1. A detailed description of the CFR engine and its main components will be described in the experimental set-up section of this paper.

Table A1.1 WVU CFR engine specifications

\begin{tabular}{|c|c|c|}
\hline SPECIFICÁTION & ENGLISH & INTERNÁ TIONÁ L \\
\hline Tipe & CFR single culinder, bur stroke & CFR single culinder, fur stroke \\
\hline Bore & $3.250^{\circ \prime}$ & $82.55 \mathrm{~mm}$ \\
\hline Stroke & $45^{\prime \prime}$ & $1142 \mathrm{~mm}$ \\
\hline Displacement & 37.33 cubic inches & $612.5 \mathrm{~cm} 3$ \\
\hline Engine Speed & 900 & 900 \\
\hline Compression & Variable & Variable \\
\hline Patio & $4: 1$ to $18: 1$ & $4: 1$ to $18: 1$ \\
\hline
\end{tabular}

The displacement volume at sea level of the WVU CFR single cylinder engine can be obtained from equation (6.1) and using the data from Table A.1 as follows

$$
V d=\frac{\pi^{*} b^{2} * s}{4}=\frac{\pi^{*}\left(8.255^{2} \mathrm{~cm}^{2}\right) * 11.42 \mathrm{~cm}}{4}=612.5 \mathrm{cc}
$$

Thus at sea level the maximum amount of air-fuel mixture entering is limited to $612.5 \mathrm{cc}$ sea-level conditions ( $\rho$ air $=1.225 \mathrm{~kg} / \mathrm{m}^{3}$ ).

The WVU CFR engine runs at 900 RPM with a volumetric air flow rate of 7 SCFM, thus using $\mathrm{n}=2$ (a four-stroke engine takes 2 revolutions per cycle) the actual displacement volume can be calculated with equation (6.2)

$$
V_{\text {dact }}=\frac{\dot{V}}{\frac{N}{n}}=\frac{7 \mathrm{ft}^{3}}{\frac{900}{2}}=0.015 \mathrm{ft}^{3}=439 c c
$$

The associated volumetric efficiency, $\left(\eta_{v o l}\right)$, is given by equation (6.3)

$$
\eta_{v o l}=V_{d a c t} / V_{d} 439 c c / 612.5 c c=71.6 \%
$$


Based on the previous calculations, it was determined that the design of the "air injection" equipment to limit the amount of hot, high-pressure air injection to $439 \mathrm{cc}$ of standard air. A compression ratio limit $\mathrm{C} . \mathrm{R}=8$ was selected to be below the design limit of the CFR Engine (C.R=16). When $439 \mathrm{cc}$ of air is injected, all the pressure inside the cylinder is doubled like running with a compression ratio of $2 \times 6=16$.

The heater volume, $V_{\text {heater, }}$ can be obtained from equation (6.5) for a maximum released pressure of $700 \mathrm{psig}$, a minimum temperature of 900 degree $\mathrm{F}$, and a cut-off pressure of 200 psig. Pref $=14.7 \mathrm{psi}$ and Tre $f=519$ degree $\mathrm{R}$ at sea level

$$
V_{\text {heater }}=\frac{p_{\text {ref }} * V d_{\text {act }} * T_{\max }}{\left[p_{\max }-p_{\text {cutoff }}\right] * T_{\text {ref }}} \frac{14.7 p s i a * 439 c c *(900+460) R}{[(700+14.7)-(200+14.7)] p s i a *(519 R)}=33.82 c c
$$

The mass injected, $m_{i}$, at sea level is

$$
m_{i}=\frac{p_{\text {ref }} * V_{\text {dact }}}{R^{*} T_{\text {ref }}}
$$

In SI units

$$
m_{i}=\frac{101325 P a * 0.000439 m^{3}}{(287 \mathrm{~J} / \mathrm{kg} * \mathrm{~K}) * 288 \mathrm{~K}}=0.00053 \mathrm{~kg}
$$

The volume of hot pressure air injected into the cylinder at sea level conditions, $V_{i}$, can be calculated from equation (6.6).

$$
V_{i}=\frac{m_{i} * R^{*} T_{\text {ref }}}{p_{\text {ref }}}
$$

In SI units

$$
V_{i}=\frac{0.00053 \mathrm{~kg} *(287 \mathrm{~J} / \mathrm{kg} * \mathrm{~K}) * 288 \mathrm{~K} * 100^{3}}{101325 \mathrm{~Pa}}=432.3 \mathrm{cc}
$$


The temperature, $T_{2}$, and pressure, $p_{2}$, in the cylinder at TDC before air injection are calculated using equations (6.7) and (6.8) respectively,

where:

$$
\begin{aligned}
& \text { C.R }=8 \\
& \mathrm{k}=1.4 \\
& \mathrm{p}_{1}=14.7 \mathrm{psi} \\
& \mathrm{T}_{1}=298 \mathrm{~K} .
\end{aligned}
$$

Thus, $p_{2}$ is given by

$$
p_{2}=p_{1} * r^{k}=14.7 \mathrm{psi} * 8^{1.4}=270 \mathrm{psi}
$$

and $\mathrm{T}_{2}$ by

$$
T_{2}=T_{1} * r^{(k-1)}=298 \mathrm{~K}^{*} 8^{(1.4-1)}=685 \mathrm{~K}
$$

The final temperature, $\mathrm{T}$, in the cylinder after injection can be obtained by interpolation using the specific internal energy value, $u(T)$, calculated from equation (6.16)

$$
u(T)=\frac{m_{C} * u\left(T_{c}\right)+m_{i} * h\left(T_{i}\right)}{m_{c}+m_{i}}
$$

where:

$$
\begin{aligned}
& m_{c}=m_{i}=0.00053 \mathrm{~kg} \\
& T_{c}=T_{2}=685 \mathrm{~K} \\
& T i=T_{\text {max }}=756 \mathrm{~K}(900 \text { degree } \mathrm{F}) .
\end{aligned}
$$

The specific internal energy, $u\left(T_{c}\right)$, is obtained by interpolation as shown in Table A1.2

Table A1.2 Interpolation values for $\mathbf{u}(\mathrm{Tc})$

\begin{tabular}{|c|c|}
\hline $\mathrm{T}(\mathrm{K})$ & $\mathrm{u}(\mathrm{kJ} / \mathrm{kg})$ \\
\hline 680 & 496.62 \\
\hline 685 & $\mathrm{X}$ \\
\hline 690 & 504.45 \\
\hline
\end{tabular}

$$
u\left(T_{c}\right)=500.54 \mathrm{~kJ} / \mathrm{kg}
$$


The specific enthalpy, $h(T i)$, is obtained by interpolation as shown in Table A1.3

Table A1.3 Interpolation values for $h(\mathrm{Ti})$

\begin{tabular}{|c|c|}
\hline $\mathrm{T}(\mathrm{K})$ & $\mathrm{h}(\mathrm{kJ} / \mathrm{kg})$ \\
\hline 750 & 767.29 \\
\hline 756 & $\mathrm{X}$ \\
\hline 760 & 778.18 \\
\hline
\end{tabular}

$$
h\left(T_{i}\right)=773.82 \mathrm{~kJ} / \mathrm{kg}
$$

Replacing the values of $u\left(T_{c}\right)$, and $h\left(T_{i}\right)$ into equations (6.16) and solving for $u(T)$

$$
u(T)=\frac{0.00053 \mathrm{~kg} *(500.54+773.82) u\left(T_{c}\right) \mathrm{kJ} / \mathrm{kg}}{2 * 0.00053 \mathrm{~kg}}
$$

Thus $u(T)=637.18 \mathrm{~kJ} / \mathrm{kg}$.

By interpolation, using the specific internal energy value, $u(T)$, the final temperature after the air injection is obtained as shown in Table A1.4

Table A1.4 Interpolation values for $\mathbf{u}(\mathrm{T})$

\begin{tabular}{|c|c|}
\hline $\mathrm{T}(\mathrm{K})$ & $\mathrm{u}(\mathrm{kJ} / \mathrm{kg})$ \\
\hline 840 & 624.95 \\
\hline $\mathrm{X}$ & 637.18 \\
\hline 860 & 641.4 \\
\hline
\end{tabular}

$$
T=854.86 \mathrm{~K}
$$

The final temperature is calculated using 6.19 and the final temperature, $\mathrm{T}$, calculated above and is given by

$$
p=p c * \frac{T}{T_{c}} *\left(\frac{m c+m i}{m c}\right)
$$

where:

$$
\begin{aligned}
& p_{\mathrm{c}}=p_{2} \\
& m_{c}=m_{i}
\end{aligned}
$$

$$
p=270 p s i * \frac{854.86 K}{685 K} * 2 .
$$


Thus, the final pressure, $p$, after the air injection is $674 \mathrm{psi}$.

The summary of the results is presented in Table A1.5.

Table A1.5 Summary of air-injection calculations

\begin{tabular}{|l|c|l|c|}
\hline & Air Heater & \multicolumn{1}{|c|}{$\begin{array}{c}\text { Cylinder Before Air } \\
\text { Injection }\end{array}$} & $\begin{array}{c}\text { Cylinder After Air } \\
\text { Injection }\end{array}$ \\
\hline Temperature & $756 \mathrm{~K}(900 \mathrm{~F})$ & $685 \mathrm{~K}(773 \mathrm{~F})$ & $855 \mathrm{~K}(1079 \mathrm{~F})$ \\
\hline Pressure & $714.7 \mathrm{psia}$ & \multicolumn{3}{|l|}{$270 \mathrm{psia}$} & $674 \mathrm{psia}$ \\
\hline Volume Heater & $33.82 \mathrm{cc}$ & $\begin{array}{l}\text { Volume Displacement } \\
\text { at Sea Level }\end{array}$ & $612.5 \mathrm{cc}$ \\
\hline $\begin{array}{l}\text { Mass Injected at } \\
\text { Sea Level }\end{array}$ & $0.00053 \mathrm{~kg}$ & $\begin{array}{l}\text { Volume Displacement } \\
\text { (actual) }\end{array}$ & $439 \mathrm{cc}$ \\
\hline Compression Ratio & 8 & Volumetric Efficiency & $71.60 \%$ \\
\hline
\end{tabular}

The value obtained for the final temperature, $T$, after the air injection is well above the auto-ignition temperature of natural, gasoline, and diesel fuels as illustrated in Table A1.6.

Table A1.6 Fuels properties

\begin{tabular}{|l|c|c|c|}
\hline Property & Natural Gas & Gasoline & Diesel \\
\hline Flammability Limits (volume \% in air) & $5.0-15$ & $1.4-7.6$ & $0.6-5.5$ \\
\hline Autoignition Temperature $\left({ }^{\circ} \mathrm{F}\right)$ & 842 & 572 & 446 \\
\hline Minimum Ignition Energy in Air (10-6 BTU) & 0.27 & 0.23 & 0.23 \\
\hline Peak Flame Temperature $\left({ }^{\circ} \mathrm{F}\right)$ & 3423 & 3591 & 3729 \\
\hline
\end{tabular}

*Numbers in parentheses refer to References. Source: Properties of Alternative Fuels (Murphy, 1994) 


\section{Appendix C: Compressed Air Batch Analysis}

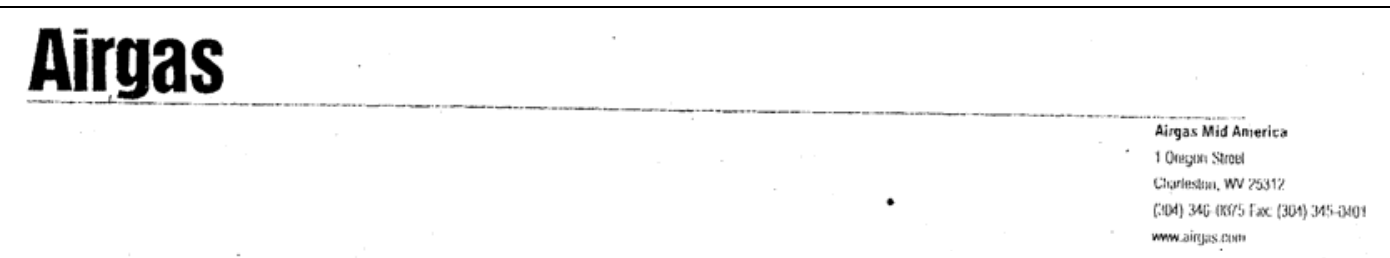

Certificate of Batch Analysis

Compressed Air, Breathing, Type 1, Grade D

Cylinder

LOT NUMBER

EU 00 S $298 \quad$ BA

Cubic Feet 311

Lot Nui Exp Date 10/25/2010

Test

Serial Number of Cylinder Tested 7602975

Oxygen Contents

Specifications

$19.5-23.5 \%$

Moisture Contents (dew point --50 F)

Max. 63 PPM

Lot Analysis

Condensed Hydrocarbon Contents

Max. $5 \mathrm{mg} / \mathrm{m} 3$

Carbon Monoxide Content

Max. 10 PPM

$20,9 \%$

$4 \mathrm{plm}$

Odor

Carbon Dioxide Content

no appreciable odor

Max. 1000 PPM

$$
\because 6 A
$$

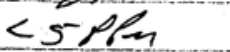

Carbon Dipide c

Tested per specifications of Type 1 , Grade D according to CGA G $-7.1-1989$

Suppliers Signature

Date $10-25-05$

$10-21-03$ 


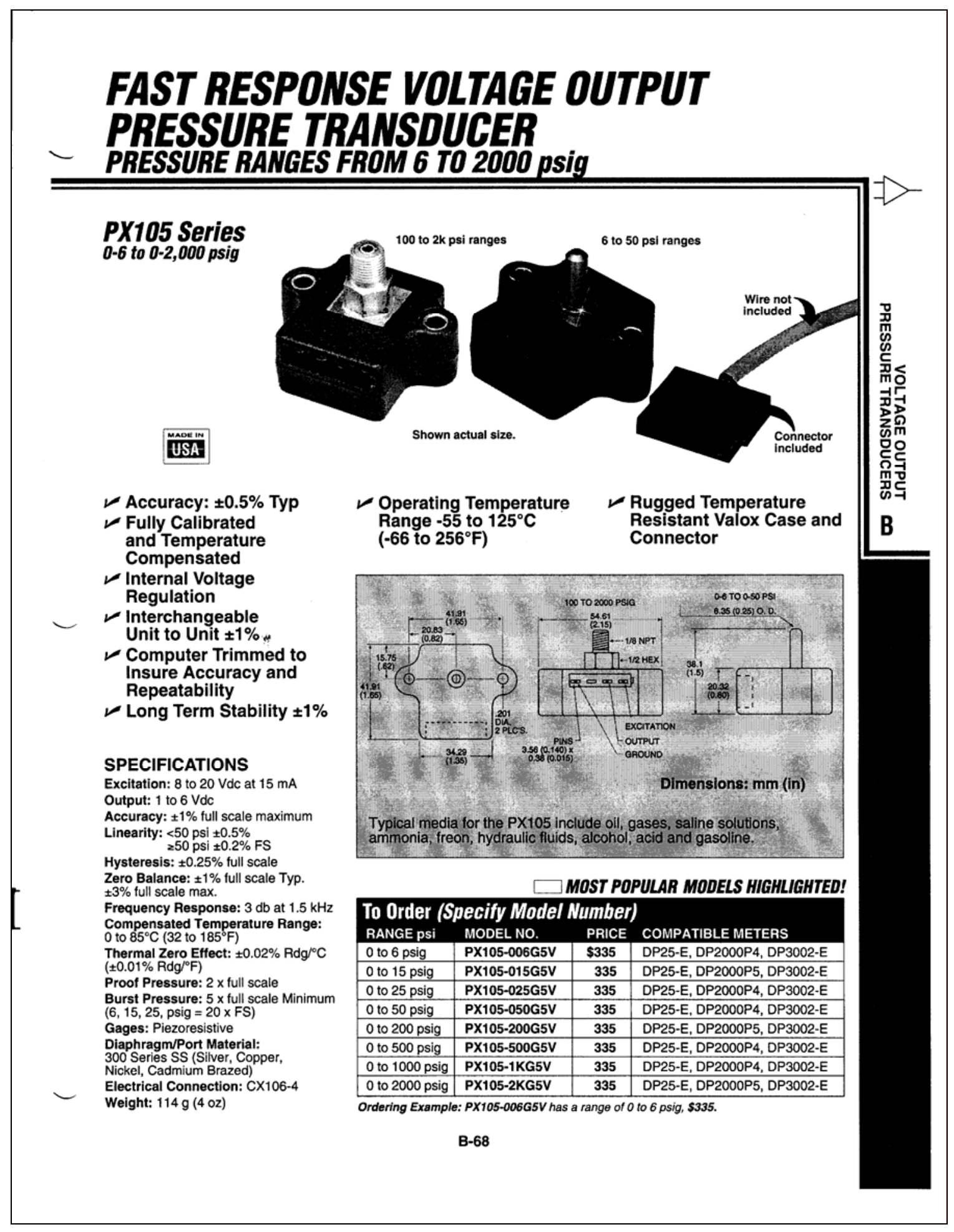




\section{Appendix E: Solenoid Valve Datasheet}

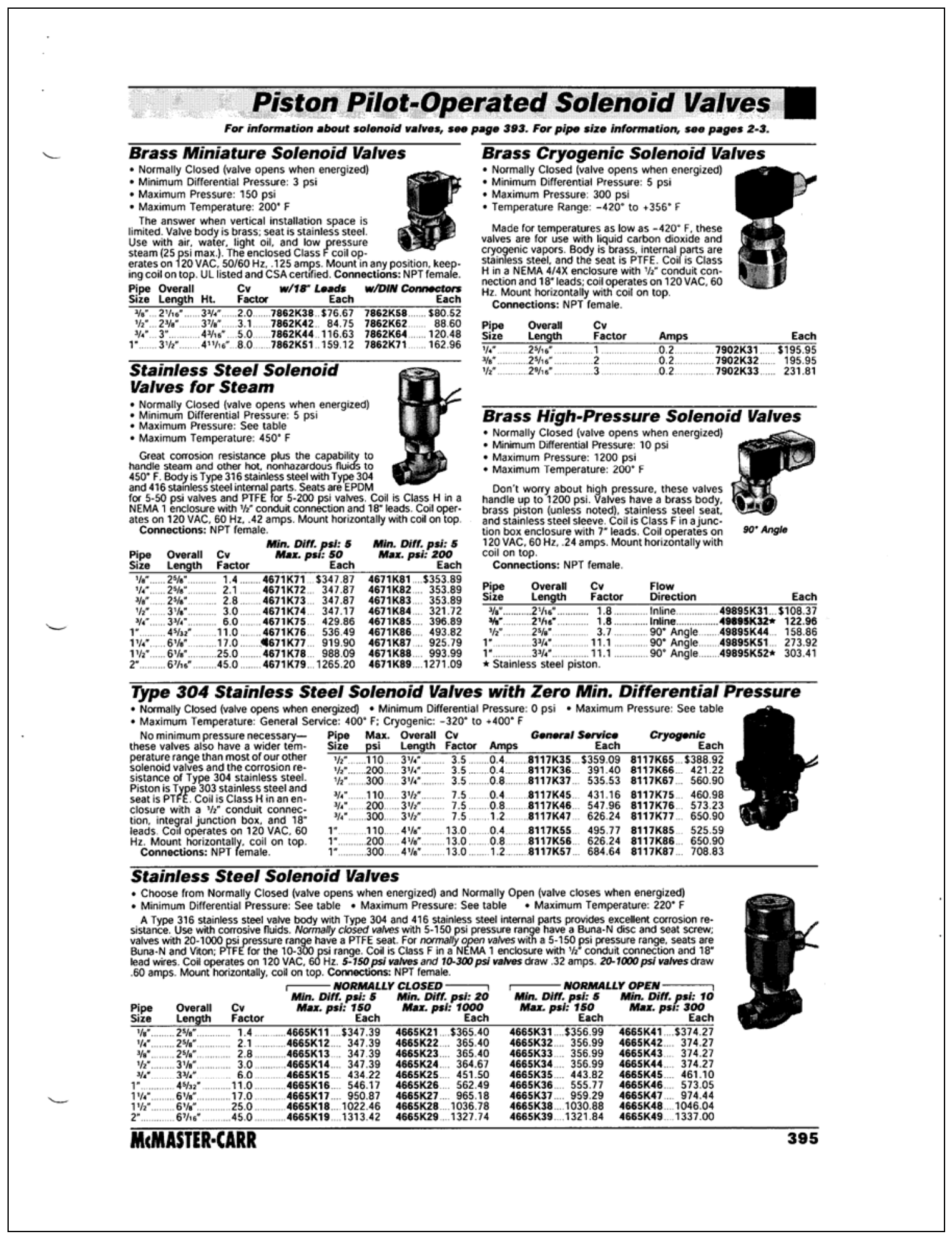




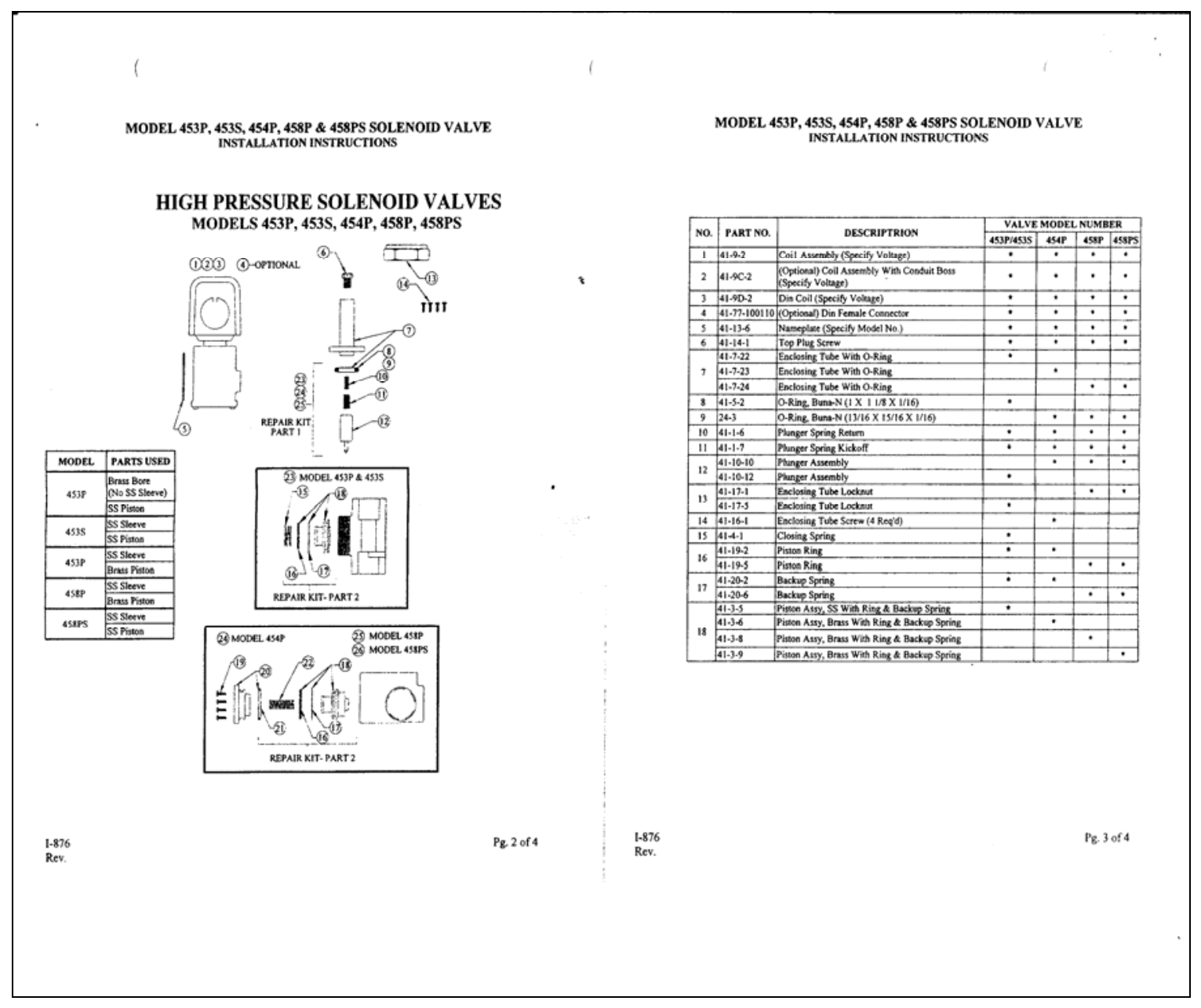




\section{Appendix F: Double Acting Tie-Rod Hydraulic Cylinder Datasheet}

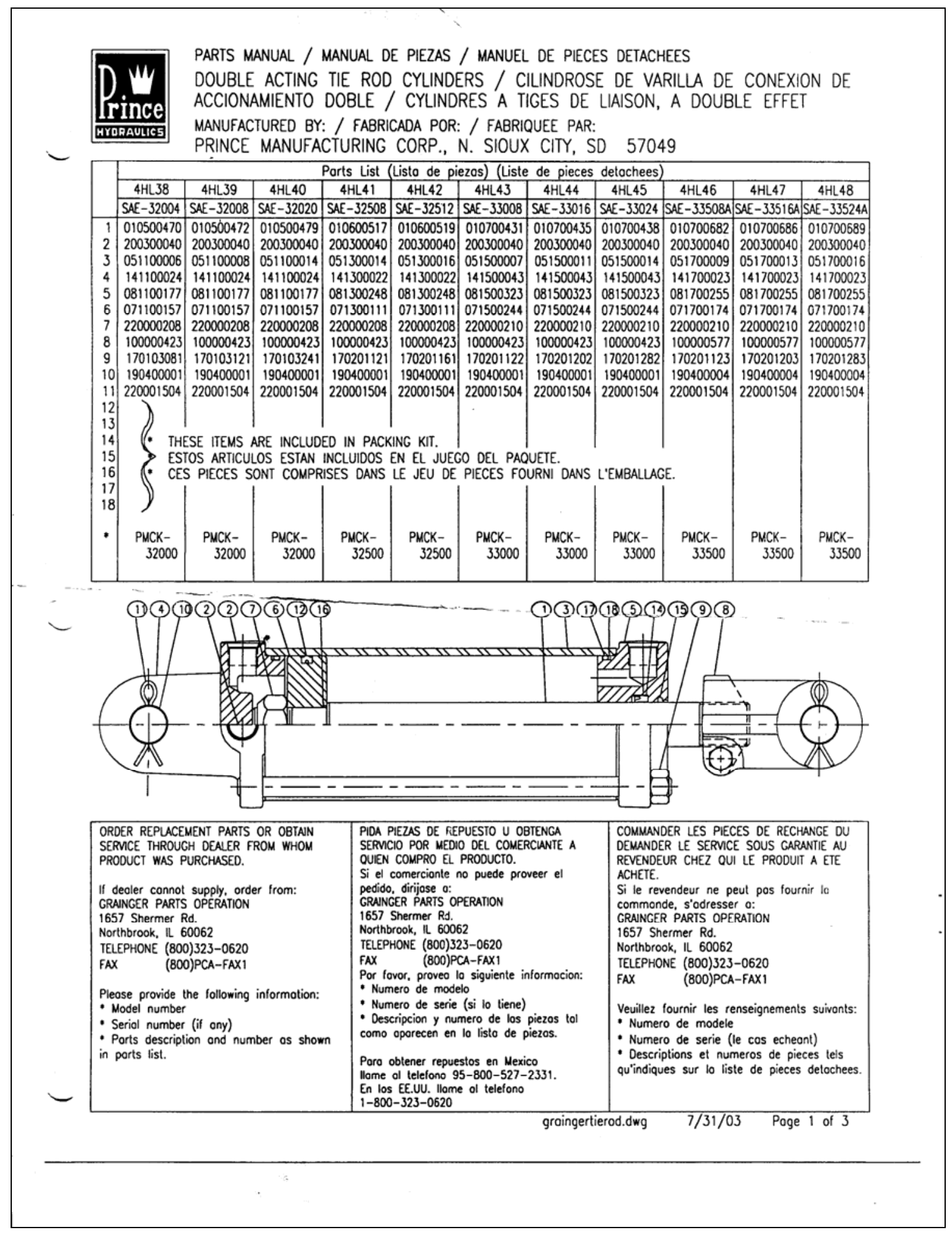




\section{Appendix G: First Air Injector Design Drawing}

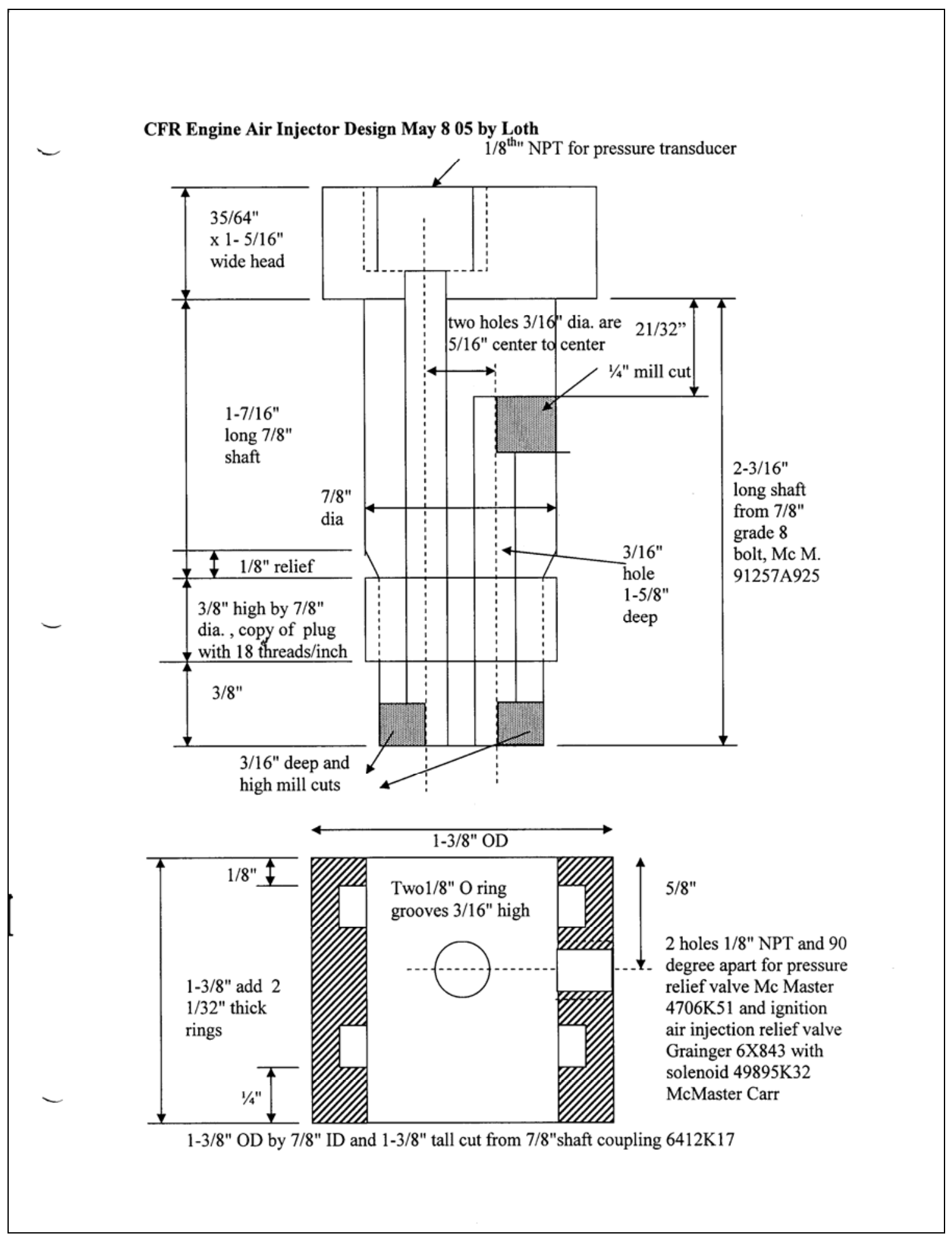


Appendix H: Spark Plug Adapter Drawing

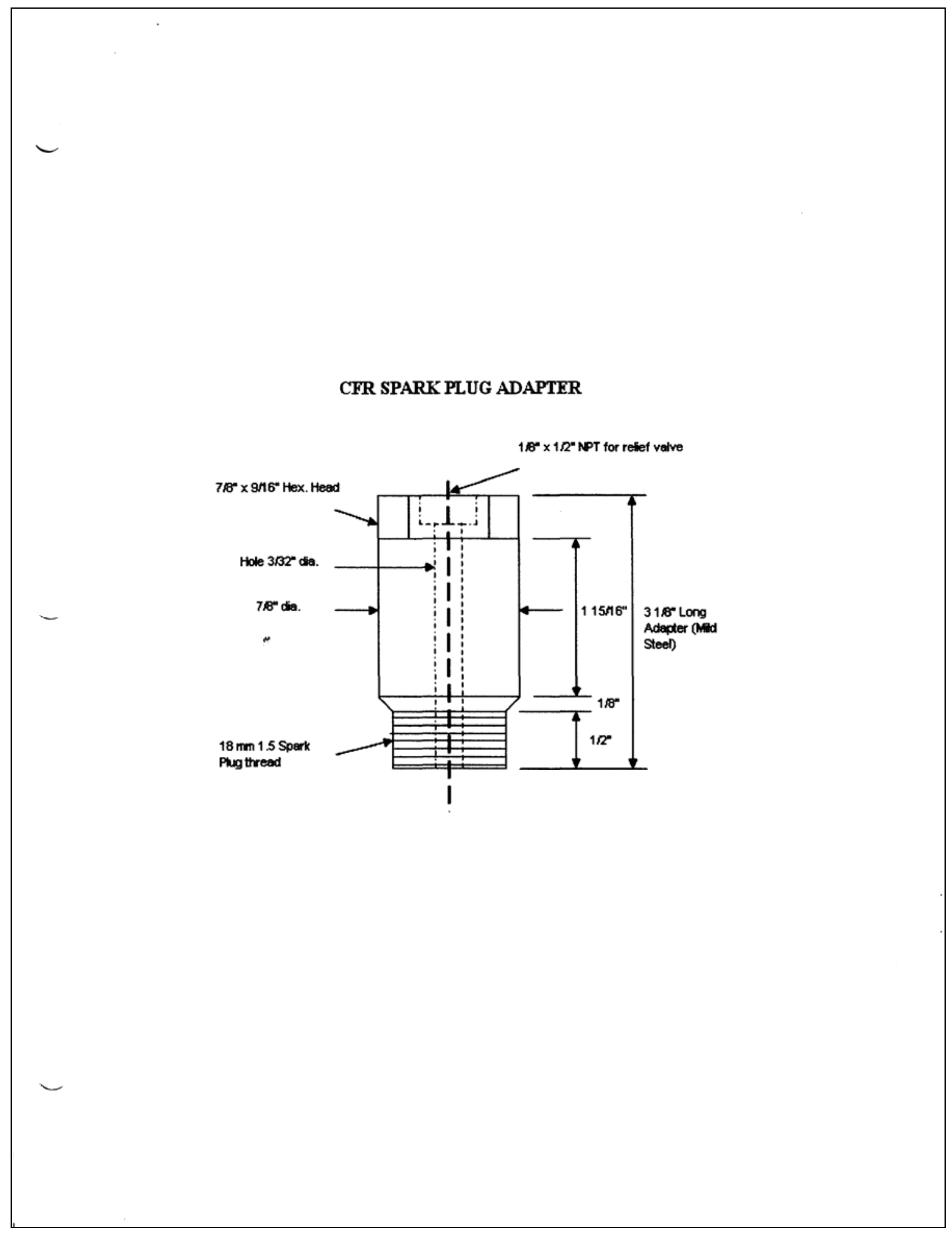




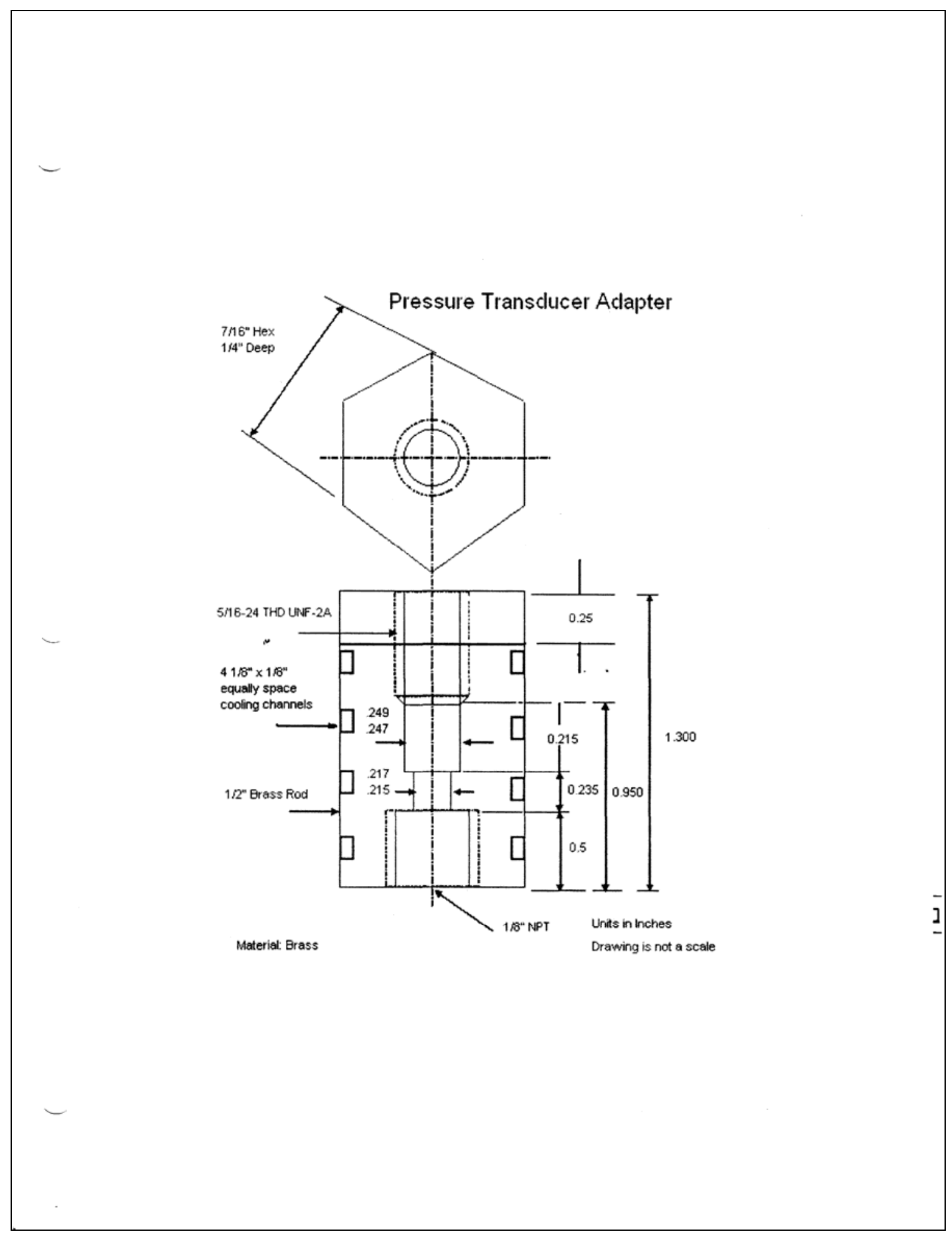




\section{Appendix J: Three (3) Way Ball Valve Datasheet}

\section{Type 316 Stainless Steel Ball Valves}

For information about ball valves, see page 350. For information about pipe size, see pages 2-3.

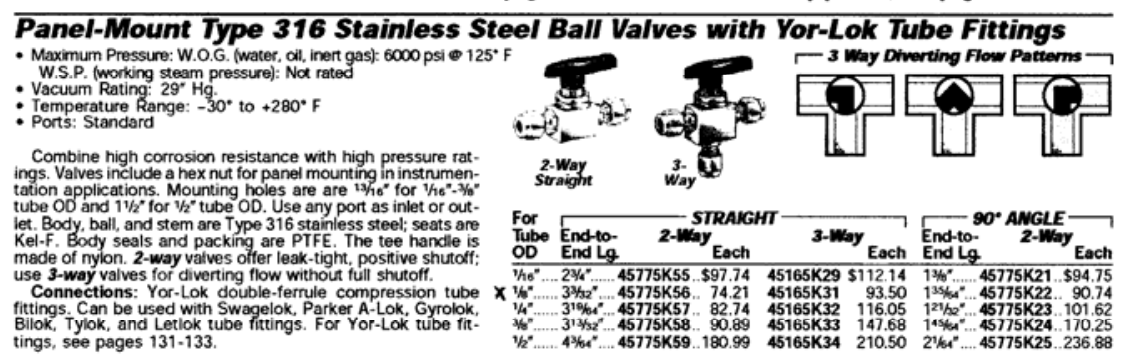

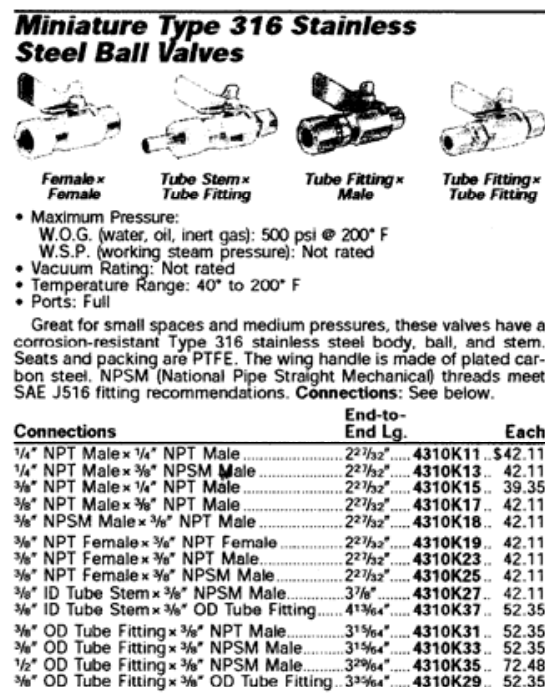

High-Pressure Miniature Type 316 Stainless Steel Ball Valves

$=-a_{\text {Malo }}^{\text {Malex }}$

- Maximum Pressure: W.O.G. (water, oil, inert gas): $1000 \mathrm{psi}$ ๑ $150^{\circ} \mathrm{F}$

- W.S.P. (Working steam pressure): 150 psi o $368^{\circ} \mathrm{F}$

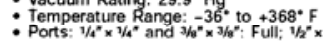

Ideal for limited space and high pressure applications. Etrther pon can be used as inlet or outlet. Body, ball, and stem are Type 316 stain

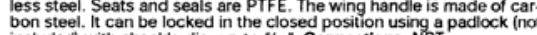
bon steel. Ii can be locked in the closed position using a padlock (nod
included) with shackle dia. up to $\% 6^{6}$. Connections: NPT. Pipe End-to-
Stzo End Le
End Each Pipe End-to-

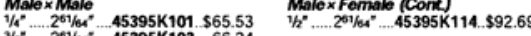

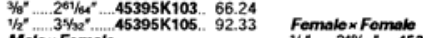

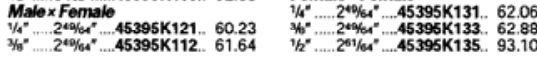
MCMASTER-CARR
Type 316 Stainless Steel Ball Valves with Yor-Lok or BSPP Connections

- Maximum Pressure:
W. 0.6 . (water, oil, inert gas):

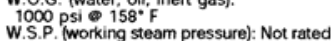
Vacuum Rating: No rated - Ports: Standara

Body, ball, and blowoun-proof stem are Type 316 stainless steel. Seat and packing are glass.
filled PTFE. Lever handles are made of Type 302 tainless steel with a vinyl grip. pression tube fittings or BSPP (British Standard Pipe Parallel) threaded fittings.

These varves with Yor-Lok Tubo Fintingstions. Can be used with Yor.lok swagelox Parker-A-Lok, Gyrolok, Bilok, and Letiok tube
fititings. For Yormale Ihroasded

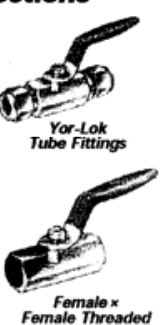
Ball Valves wheh BSPP Thres.
BSPP connection is required

For

End-to-
End Lg. Yor-Lok Tube Fittings<smiles>[W]#[W]</smiles>
$3 / 2$
$1 \%$

$\begin{array}{ll}\text { Pipe } & \text { Endto- } \\ \text { Sndize } & \end{array}$

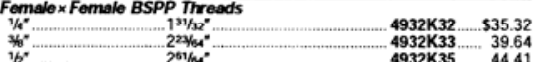
Matex Fomale BSPP Troods

\section{Type 316 Stainless Steel Ball Valves} with Ratchet-Hole Handle

- Maximum Pressure; W.O.G. (water, all, inert gas) W.S.P. (working steam pressure): 140 psi $160^{\circ}$ : Vacuum Rating: $29^{\circ} \mathrm{Hg} \cdot$ to $+392^{*} \mathrm{~F}$ - Ports: Full

A hole in the handle of these valves accommodates a $3 \sigma^{*}$ square and sterm are Type 316 stainless steel. Seats and vacking are PTFE. The lever is Type 304 stainless steel and is lockable using a padlock Connactions: NPT forp to

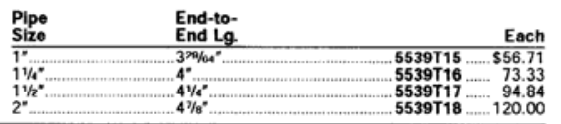

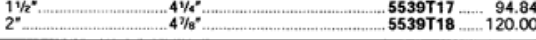
357 


\section{Appendix K: Air Pressure Relief Valve Datasheet}

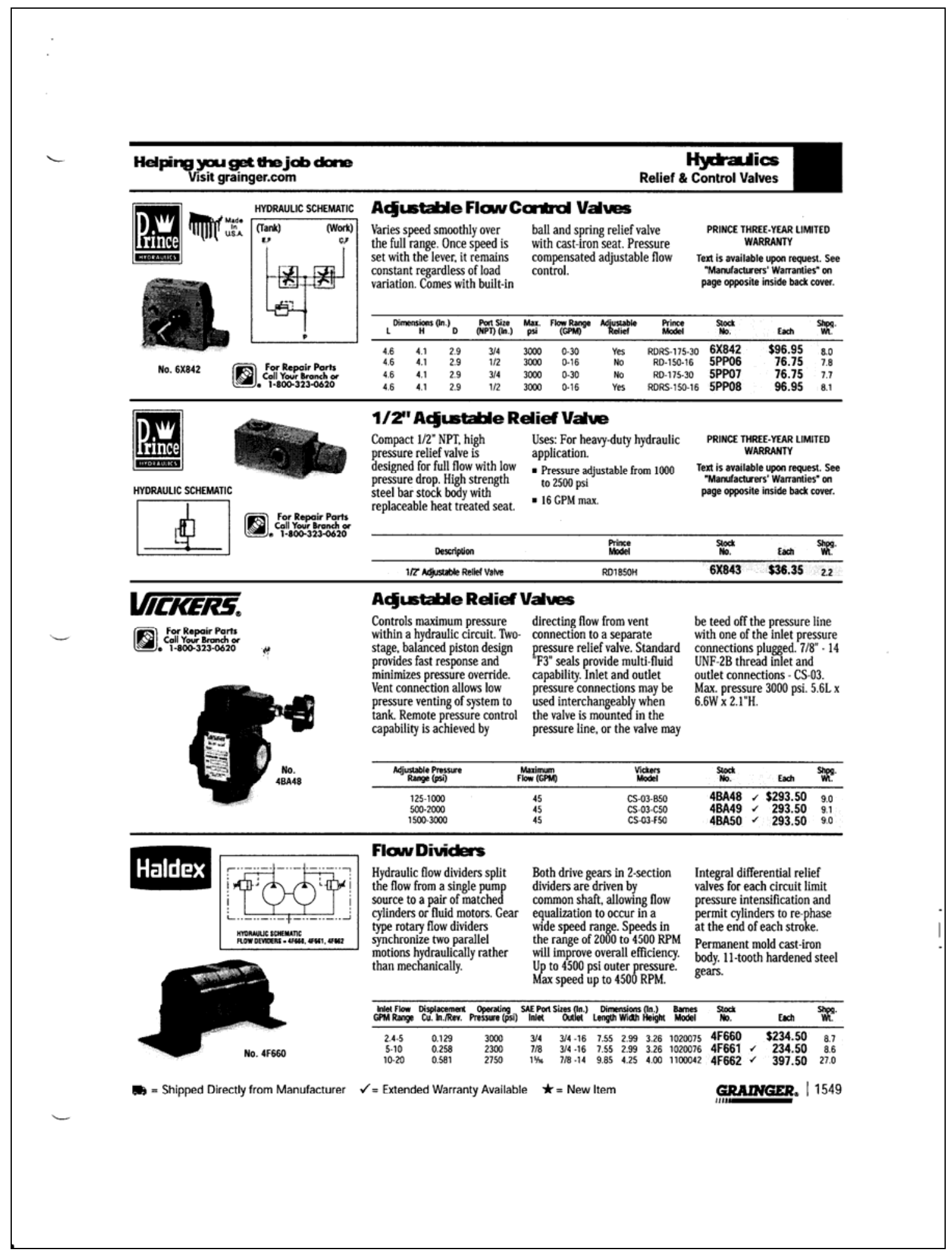


RD-1850-H/6X843

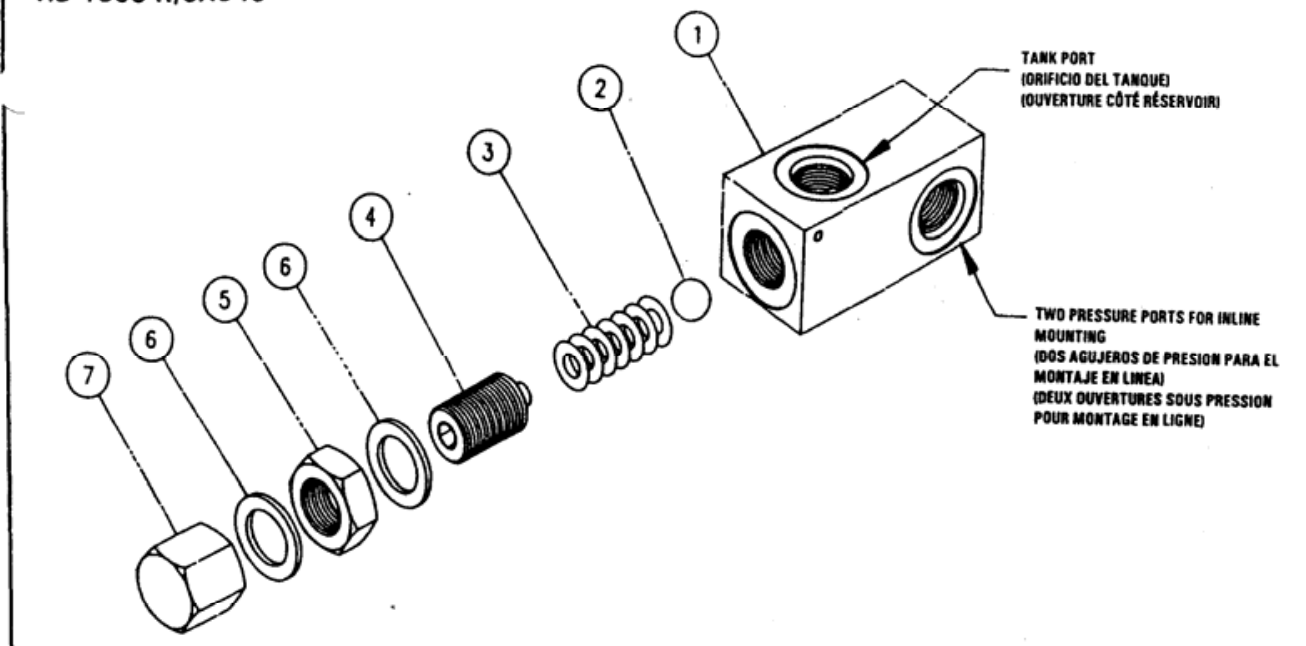

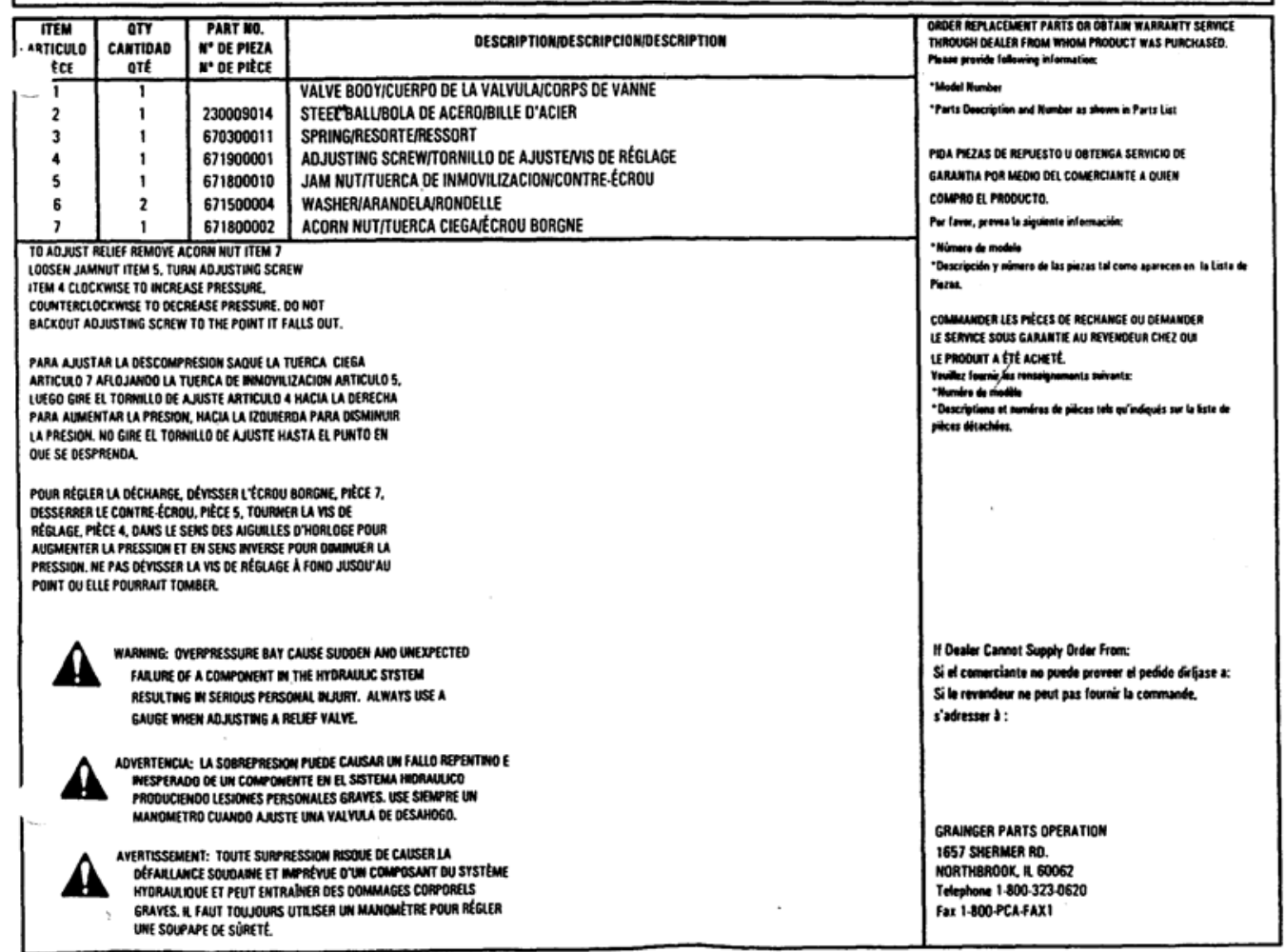




\section{Appendix L: Dytran Piezoelectric Pressure Transducer Datasheet}

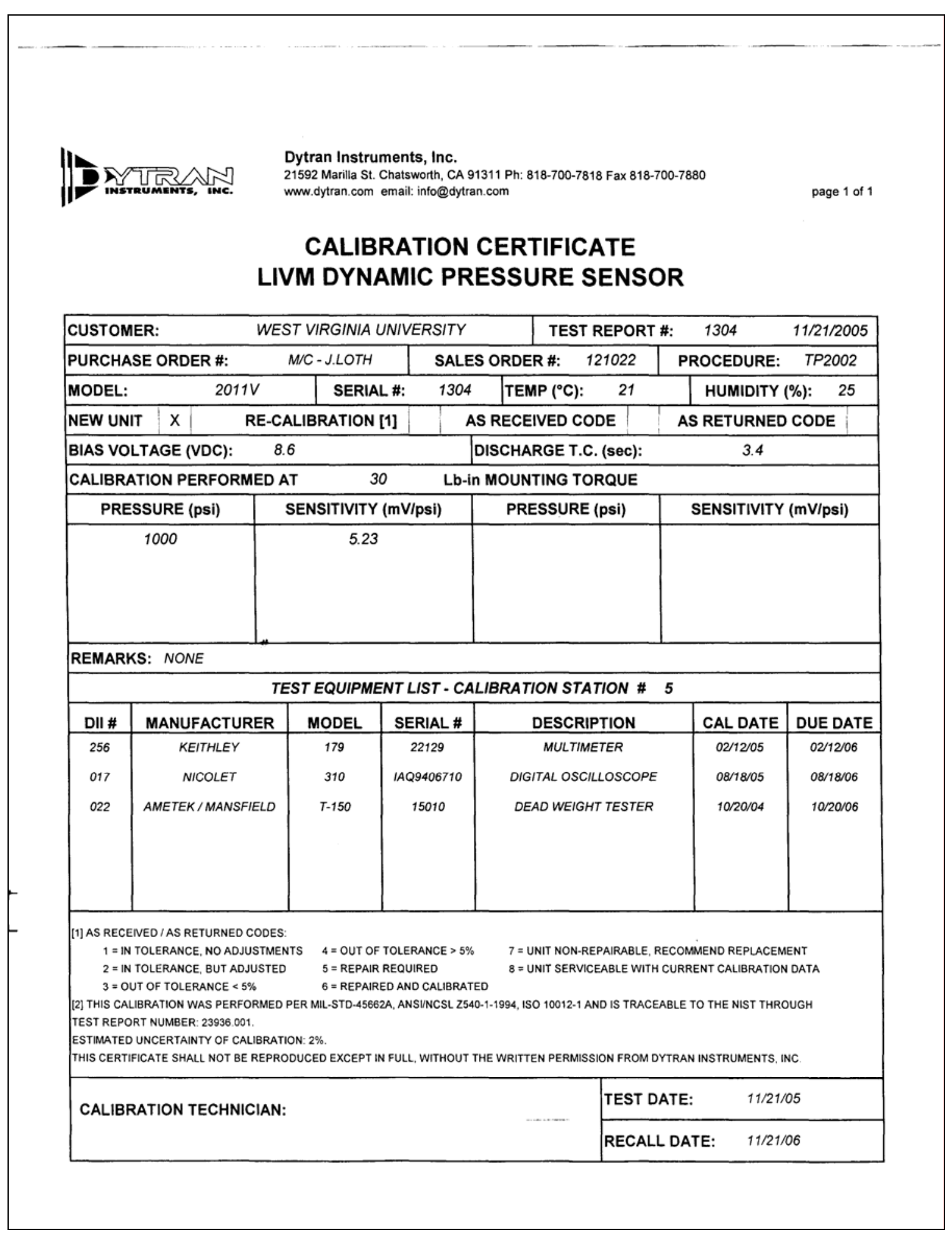


SPECIFICATIONS MODELS 2011V \& 2011V1

DYNAMIC PRESSURE SENSOR

SPECIFICATION

VALUE

UNITS

PHYSICAL (BOTH MODELS)

WEIGHT

SIZE (HEX X HEIGHT)

CONNECTOR AXIALYMOUNTED AT TOP

BODY/CONNECTOR MATERIAL

DIAPHRAGM MATERIAL

\section{PERFORMANCE}

MODEL

SENSITIVITY, NOM

RANGE F.S. FOR + 5 VOLTS OUT

MAXIMUM PRESSURE

MOUNTED RESONANT FREQUENCY, NOM

MINIMUM RISE TIME OF INPUT PRESSURE PULSE

EQUIV. ELECTRICALNOISE FLOOR (RESOLUTION)

NON-LINEARITY (ZERO BASED BEST FIT ST.LINE) [1]

ACCELERATION SENSITNT, AXIAL DIRECTON

DISCHARGE TIMEO CONSTA

ENVIRONMENTAL (BOTH MODELS)

MAXIMUM VIBRATION

MAXIMUM SHOCK

MAXIMUM FLASH TEMMPERATURE AT DIAPHRAGM

THERMAL COEFFICIENT OF SENSITIVITY

ENVIRONMENTAL SEAL

\section{ELECTRICAL (BOTH MODELS)}

EXCITATION (COMPLIANCE) VOLTAGE RANGE

EXCITATION CURRENT RANGE [2]

OUTPUT IMPEDANCE, NOM.

OUTPUT BIAS VOLTAGE, NOM
OUTPUT SIGNAL POLARITY FOR INCREASING PRESSURE

\section{0}

3.0 GRAMS

3/8-24 UNF-2A MALE THREAD

NCHES

-2A MICRO-COAXIAL

$\begin{array}{ll}\text { STAINLESS STEEL, HARDENED } & 17.4 \mathrm{PH} \\ \text { STAINLESS STEEL, ANNEALED } & 17.4 \mathrm{PH}\end{array}$

$\begin{array}{ll}2011 \mathrm{~V} 1 & \\ 1.66 & \mathrm{mV} / \mathrm{Psi} \\ 3000 & \mathrm{Psi} \\ 5000 & \mathrm{Psi} \\ 130 & \mathrm{kHz} \\ 2 & \mu \mathrm{SEC} \\ .003 & \mathrm{PSi} \\ \pm 1 & \% \mathrm{~F} . \mathrm{S} . \\ .006 & \mathrm{PSi} / \mathrm{G} \\ 4.0 & \mathrm{HzC} \\ .04 & \mathrm{~Hz}\end{array}$

1000

3,000

$+3000$

HERMETIC

G's RMS

G,' S PEAK

${ }^{\circ} \mathrm{F}$

WELDED/GLASS TO METAL

+18 TO +30

2 TO 20

100
+10

POSITIVE GOING
VDC

Ohms

SUPPLIED ACCESSORIES

MODEL. 6606 SEAL, BRASS, 2 SUPPLIED.

NOTES:

(1) PERCENT FULL SCALE, ZERO BASED BEST FIT STRAIGHT LINE METHOD.

2) FROM CONSTANT CURRENT TYPE POWER UNIT ONLY. THESE SENSORS MUST NOT BE CONNECTED TO A

3 A CALIBRATION CERTIFICATE TRACEABLE TO NIST IS SUPPLIED WITH EACH INSTRUMENT. 


\section{Piezotron ${ }^{\mathrm{TM}}$ Coupler}

\section{Versatile Voltage Mode Piezoelectric Sensor Power Supply/Coupler}

A flexible, simple to use signal conditioner that provides excitation power, signal tailoring and acts as an interface between voltage mode piezoelectric sensors and measuring instruments.

Single channel unit powered by internal AA batteries or an AC/DC adaptor.

- Selectable gain and low pass, plug-in filters - High pass filtering, panel selectable

- Monitor the condition of the sensors and cables

- Exclusive "Rapid Zero" feature

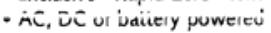

- Conforming to CE

\section{Description}

The signal conditioner provides the constant current excitation required by low impedance, voltage mode sensors with

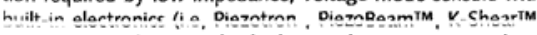
and (eramic Shear) or for high impedance sensors with an external impedance converter. Sensor power is supplied by the same two-wire cable that provides the low impedance

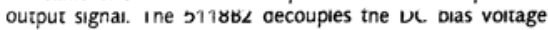
from the output signal and provides a $2 \mathrm{~mA}$ constant current source which can also be factory adjusted between 2 to 18 $\mathrm{mA}$ Rias indirators disnlav the mondition of the cenconr and cable. Amplifier gains of $1 x, 10 x$ and $100 x$ are selectable from a front panel switch. High-pass filter cutoff frequencies $(-3 d B)$ 0.006 and $0.03 \mathrm{~Hz}$ are also selectable by a switch on the front panei.

Plug-in, low pass filters are available to limit the frequency response of the amplifier. These low pass filters can be used

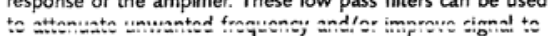
noise ratio. Bias voltage is monitored and displayed with three front panel-mounted LEDs. Bias voltage in the range of 2 to $21 \mathrm{~V}$ is normal and results in a green "OK" LED indication. Bias voltage below $2 \mathrm{~V}$ or above $21 \mathrm{~V}$ results in a red "LOW" or "HIGH" indication. A "LOW" generally indicates a short circuit in the cable or sensor while "HIGH" means an open siresuit

The coupler warns of a low battery audibly, with an intermittent chirping sound. Battery lifetime is about 12 hours at a sensor current of $2 \mathrm{~mA}$. Coupler power can be provided from three sources: four AA 1.5 volt batteries, AC-operated from a power line adaptor, or regulated DC source between 6 and 28VDC. A unique "Rapid Zero" feature, allows the coupler to

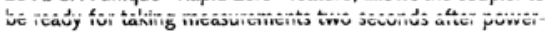
ing. When changing gain or filter settings, the $5118 \mathrm{~B} 2$ is ready to use in two seconds.
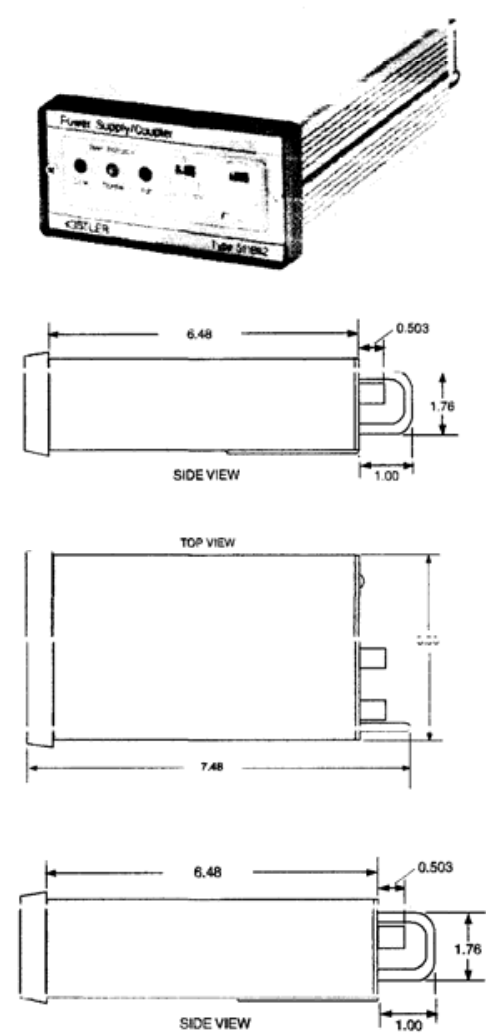

Application

The primary use for the $5118 \mathrm{~B} 2$ is to provide excitation power and signal tailoring for low impedance, voltage mode piezoelectnc pressure, torce and acceleration sensors. its small size and rugged construction provides an excellent portable measurement system both in the laboratory or in the field. 


\begin{tabular}{|c|c|c|c|}
\hline \multicolumn{4}{|l|}{ Tecininicicil Vatáa } \\
\hline \multicolumn{2}{|l|}{ INPUT: } & & \\
\hline \multicolumn{2}{|c|}{ Senser Supphy' Current } & $\mathrm{mA}$ & $2(1)$ \\
\hline \multicolumn{2}{|c|}{ Signal Voltage } & v & \pm 5 \\
\hline \multicolumn{2}{|c|}{ Gain } & & $1 x, 10 x, 100 x$ \\
\hline \multicolumn{4}{|c|}{ Bandwidth: } \\
\hline \multicolumn{4}{|c|}{ High Pass (switch selectable) } \\
\hline \multirow[t]{2}{*}{ Frequency } & $-3 \mathrm{db}$ & $\mathrm{Hz}$ & $0.03,0.006$ \\
\hline & $-5 d b$ & $\mathrm{~Hz}$ & $0.10,0.02$ \\
\hline \multicolumn{2}{|c|}{ Time Constant } & $s$ & 5,25 \\
\hline \multicolumn{4}{|c|}{ Low Pass (no filter; $1 \pm 5 \mathrm{~V}$ out) } \\
\hline \multirow[t]{2}{*}{ Gain $1 x$} & $-3 \mathrm{db}$ & $\mathrm{kHz}$ & $>100$ \\
\hline & $-5 \%$ & $\mathrm{kHz}$ & $>40$ \\
\hline \multirow[t]{2}{*}{ Gain 10x } & $-3 \mathrm{db}$ & $\mathrm{kHz}$ & $>100$ \\
\hline & $-5 \%$ & $\mathrm{kHz}$ & $>20$. \\
\hline \multirow[t]{2}{*}{ जิain iû̀ิx } & -Şü & kinc & $>30$ \\
\hline & $-5 \%$ & $\mathrm{kHz}$ & $>12$ \\
\hline \multicolumn{2}{|c|}{$\operatorname{sain} 14,10$} & $m y=$ & $=2$ \\
\hline \multicolumn{2}{|c|}{ Gain 100x } & $\mathrm{mV}$ rms & $<5$ \\
\hline \multicolumn{2}{|c|}{ Output Impedance max. } & $\Omega$ & 100 \\
\hline \multicolumn{2}{|c|}{ Voltage Swing max. } & $\mathrm{v}$ & \pm 10 \\
\hline \multicolumn{2}{|c|}{ Connectors input/output } & type & BNC neg. \\
\hline \multicolumn{2}{|c|}{ Connector power } & type & $\begin{array}{l}2.1 \times 5.5 \mathrm{~mm} \\
\text { concentric }\end{array}$ \\
\hline \multicolumn{2}{|c|}{ Internal Battery (4 each) } & type & $\begin{array}{l}1.5 \mathrm{~V} \text { AA, } \\
\text { alkaline }\end{array}$ \\
\hline \multicolumn{2}{|c|}{$\begin{array}{l}\text { Temperature Range Operating } \\
\text { (alkaline batteries) }\end{array}$} & ${ }^{\circ} \mathrm{F}$ & $-5 \ldots 125$ \\
\hline \multicolumn{2}{|c|}{ Storage (w/o batteries) } & ${ }^{\circ} \mathrm{F}$ & $-20 \ldots 140$ \\
\hline \multicolumn{2}{|c|}{ External Voltage Source ${ }^{(2)}$} & VDC & $6 \ldots 28$ \\
\hline \multicolumn{2}{|c|}{ viveight } & ii & $1 . i$ \\
\hline
\end{tabular}

$1 \mathrm{~s}=9.80665 \mathrm{~m} / \mathrm{s}, 1$ inch $=25.4 \mathrm{~mm}, 1 \mathrm{gram}=0.03527 \mathrm{or}, 1 \mathrm{bft}-\mathrm{hn}=0.1129 \mathrm{Nm}$
Nivinitinis

The $5118 \mathrm{~B} 2$ is a single unit piezoelectric sensor power supply and signal conditioner housed in a extruded aluminum case. It is primanly intended for laboratory bench top use. For permanent installations, the unit can be panel mounted using optional adapters

Ordering Information

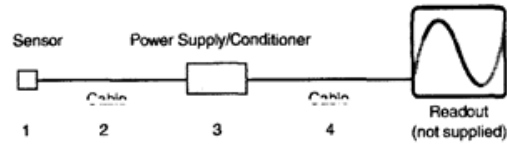

= specify cable length in meters

i- serisur iuw inapeciarice, vuilage mucie

2-1761Bsp sensor cable, 10-32 pos. to BNC pos

3-511882 power/supply coupler

4 - 1511sp outout cable. BNC pos. to BNC pos.

\section{Optional Accessorie}

5752 power adaptor, $115 \mathrm{VAC}, 60 \mathrm{~Hz}$

5757 power adaptor, $230 \mathrm{VAC}, 50 \mathrm{~Hz}, \mathrm{CE}$

certified

5236A Inw-nacs filtar put-nff frenuanry: in $\mathrm{Hz}$

$(10,20,50,100,200$, or 500 )

5327A... low-pass filter, cut-off frequency; in $\mathrm{kHz}$ $(1,2,5,10,20)$

S3L4A... nigh-pass filter, cut-oif frequency; in $\mathrm{Hz}$ $(1,10,100)$

$5702 \quad$ panel mounting kit

704-2068-001 power cable (6ft) with mating plug to pigtails 


\section{Appendix N: Data Acquisition Unit Electric Diagram}

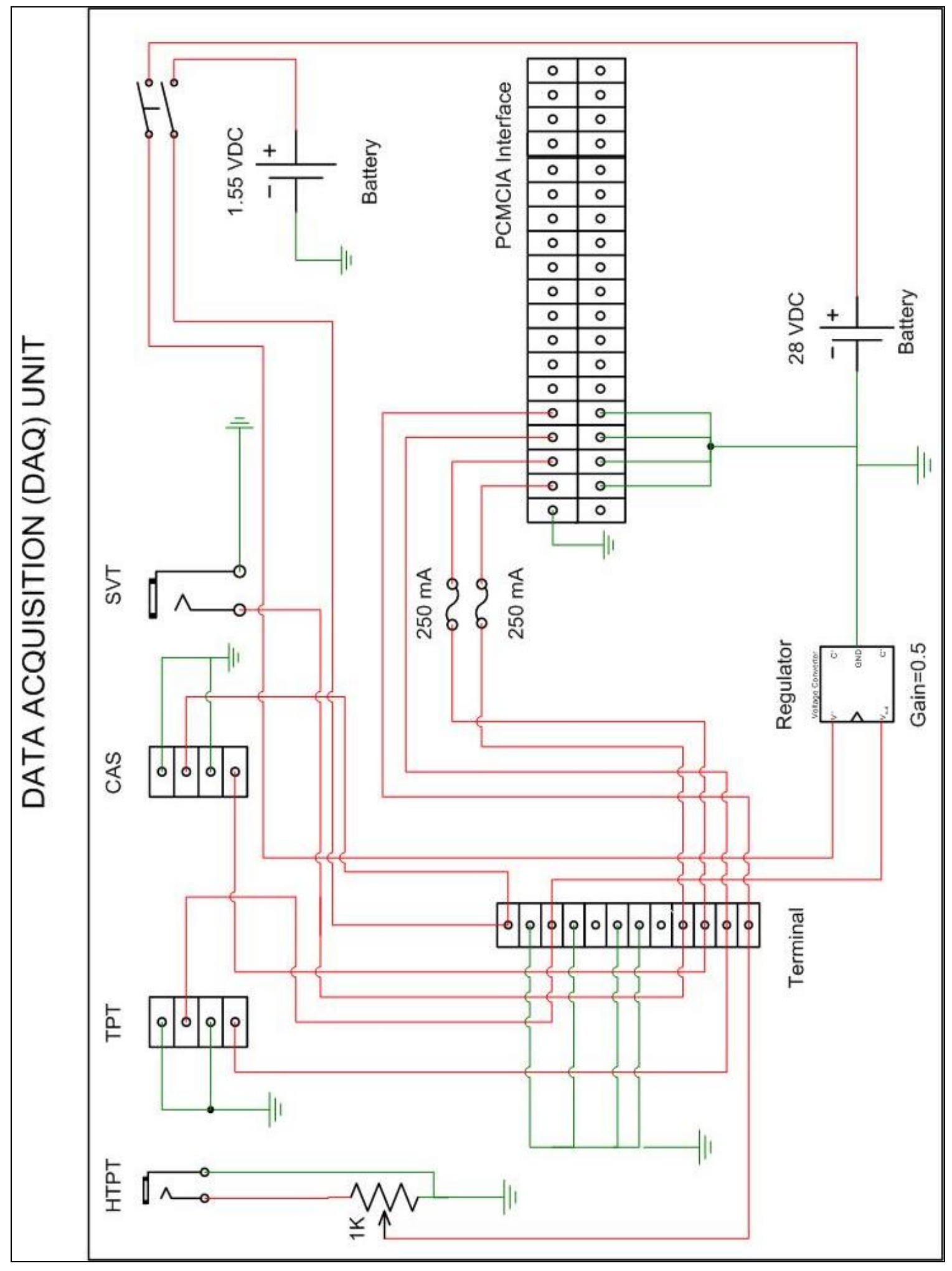




\section{Appendix O: Omega Data Acquisition Card Datasheet}

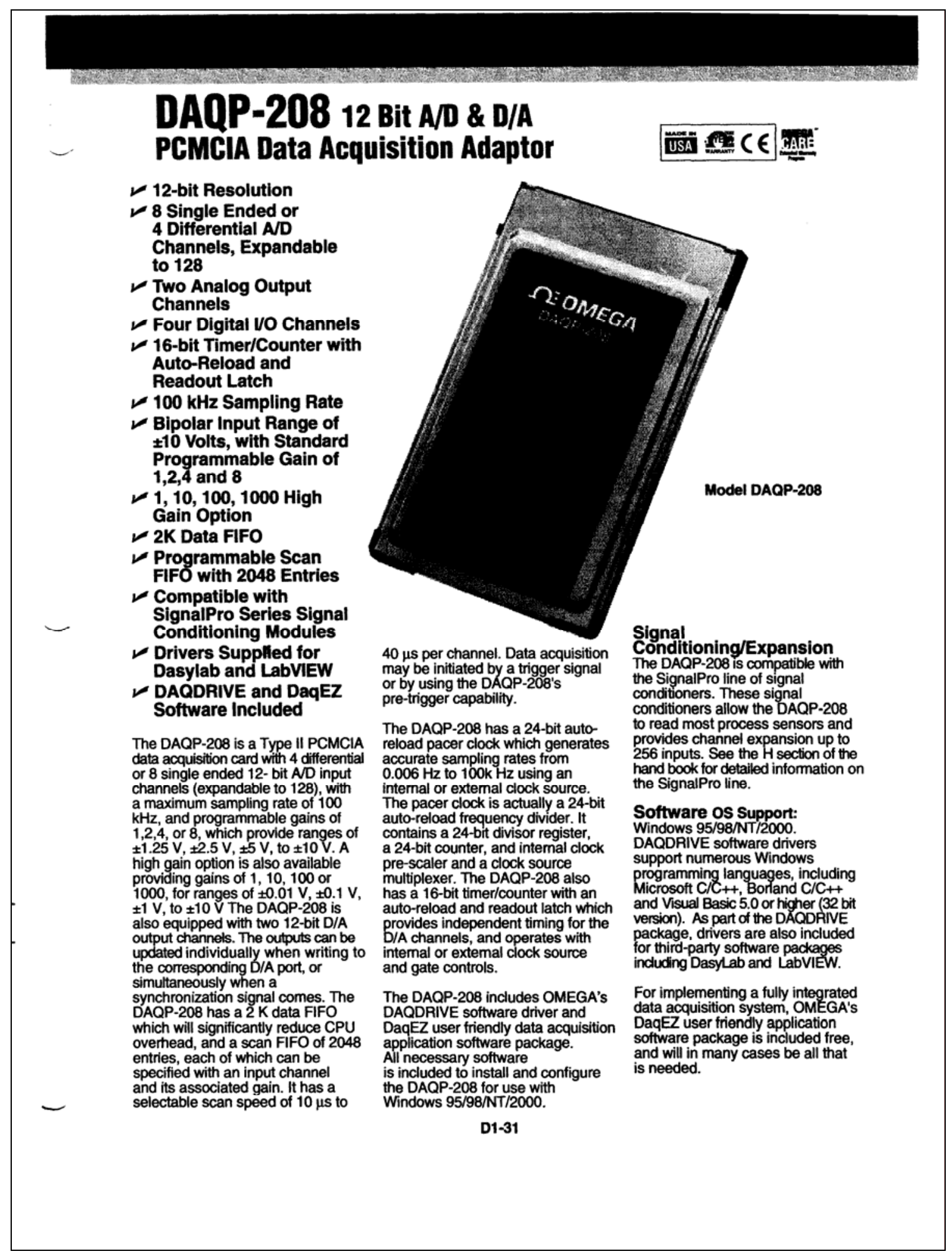




\section{Appendix P: Microchip Pic16F72 Chip Diagram}

\section{S1 \\ MicROCHIP}

\section{PIC16F72}

\section{8-Pin, 8-Bit CMOS FLASH MCU with A/D Converter}

Device Included:

- PIC16F72

High Performance RISC CPU:

- Only 35 single word instructions to learn

- All single cycle instructions except for program branches, which are two-cycle

- Operating speed: DC - $20 \mathrm{MHz}$ clock input DC - 200 ns instruction cycle

$2 \mathrm{~K} \times 14$ words of Program Memory, $128 \times 8$ bytes of Data Memory (RAM)

- Pinout compatible to PIC16C72/72A and PIC16F872

- Interrupt capability

- Eight-level deep hardware stack

- Direct, Indirect and Relative Addressing modes

Peripheral Features:

- High Sink/Source Current: 25 mA

- Timer0: 8-bit timer/counter with 8-bit prescaler

- Timer1: 16-bit timer/counter with prescaler, can be incrememted during SLEEP via external crystal/clock

- Timer2: 8-bit timer/counter with 8-bit period register, prescaler and postscaler

- Capture, Compare, PWM (CCP) module

- Capture is 16-bit, max. resolution is $12.5 \mathrm{~ns}$

- Compare is 16-bit, max. resolution is 200 ns

- PWM max. resolution is 10-bit

- 8-bit, 5-channel analog-to-digital converter

- Synchronous Serial Port (SSP) with SPI ${ }^{\mathrm{TM}}$ (Master/Slave) and $\mathrm{I}^{2} \mathrm{C}^{\mathrm{TM}}$ (Slave)

- Brown-out detection circuitry for Brown-out Reset (BOR)

\section{CMOS Technology:}

- Low power, high speed CMOS FLASH tectnnology

- Fully static design

- Wide operating voltage range: $2.0 \mathrm{~V}$ to $5.5 \mathrm{~V}$

- Industrial temperature range

- Low power consumption:

- <0.6 mA typical @ 3V, 4 MHz

- $20 \mu$ A typical @ 3V, 32 kHz

$-<1 \mu \mathrm{A}$ typical standby current
Pin Diagrams

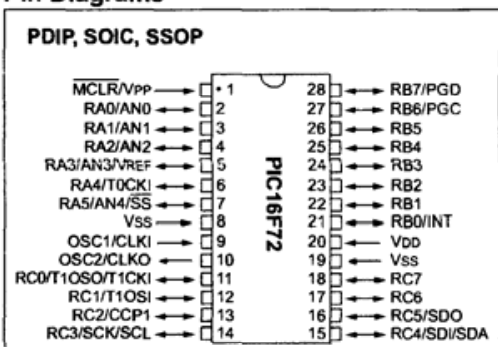

QFN

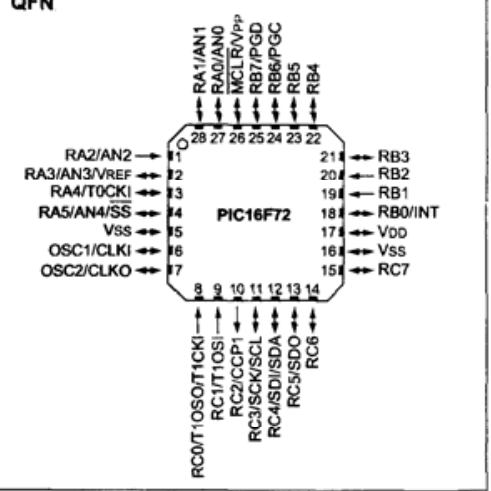

Special Microcontroller Features:

- 1,000 erase/write cycle FLASH program memory typical

- Power-on Reset (POR), Power-up Timer (PWRT) and Oscillator Start-up Timer (OST)

- Watchdog Timer (WDT) with its own on-chip

$\mathrm{RC}$ oscillator for reliable operation

- Programmable code protection

- Power saving SLEEP mode

- Selectable oscillator options

- In-Circuit Serial Programming ${ }^{\text {MM }}$ (ICSP ${ }^{\mathrm{MM}}$ ) via 2 pins

- Processor read access to program memory 


\section{Appendix Q: Microcontroller Unit Program}

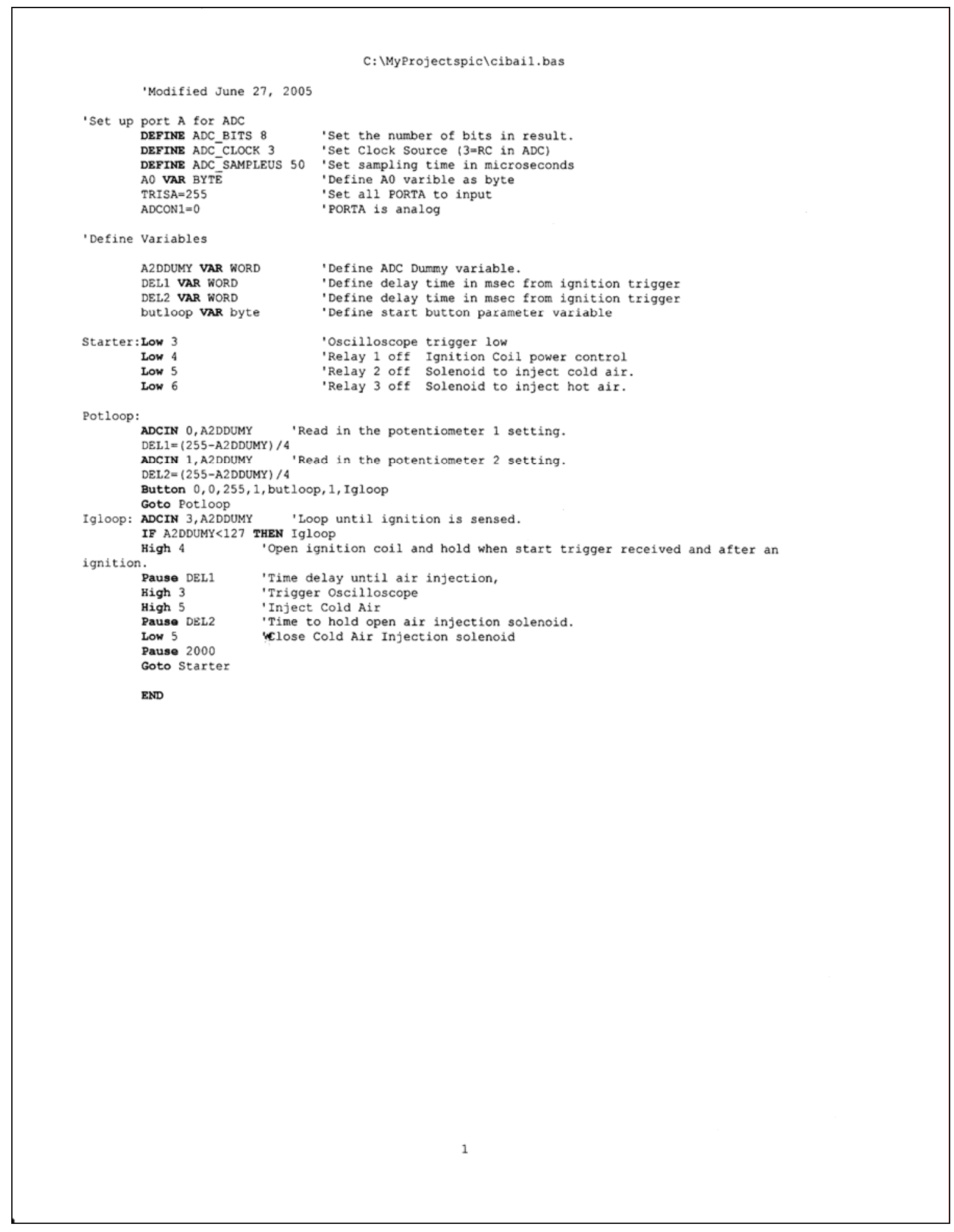




\section{Appendix R: Sample Calculations Air-Fuel and Equivalence Ratios}

\begin{tabular}{|c|c|c|c|c|c|c|}
\hline \multirow{3}{*}{ Parameters } & \multirow{2}{*}{\multicolumn{3}{|c|}{\begin{tabular}{|c|} 
Intake Temperature $=70^{\circ} \mathrm{F}$ \\
Fuel Level (F.L)
\end{tabular}}} & \multirow{2}{*}{\multicolumn{3}{|c|}{\begin{tabular}{|c|} 
Intake Temperature $=250^{\circ} \mathrm{F}$ \\
Fuel Level (F.L)
\end{tabular}}} \\
\hline & & & & & & \\
\hline & 0.5 in & 1 in & 1.5 in & 0.5 in & 1 in & 1.5 in \\
\hline Actual Pressure (in $\mathrm{Hg}$ ) & 30.46 & 30.46 & 30.46 & 30.46 & 30.46 & 30.46 \\
\hline Reference Pressure (psi) & 14.7 & 14.7 & 14.7 & 14.7 & 14.7 & 14.7 \\
\hline Actual Temperature $\left(70^{\circ} \mathrm{F}\right)$ & 70 & 70 & 70 & 70 & 70 & 70 \\
\hline Reference Temperature ( $\left.{ }^{\circ} \mathrm{F}\right)$ & 59 & 59 & 59 & 59 & 59 & 59 \\
\hline Density Gasoline at $70^{\circ} \mathrm{F}(\mathrm{Kg} / \mathrm{L})$ & 0.75 & 0.75 & 0.75 & 0.75 & 0.75 & 0.75 \\
\hline Volume Gasoline $(\mathrm{mL})$ & 50 & 50 & 50 & 50 & 50 & 50 \\
\hline Time Recorded Gasoline (sec) & 106.34 & 139.8 & 155.4 & 145.67 & 188.23 & 210.45 \\
\hline Density Air at $70 \mathrm{~F}\left(\mathrm{Kg} / \mathrm{m}^{\wedge} 3\right)$ & 1.205 & 1.205 & 1.205 & 0.88 & 0.88 & 0.88 \\
\hline Air Flow Rate (SCFM) & 7 & 7 & 7 & 7 & 7 & 7 \\
\hline Time Recorded Air (sec) & 60 & 60 & 60 & 60 & 60 & 60 \\
\hline
\end{tabular}

\section{Calculations}

\begin{tabular}{|c|c|c|c|c|c|c|}
\hline Actual Pressure (psi) & 14.97 & 14.97 & 14.97 & 14.97 & 14.97 & 14.97 \\
\hline Air Flow Rate (CFM) & 6.99 & 6.99 & 6.99 & 6.99 & 6.99 & 6.99 \\
\hline Mass of Gasoline $(\mathrm{Kg})$ & 0.0375 & 0.0375 & 0.0375 & 0.0375 & 0.0375 & 0.0375 \\
\hline Mass Flow Rate of Gasoline (Kg/hr) & 1.27 & 0.97 & 0.87 & 0.93 & 0.72 & 0.64 \\
\hline Mass of Air $(\mathrm{Kg})$ & 0.24 & 0.24 & 0.24 & 0.17 & 0.17 & 0.17 \\
\hline Mass Flow Rate of Air (Kg/hr) & 14.33 & 14.33 & 14.33 & 10.47 & 10.47 & 10.47 \\
\hline Actual Air-Fuel Ratio (A/F) & 11.29 & 14.84 & 16.50 & 11.29 & 14.59 & 16.32 \\
\hline Stoichiometric Air-Fuel Ratio (A/F) & 14.70 & 14.70 & 14.70 & 14.70 & 14.70 & 14.70 \\
\hline Equivalence Ratio & 1.30 & 0.99 & 0.89 & 1.30 & 1.01 & 0.90 \\
\hline CIBAI Air-Fuel Ratio & 23 & 30 & 33 & 23 & 29 & 33 \\
\hline CIBAI Equivalence Ratio & 0.65 & 0.50 & 0.45 & 0.65 & 0.50 & 0.45 \\
\hline
\end{tabular}




\section{Appendix S: Sample Estimated In-Cylinder Bulk Temperature}

\section{Engine Operating Conditions}

\begin{tabular}{|l|r|}
\hline Cycle Duration (sec) & 0.131 \\
\hline Crank Angle Rate (dtheta/dt) & 5496.18 \\
\hline RPM & 916.03 \\
\hline Crank Angle Differential (dtheta CA) & 0.55 \\
\hline Sampling Rate (Hertz) & 10000 \\
\hline Air Flow Rate (SCFM) & 7 \\
\hline Intake Temperature (K) & 294 \\
\hline Air Gas Constant (KJ/kg-K) & 0.287 \\
\hline Barometric Pressure (in Hg) & 30.14 \\
\hline Barometric Pressure (psia) & 14.81 \\
\hline Exhaust Temperature (K) & 588.56 \\
\hline
\end{tabular}

\section{Engine Specifications}

\begin{tabular}{|l|r|}
\hline Displacement Volume (cc) & 612.5 \\
\hline Clearance Volume (cc) & 111.36 \\
\hline Plumbing Volume (cc) & 3.00 \\
\hline Compression Ratio (C.R) & 6.5 \\
\hline Adjusted Compression Ratio (C.R) & 6.36 \\
\hline Stroke (in) & 4.5 \\
\hline Crank Offset (in) & 2.25 \\
\hline Bore (in) & 3.25 \\
\hline
\end{tabular}

\section{Calculation Volumetric Efficiency}

\begin{tabular}{|l|r|}
\hline Displacement Volume (in^3) & 37.33 \\
\hline Total Volume (in^3) & 44.31 \\
\hline Actual Volume Clearance (in^3) & 6.98 \\
\hline Cylinder Mass Before Injection (Kg) & 0.00052 \\
\hline Volumetric Efficiency & $70.7 \%$ \\
\hline
\end{tabular}

\section{Calculation Rate of Injection (dm/dt)}

\begin{tabular}{|l|r|}
\hline Air Heater Volume (cc) & 33 \\
\hline Injector Ball Valve Check Cracking Pressure (psi) & 514.7 \\
\hline Air Heater Pressure Before Injection (psi) & 814.7 \\
\hline Average Pressure (pa) & 4582974 \\
\hline Mass Heater Before Injection (kg) & 0.0011 \\
\hline Mass Heater Left After Injection (kg) & 0.0007 \\
\hline Mass Injected (kg) & 0.0004 \\
\hline Delta t Injected (sec) & 0.012 \\
\hline $\mathrm{A}^{*}(\mathrm{sq} . \mathrm{m})$ & 0.00000441 \\
\hline $\mathrm{D}^{\star}(\mathrm{mm})$ & 2.37 \\
\hline $\mathrm{dm} / \mathrm{dt}(\mathrm{kg} / \mathrm{s})$ & $3.367 \mathrm{E}-06$ \\
\hline
\end{tabular}

\section{Estimated In-Cylinder Temperature}

\begin{tabular}{|l|r|}
\hline Start Injection (CA) & 340.45 \\
\hline Selected Crank Angle (CA) & 400.95 \\
\hline Pressure at CA (Psia) & 342.47 \\
\hline Volume at CA (in^3) & 12.45 \\
\hline Mass Injected (Kg) & $3.703 \mathrm{E}-04$ \\
\hline Cylinder Mass After Injection at CA (Kg) & 0.0009 \\
\hline Estimated In-Cylinder Temperature (K) & 1866.9 \\
\hline
\end{tabular}

